\title{
WestVirginiaUniversity
}

THE RESEARCH REPOSITORY @ WVU

Graduate Theses, Dissertations, and Problem Reports

2006

\section{Bimetallic carbides as catalysts for dry reforming and steam reforming}

Huifang Shao

West Virginia University

Follow this and additional works at: https://researchrepository.wvu.edu/etd

\section{Recommended Citation}

Shao, Huifang, "Bimetallic carbides as catalysts for dry reforming and steam reforming" (2006). Graduate Theses, Dissertations, and Problem Reports. 4269.

https://researchrepository.wvu.edu/etd/4269

This Dissertation is protected by copyright and/or related rights. It has been brought to you by the The Research Repository @ WVU with permission from the rights-holder(s). You are free to use this Dissertation in any way that is permitted by the copyright and related rights legislation that applies to your use. For other uses you must obtain permission from the rights-holder(s) directly, unless additional rights are indicated by a Creative Commons license in the record and/ or on the work itself. This Dissertation has been accepted for inclusion in WVU Graduate Theses, Dissertations, and Problem Reports collection by an authorized administrator of The Research Repository @ WVU.

For more information, please contact researchrepository@mail.wvu.edu. 


\title{
BIMETALLIC CARBIDES AS CATALYSTS FOR DRY REFORMING AND STEAM REFORMING
}

\author{
by \\ Huifang Shao \\ Dissertation Submitted to the \\ College of Engineering and Mineral Resources at West Virginia University \\ IN PARTIAL FULFILMENT OF THE REQUIREMENTS FOR THE DEGREE OF \\ "DOCTOR OF PHILOSOPHY IN CHEMICAL ENGINEERING" \\ Dr. Edwin L. Kugler \\ Dr. Dady B. Dadyburjor \\ Mr. Jean B. Cropley \\ Dr. Abolghasem Shamsi \\ Dr. Charter D. Stinespring
}

Department of Chemical Engineering

West Virginia University

2006

Key Words: catalyst, carbide, reforming, methane 


\section{BIMETALLIC CARBIDES AS CATALYSTS FOR}

\section{DRY REFORMING AND STEAM REFORMING}

\section{Huifang Shao}

\section{Abstract}

In this work, a series of novel bimetallic carbide catalysts has been successfully prepared in house, by changing the metallic elements therein and the ratio of $\mathrm{CO}_{2} / \mathrm{CO}$ in carburization process. Co-W-C and Ni-W-C are the elements in the bimetallic carbides to be discussed in this dissertation. Following the preparation, different techniques were applied to characterize the catalyst from the bulk phase to the surface.

For Co-W-C, the catalytic evaluation were carried out for three reactions, methane dry reforming (DRM), methane steam reforming (SRM) and methanol steam reforming (SRMeOH). This bimetallic carbide is stable and active for DRM after proper pretreatment, while less so for SRM and SRMeOH. Afterwards, the effect of temperature history on the catalytic properties was investigated for DRM of Co-W-C. The effect is significant, and the reactivity can be improved a lot after being exposed to methane at $850^{\circ} \mathrm{C}$.

For Ni-W-C, the catalytic properties were evaluated only for DRM. This Ni-W-C also has high reactivity and good stability for DRM, with very low coke formation. Similar to the work for Co-W-C, the effect of temperature history was also studied. No obvious difference has been found in the catalytic performance before and after exposure to methane at $850^{\circ} \mathrm{C}$.

For both Co-W-C and Ni-W-C, the fresh and spent catalysts (both before and after exposure to high temperature) have been collected for characterization, including XRD, TPR, SEM, EDAX and NEXAFS. Consistent characterization measurement results were obtained. To exhibit reasonable reactivity, those catalysts transform into the stable and active phases, a mixture material of $\mathrm{Co}$ (or Ni), WC and C. For Co-W-C, before it is exposed to $850^{\circ} \mathrm{C}$, the presence of some form of oxide $\left(\mathrm{CoWO}_{4}\right)$ makes the catalyst ineffective for DRM. However, once the stable and active phases are formed by exposure to methane at $850^{\circ} \mathrm{C}$, they can be maintained even though the catalyst is brought back to a low temperature. In the application of Co-W-C in steam reforming, the presence of water could prevent necessary carbon laydown to transform the catalyst into final active phases, by decreasing the reactivity of the catalyst.

Key Words: catalyst, carbide, reforming, methane 


\section{Acknowledgements}

I would like to extend my deepest appreciation to Dr. Edwin L. Kugler and Dr. Dady B. Dadyburjor for their solid support and patient supervision. Their passion to the research leads me into science, their ardor of the work drives me ahead, and their insight into the world widens my scope of knowledge.

I also would like to thank Dr. Jingguang Chen for NEXAFS characterization, Dr. Mohindar Seehra's group for XRD measurements, and Mr. Steve Carpenter for SEM and EDAX analysis. Their kind assistance makes significant contributions to my dissertation. I also would like to express my appreciation to the other three committee members, Mr. Jean B. Cropley, Dr. Abolghasem Shamsi and Dr. Charter Stinespring for their extended support. Their suggestions and instructions to my research are very helpful for me to complete this $\mathrm{PhD}$ program.

In addition, I would like to thank all the faculties and staffs in the Department of Chemical Engineering, who are always glad to fulfill my requests for help. It is also a great enjoyment to work with those coworkers in the lab in the past four and a half years.

Strong support from my family will be forever remembered. No word can really convey my sincere gratitude to my husband, my daughter, my parents, my brother and sister-in-law, who are standing beside me all the time. Tons of love to you all! 


\section{Table of Contents}

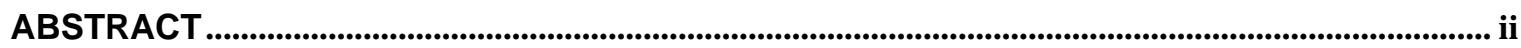

ACKNOWLEDGEMENTS ......................................................................................................................................ii

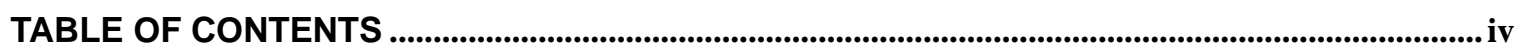

LIST OF FIGURES ................................................................................................................................................... vii

LIST OF TABLES

CHAPTER 1 INTRODUCTION .......................................................................................................................... 1

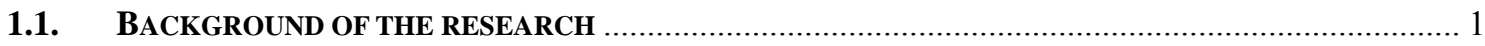

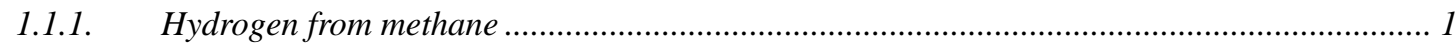

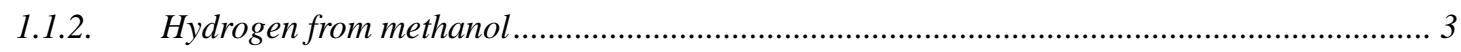

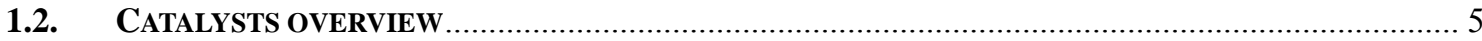

CHAPTER 2 LITERATURE REVIEW

2.1. SIGNIFICANCE OF HYDROGEN PRODUCTION IN FUTURE ENERGY CONSUMPTION ......................... 8

2.2. INTRODUCTION OF SEVERAL PRACTICAL ROUTES TO PRODUCE HYDROGEN .............................. 9

2.3. CONVENTIONAL CATALYST USED IN THIS RESEARCH FIELD ..................................................... 12

2.4. OVERVIEW OF REACTION MECHANISM AND KINETICS FOR HYDROGEN PRODUCTION PROCESS 20

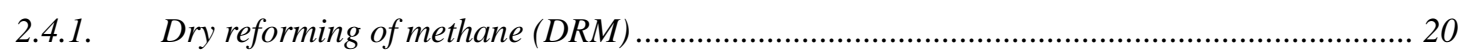

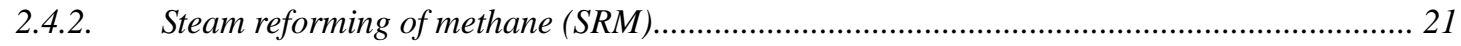

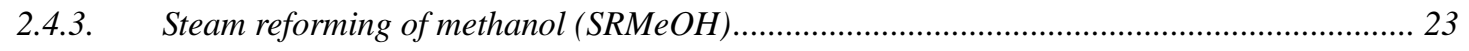

2.5. REVIEW OF SOME TECHNIQUE USED FOR CATALYST CHARACTERIZATION .................................. 26

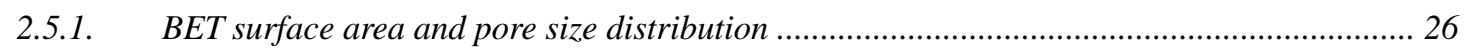

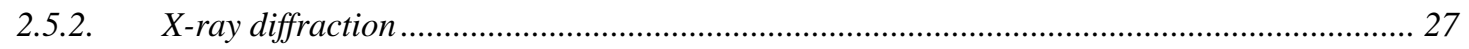

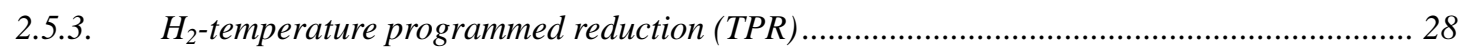

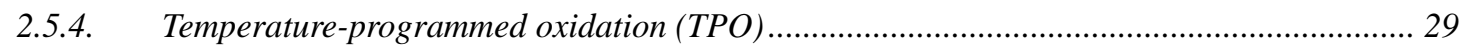

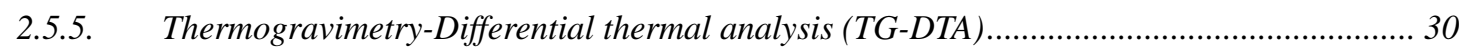

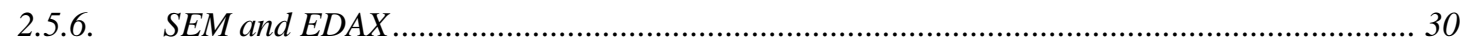

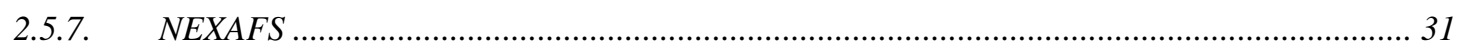

CHAPTER $3 \quad$ EXPERIMENTAL SETUP AND PROCEDURE.............................................................. 33

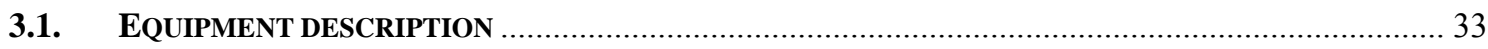

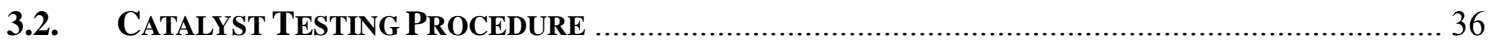

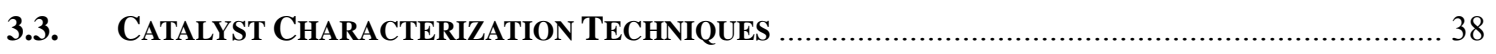

\section{CHAPTER 4 PREPARATION AND CHARACTERIZATION OF BIMETALLIC CARBIDE \\ CATALYST}

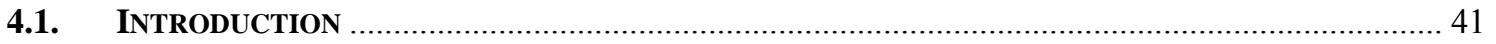




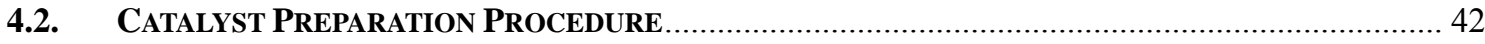

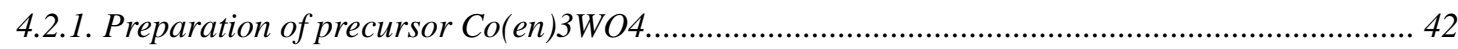

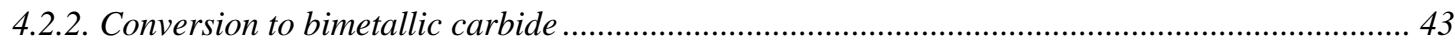

4.3. EFFECT OF RATIO OF $\mathrm{CO}_{2}$ /CO FOR PREPARING BIMETALLIC CO-W-C CATALYST ...................... 45

4.4. CHARACTERIZATION OF THE BIMETALLIC CARBIDE CATALYST ……..................................... 50

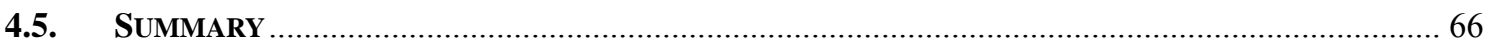

CHAPTER 5 CATALYTIC STUDY OF CO-W-C CATALYST ............................................................... 67

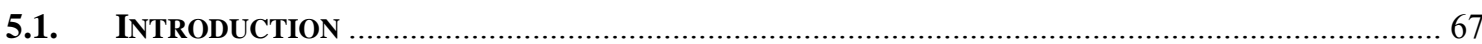

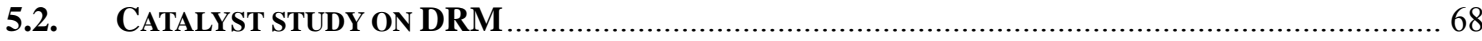

5.2.1. Reactivity and stability of $\mathrm{Co}-W-C$ catalysts prepared with different ratios of $\mathrm{CO}_{2}$ to $\mathrm{CO} \ldots 68$

5.2.2. Characterization of spent catalyst after catalytic test .......................................................... 76

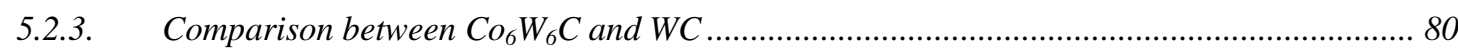

5.2.4. Investigation of effect of exposure to high temperature on the catalytic performance of

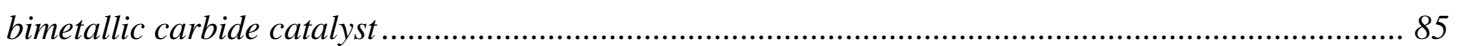

5.2.5. Characterization of the catalyst before and after exposure to high temperature .................. 89

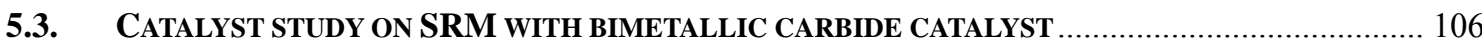

5.4. CATALYST STUDY ON SRMEOH WITH BIMETALLIC CARBIDE CATALYST..................................112

5.4.1. Results of SRMeOH with different ratios of Methanol to water ............................................117

5.4.2. Effect of time on stream on SRMeOH............................................................................119

5.4.3. Product distribution of SRMeOH at different temperatures ............................................... 120

5.4.4. Empirical kinetic study for SRMeOH with this in-house bimetallic carbide catalyst........... 123

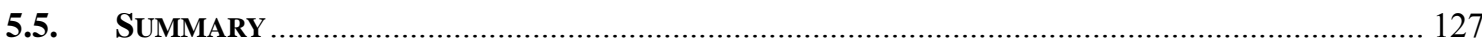

CHAPTER 6 CATALYTIC STUDY OF NI-W-C CATALYST .............................................................. 129

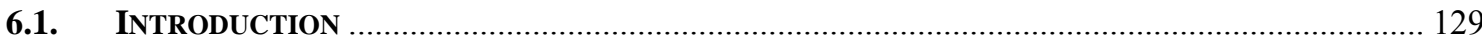

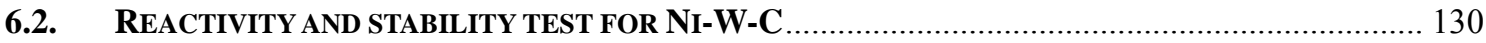

6.3. INVESTIGATION OF EXPOSURE TO HIGH TEMPERATURE ON THE CATALYTIC PERFORMANCE OF

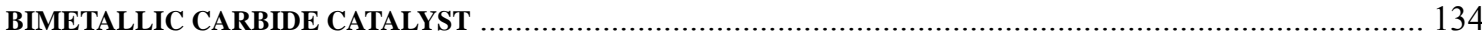

6.4. CHARACTERIZATION OF NI-W-C CARBIDE CATALYST BEFORE AND AFTER EXPOSURE TO

$\mathbf{8 5 0}^{\circ} \mathrm{C}$

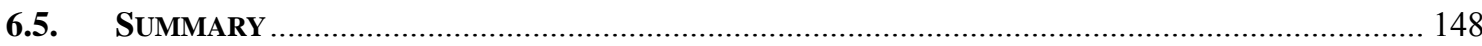

CHAPTER 7 CONCLUSIONS AND RECOMMENDATIONS FOR FUTURE WORK ................. 149

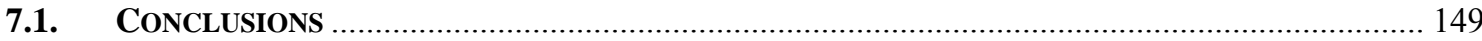

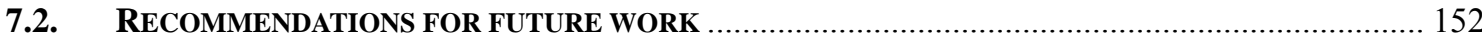

7.2.1. Further characterization of bimetallic carbide catalyst.................................................... 152

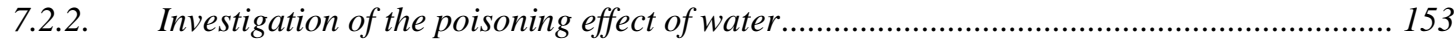

7.2.3. Application of bimetallic carbide for other hydroprocessing ............................................... 153

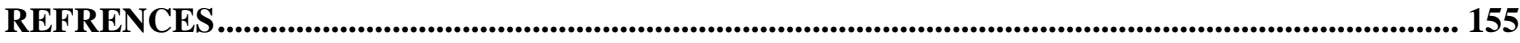

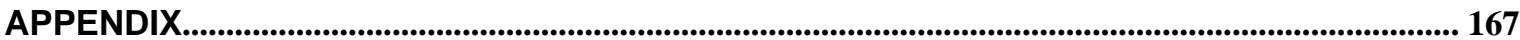




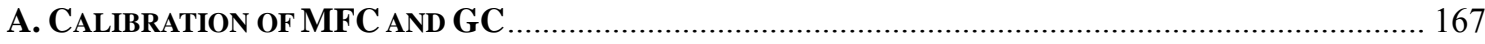

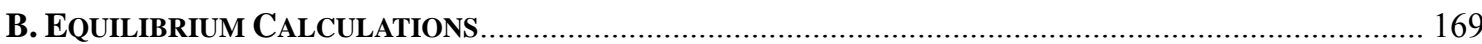

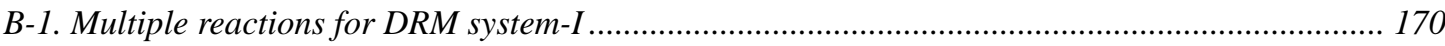

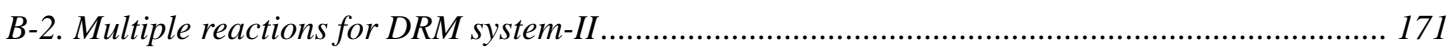

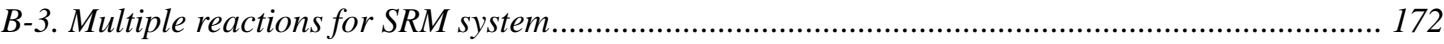

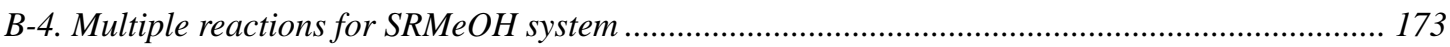




\section{List of Figures}

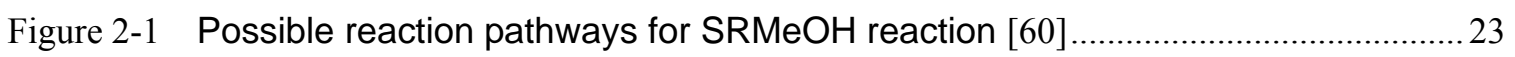

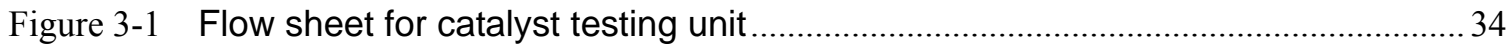

Figure 4-1 Ternary phase diagram of cobalt-tungsten-carbon at $1400 \mathrm{~K}$ [67] ......................... 46

Figure 4-2 Relationship between process carbon activity and $\mathrm{CO}_{2} / \mathrm{CO}$ ratio ........................... 48

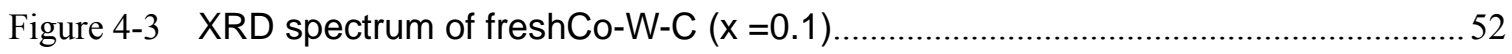

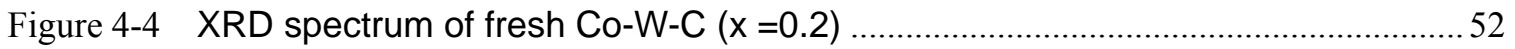

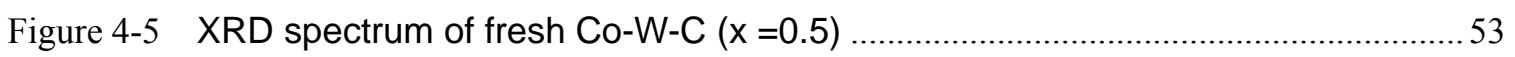

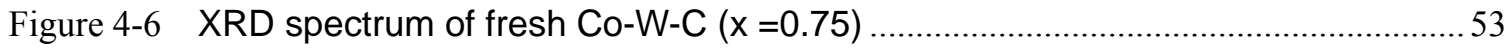

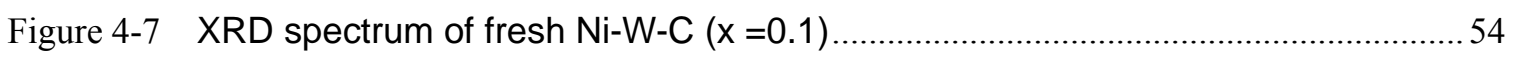

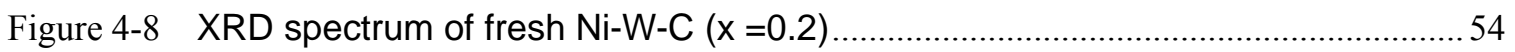

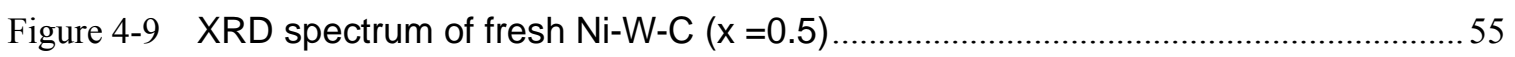

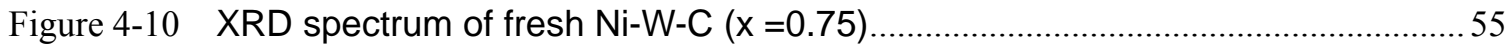

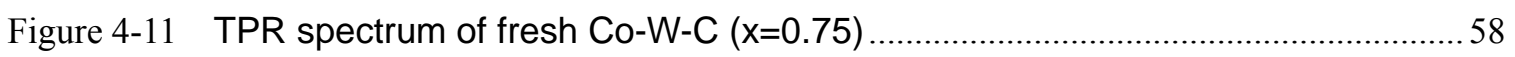

Figure 4-12 TPR spectrum of fresh $\mathrm{Co}_{6} \mathrm{~W}_{6} \mathrm{C}$ from Nanodyne Company.................................59

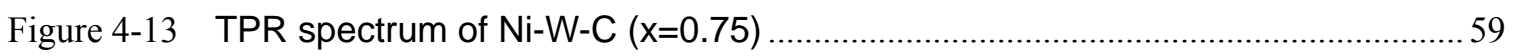

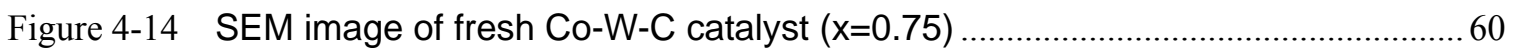

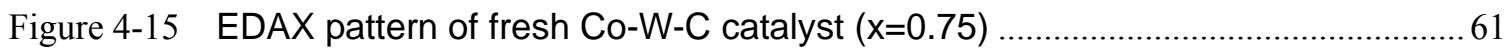

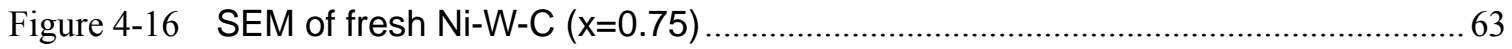

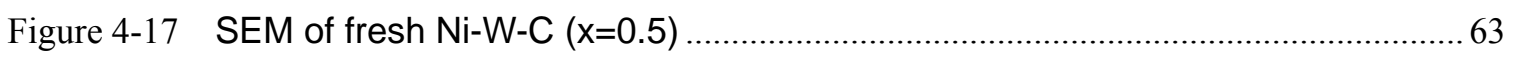

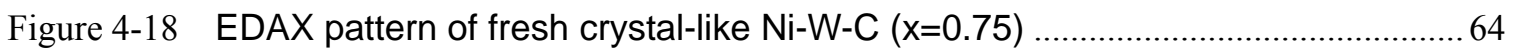

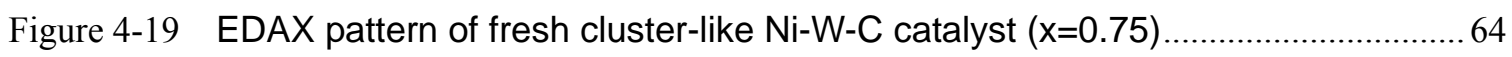

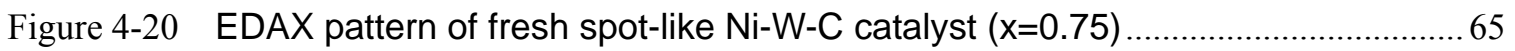

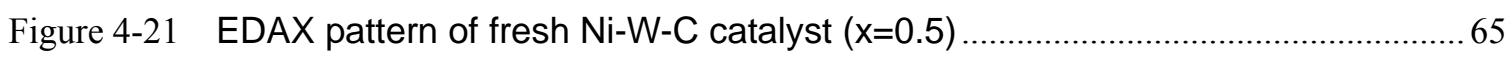

Figure 5-1 Equilibrium calculation of multiple reactions for DRM system as a function of

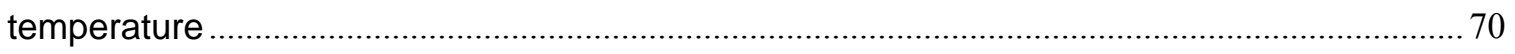

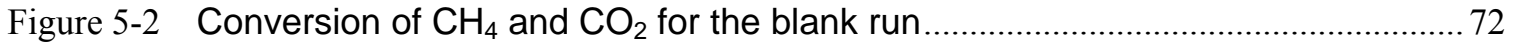

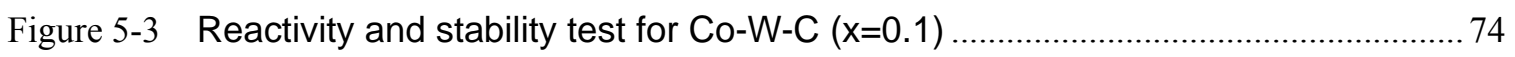

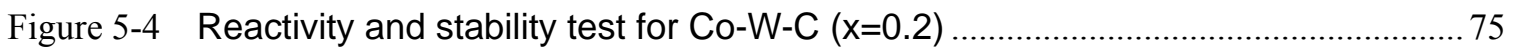

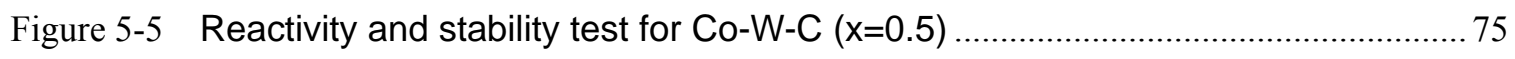

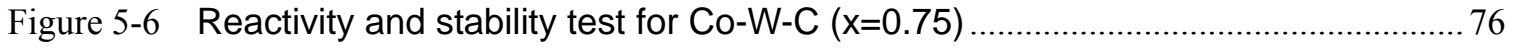

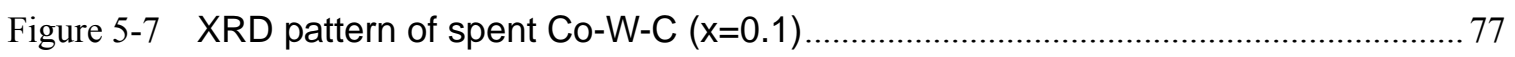

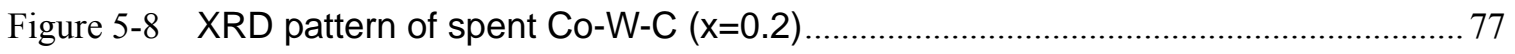

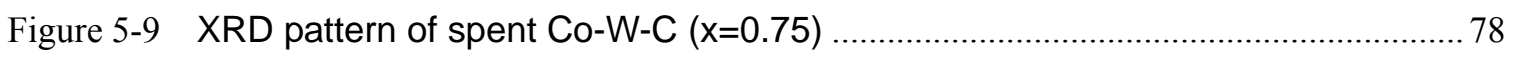

Figure 5-10 Reactivity and stability test for the physical-mixture of $\mathrm{Co}+$ WC ......................... 81

Figure 5-11 Comparison of conversions over $\mathrm{Co}_{6} \mathrm{~W}_{6} \mathrm{C}(\mathrm{x}=0.75)$ \& the physical-mixture ........ 81

Figure 5-12 XRD pattern of spent physical-mixture Co-W-C after $850^{\circ} \mathrm{C}$............................... 83

Figure 5-13 Reactivity and stability test for in-situ TPR prepared $\mathrm{WC}$ from $\mathrm{WO}_{3} \ldots \ldots \ldots \ldots \ldots . . . . . . . . .84$

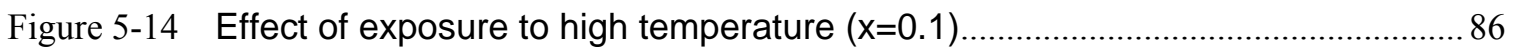




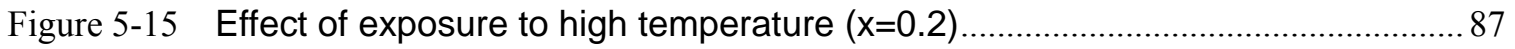

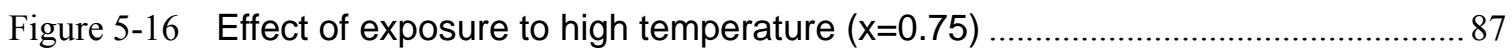

Figure 5-17 XRD pattern of spent Co-W-C $(x=0.1)$ after the first $700^{\circ} \mathrm{C}$ stage, i.e. before exposure to $850^{\circ} \mathrm{C}$.

Figure 5-18 XRD pattern of spent Co-W-C $(x=0.1)$ after the third $700^{\circ} \mathrm{C}$ stage and exposure to $850^{\circ} \mathrm{C}$

Figure 5-19 XRD pattern of spent $\mathrm{Co}-\mathrm{W}-\mathrm{C}(\mathrm{x}=0.2)$ after the first $700^{\circ} \mathrm{C}$ stage, i.e. before exposure to $850^{\circ} \mathrm{C}$

Figure 5-20 XRD pattern of spent Co-W-C $(x=0.2)$ after the third $700^{\circ} \mathrm{C}$ stage and exposure to $850^{\circ} \mathrm{C}$

Figure 5-21 XRD pattern of spent Co-W-C ( $x=0.75)$ after the first $700^{\circ} \mathrm{C}$ stage, i.e. before exposure to $850^{\circ} \mathrm{C}$.

Figure 5-22 XRD pattern of spent Co-W-C $(x=0.75)$ after the second $700^{\circ} \mathrm{C}$ stage and

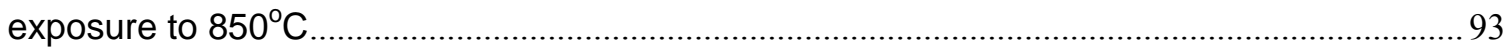

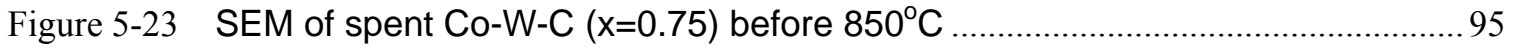

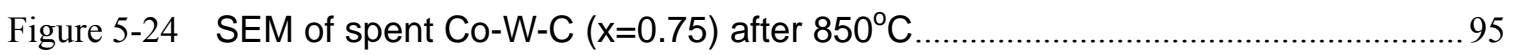

Figure 5-25 SEM Images of carbon deposits on spent Co-W-C $(x=0.75)$ after $850^{\circ} \mathrm{C} \ldots \ldots \ldots . . .96$

Figure 5-26 EDAX pattern of spent Co-W-C $(x=0.75)$ before exposure to $850^{\circ} \mathrm{C} \ldots \ldots \ldots \ldots \ldots . . . . . . . .96$

Figure 5-27 EDAX pattern of spent Co-W-C $(x=0.75)$ after exposure to $850^{\circ} \mathrm{C}$...................... 96

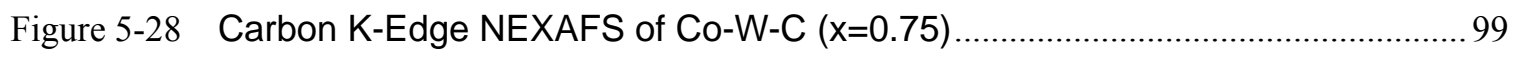

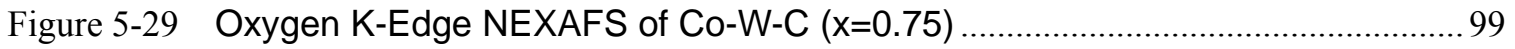

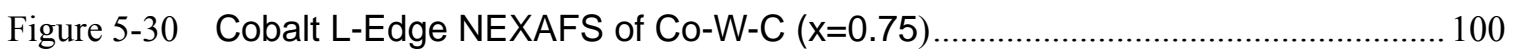

Figure 5-31 XRD pattern of fresh Co-W-C $(x=0.75)$ only reduced with $\mathrm{H}_{2} \ldots \ldots \ldots \ldots \ldots \ldots \ldots \ldots \ldots \ldots . . . . . . . . . . .104$

Figure 5-32 XRD pattern of spent Co-W-C $(x=0.75)$ flushed with $\mathrm{Ar}$ at $850^{\circ} \mathrm{C} \ldots \ldots \ldots \ldots \ldots \ldots . . . . . . . . . .104$

Figure 5-33 Equilibrium calculation of multiple reactions for SRM system as a function of

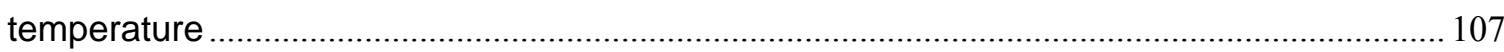

Figure 5-34 Reaction test for SRM with Co-W-C ( $\mathrm{x}=0.75), \mathrm{T}=850^{\circ} \mathrm{C}, \mathrm{P}=1 \mathrm{~atm} \ldots \ldots \ldots \ldots \ldots \ldots . . . . . . . . . .108$

Figure 5-35 Equilibrium calculation of multiple reactions for $\mathrm{SRMeOH}$ system as a function

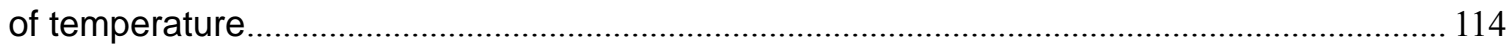

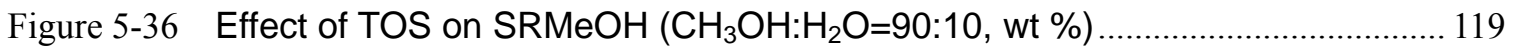

Figure 5-37 Reaction results for SRMeOH with Co-W-C $(x=0.75)$ at low temperature range124

Figure 5-38 Reaction results for SRMeOH with Co-W-C $(x=0.75)$ after exposure to $850^{\circ} \mathrm{C} 125$

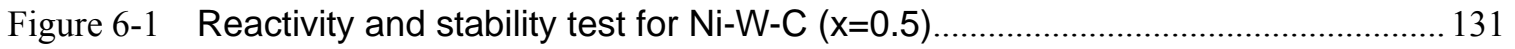

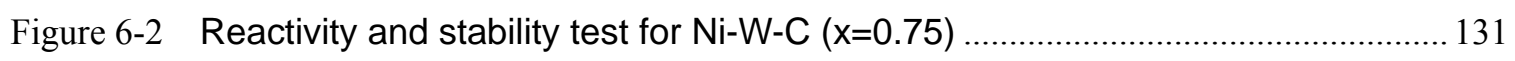

Figure 6-3 Effect of exposure to high temperature for Ni-W-C $(x=0.75) \ldots \ldots \ldots \ldots \ldots \ldots \ldots \ldots \ldots . . . . . . . . . . . . . . .135$

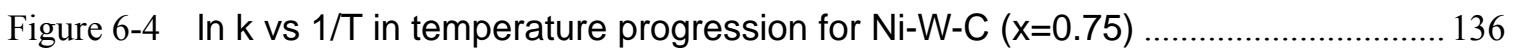

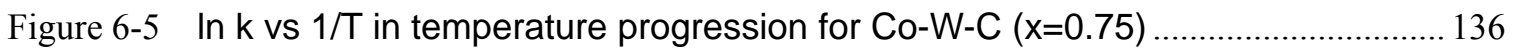

Figure 6-6 XRD pattern of spent Ni-W-C $(x=0.75)$ at $1 \mathrm{st} 700^{\circ} \mathrm{C}$ stage, i.e.,before exposure to $850^{\circ} \mathrm{C}$

Figure 6-7 XRD pattern of spent Ni-W-C $(x=0.75)$ at 2 nd $7000 \mathrm{C}$ stage, i.e., after exposure to $850^{\circ} \mathrm{C}$ 
Figure 6-8 Ni-W-C ( $x=0.75)$ spent catalyst at 1 st $700^{\circ} \mathrm{C}$ (before exposure to $\left.850^{\circ} \mathrm{C}\right) \ldots \ldots \ldots . . .142$

Figure 6-9 Ni-W-C ( $x=0.75)$ spent catalyst at $2 \mathrm{nd} 700^{\circ} \mathrm{C}$ (after exposure to $850^{\circ} \mathrm{C}$ )............ 142 Figure 6-10 EDAX pattern of spent Ni-W-C $(x=0.75)$ at 1 st $700^{\circ} \mathrm{C}$, i.e., before exposure to

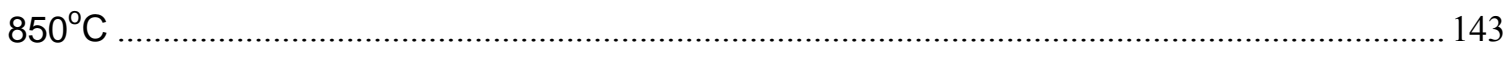

Figure 6-11 EDAX pattern of spent Ni-W-C $(x=0.75)$ at 2 nd $700^{\circ} \mathrm{C}$, i.e., after exposure to $850^{\circ} \mathrm{C}$

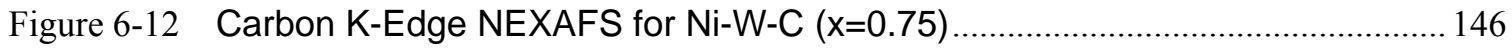

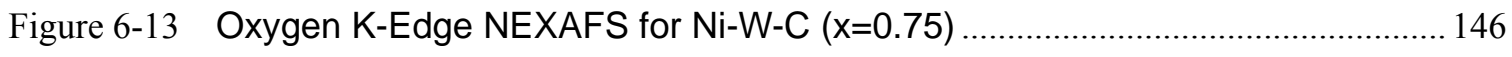

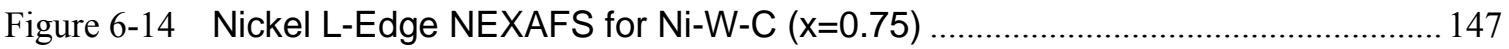




\section{List of Tables}

Table 2-1 Summary of catalytic reforming of $\mathrm{CO}_{2} / \mathrm{CH}_{4}$ in the literature.................................. 15

Table 2-2 Summary of catalytic reforming of $\mathrm{H}_{2} \mathrm{O} / \mathrm{CH}_{3} \mathrm{OH}$ in the literature ............................. 17

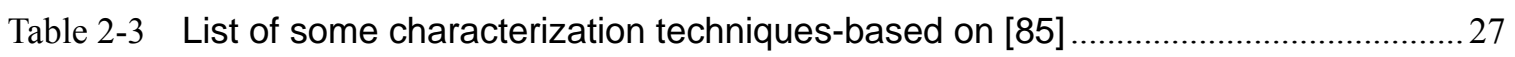

Table 4-1 Preparation of Co-W-C by carburization .................................................................... 44

Table 4-2 Relationship between $x$ and $a_{c}{ }^{*}$ (equation 4-5) ...................................................... 49

Table 4-3 Bulk components of carbide catalysts with different ratios of $\mathrm{CO}_{2} / \mathrm{CO}$...................50

Table 4-4 Bulk components of carbide catalysts with different ratios of $\mathrm{CO}_{2} / \mathrm{CO}$....................56

Table 5-1 Observations of SRMeOH at different ratios of $\mathrm{CH}_{3} \mathrm{OH}$ to $\mathrm{H}_{2} \mathrm{O}$............................ 117

Table 5-2 Gas product distribution for $\mathrm{CH}_{3} \mathrm{OH}: \mathrm{H}_{2} \mathrm{O}=6: 4$ (wt basis) ................................... 122

Table 5-3 Pseudo-second-order rate constants for methanol consumption .......................... 126

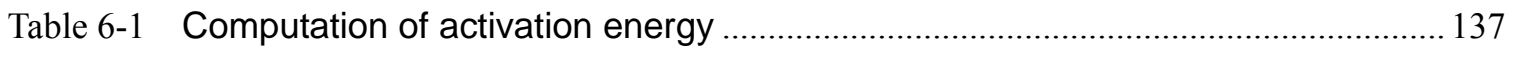




\section{CHAPTER 1 INTRODUCTION}

\subsection{Background of the research}

Hydrogen is very attractive as an alternative energy carrier due to the increasing demand of energy and concerns about environment protection. Hydrogen can be made from fossil fuels such as methane, or renewable resources such as methanol.

\subsubsection{Hydrogen from methane}

\subsubsection{Introduction}

To make natural gas, an abundant fossil fuel resource, efficiently and economically more viable, lots of research has been carried out into the reforming studies $[1,2]$. Existing industrial processes use methane as a primary feedstock for producing a mixture of carbon monoxide and hydrogen, called synthesis gas (syngas) [3, 4]. The obtained syngas then serves as the feedstock for a variety of downstream processes, such as methanol synthesis, Fischer-Tropsch synthesis or ammonia synthesis $[5,6,7]$. Three processes are used to manufacture the syngas:

1) Steam reforming: $\quad \mathrm{CH}_{4}+\mathrm{H}_{2} \mathrm{O} \rightarrow \mathrm{CO}+3 \mathrm{H}_{2}$

$$
\left(\Delta \mathrm{H}^{\ominus}=+49.3 \mathrm{kcal} / \mathrm{mol}\right)
$$

2) Partial oxidation: $\mathrm{CH}_{4}+\frac{1}{2} \mathrm{O}_{2} \rightarrow \mathrm{CO}+2 \mathrm{H}_{2}$

$$
\left(\Delta \mathrm{H}^{\Theta}=-8.5 \mathrm{kcal} / \mathrm{mol}\right)
$$

3) Dry reforming: $\quad \mathrm{CH}_{4}+\mathrm{CO}_{2} \rightarrow 2 \mathrm{CO}+2 \mathrm{H}_{2}$ 


$$
\left(\Delta \mathrm{H}^{\Theta}=+59.1 \mathrm{kcal} / \mathrm{mol}\right)
$$

\subsubsection{Dry reforming of methane}

In the last several decades, dry reforming of methane (DRM, equation 1-3) with carbon dioxide has become more attractive because it produces syngas with high purity [8-12]. In addition, this method is quite beneficial to environmental protection since both $\mathrm{CO}_{2}$ and $\mathrm{CH}_{4}$ are greenhouse gases [13-16]. However, the feasibility of DRM depends strongly on the price and availability of $\mathrm{CO}_{2}$ and the pressure at which the process will be operated. The produced syngas has a ratio of $\mathrm{H}_{2}$ to $\mathrm{CO}$ equal to 1 , so the mixture can serve as the feedstock to manufacture alcohol (via the oxoalcohol synthesis), dimethyl ether and acetic acid. Compared with the other two processes, DRM has a higher risk of catalyst deactivation due to carbon deposition. In the process of DRM, several side reactions may take place. These include:

1) Methane decomposition: $\boldsymbol{C H}_{4} \rightarrow \boldsymbol{C}+\mathbf{2} \boldsymbol{H}_{2}$

$$
\left(\Delta \mathrm{H}^{\ominus}=+17.92 \mathrm{kcal} / \mathrm{mol}\right)
$$

2) Boudouard reaction: $\mathbf{2 C O} \rightarrow \mathrm{C}+\mathrm{CO}_{2}$

$$
\left(\Delta \mathrm{H}^{\ominus}=-41.15 \mathrm{kcal} / \mathrm{mol}\right)
$$

3) Reverse water gas shift: $\boldsymbol{H}_{2}+\mathrm{CO}_{2} \rightarrow \mathbf{C O}+\boldsymbol{H}_{2}$

$$
\left(\Delta \mathrm{H}^{\Theta}=+9.81 \mathrm{kcal} / \mathrm{mol}\right)
$$




\subsubsection{Steam reforming of methane}

Steam reforming of methane (SRM, equation 1-1) is a major source of synthesis gas, and has been developed for many years [17]. Nowadays, steam reforming of hydrocarbons has been used widely for its higher processing efficiency and cost effectiveness. Among all the hydrocarbons, steam reforming of methane is the most dominating one, which occupies around $75 \%$ of the total units for steam reforming of hydrocarbons [18]. Hydrogen or syngas can be produced from SRM. Compared with the other two processes, SRM can produce the highest ratio of $\mathrm{H}_{2}$ to $\mathrm{CO}(3: 1)$. However, this process suffers from severe limitations like poor selectivity for carbon monoxide [19].

\subsubsection{Hydrogen from methanol}

Using renewable resources to produce hydrogen has particular interests and great environment benefits, and is supposed to be a great alternative for the use of petroleum and coal base combustion. Among those renewable sources, methanol is regarded as one of the important liquid sources of hydrogen. Using methanol as the source for hydrogen production has many advantages [20]:

1) Methanol is a simple molecule with a high molar ratio of hydrogen to carbon $(4: 1)$

2) Methanol is a liquid at ambient conditions, so is convenient to transport 
3) Methanol reforming requires mild reaction conditions: low reaction temperature and pressure

4) There is a low selectivity to $\mathrm{CO}(\mathrm{CO}$ is poisonous $)$ and $\mathrm{CH}_{4}$, compared to the reforming of alkane or higher alcohols

5) Great environment benefits: no emission of pollutants (such as nitrogen oxide, sulfur oxide or soot particles)

Similar to methane reforming, there are also three ways to produce hydrogen from methanol [21]:

1) Decompostion: $\quad \mathrm{CH}_{3} \mathrm{OH} \rightarrow \mathrm{CO}+2 \mathrm{H}_{2}$

$$
\left(\Delta \mathrm{H}^{\mathrm{e}}=+21.77 \mathrm{kcal} / \mathrm{mol}\right)
$$

2) Partial oxidation: $\mathrm{CH}_{3} \mathrm{OH}+\frac{1}{2} \mathrm{O}_{2} \rightarrow \mathrm{CO}_{2}+2 \mathrm{H}_{2}$

$$
\left(\Delta \mathrm{H}^{\ominus}=-45.93 \mathrm{kcal} / \mathrm{mol}\right)
$$

3) Steam reforming: $\quad \mathrm{CH}_{3} \mathrm{OH}+\mathrm{H}_{2} \mathrm{O} \rightarrow \mathrm{CO}_{2}+3 \mathrm{H}_{2}$

$$
\left(\Delta \mathrm{H}^{\ominus}=+11.96 \mathrm{kcal} / \mathrm{mol}\right)
$$

Steam reforming of methanol (SRMeOH, equation 1-9) produces a higher ratio of $\mathrm{H}_{2}$ to carbon oxides (3:1). Methanol partial oxidation (equation 1-8) is exothermic, while the other two methods are endothermic. However, attention should be paid to prevent the sudden temperature rise in the partial oxidation process, which will bring about hot spots in the reactor and then deactivate the catalysts. Especially high energy 
is required for methanol decomposition (equation 1-7) because it is strongly endothermic. Therefore, methanol steam reforming is the best way to produce hydrogen-rich gas from methanol under mild reaction conditions. This hydrogen-rich gas can be fed to a fuel cell that generates electrical power by the electrochemical conversion of hydrogen with oxygen from the air $[22,23]$. The only exhaust of this process is water vapor and carbon dioxide. This is particularly promising in the application for the demand of clean and efficient power generation. In addition, the by-product $\mathrm{CO}_{2}$ can be fixed and stored by plant biomass which can be used subsequently for further hydrogen production.

\subsection{Catalysts overview}

Due to the importance of the methane reforming reaction, considerable efforts have been made to explore desirable catalysts to achieve both high activity and good stability [24]. Nickel-based catalysts have been widely applied in methane reforming in industry because of the fast turnover rate and low cost [25]. But this type of catalyst also deactivates rapidly because it catalyzes coke formation via methane decomposition (equation 1-4) and CO disproportionation (Boudouard reaction, equation 1-5) [26,27]. The deactivation of the catalysts is also explained by sintering of the metal particles. Modifications of nickel-based catalysts have been proposed to overcome this shortcoming, such as introducing some alkali or alkaline earth metal [3], or passivating the catalyst with sulfur [28]. Noble metal catalysts (Rh, Ru, Pd, Pt, Ir) exhibit high 
reactivity and low coke formation in the reforming process. However, low availability and high cost limits their application [29]. According to the U.S. Geological Survey, the world reserves of platinum-group metals (PGM) are estimated to be approximately 100,000 kilograms (world reserves of platinum alone are estimated to be approximately 53,000 kilograms) [30]. Besides, the catalyst support and the metal particle size strongly affect the catalytic performance for some noble metal catalysts, like Pt.

Copper-based catalysts have been used commercially for methanol steam reforming. The catalyst activity is generally proportional to the $\mathrm{Cu}$ surface area (number of active sites) [31]. However, these catalysts have a number of limitations, including instability at high temperatures and the need for precise control of the pretreatment conditions.

In the last 20 years, metal carbides, particularly transition metal carbides [32, 33], have caused notable interest in methane reforming as well as methanol reforming. Since the starting materials for the production of the metal carbide catalyst are more abundant and cheaper compared to the noble metal catalysts, and the reactivity and stability of the catalyst itself are both satisfactory [34], it is very possible that the carbide catalyst can replace the noble metal catalysts in some application, including methane dry reforming and methanol steam reforming. Moreover, the carbide catalyst is expected to inhibit carbon deposition, therefore increasing the stability and reactivity of the catalyst in practical application. 


\section{CHAPTER 2 LITERATURE REVIEW}

Due to the increasing demands of energy and concerns of environment protection, production and use of clean and efficient energy have become particularly important and urgent nowadays. Methane dry reforming and methanol steam reforming are two attractive alternatives to produce hydrogen [22]. To make the production process more successful and efficient, many catalysts have been developed and studied since 1920's. Undoubtedly, the catalyst preparation methods will influence their properties and catalytic performances in the reforming reaction. Traditionally, a nickel-based catalyst has been used in methane reforming [35], while a copper-based catalyst has been widely applied in methanol steam reforming. But serious coke deposition of nickel catalyst itself has brought about many improvements and modifications in the studies. In the application of copper-based catalyst in methanol steam reforming, problems have also been encountered, such as instability and deactivation at high temperature. Noble-metal catalysts exhibit better activity and suffer less instability, as compared to nonnoble catalysts. However, the high price and low availability of noble metals limit their attractive advantages. Recently, a novel carbide catalyst has been developed and shown to have similar catalytic and stability as noble metals. This has aroused much attention in the catalyst development for methane as well as methanol reforming reaction [36]. 


\subsection{Significance of hydrogen production in future energy consumption}

Nowadays, fossil-fuel consumption and $\mathrm{CO}_{2}$ emission have become big challenges worldwide. With the development of fuel cell systems and the increasing demand for zero-emission fuels, the share of hydrogen in the energy market is expanding. Hydrogen has been considered as an excellent energy vector when used either directly as a fuel in internal combustion engines, or indirectly to supply electricity using fuel cells. Fuel cells have emerged as promising devices for clean and efficient generation of power for meeting global energy needs [36]. Hydrogen fuel cells especially have a low impact on the environment. In small quantities, hydrogen has been applied in fuel cells to produce electric power to drive machines. In bulk, hydrogen can be used to fuel large gas turbines driving electric power generators and be feedstock for synthesis of other important chemicals $[30,37,38]$. It is possible that a new infrastructure will be built up to power the so-called hydrogen economy in the future.

However, hydrogen does not exist on planet earth in the natural state, even though it is the most abundant element in the universe. It is only an "energy carrier", not an "energy source". Hence, production of a significant amount of hydrogen represents a crucial challenge to solve the problems of severe energy consumption. This challenge is going to be multidimensional, involving innovations of hydrogen production and distribution process, more efficient engines, and cost [30]. 


\subsection{Introduction of several practical routes to produce hydrogen}

Hydrogen can be produced from many sources and with a diversified mix of technology. In industry, most hydrogen is produced by reforming or by partial oxidation of hydrocarbons. Natural gas, a combustible gas that exists in porous rock and is near accumulations of crude oil [2], is the most important and widely used hydrogen source in industry. Due to its low carbon content and easy availability in practice, it may account for $76 \%$ of the total feedstock. In small quantities, or when high purity $\mathrm{H}_{2}$ is required, processes such as water electrolysis, ammonia decomposition or methanol reforming over suitable catalysts can be applied. In the following text, four routes will be reviewed individually: three methane-reforming processes (methane steam reforming, methane partial oxidation and methane dry reforming), and methanol steam reforming.

Currently, steam reforming of methane (SRM) is the most highly developed and cost effective method for generating hydrogen from natural gas in the abundance required $[19,39]$. This is also the most efficient method, giving conversions of $70 \%$ to $80 \%$. Its main disadvantage is that this reaction is endothermic and needs to be operated at a relatively high temperature range, therefore an external heating supply is required. The high operating temperature $\left(\sim 800^{\circ} \mathrm{C}\right)$ does not favor the water-gas-shift reaction thermodynamically and much $\mathrm{CO}$ is contained in the products [40]. Hence, a water-gas-shift reactor will often be added after the steam reformer. This reactor will be 
operated at lower temperatures $\left(250^{\circ} \mathrm{C}-400^{\circ} \mathrm{C}\right)$ to convert $\mathrm{CO}$ to $\mathrm{CO}_{2}$ and thereby to produce more hydrogen. The combination of steam reformer and water gas shifter is more practical and efficient in industrial application.

Partial oxidation has a greater selectivity to synthesis gas production and a more desirable $\mathrm{H}_{2} / \mathrm{CO}$ ratio $(2: 1)$ than steam reforming [41]. In addition, it is the only exothermic reaction among these three types of methane reforming [42]. This feature indicates that the reaction can be initiated by a simple combustion process, and it leads to quick startup. Once the system is running, little external energy supply is required to maintain the reaction. However, it is very difficult to remove the excess reaction heat from this partial oxidation reactor, and the heat accumulation inside the reactor brings about severe consequences (such as hot spots) and makes it difficult to control the process. In practice, this reaction is accompanied by steam reforming and water gas shift reactions. The product will have a very close composition as thermodynamic equilibrium at high conversions.

Methane dry reforming (DRM) is another attractive route to produce hydrogen by using natural gas. One outstanding advantage of this process uses greenhouse gas $\mathrm{CO}_{2}$ as the feedstock. This can decrease the $\mathrm{CO}_{2}$ emission and can be beneficial to the global environment $[10,15]$. The main drawback of DRM is severe coke formation via methane decomposition and carbon monoxide disproportionation [27] and high energy requirement. Three alternatives are available to reduce the coke build up in the reactor 
system. These are: 1) co-feeding water to couple with steam reforming [43]; 2) co-feeding oxygen to couple with partial oxidation [2];3) finding some suitable catalyst which would retard coke formation on the surface of the catalyst while still being active for DRM $[15,35,44]$. The first two alternatives are intended to supply more oxygen to remove carbon deposits, preventing coke accumulation. The third involves the development of new catalyst or the modification of those conventional catalysts.

Methanol steam reforming (SRMeOH) was first discovered in 1921 by Dane J.A. Christiansen [45]. Many efforts have been made to study the mechanism and extend its application since then. It is an attractive route to produce hydrogen because methanol is potentially a good available source of hydrogen, exists as liquid at ambient conditions, and has a high elemental ratio of hydrogen to carbon (4:1) [21, 46, 47]. Moreover, the reaction has a relatively low selectivity for byproducts such as $\mathrm{CO}$ and $\mathrm{CH}_{4}$, compared to the reforming of alkanes or higher alcohols. But if this technique is to be applied in a proton exchange membrane fuel cell (PEMFC) as expected, the content of CO should be kept at a very low level. According to the research by Lemons [45], with the existence of only $20 \mathrm{ppm} \mathrm{CO}$, the current density at 0.6 volt is divided by two, and by four with $100 \mathrm{ppm}$. Therefore, one of the main obstacles to using SRMeOH for fuel cells is how to meet the demands of low level of $\mathrm{CO}$ content in product composition. 


\subsection{Conventional catalyst used in this research field}

To make supported catalysts, the chosen support is required to be calcined and pressed into pellets at a certain pressure for a certain time [48, 49]. Incipient wetness impregnation is a common method used to prepare metal supported catalysts [15]. After those pellets are crushed and sieved, the support is impregnated in a metal-containing solution followed by drying and calcination. Ashcroft et al. [50] proposed an improved vacuum wetness technology, through which they could obtain highly dispersed noble metal catalysts. With desirable high dispersion, the catalyst could retain sufficient catalytic reactivity while suppressing carbon deposition.

Many metal oxides or activated carbon have been chosen as the support candidates for the metal catalyst [12]. It has been found that the properties of supports play an important role on metal dispersion. The interaction between support and metal affects the catalytic performance, including reactivity, selectivity, as well as resistance to coke formation [51]. Hou et al. [14, 52] found that mesoporous $\mathrm{Al}_{2} \mathrm{O}_{3}$-supported nickel catalysts exhibited the highest activity, stability and excellent coke-resistance ability for $\mathrm{CH}_{4}$ reforming with $\mathrm{CO}_{2}$ among several oxide-supported $\mathrm{Ni}$ catalysts (including mesoporous $\mathrm{Al}_{2} \mathrm{O}_{3}, \gamma-\mathrm{Al}_{2} \mathrm{O}_{3}, \alpha-\mathrm{Al}_{2} \mathrm{O}_{3}, \mathrm{SiO}_{2}, \mathrm{MgO}, \mathrm{La}_{2} \mathrm{O}_{3}, \mathrm{CeO}_{2}$ and $\mathrm{ZrO}_{2}$ ). The porous structure is probably more favorable to the interaction between support and metal while the mesoporous supports may have a more stable structure compared to microporous ones. Investigating methane dry reforming with platinum catalysts, Bitter 
et al. [27] also pointed out that the support has a significant influence on the activity of the Pt/support catalyst. Unsupported $\mathrm{Pt}$ black and $\mathrm{Pt} / \mathrm{SiO}_{2}$ show only a very low and unstable reactivity, whereas $\mathrm{Pt}$ supported on $\gamma-\mathrm{Al}_{2} \mathrm{O}_{3}, \mathrm{TiO}_{2}$ or $\mathrm{ZrO}_{2}$ is much more active and stable for DRM [15]. In addition, Pt seems to be structure sensitive to methane dry reforming [44], which may account for the different extent of carbon deposition that can form quickly, and carbon deposition will deactivate the catalyst. It was also found that Pt atoms located on the support-metal perimeter determine the reactivity to a much greater extent, and those atoms play a more important role in the catalytic performance. [48]

Conventionally, nickel-based catalysts and supported noble catalysts have been widely used for DRM. But coke formation is very severe with those catalysts. Coke will block the active sites on the surface of catalyst, and this can lead to catalyst deactivation and even damage to the reactor [53]. In practice, large amounts of oxidants are often present in the system, preventing much carbon formation on the surface of the catalyst [49]. It has been found [29] that carbon whiskers on nickel catalysts are formed via a mechanism involving dissolution of adsorbed carbon atoms in the nickel crystal and nucleation of the whisker from Ni-surfaces, probably close to the (111) plane. To solve the problem of severe coke formation, the catalyst has been modified. Nielson et al. [28] observed that carbon-free steam reforming of methane could be obtained on a partly sulfur-passivated nickel catalyst would result in formation of whisker carbon under 
conditions in the absence of sulfur,. Recently, addition of alkali or alkaline earth promoters to catalysts was shown to be effective in preventing coke formation from methane during the reforming reaction $[3,26]$. The addition of promoters could change the nature of the support [35], because $\mathrm{CO}_{2}$ is adsorbed strongly on the surface of basic catalysts and covers a large part of the surface at low $\mathrm{CO}_{2}$ partial pressures, and this inhibits carbon deposition. However, the effect of this improvement depends on the nature of the promoters themselves [12]. For example, adding $\mathrm{Na}_{2} \mathrm{O}$ and $\mathrm{MgO}$ to the $\mathrm{Al}_{2} \mathrm{O}_{3}$-supported nickel catalyst will decrease the activity and stability due to the blockage to the $\mathrm{Ni}$ active sites, while $\mathrm{CaO}, \mathrm{La}_{2} \mathrm{O}_{3}$, and $\mathrm{CeO}_{2}$ help to maintain the reactivity and significantly improve the stability.

Table 2-1 lists the results of catalytic dry reforming of methane over some supported and unsupported catalysts. It includes traditional nickel-based catalyst, noble metal and novel carbide catalysts. Besides, the effect of support on the catalytic reactivity is also presented in the table.

As commonly used catalysts for methanol steam reforming, the copper-based catalysts are restricted by instability at high temperatures and the need for precise control of the pretreatment conditions. Many improvements have been made lately. Among the copper-based catalysts, Breen et al. [31] showed that the sequentially precipitated $\mathrm{Cu} / \mathrm{ZnO} / \mathrm{ZrO}_{2} / \mathrm{Al}_{2} \mathrm{O}_{3}$ materials had the highest activities and stabilities for the steam reforming of methanol, and the hydrogen production rate can reach $580 \mathrm{~mol} / \mathrm{kgcat} / \mathrm{h}$ at 
$225^{\circ} \mathrm{C}$. Li et al. [56] prepared $\mathrm{Cu} / \mathrm{Zn}(\mathrm{Zr}, \mathrm{Ce}) \mathrm{Al}_{2} \mathrm{O}_{3}$ catalysts from layered double hydroxide (LDH) precursors. They found that the addition of $\mathrm{Zr}$ enhances the rates of methanol conversion and $\mathrm{H}_{2}$ production greatly, and the addition of Ce improves both the

Table 2-1 Summary of catalytic reforming of $\mathrm{CO}_{2} / \mathrm{CH}_{4}$ in the literature

\begin{tabular}{|c|c|c|c|c|}
\hline $\mathrm{Catalyst}$ & $\mathrm{CO}_{2} / \mathrm{CH}_{4}$ & $\mathrm{Temp}\left({ }^{\circ} \mathrm{C}\right)$ & $\mathrm{X}_{\mathrm{CH} 4}(\%)$ & Ref \\
\hline $\mathrm{Ni} / \mathrm{NaY}$ & $1: 1$ & 600 & 84.0 & 8 \\
\hline $\mathrm{Ni} / \mathrm{Al}_{2} \mathrm{O}_{3}$ & $1: 1$ & 600 & 36.3 & 8 \\
\hline $\mathrm{Ni} / \mathrm{SiO}_{2}$ & $1: 1$ & 600 & 14.9 & 8 \\
\hline $\mathrm{Ni} / \alpha-\mathrm{Al}_{2} \mathrm{O}_{3}$ & $1: 1$ & 800 & 92.4 & 54 \\
\hline $\mathrm{Ni} / \gamma-\mathrm{Al}_{2} \mathrm{O}_{3}$ & $1: 1$ & 800 & 95.8 & 54 \\
\hline $\mathrm{Ni} / \alpha-\mathrm{Al}_{2} \mathrm{O}_{3}$ & $1: 1$ & 800 & 71.5 & 25 \\
\hline $\mathrm{Ca}{ }_{0.1} \mathrm{Ni} / \alpha-\mathrm{Al}_{2} \mathrm{O}_{3}$ & $1: 1$ & 800 & 84.1 & 25 \\
\hline $\mathrm{K} 0.5 \mathrm{Ni} / \alpha-\mathrm{Al}_{2} \mathrm{O}_{3}$ & $1: 1$ & 800 & 64.1 & 25 \\
\hline $\mathrm{K}_{0.5} \mathrm{Ca} 0.1 \mathrm{Ni} / \alpha-\mathrm{Al}_{2} \mathrm{O}_{3}$ & $1: 1$ & 800 & 74.4 & 25 \\
\hline $1 \% \mathrm{Pt} / \mathrm{ZrO}_{2}$ & $2: 1$ & 800 & 95.0 & 48 \\
\hline $1 \% \mathrm{Pt} / \mathrm{TiO}_{2}$ & $2: 1$ & 800 & 74.8 & 48 \\
\hline $1 \% \mathrm{Pt} / \mathrm{Al}_{2} \mathrm{O}_{3}$ & $2: 1$ & 800 & 40.5 & 48 \\
\hline $\mathrm{Pd} / \mathrm{Al}_{2} \mathrm{O}_{3}$ & $1: 1$ & 777 & $70-75$ & 55 \\
\hline $\mathrm{Ru} / \mathrm{Al}_{2} \mathrm{O}_{3}$ & $1: 1$ & 777 & $60-70$ & 55 \\
\hline $\mathrm{Rh} / \mathrm{Al}_{2} \mathrm{O}_{3}$ & $1: 1$ & 777 & $85-90$ & 55 \\
\hline $\mathrm{Ir} / \mathrm{Al}_{2} \mathrm{O}_{3}$ & $1: 1$ & 777 & $65-75$ & 55 \\
\hline$\beta-\mathrm{Mo}_{2} \mathrm{C}$ & $1: 1$ & 847 & 62.5 & 44 \\
\hline $\mathrm{WC}$ & $1: 1$ & 847 & 62.7 & 44 \\
\hline $5 \% \beta-\mathrm{Mo}{ }_{2} \mathrm{C}_{2} \mathrm{Al}_{2} \mathrm{O}_{3}$ & $1: 1$ & 847 & 65.2 & 44 \\
\hline
\end{tabular}


$\mathrm{H}_{2}$ selectivity and the $\mathrm{CO}_{2}$ selectivity. Therefore, the complex $\mathrm{Cu} / \mathrm{Zn}(\mathrm{Zr}, \mathrm{Ce}) \mathrm{Al}_{2} \mathrm{O}_{3}$ catalysts reveal good catalytic performances in the SRMeOH reaction at a lower temperature. Iwasa et al. [57] carried out a study of methanol steam reforming using catalysts based on copper or group VIII metals ( $\mathrm{Ni}, \mathrm{Rh}, \mathrm{Pd}$, and $\mathrm{Pt}$ ) supported on various oxides $\left(\mathrm{SiO}_{2}, \mathrm{Al}_{2} \mathrm{O}_{3}, \mathrm{ZnO}, \mathrm{MgO}, \mathrm{La}_{2} \mathrm{O}_{3}, \mathrm{NdO}_{3}, \mathrm{MnO}_{2}, \mathrm{Cr}_{2} \mathrm{O}_{3}, \mathrm{HfO}_{2}, \mathrm{Nb}_{2} \mathrm{O}_{5}\right)$. Iwasa et al. found that copper-based catalysts and the $\mathrm{Pd} / \mathrm{ZnO}$ catalyst exhibit high catalytic performance (activity and selectivity) as well as good stability over a wide temperature range in the reforming process. Chin et al. [58] investigated $\mathrm{Pd} / \mathrm{ZnO}$ for steam reforming of methanol. Unlike other noble metal-based catalysts, $\mathrm{Pd} / \mathrm{ZnO}$ catalysts not only exhibit high activity, but more importantly very low selectivity to CO. Under the conditions examined, the decomposition activity of methanol is negligibly low. The novel function is attributed to the formation of a highly structured $\mathrm{Pd}-\mathrm{Zn}$ alloy at moderate temperatures under mild reducing environments.

Table 2-2 lists the results of catalytic steam reforming of methanol over some frequently used catalysts, mainly copper-based catalysts, noble metal supported ones and bimetallic carbides.

Carbides of transition metals, especially of tungsten and molybdenum, have been found to have excellent catalytic activity, stability, selectivity and other good properties in a wide range of reactions [44]. Therefore they have been of interest in catalysis studies lately. Initially, this kind of catalyst was mostly prepared using the traditional 
method from the metallurgical industry [59], involving the reaction of metal alloys, metal

Table 2-2 Summary of catalytic reforming of $\mathrm{H}_{2} \mathrm{O} / \mathrm{CH}_{3} \mathrm{OH}$ in the literature

\begin{tabular}{|c|c|c|c|c|}
\hline Catalyst & $\mathrm{H}_{2} \mathrm{O} / \mathrm{CH}_{3} \mathrm{OH}$ & $\begin{array}{c}\mathrm{H}_{2} \text { production rate } \\
(\mathrm{mol} / \mathrm{kgcat} / \mathrm{h})\end{array}$ & $\begin{array}{l}\text { Temp } \\
\left({ }^{\circ} \mathrm{C}\right)\end{array}$ & Ref \\
\hline $\mathrm{Cu} / \mathrm{Zn}(70 / 30)$ & $1.3: 1$ & 443 & 225 & 31 \\
\hline $\mathrm{Cu} / \mathrm{Zr}(70 / 30)$ & $1.3: 1$ & 158 & 225 & 31 \\
\hline $\mathrm{Cu} / \mathrm{Zn} / \operatorname{Zr}(70 / 18 / 12)$ & $1.3: 1$ & 389 & 225 & 31 \\
\hline $\mathrm{Cu} / \mathrm{Zn} / \mathrm{Al}(70 / 18 / 12)$ & $1.3: 1$ & 382 & 225 & 31 \\
\hline $\mathrm{Cu} / \mathrm{Zn} / \mathrm{Zr} / \mathrm{Al}(70 / 18 / 10 / 2)$ & $1.3: 1$ & 580 & 225 & 31 \\
\hline $\mathrm{Cu} / \mathrm{Zn} / \mathrm{Zr} / \mathrm{Al} / \mathrm{Y}(70 / 17 / 10 / 2 / 1)$ & $1.3: 1$ & 554 & 225 & 31 \\
\hline $\mathrm{Cu} / \mathrm{Zn} / \mathrm{Zr} / \mathrm{Al} / \mathrm{La}(70 / 17 / 10 / 2 / 1)$ & $1.3: 1$ & 497 & 225 & 31 \\
\hline $\mathrm{CuO} / \mathrm{CeO}_{2}(80 / 20)$ & $1.5: 1$ & 260 & 250 & 59 \\
\hline $\mathrm{CuO} / \mathrm{CeO}_{2} / \mathrm{ZrO}_{2}(80 / 10 / 10)$ & $1.5: 1$ & 340 & 250 & 59 \\
\hline $\mathrm{CuO} / \mathrm{CeO}_{2} / \mathrm{Al}_{2} \mathrm{O}_{3}(80 / 10 / 10)$ & $1.5: 1$ & 320 & 250 & 59 \\
\hline $\mathrm{CuO} / \mathrm{CeO}_{2} / \mathrm{Y}_{2} \mathrm{O}_{3}(80 / 10 / 10)$ & $1.5: 1$ & 300 & 250 & 59 \\
\hline $2 \% \mathrm{Pd} / \mathrm{ZnO}$ & $1: 1$ & 68 & 230 & 60 \\
\hline $10 \% \mathrm{Pd} / \mathrm{ZnO}$ & $1: 1$ & 173 & 230 & 60 \\
\hline $2 \% \mathrm{Pd} / \mathrm{CeO}_{2}$ & $1: 1$ & 151 & 230 & 60 \\
\hline $10 \% \mathrm{Pd} / \mathrm{CeO}_{2}$ & $1: 1$ & 227 & 230 & 60 \\
\hline $0.4 \% \mathrm{Ni} / \mathrm{Mo}_{2} \mathrm{C}$ & $1: 1$ & 18 & 450 & 61 \\
\hline $3 \% \mathrm{Ni} / \mathrm{Mo}_{2} \mathrm{C}$ & $1: 1$ & 44 & 450 & 61 \\
\hline $6 \% \mathrm{Ni} / \mathrm{Mo} 2 \mathrm{C}$ & $1: 1$ & 76 & 450 & 61 \\
\hline $9 \% \mathrm{Ni} / \mathrm{Mo}_{2} \mathrm{C}$ & $1: 1$ & 173 & 450 & 61 \\
\hline
\end{tabular}


hydrides, or metal oxides with appropriate amounts of carbon in a protective or reducing atmosphere. However this method is accompanied by problems, such as high reaction temperature required and low surface area obtained.

High-surface-area early transition metal carbide materials (i.e. $\beta-\mathrm{Mo}_{2} \mathrm{C}, \alpha-\mathrm{WC}$ ) can be prepared by temperature-programmed reduction (TPR) of the relevant oxides (i.e. $\mathrm{MoO}_{3}, \mathrm{WO}_{3}$ ) in a flowing carburizing gas mixture, $\mathrm{CH}_{4}$ or $\mathrm{CH}_{4} / \mathrm{H}_{2}[32,34]$. Due to strong electronic similarities between the carbide catalysts and noble metal catalysts, similar catalytic performance for methane reforming reaction has also been reported for these two catalyst types, including resistance to coke formation [18, 62-64]. The activity of these carbides as compared to the noble metals is ordered as [44] $\mathrm{Ru}>\mathrm{Rh} \cong$ $\mathrm{Mo}_{2} \mathrm{C}>\mathrm{Ir}>\mathrm{WC}>\mathrm{Pd}>\mathrm{Pt} . \quad$ Surprisingly, the type of transition metal carbide prepared using the above method can only exhibit stable activity at elevated pressure. The reactivity decreases dramatically after a short period of time on stream at atmospheric pressure because of oxidation by $\mathrm{CO}_{2}$. In addition, Thomson et al. [65] also showed that this transition metal carbide $\mathrm{Mo}_{2} \mathrm{C}$ is subject to oxidation by oxygen, carbon dioxide or water, by a mechanism which is not clear yet. But the consequence is the deactivation of the catalyst by transforming those active carbides into ineffective oxides.

Polizzoti et al. [66, 67] proposed an alternative method to obtain eta-phase bimetallic carbides in powder form by temperature programmed reaction (TPR) of the corresponding precursor in flowing $\mathrm{CO}_{2} / \mathrm{CO}$ mixture. The precursor salt compound 
includes two eta-phase-forming metals and a ligand containing carbon. The carbon content can be controlled by adjusting the ratio of $\mathrm{CO}_{2}$ to $\mathrm{CO}$ and giving different carbon activity in the carburization process. With various carbon contents in the bimetallic carbide catalysts, the phase of the carbides may also change in accordance to the ternary phase diagram. In addition, two different metallic elements can be chosen from similar element groups. For example, early transition metals molybdenum and tungsten are typical elements from Group VIB. The second metal is selected from the group consisting of $\mathrm{Fe}, \mathrm{Co}, \mathrm{Ni}$, Mo and $\mathrm{W}$. In this work, different bimetallic carbides will be prepared in house in order to be used for reforming reaction by changing the metal elements and varying $\mathrm{CO}_{2} / \mathrm{CO}$ ratio during the carburization. 


\subsection{Overview of reaction mechanism and kinetics for hydrogen production process}

\subsubsection{Dry reforming of methane (DRM)}

The reaction kinetics for methane dry reforming depend on the type of catalyst, and may change with the temperature range under which the reaction takes place [68-75]. Hence, up to now there is still no agreement on the reaction kinetics that have been expressed for DRM. Through experimental data and some experience, some generally accepted reaction kinetics and mechanism have been reported.

Wang et al. [3] put forward the following sequence of steps for the methane dry reforming with nickel-based catalyst:

1) dehydrogenation of methane to form surface carbon and hydrogen

$$
\mathrm{CH}_{4} \rightarrow \mathrm{C}(\mathrm{a})+4 \mathrm{H}(\mathrm{a})
$$

2) reduction of carbon dioxide to carbon monoxide

$$
\mathrm{CO}_{2}(\mathrm{~g}) \rightarrow \mathrm{CO}(\mathrm{a})+\mathrm{O}(\mathrm{a})
$$

3) formation of carbon monoxide via reaction between carbon and oxygen

$$
C(a)+O(a) \rightarrow C O(a)
$$

4) desorption of carbon monoxide and hydrogen

$$
\begin{aligned}
& \mathrm{CO}(\mathrm{a}) \rightarrow \mathrm{CO}(\mathrm{g}) \\
& 2 \mathrm{H}(\mathrm{a}) \rightarrow \mathrm{H}_{2}(\mathrm{~g})
\end{aligned}
$$


Iyer et al. [76] proposed the reaction mechanism based on DRM with $\mathrm{Co}_{6} \mathrm{~W}_{6} \mathrm{C}$ (from Nanodyne Company) under differential conditions. The experimental studies were carried over a temperature range between $500^{\circ} \mathrm{C}$ and $600^{\circ} \mathrm{C}$ A Langmuir-Hinshelwood type of model was set up, which includes a series of reaction steps:

$$
\begin{aligned}
& \mathrm{CH}_{4}+* \leftrightarrow \mathrm{CH}_{x} *+(\mathrm{x} / 2) \mathrm{H}_{2} \\
& \mathrm{CO}_{2}+* \leftrightarrow \mathrm{CO}+\mathrm{O} * \\
& \mathrm{CH}_{x} *+\mathrm{O} * \rightarrow \mathrm{CO}+(\mathrm{x} / 2) \mathrm{H}_{2}+2 * \\
& \mathrm{CH}_{x} * \leftrightarrow \mathrm{C} *+(\mathrm{x} / 2) \mathrm{H}_{2} \\
& \mathrm{H}_{2}+\mathrm{O} * \leftrightarrow \mathrm{H}_{2} \mathrm{O}+* \\
& \mathrm{C} *+\mathrm{O} * \leftrightarrow \mathrm{CO}+2 *
\end{aligned}
$$

Compared with the other reaction kinetics and mechanism, this model proposed incorporated all possible reactions in the reforming process, including not only methane reforming, but also water production via reverse water gas shift, carbon deposition via methane decomposition, and carbon removal via reverse Boudouard reaction, some of which may have not been considered in the other scheme.

\subsubsection{Steam reforming of methane (SRM)}

The original reaction mechanism was proposed in 1967 by Bodrov and 
Apel'baum [77, 78], who described results over a nickel foil.

$$
\begin{aligned}
& \mathrm{CH}_{4}+2 * \rightarrow \mathrm{CH}_{3} *+\mathrm{H} * \\
& \mathrm{CH}_{3} * \rightarrow \mathrm{CH}_{2} *+\mathrm{H} * \\
& 2 \mathrm{H} * \leftrightarrow \mathrm{H}_{2}+2 * \\
& \mathrm{CH}_{2} *+\mathrm{H}_{2} \mathrm{O} \leftrightarrow \mathrm{CO} *+2 \mathrm{H}_{2} \\
& \mathrm{CO} * \leftrightarrow \mathrm{CO}+*
\end{aligned}
$$

The adsorbed $\mathrm{CH}_{4}$ dissociates consecutively into $\mathrm{CH}_{2}{ }^{*}$, rendering $\mathrm{H}^{*}$ to form molecular hydrogen, which would desorb from catalyst surface. $\mathrm{CH}_{2} *$ reacts with $\mathrm{H}_{2} \mathrm{O}$ to produce $\mathrm{CO}^{*}$ and $\mathrm{H}_{2}$. Afterwards, $\mathrm{CO}$ is desorbed and releases the active site. In this scheme, the water gas shift and reverse Boudouard reactions were not considered.

It has been realized that the dissociation of methane on a nickel catalyst to form surface-bound methyl and hydrogen is the rate-limiting step in steam reforming [79]. This limiting effect is more outstanding at low pressure. Because of this, the commercial process for SRM is often operated at elevated pressures (30 atm). By molecular beam-high resolution electron energy loss (HREEL) techniques, Ceyer et al. [80] investigated the dynamics of the activated dissociative chemisorption of methane on $\mathrm{Ni}$ (111). They identified adsorbed methyl radical as the product of methane dissociation. It was also found that the barrier to the dissociation can be overcome by increasing translational energy in low pressure, ultrahigh vacuum surface science. 


\subsubsection{Steam reforming of methanol (SRMeOH)}

Similarly, some uncertainties still exist in the reaction mechanism and kinetics of methanol steam reforming. Some possible pathways are listed in Figure 2-1 [60]:

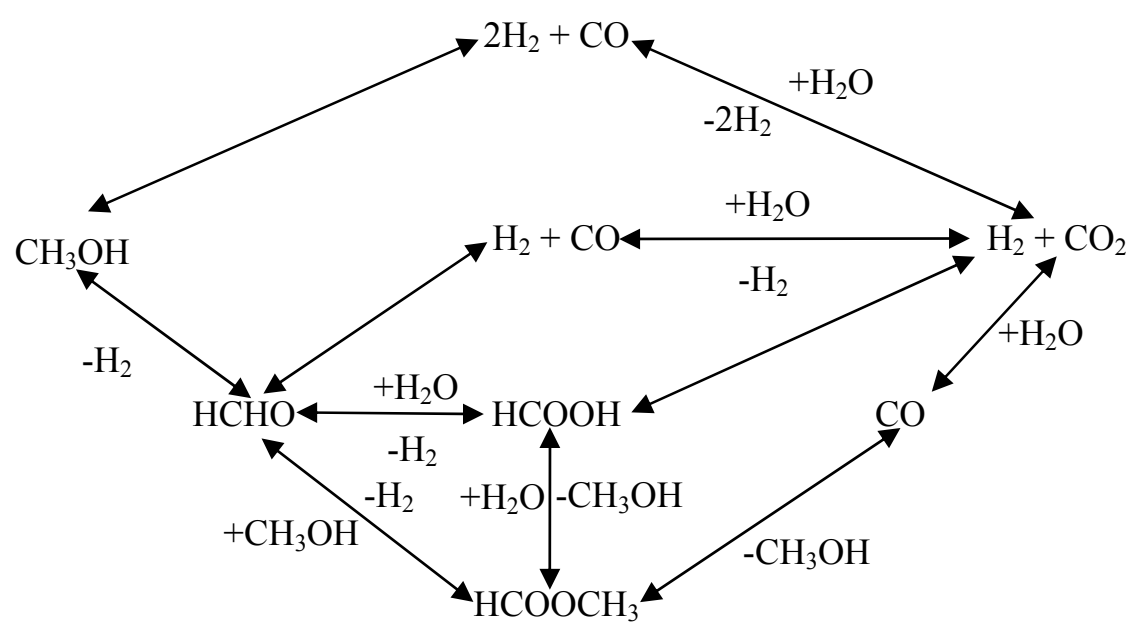

Figure 2-1 Possible reaction pathways for SRMeOH reaction [60]

Many species can be produced as either intermediates or final products by this complicated reaction network, including $\mathrm{H}_{2}, \mathrm{CO}, \mathrm{CO}_{2}, \mathrm{HCHO}, \mathrm{HCOOH}$, and $\mathrm{HCOOCH}_{3}$. In fact, the mechanism and kinetics of the reforming reaction depends strongly on the catalyst used including the support type and the loading.

Over $\mathrm{Cu} / \mathrm{ZnO} / \mathrm{Al}_{2} \mathrm{O}_{3}$, Peppley et al. $[81,82]$ propose that there are three reactions involved in the whole process:

Methanol and steam reacting directly to form $\mathrm{H}_{2}$ and $\mathrm{CO}_{2}$ 
$\mathrm{CH}_{3} \mathrm{OH}+\mathrm{H}_{2} \mathrm{O} \leftrightarrow 3 \mathrm{H}_{2}+\mathrm{CO}_{2}$

Methanol decomposition to $\mathrm{H}_{2}$ and $\mathrm{CO}$

$\mathrm{CH}_{3} \mathrm{OH} \leftrightarrow 2 \mathrm{H}_{2}+\mathrm{CO}$

Water-gas shift reaction

$\mathrm{CO}+\mathrm{H}_{2} \mathrm{O} \leftrightarrow \mathrm{H}_{2}+\mathrm{CO}_{2}$

The kinetic model was developed based on an analysis of the surface mechanism.

In terms of detailed reaction rate data and kinetic modeling, three key features of the mechanism were pointed out by Pepply et al. [81, 82]:

1) Hydrogen adsorption does not compete for the active sites on which the oxygen-containing species adsorb;

2) Active sites for the decomposition reaction are different from those for the methanol-steam reaction and the water-gas shift reaction;

3) The rate-determining step (RDS) for both the methanol steam reaction and the methanol decomposition reaction is the dehydrogenation of adsorbed methoxy groups, while the RDS for the water-gas shift reaction is the formation of an intermediate formate species.

The above mechanism is a typical one in which carbon monoxide is formed. There is another alternative mechanism without $\mathrm{CO}$ formation in the reforming process. Jiang et al. [83, 84] also investigated the steam reforming of methanol over a 
$\mathrm{Cu} / \mathrm{ZnO} / \mathrm{Al}_{2} \mathrm{O}_{3}$ catalyst, but came to a fairly different conclusion from that of Pepply et al. mechanism $[81,82]$. The whole process could be described as:

Methanol first dehydrogenates to formaldehyde,

$$
\mathrm{CH}_{3} \mathrm{OH} \rightarrow \mathrm{HCHO}+\mathrm{H}_{2}
$$

Hydrolysis of formaldehyde to formic acid

$$
\mathrm{HCHO}+\mathrm{H}_{2} \mathrm{O} \rightarrow \mathrm{HCOOH}+\mathrm{H}_{2}
$$

Finally carbon dioxide and hydrogen is produced by decomposition of formic acid:

$$
\mathrm{HCOOH} \rightarrow \mathrm{H}_{2}+\mathrm{CO}_{2}
$$

This scheme is very similar to the one proposed by Thompson et al. [61], who studied the reaction using $\mathrm{ZnO}$ and $\mathrm{CeO}_{2}$ supported copper catalysts. Detailed studies of the kinetics of the reactions showed that methanol dehydrogenation is the rate determining step. By fitting the rate data with Langmuir-Hinshelwood model, it was found that hydrogen extraction from adsorbed methoxy groups was rate determining to the overall processes. 


\subsection{Review of some techniques used for catalyst characterization}

Generally speaking, the performance of a catalyst can be evaluated by three principal properties: reactivity, selectivity and stability [85]. Catalyst characterization is a very important discipline in catalysis, which can bridge the fundamental relationships between the structure of catalyst and its catalytic properties. Here, the structure includes bulk as well as surface properties. In the following, several characterization techniques will be reviewed. Table 2-3 lists some common techniques and their related information.

\subsubsection{BET surface area and pore size distribution}

Brunauer, Emmett and Teller (BET) successfully put forward a method to measure the surface of a material based on multiple-layer physisorption in 1938 [86]. According to the BET equation, the surface area can be calculated from nitrogen adsorption isotherms at liquid nitrogen temperatures.

Further, the total pore volume can be determined at $\mathrm{P} / \mathrm{P}_{0}$ equal to 0.98 [52], where $\mathrm{P}$ is the saturation pressures for curved interface and $\mathrm{P}_{0}$ is the saturation pressure for flat interface. The surface area and pore volume of the micropores can be obtained by the t-plot method. By

$$
R_{p}=2 V_{l i q} / S_{B E T}
$$

the average pore size $\mathrm{R}_{\mathrm{p}}$ can be known, where $\mathrm{V}_{\text {liq }}$ is the volume of liquid adsorbed in the 
pore.

Table 2-3 List of some characterization techniques-based on [85]

\begin{tabular}{|c|c|c|c|c|}
\hline Acronym & Full Name & In & Out & Information \\
\hline BET & $\begin{array}{l}\text { Brunauer, Emmett and } \\
\text { Teller Surface Analysis }\end{array}$ & Gas & Gas & Surface Area \\
\hline XRD & X-Ray Diffraction & X-Ray & X-Ray & $\begin{array}{c}\text { Bulk Structure, } \\
\text { Particle Size }\end{array}$ \\
\hline $\begin{array}{l}\text { TPR } \\
\text { TPO } \\
\text { TPH }\end{array}$ & $\begin{array}{c}\text { Temperature } \\
\text { Programmed Reduction } \\
\text { Oxidation } \\
\text { Hydrogenation }\end{array}$ & Heat + Gas & Gas & $\begin{array}{c}\text { Mechanism of Bulk } \\
\text { and Surface } \\
\text { Reactions }\end{array}$ \\
\hline DTA & $\begin{array}{c}\text { Differential Thermal } \\
\text { Analysis }\end{array}$ & Gas & Gas & $\begin{array}{c}\text { Measure the amount } \\
\text { of coke }\end{array}$ \\
\hline SEM & $\begin{array}{l}\text { Scanning Electron } \\
\text { Microscopy }\end{array}$ & electron & electron & Morphology \\
\hline EDAX & $\begin{array}{c}\text { Energy Dispersive } \\
\text { X-Ray Analysis }\end{array}$ & electron & X-Ray & Composition \\
\hline NEXAFS & $\begin{array}{l}\text { Near Edge X-Ray } \\
\text { Adsorption Fine } \\
\text { Structure }\end{array}$ & X-Rays & X-Rays & Local Structure \\
\hline
\end{tabular}

\subsubsection{X-ray diffraction}

$\mathrm{X}$-ray diffraction (XRD) is a very frequent and well developed measurement to 
identify the collective phases of the catalyst, monitor the kinetics of bulk transformations and estimate approximate particle size. XRD is used to characterize crystalline phases inside catalysts by means of lattice structural parameters and the Bragg equation (2-26):

$$
\begin{aligned}
& \boldsymbol{n} \lambda=\mathbf{2 d} \sin \theta \quad \mathrm{n}=1,2, \ldots \ldots \\
& \text { where } \quad \lambda: \quad \text { wavelength of the X-rays } \\
& \mathrm{d}: \quad \text { distance between two lattice planes } \\
& \theta: \quad \text { angle between the incoming X-rays and the normal to the reflecting } \\
& \quad \text { lattice place }
\end{aligned}
$$

To characterize a powder sample, a stationary source (usually $\mathrm{CuK} \alpha$ ) coupled with a movable detector will be used, and the intensity of the diffracted radiation is scanned as a function of the angle $2 \theta$ between the incoming and diffracted beams [85]. The particle size of powder sample can be roughly estimated from X-ray line broadening. Another attractive advantage of this technique is that X-rays have enough penetrating power to investigate the catalyst in situ, which provides a more convenient and accurate method to observe the phase change of the catalyst during the reaction.

\subsection{3. $\mathrm{H}_{2}$-temperature programmed reduction (TPR)}

Reduction is almost an inevitable stage in the manufacture of metallic catalyst, which often plays an important role in the catalytic performance. $\mathrm{H}_{2}$ is typically being 
used as a reducing agent. By measuring the hydrogen amounts before and after the reaction, a TPR spectrum can be plotted, which is the variation of hydrogen consumption as a function of temperature. TPR provides the useful information of the temperature required for the complete reduction of a catalyst [85]. The position and size of the peaks in the spectrum can describe the interaction of the particles and the properties of the metal oxide.

Carbon formation is a problem encountered by many researchers in the development of the catalyst for methane reforming. Carbon formation on the spent catalyst can be determined both qualitatively and quantitatively. Bradford et al. [15] quantify carbon deposits by integrating the $\mathrm{CH}_{4}$ evolution spectra from flowing $\mathrm{H}_{2}$ coupled with on-line GC.

\subsubsection{Temperature-programmed oxidation (TPO)}

TPO can be used to determine the morphology and properties of carbon deposits.

[14] TPO yields peaks at three different temperatures leading to three types of carbon deposits. The first one is $\mathrm{C}_{\alpha}$, the highly reactive carbon and the intermediate in the reforming reaction, which is good for the reaction. The second one is $\mathrm{C}_{\beta}$, whisker carbon formed on or close to the metal. The third one is the most stable carbon $\mathrm{C}_{\gamma}$, the graphite coke formed on the catalyst. $\mathrm{C}_{\beta}$ and $\mathrm{C}_{\gamma}$ deactivate the catalyst in the reaction. 


\subsubsection{Thermogravimetry-Differential thermal analysis (TG-DTA)}

The amount of coke deposits can be analyzed quantitatively with TG-DTA. Hou et al. [14] reported that the amount of coke formed in the reforming process can be calculated from the TG-DTA test result [87]. By measuring the weight loss during TG test, the amount of coke formed in the process of reforming reaction can be determined. The position of the weight loss peak indicates the type of deposited carbon.

\subsubsection{SEM and EDAX}

Scanning electron microscopy (SEM) is fairly straightforward to investigate the size and morphology of the catalyst. SEM is carried out by rastering a narrow electron beam over the surface and detecting the electrons yield as a function of the position of the primary beam [85]. Two types of electrons can be detected by this technique: secondary and backscattered electrons. Secondary electrons $(<50 \mathrm{eV})$ originate from the sample surface, and carry information of morphology of the sample. Backscattered electrons $(>50 \mathrm{eV})$ are from a deeper position under the surface and can provide insight of the chemical components of the sample. Because scattering efficiency is related to the atomic number, bright areas in the image often indicate high concentrations of heavy elements. The whole effect of contrast formed in the image is due to the different morphology and composition of the catalyst surface.

Energy dispersive analysis of X-rays (EDAX) is used to identify the elemental 
composition of the sample, and works as an integrated feature of SEM. During EDAX analysis, the sample is bombarded with an electron beam inside the SEM. The bombarding electrons collide with and ionize atoms in the sample. An energy level vacated by an ejected inner shell electron will eventually be occupied by an electron from an outer shell, which has a higher energy level. For this to occur, however, the outer shell electron must give up some of its energy. One way this can happen is by the emission of an X-ray. The energy of the X-ray is equal to the difference in energy of the two electron levels and is unique for each specified atom. Thus, by measuring the amounts of energy carried in the X-rays being released by a sample during electron beam bombardment, the atom from which the X-ray is emitted can be uniquely identified.

\subsubsection{NEXAFS}

Near edge X-ray absorption fine structure (NEXAFS) typically represents the energy region from the absorption edge to about $50 \mathrm{eV}$ above the edge [86, 88]. It can specify an element well because of the excitation of core electrons, can provide information about the average interaction between the surface and adsorbates, and can determine the molecular orientation by varying the incidence angles of the polarized synchrotron beam. In the measurement, the electrons are excited from a core level to partially filled and empty state, therefore the peak positions and lineshapes of patterns embody important information with regards to the physical and chemical properties. 
NEXAFS has been recognized as a powerful characterization technique for transition metal compounds. They can be in the form of a bulk single crystal, well-characterized overlayers on parent metals or powder materials. By investigating K-edge features of $2 p$ elements $(C, N, O)$, L-edge features of $3 p$ elements $(S, P)$ and $3 d$ elements $(\mathrm{Co}, \mathrm{Ni}, \mathrm{Fe}, \mathrm{V})$, and $\mathrm{M}$-edge feature of $4 \mathrm{~d}$ elements (Mo), unique and important information can be obtained to characterize the catalyst from the characteristic peak position and intensity, both before and after reaction. In addition, the interaction between metal and nonmetal can also be detected from the shift of peak position or the change of peak intensity. 


\section{CHAPTER 3 EXPERIMENTAL SETUP AND PROCEDURE}

\subsection{Equipment description}

As shown in Figure 3-1, the catalyst-testing unit is computer controlled with a commercial software package In Touch by Wonderware Company. For safety, the entire unit is set in a walk-in-hood, except for the computer and gas chromatograph (GC). Besides, two sensors for detecting the combustive gas are installed in the hood area. Using the current software, most of the operating parameters can be preset from the computer controlling station, including the temperature, flow rate, time interval. However, the reaction pressure can only be manually adjusted by the back-pressure regulator (Model P/N 101182, GO Regulator Inc.). Both mechanical and electrical pressure gauges are supplied to provide pressure readings in the reactor. The safe operating range is up to 100 psig for pressure and up to $900^{\circ} \mathrm{C}$ for temperature. The reaction will shut down automatically once the operation parameters are beyond those limits.

Four separate lines are supplied for gas feed, each of which can be controlled by a Brooks mass-flow controller (Model No.5850E) individually. The gas flow rate in each line can be set from the computer individually, but each mass-flow controller is required to be calibrated before use (see Appendix A). In the experiments dealing with steam reforming reactions, the liquid is introduced by a HPLC pump (ISCO Model 2350) from an independent line. To prevent the liquid line (which is $1 / 16$ in OD) being blocked by 


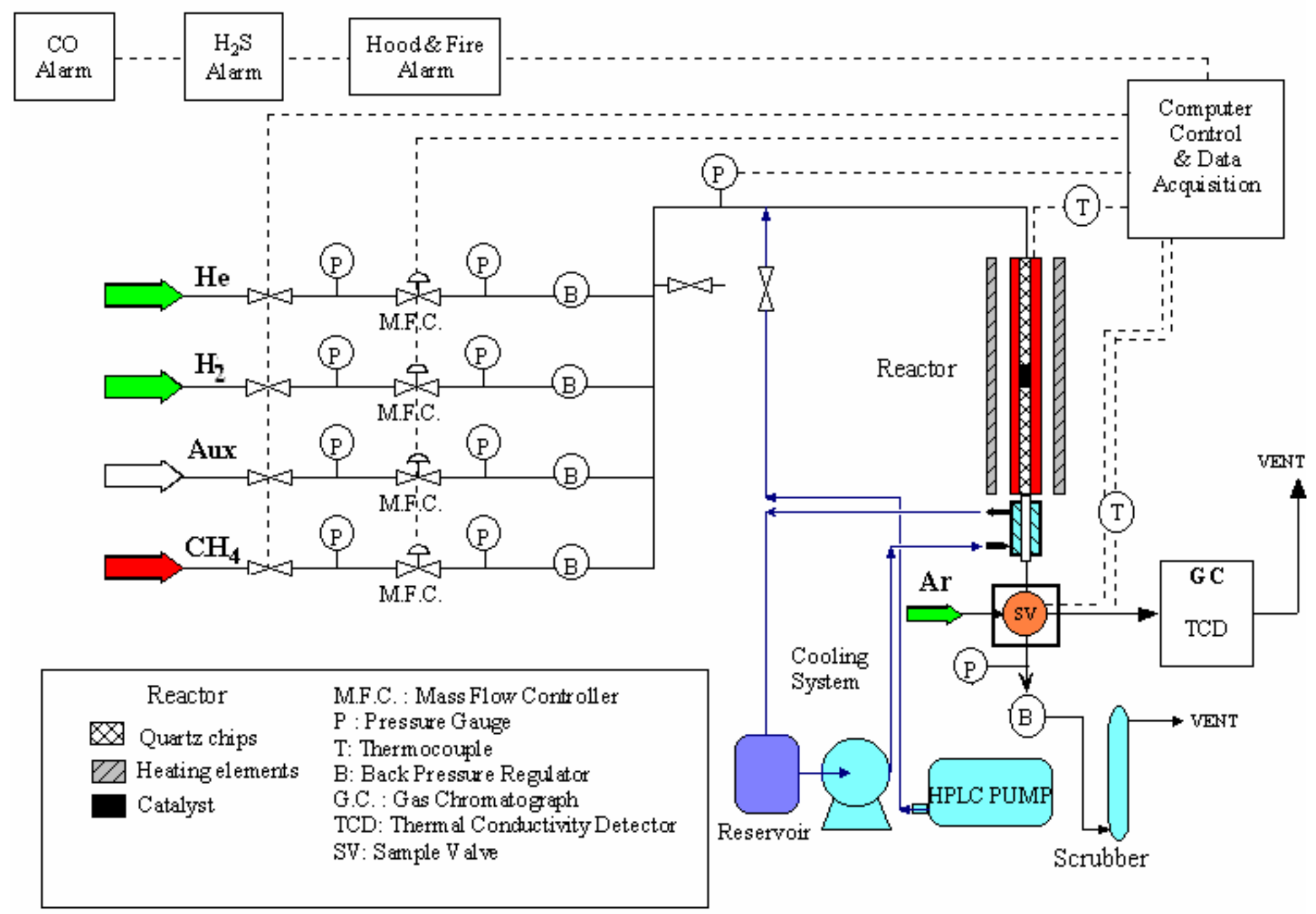

Figure 3-1 Flow sheet for catalyst testing unit 
the pressure inside the reactor, a valve is added before the liquid enters the reactor. The valve will not open until the pressure inside the pump is at least 40 psi higher than that in the reactor. However, the liquid line can be omitted for methane dry reforming, in which no liquid is fed as reactant.

Reactions are performed in a stainless-steel reactor (SS 304L) with an outer diameter of 0.5 in and a length of 25 in placed in an 18 in single-zone furnace from Applied Test Systems. Prior to the reaction, the reactor needs to be heat-treated at $850^{\circ} \mathrm{C}$ for two hours followed by lining with silica by Restek Corporation. A stainless-steel sheathed thermocouple (K-type, Model CAIN-116U-18, Omega Engineering Inc.) is inserted into the center of the catalyst bed to monitor and control the reaction temperature range.

The products are sampled immediately downstream at a preset interval using a Valco six-port gas-sampling valve set at the same pressure as the reactor and at a minimum temperature of $120^{\circ} \mathrm{C}$. A SS frit $\left(1 / 2\right.$ " OD" $\times 1 / 32^{\prime \prime}$ thick $\times 2$ micron, Alltech Associates Inc.) is added before the product stream enters the sampling valve in order to prevent coke or catalyst residue from falling down to damage the sampling valve. In case the hot effluent gases may heat up the valve to a temperature beyond its operating range, a cooling system is added between the reactor outlet and the sampling valve and is circulated with silicon oil (Corning Company) at $150^{\circ} \mathrm{C}$. The composition of produced gas mixture is analyzed using an on-line Hewlett-Packard 5890 gas chromatograph (GC) 
equipped with a thermal-conductivity detector (TCD), which provides quantitative analysis for $\mathrm{H}_{2}, \mathrm{CO}, \mathrm{CH}_{4}, \mathrm{CO}_{2}, \mathrm{H}_{2} \mathrm{O}$, and $\mathrm{CH}_{3} \mathrm{OH}$. Adequate separation of the products is achieved using a Haysep-DB packed column, $30 \mathrm{ft} \times 1 / 8$ in. Helium is the internal standard while argon serves as the carrier gas. Calibration of the GC using various ratios of the reactants and products resulted in a mass/area relationship for each gas species (see Appendix A). The GC is controlled using Hewlett-Packard Chemstation software by the same computer in a multitasking MS windows environment. The oven temperature is maintained isothermal at $150^{\circ} \mathrm{C}$, the inlet temperature is set at $150^{\circ} \mathrm{C}$, and TCD detector temperature is fixed at $255^{\circ} \mathrm{C}$. The total carrier gas flow rate is fixed at $70 \mathrm{cc} / \mathrm{min}$. Half the carrier gas acts as the reference, while the other half moves the sample from the loop through the column. The GC feed line from the sample loop is heated by heating tapes and maintained at a temperature around $150^{\circ} \mathrm{C}$ to prevent condensation of the products. Under these conditions, all the gases to be analyzed can be separated after passing through the column in the GC. The reactor effluent (vapor phase) that is not passed through the GC is vented to the hood after passing through a scrubber.

\subsection{Catalyst Testing Procedure}

For each run, the empty reactor is first tested without loading any catalyst, to check the catalytic activity of the reactor itself. In the catalyst testing, typically $300 \mathrm{mg}$ 
of the catalyst sample is used. The catalyst is loaded on top of quartz wool, which is placed in the center of the reactor. After setting the quartz wool, the downstream of the reactor is filled with fine quartz chips (approx. 1/16 in), and the bottom is sealed with some quartz wool. All these chips have to be washed and dried before using to prevent the quartz fines from plugging the reactor. Then the catalyst is put into the reactor through a funnel from the top of the reactor, followed by tapping to ensure that all the catalyst sits in the center of the reactor. Next the thermocouple is inserted into the reactor, making sure that the tip of the thermocouple touches the catalyst bed, and the top fitting is then connected. Finally, some more quartz chips are added from the side opening of the reactor to fill the upstream of the reactor. The loaded reactor is then mounted in the set up with the furnace enclosure. The system is then checked for leaks by flowing an inert gas (argon) at elevated pressure (60 psig).

The catalyst is pretreated by being reduced with flowing hydrogen (ultra high purity) at $60 \mathrm{scc} / \mathrm{min}$ for one hour, followed by one hour of flushing with argon (ultra high purity). The GC is switched on only after ensuring the flow of the carrier gas through the column and TCD (35 cc/min for each path). The reaction starts once the pretreatment finishes. The flow rates and the temperature can be adjusted with the computer. But in the case of steam reforming, the flow rate of the liquid is set manually from the control panel of the HPLC pump. The reaction pressure can only be adjusted by the back-pressure regulator. The computer can be preset to take samples at specified time intervals (mostly every hour) and also to analyze samples for a certain time period 
(28 minutes). The computation work will be based on the calibration result as well as $\mathrm{GC}$ analysis data report.

\subsection{Catalyst Characterization Techniques}

Catalysts surface areas are determined by using $\mathrm{N}_{2}$ Brunauer-Emmett-Teller (BET) isotherms using an Omnisorp 360, and the detailed measurement was done by Professor Kugler. The sample is first evacuated overnight under high vacuum to degas surface at $300^{\circ} \mathrm{C}$. Thereafter, the sample is isolated from vacuum and cooled to room temperature, followed by being placed in liquid nitrogen bath. After purging the system and evacuating the manifold to high vacuum, the measurement is automatically initiated, including the calibration and calculation of sample surface area. Detailed calculations were performed by instrument manufacture's software. The true density (TD) of the samples was measured using AccuPyc 1330 manufactured by Micromeritics.

Temperature programmed reduction (TPR) is carried out to track the reduction peaks of the catalyst to obtain information on oxidation-reduction properties of the materials. Typically, around 100mg of the material is loaded in a quartz U-tube (1/4 in OD) reactor, which is then placed in a temperature controlled furnace. A thermocouple is inserted on the top of the catalyst to monitor the temperature. With flowing $5 \% \mathrm{H}_{2}$ balanced in $\mathrm{Ar}$, the temperature is increased from room temperature to $865^{\circ} \mathrm{C}$ at a heating rate of $10^{\circ} \mathrm{C} / \mathrm{min}$, and held there for 2 hours. The effluent gas is passed through an 
on-line GC. The amount of $\mathrm{H}_{2}$ consumption can be recorded and analyzed by TCD as a function of time (and therefore temperature). After the temperature program finishes, the furnace is shut down, and the reactor cools down automatically.

Bulk crystalline components and properties of the materials are identified by traditional XRD analysis, which was carried out by Professor Seehra's research group. The measurement is carried out using a Rigaku D-MAXB diffractometer and monochromatic radiation $\mathrm{Cu} \mathrm{K \alpha}$, which has an energy of $8.04 \mathrm{keV}$ and a wavelength of $1.5418 \mathrm{~nm}$. The voltage applied to the target specimen is $40 \mathrm{kV}$, and the filament current is preset to $30 \mathrm{meV}$. The scanning range of angle $2 \theta$ is from 5 to 100 degrees at a constant speed 0.06 degree $/ 5 \mathrm{sec}$.

Scanning electron microscopy (SEM) is used to investigate the surface structure of the catalyst, and chemical analysis can be detected by energy dispersive analysis of $\mathrm{X}$-rays (EDAX). The instrument used for SEM and EDAX measurement is a model S-4700 field scanning electron microscope manufactured by Hitachi, and the analysis is processed with Genesis software. The Hitachi S-4700 SEM operates using a cold-field emission electron source. A single crystal tungsten tip with a $100 \mathrm{~nm}$ curvature radius acts as a cathode. With two sets of anodes and in a high vacuum environment (as low as $1 \times 10^{-8} \mathrm{~Pa}$ at the last ion pump), the instrument is able to generate an electron beam with a virtual source size as small as $3 \mathrm{~nm}$ in diameter. The $\mathrm{S}-4700$ has a detector combining secondary (SE) and backscattered (BSE) electron detection in a single unit, 
which can provide more reliable and complete information of morphology and chemistry. The typical accelerating voltage used in this work is $5-20 \mathrm{kV}$, depending on the resolution. Image processing and data recording proceed automatically once the test starts. This part of work has been done by Steve Carpenter.

NEXAFS measurements are performed at the U1A Beamline, National Synchrotron Light Source (NSLS), Brookhaven National Laboratory by the research group of Professor Jingguang Chen, University of Delaware. The powder catalyst is required to be pressed into a sample holder first. The typical dimension for the sample holder cup is $1 \mathrm{~cm}$ in diameter and $0.1 \mathrm{~cm}$ in depth. Electron yield intensities are measured with a channeltron multiplier with a front-end bias of - $100 \mathrm{~V}$, to reduce signals from secondary electrons. The NEXAFS spectra are measured as a function of the incident X-ray photon energy with an energy resolution of approximately $0.8 \mathrm{eV}$. For carbon K-edge NEXAFS, the incident photon energy is $270-330 \mathrm{eV}$; for the oxygen $\mathrm{K}$-edge region, the energy is $520-580 \mathrm{eV}$; and for the cobalt L-edge region, the energy is $760-820 \mathrm{eV}$. 


\section{CHAPTER 4 PREPARATION AND CHARACTERIZATION OF BIMETALLIC CARBIDE CATALYST}

\subsection{Introduction}

As mentioned earlier, there is considerable interest in developing novel and potentially active catalysts for natural gas reforming. Lately, early-transition-metal carbide catalysts have been found to be very promising for methane reforming with mild reactivity and stability as well as reasonable cost. The addition of the second metallic element to improve catalytic performance is one of the main objectives in this work.

This chapter details the method of preparing this novel bimetallic carbide catalyst. Afterwards, the effect of an important parameter, the $\mathrm{CO}_{2} / \mathrm{CO}$ ratio during the carburization process, on the final product is discussed. Finally, the characterization of the in-house prepared carbide catalysts are presented using different techniques, including BET, TPR, XRD, SEM \& EDAX. This work can provide both bulk and surface properties of the carbide catalysts, thereby helping to explain observations in catalyst testing and evaluation. 


\subsection{Catalyst Preparation Procedure}

Preparation of the bimetallic carbide catalyst is described in the patent by Polizzotti et al. [67]. This eta-phase carbide has the general form of $\mathrm{X}_{6} \mathrm{Y}_{6} \mathrm{C}_{\mathrm{m}}$ [66]. In this structure, $\mathrm{X}$ corresponds to either $\mathrm{W}$, or Mo, or the combination of these two metals. $\mathrm{Y}$ is selected from the group consisting of $\mathrm{Fe}, \mathrm{Co}, \mathrm{Ni}$, individual element or random combination. The value of $\mathrm{m}$ ranges from 1 to 2 , depending on the carbon activity in the carburization process. The detailed preparation procedure for cobalt tungsten carbide $\left(\mathrm{Co}_{6} \mathrm{~W}_{6} \mathrm{C}\right)$ used in this work is described below.

\subsubsection{Preparation of precursor $\mathrm{Co}(\mathrm{en})_{3} \mathrm{WO}_{4}$}

$14.5 \mathrm{~g}$ of tungstic acid $\left(\mathrm{H}_{2} \mathrm{WO}_{4}\right)$ is dissolved in $400 \mathrm{ml}$ of ammonium hydroxide $\left(\mathrm{NH}_{4} \mathrm{OH}\right)$ diluted in distilled water $\left(1: 1 \mathrm{vol}, 200 \mathrm{ml} \mathrm{NH} \mathrm{NH}_{4} \mathrm{OH} 200 \mathrm{ml} \mathrm{H}_{2} \mathrm{O}\right)$ and $300 \mathrm{ml}$ of ethylenediamine $\left(\mathrm{NH}_{2} \mathrm{CH}_{2} \mathrm{CH}_{2} \mathrm{NH}_{2}\right)$, followed by heating and stirring until the solution turns into clear (labeled as Solution A). In the meanwhile, $13.8 \mathrm{~g}$ of cobalt chloride hexahydrate $\left(\mathrm{CoCl}_{2} \cdot 6 \mathrm{H}_{2} \mathrm{O}\right)$ is dissolved in $50 \mathrm{ml}$ of distilled water to get Solution B. The metal molar ratio of tungsten to cobalt is fixed at 1:1. Afterwards, Solution B is slowly added into Solution A using a dropper, overhead stirring is used to assure the mixing uniformity. $50 \%$ volume of solvent is reduced by evaporation at $60^{\circ} \mathrm{C}$ with leaving the beaker on the heating plate. The solution is cooled, and the precipitate is collected by filtering, and washing with acetone. Finally, cobalt tris(ethylenediamine) 
tungstate, $\mathrm{Co}(\mathrm{en})_{3} \mathrm{WO}_{4}$, precipitate is obtained by drying the filtered and washed cake in the hood for one day. The precipitate is ground to fine powder with the mortar and pestle before temperature programmed carburization.

\subsubsection{Conversion to bimetallic carbide}

Temperature-programmed carburization by a mixture of $\mathrm{CO}_{2}$ and $\mathrm{CO}(\mathrm{x}=$ $\mathrm{CO}_{2} / \mathrm{CO}$ ratio) is used to transform the precursor $\mathrm{Co}(\mathrm{en})_{3} \mathrm{WO}_{4}$ into carbide catalyst. Each time, $5 \mathrm{~g}$ of the precursor is placed in the center of the reactor of Figure 3-1 and supported on quartz wool. A stainless-steel sheathed K-type thermocouple is in contact with the material to control the reaction temperature. As listed in Table 4-1, the whole process consists of four stages, all of which are operated at atmospheric pressure. First, for reduction with a flowing $\mathrm{H}_{2}$-Ar (1:1) mixture, the temperature is ramped from room temperature to $650^{\circ} \mathrm{C}$ at a heating rate of $15^{\circ} \mathrm{C} / \mathrm{min}$ and then held at $650^{\circ} \mathrm{C}$ for 3 hours. Then the temperature is ramped to $850^{\circ} \mathrm{C}$ in $\mathrm{Ar}$ at $15^{\circ} \mathrm{C} / \mathrm{min}$ and held at $850^{\circ} \mathrm{C}$ for 24 hours. In the carburization stage, the temperature $\left(850^{\circ} \mathrm{C}\right)$ is high enough to remove the ligand in the precursor as a necessary amount of carbon is provided to react with the metals to make the carbide. The ratio of $\mathrm{CO}_{2}$ to $\mathrm{CO}(=\mathrm{x})$ plays an important role in the formation of final products. In this work, four different values of $\mathrm{x}$ are used, $0.1,0.2$, 0.5 and 0.75 . Finally, the $\mathrm{CO}_{2} / \mathrm{CO}$ mixture is purged by flowing argon, and the products are cooled down to room temperature before being removed from the reactor for future 
characterization and testing.

Table 4-1 Preparation of Co-W-C by carburization

\begin{tabular}{|c|c|c|c|c|c|}
\hline Stage & $\begin{array}{c}\text { Gas } \\
\text { (volume ratio)y }\end{array}$ & $\begin{array}{c}\text { Total flow rate } \\
\text { (scc/min) }\end{array}$ & Temperature $\left({ }^{\circ} \mathrm{C}\right)$ & $\begin{array}{l}\text { Time } \\
\text { (hrs) }\end{array}$ & $\begin{array}{c}\text { Pressure } \\
\text { (atm) }\end{array}$ \\
\hline 1 & $\begin{array}{l}\mathrm{H}_{2}: \mathrm{Ar} \\
(1: 1)\end{array}$ & 130 & $25 \rightarrow 650$ & 3 & 1 \\
\hline 2 & $\mathrm{Ar}$ & 190 & $650 \rightarrow 850$ & 0.5 & 1 \\
\hline 3 & $\begin{array}{c}\mathrm{CO}_{2}: \mathrm{CO} \\
(\mathrm{x}: 1)\end{array}$ & $60 *(1+x)$ & 850 & 24 & 1 \\
\hline 4 & $\mathrm{Ar}$ & 190 & $850 \rightarrow 25$ & overnight & 1 \\
\hline
\end{tabular}

Other bimetallic carbide catalysts are manufactured by following the above preparation procedure, while choosing other metallic salts as starting materials. Instead of using W, Mo can be the element X. Similarly, Ni can replace Co, because they both belong to the same family in the periodic table. So a series of carbide catalysts, Co-W-C, Ni-W-C, Co-Mo-C, and Ni-Mo-C, were made. For Ni, nickel chloride hexahydrate $\left(\mathrm{NiCl}_{2} \cdot 6 \mathrm{H}_{2} \mathrm{O}\right)$ is used; for Mo, ammonium heptamolybdate $\left(\left(\mathrm{NH}_{4}\right)_{6} \mathrm{Mo}_{7} \mathrm{O}_{24} \cdot 4 \mathrm{H}_{2} \mathrm{O}\right)$ is dissolved in ethylenediamine to make the precursor. The molar ratio between two metals involved is consistently kept at 1:1. 


\subsection{Effect of ratio of $\mathrm{CO}_{2} / \mathrm{CO}$ for preparing bimetallic $\mathrm{Co}-\mathrm{W}-\mathrm{C}$ catalyst}

Figure 4-1 is the ternary phase diagram of cobalt-tungsten-carbon at $1400 \mathrm{~K}$ [67]. As stated in the previous description of catalyst preparation, the atomic ratio $\mathrm{Co}: \mathrm{W}$ is maintained at 1:1 for preparation of metal organometallic precursor $\mathrm{Co}(\mathrm{en})_{3} \mathrm{WO}_{4}$. When carbon is added, phase changes should fall along tie line 1 of Figure 4-1 to move to the carbon vertex. Along tie line 1, different phases will appear in sequence, from $\mathrm{Co}_{6} \mathrm{~W}_{6} \mathrm{C}\left(\mathrm{M}_{12} \mathrm{C}\right)$ to $\mathrm{Co}_{3} \mathrm{~W}_{3} \mathrm{C}\left(\mathrm{M}_{6} \mathrm{C}\right)$, and finally to $\beta-\mathrm{Co} / \mathrm{WC}$.

While pointing out the similarities between transition metal carbide and platinum, Boudart et al. [62, 89] also reported that the addition of $\mathrm{C}$ could change electron distribution in the transition metal atoms, and desirable activity results could be achieved by controlling the amount of carbon. So by changing the value of $\mathrm{x}$ in the carburization, the concentration of carbon in the final phase can be controlled. This will affect the catalytic properties of the material.

During carburization with the $\mathrm{CO}_{2}-\mathrm{CO}$ mixture, the precursor, $\mathrm{Co}(\mathrm{en})_{3} \mathrm{WO}_{4}$ is transformed into the carbide by the decomposition of the organic ligand (ethylenediamine). The extra carbon is removed by the $\mathrm{CO}_{2}$ via the Reverse Boudouard reaction:

$$
\mathrm{CO}_{2}(g)+C(s) \leftrightarrow 2 \mathrm{CO}(g)
$$




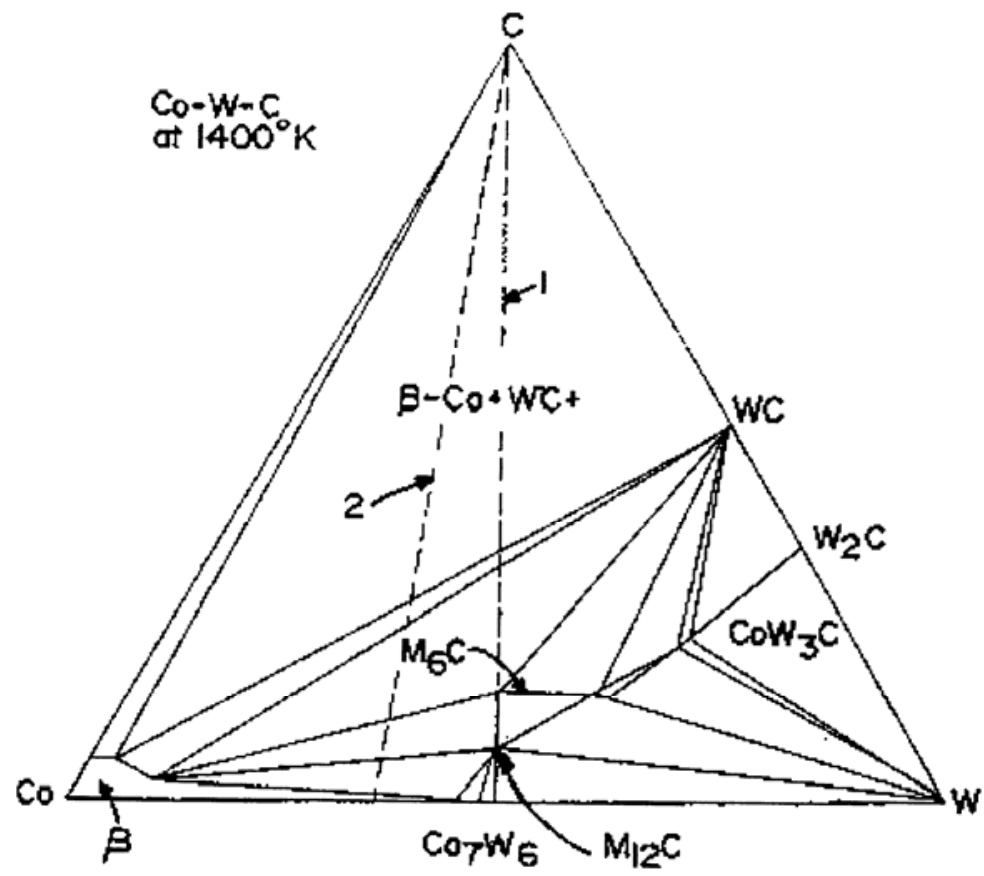

Figure 4-1 Ternary phase diagram of cobalt-tungsten-carbon at 1400K [67]

Thermodynamically, the equilibrium reaction constant $\mathrm{K}_{\mathrm{a}}$ for reaction (4-1) is defined by the relation:

$$
K_{a} \equiv \frac{\left(a_{C O, e q}\right)^{2}}{\left(a_{\mathrm{CO}_{2}, e q}\right)\left(a_{C, e q}\right)}=\exp \left(-\frac{\Delta G_{r x n}}{R T}\right)
$$

where $\Delta \mathrm{G}_{\mathrm{rxn}}$ is the standard Gibbs free energy to remove carbon via equation (4-1):

$$
\Delta G_{r x n}=-33.81 \mathrm{KJ} / \mathrm{molC} \text { at } 850^{\circ} \mathrm{C}
$$

Reaction quotient $\mathrm{J}_{\mathrm{a}}$ can be defined by the analogous relationship not at equilibrium:

$$
J_{a} \equiv \frac{\left(a_{\mathrm{CO}}\right)^{2}}{a_{\mathrm{CO} 2} a_{C}}
$$

and so 


$$
J_{a}=\frac{P_{\mathrm{CO}}^{2}}{P_{\mathrm{CO}_{2}} P_{\text {tot }} a_{c}}
$$

$\mathrm{P}_{\mathrm{CO}}$ and $\mathrm{P}_{\mathrm{CO} 2}$ are partial pressures of $\mathrm{CO}$ and $\mathrm{CO}_{2}$ respectively, and $\mathrm{P}_{\text {tot }}$ is the total pressure, fixed at $1 \mathrm{~atm}$ in this work. Since carbon is in the pure solid phase, $\mathrm{a}_{\mathrm{c}}$ is identically unity, whether or not the reaction is in equilibrium.

Under conditions when equilibrium is reached:

$$
J_{a}=\frac{P_{C O}^{2}}{P_{\mathrm{CO}_{2}} P_{\text {tot }}}=\exp \left(-\frac{\Delta G_{r \times n}}{R T}\right)=K_{a}
$$

Define process carbon activity $\mathrm{a}_{\mathrm{c}}{ }^{*}$ as:

$$
a_{c}^{*}=\frac{P_{C O}^{2}}{P_{\mathrm{CO}_{2}} P_{\text {tot }}} \exp \left(+\frac{\Delta G_{r \times n}}{R T}\right)
$$

where $\mathrm{P}_{\mathrm{CO}}, \mathrm{P}_{\mathrm{CO} 2}$ and $\mathrm{P}_{\text {tot }}$ are experimental values and $\Delta \mathrm{G}_{\mathrm{rxn}}$ is given by equation (4-2b). If $\mathrm{a}_{\mathrm{c}}{ }^{*}$ is less than 1 , then

$$
\frac{P_{\mathrm{CO}}^{2}}{P_{\mathrm{CO}_{2}} P_{\text {tot }}}<\exp \left(-\frac{\Delta G_{r x n}}{R T}\right)
$$

which implies that

$$
J_{a}<K_{a}
$$

Under these conditions, reaction (4-1) will proceed forward (from left to right), because the reaction has not reached equilibrium yet. In this case, extra solid carbon derived from the decomposition of ligand will be removed, and the precursor is transformed into the expected final carbide. 
The value of $\mathrm{a}_{\mathrm{c}}{ }^{*}$ varies with the partial pressures of $\mathrm{CO}$ and $\mathrm{CO}_{2}$. Therefore, by changing the $\mathrm{CO}_{2} / \mathrm{CO}$ ratio in the carburizing gas while keeping the total pressure constant at $1 \mathrm{~atm}$, the process carbon activity can be controlled, hence affecting the reaction direction. As long as reaction (4-1) proceeds forward (i.e., $\mathrm{a}_{\mathrm{c}}{ }^{*}<1$ ), extra solid carbon will be removed, and the corresponding carbide will be formed from the precursor.

Figure 4-2 is the relationship between process carbon activity and the $\mathrm{CO}_{2} / \mathrm{CO}$ ratio $(=\mathrm{x})$ at $850^{\circ} \mathrm{C}$ and atmospheric pressure. The value of $\mathrm{a}_{\mathrm{c}}{ }^{*}$ is less than 1 in the range when $x$ is greater than 0.026 . The value of the process carbon activity $a_{c}{ }^{*}$ decreases sharply when the ratio is between 0.026 and 0.25 .

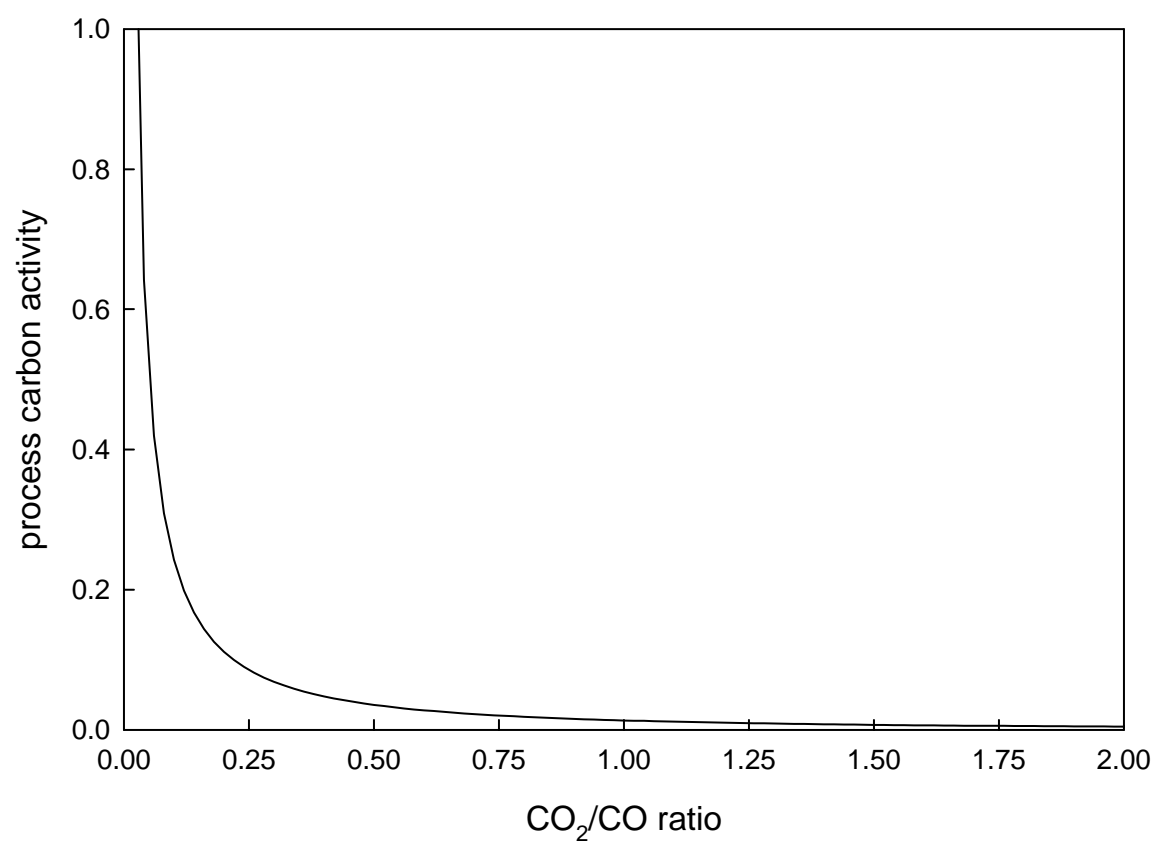

Figure 4-2 Relationship between process carbon activity and $\mathrm{CO}_{2} / \mathrm{CO}$ ratio (Calculated at $850^{\circ} \mathrm{C}$ and $P_{\text {tot }}=1 \mathrm{~atm}$ ) 
The final specific carbide phase is determined by the value of $a_{c}{ }^{*}$. Polizzotti et al. [67] report that at $a_{c}{ }^{*}=0.1$, the precursor could be completely converted to the bimetallic carbide $\mathrm{Co}_{6} \mathrm{~W}_{6} \mathrm{C}$, while a mixture of $\beta$-Co and $\mathrm{WC}$ would be formed from the same precursor at $\mathrm{a}_{\mathrm{c}}{ }^{*}=0.53$. The calculated value of the process carbon activity for the four values of $\mathrm{x}$ used in this work is shown in Table 4-2. A wide range of values of $\mathrm{a}_{\mathrm{c}}{ }^{*}$ from $0.02(\mathrm{x}=0.75)$ to $0.24(\mathrm{x}=0.1)$ could provide enough span to investigate the effect of $\mathrm{x}$ on the final product phases. The formation of bimetallic carbide $\mathrm{Co}_{6} \mathrm{~W}_{6} \mathrm{C}$ can be achieved if the ratio $\mathrm{x}$ is equal to or higher than 0.5 , while a mixture of $\beta$-Co and $\mathrm{WC}$ might be produced if the ratio $\mathrm{x}$ is equal to 0.1 .

Table 4-2 Relationship between $x$ and $\mathrm{a}_{\mathrm{c}}$ * (equation 4-5)

$\left(\mathrm{T}=850^{\circ} \mathrm{C}, \mathrm{P}_{\text {total }}=1 \mathrm{~atm}\right)$

\begin{tabular}{|c|c|c|c|}
\hline $\mathbf{C O}_{2} / \mathbf{C O}$ & $\mathbf{P}_{\mathbf{C O 2}}(\mathbf{a t m})$ & $\mathbf{P}_{\mathbf{C O}}(\mathbf{a t m})$ & $\mathrm{a}_{\mathrm{c}}{ }^{*}$ \\
\hline 0.1 & 0.0909 & 0.9091 & 0.2427 \\
\hline 0.2 & 0.1667 & 0.8333 & 0.1113 \\
\hline 0.5 & 0.3333 & 0.6667 & 0.0356 \\
\hline 0.75 & 0.4286 & 0.5714 & 0.0203 \\
\hline
\end{tabular}




\subsection{Characterization of the bimetallic carbide catalyst}

It is well accepted that higher surface areas are more desired in catalysts to achieve better reactivity. The specific surface area (SSA, surface area per gram) of the catalysts was measured, and the results are listed in Table 4-3. The last column in the table is the true density (TD) of the samples. The higher the SSA of a sample, the lower its TD. The material made with ratio $\mathrm{x}$ equal to 0.2 has the highest surface area and the lowest true density. The samples made with ratio values $\mathrm{x}$ equal to 0.5 and 0.75 have SSA values similar to the Nanodyne sample used earlier. Generally, the surface area will decrease if the catalyst has been treated at high temperature. However, Thomson et al. [65] have shown that the catalytic performance of $\mathrm{Mo}_{2} \mathrm{C}$ for methane steam reforming at high pressure is independent of the surface area. Good stability and activity results were achieved by them for low surface area $\mathrm{Mo}_{2} \mathrm{C}$ for over 96 hours. The in-house low-surface-area carbide catalysts will also be evaluated in the next two chapters.

Table 4-3 Bulk components of carbide catalysts with different ratios of $\mathrm{CO}_{2} / \mathrm{CO}$

\begin{tabular}{|c|c|c|}
\hline $\mathbf{C O}_{2} / \mathbf{C O}$ ratio $(=\boldsymbol{x})$ & $\boldsymbol{S S A}\left(\mathbf{m}^{2} / \boldsymbol{g}\right)$ & $\mathbf{T D}\left(\mathbf{g} / \mathbf{c m}^{3}\right)$ \\
\hline 0.1 & 11.09 & 7.16 \\
\hline 0.2 & 33.10 & 5.43 \\
\hline 0.5 & 2.05 & 13.61 \\
\hline 0.75 & 2.37 & 17.90 \\
\hline Nanodyne Sample & 3.14 & 17.39 \\
\hline
\end{tabular}

The following eight XRD spectra (Figures 4-3 through 4-10) show bulk 
components for fresh carbide catalysts made with the four different $\mathrm{CO}_{2} / \mathrm{CO}$ ratios (values of $\mathrm{x}$ of tables $4.2 \& 4.3$ ). Figures $4-3$ through $4-6$ correspond to fresh cobalt tungsten carbides, and Figures 4-7 through 4-10 correspond to fresh nickel tungsten carbides. A summary of bulk components for these catalysts is listed in Table 4-4.

Both cobalt tungsten carbide and nickel tungsten carbide undergo a change from a mixture of WC and either Co or Ni to the bimetallic carbide with increasing values of $\mathrm{x}$. For example, at $\mathrm{x}=0.1$ (Figure 4-3), $\mathrm{Co}-\mathrm{W}-\mathrm{C}$ has as bulk phases of $\mathrm{Co}_{3} \mathrm{~W}_{3} \mathrm{C}, \mathrm{WC}$ and $\mathrm{Co}$. As the ratio $\mathrm{x}$ increases to 0.2 (Figure 4-4), only the peak of $\mathrm{Co}_{3} \mathrm{~W}_{3} \mathrm{C}$ is detected in $\mathrm{XRD}$. After the ratio $x$ goes up to 0.5 and 0.75 (Figure 4-5 and 4-6), pure $\mathrm{Co}_{6} \mathrm{~W}_{6} \mathrm{C}$ is found in the bulk phase. In fact, $\mathrm{Co}_{3} \mathrm{~W}_{3} \mathrm{C}$ and $\mathrm{Co}_{6} \mathrm{~W}_{6} \mathrm{C}$ share very similar XRD patterns except that their characteristic peaks shift slightly, which may be due to the change of lattice size.

The transformations to bimetallic carbides can be discussed with respect to the process carbon activity, Figure 4-2 and Table 4-4. From Figure 4-2, the phase change from $\mathrm{Co}+\mathrm{WC}$ to $\mathrm{Co}_{6} \mathrm{~W}_{6} \mathrm{C}$ takes place where the value of $\mathrm{a}_{\mathrm{c}}{ }^{*}$ (the process carbon activity) becomes larger than 0.53 , which corresponds to the ratio of $\mathrm{CO}_{2}$ to $\mathrm{CO}$ at 0.12 . Complete transformation into $\mathrm{Co}_{6} \mathrm{~W}_{6} \mathrm{C}$ requires a still lower value of $\mathrm{a}_{\mathrm{c}}{ }^{*}$, less than 0.1 , therefore the ratio of $\mathrm{CO}_{2}$ to $\mathrm{CO}$ should be greater than 0.5 . The sample made with the $\mathrm{CO}_{2} / \mathrm{CO}$ ratio of 0.75 shows an $\mathrm{XRD}$ pattern very similar to that of the $\mathrm{Co}_{6} \mathrm{~W}_{6} \mathrm{C}$ material from Nanodyne Company [76]. 


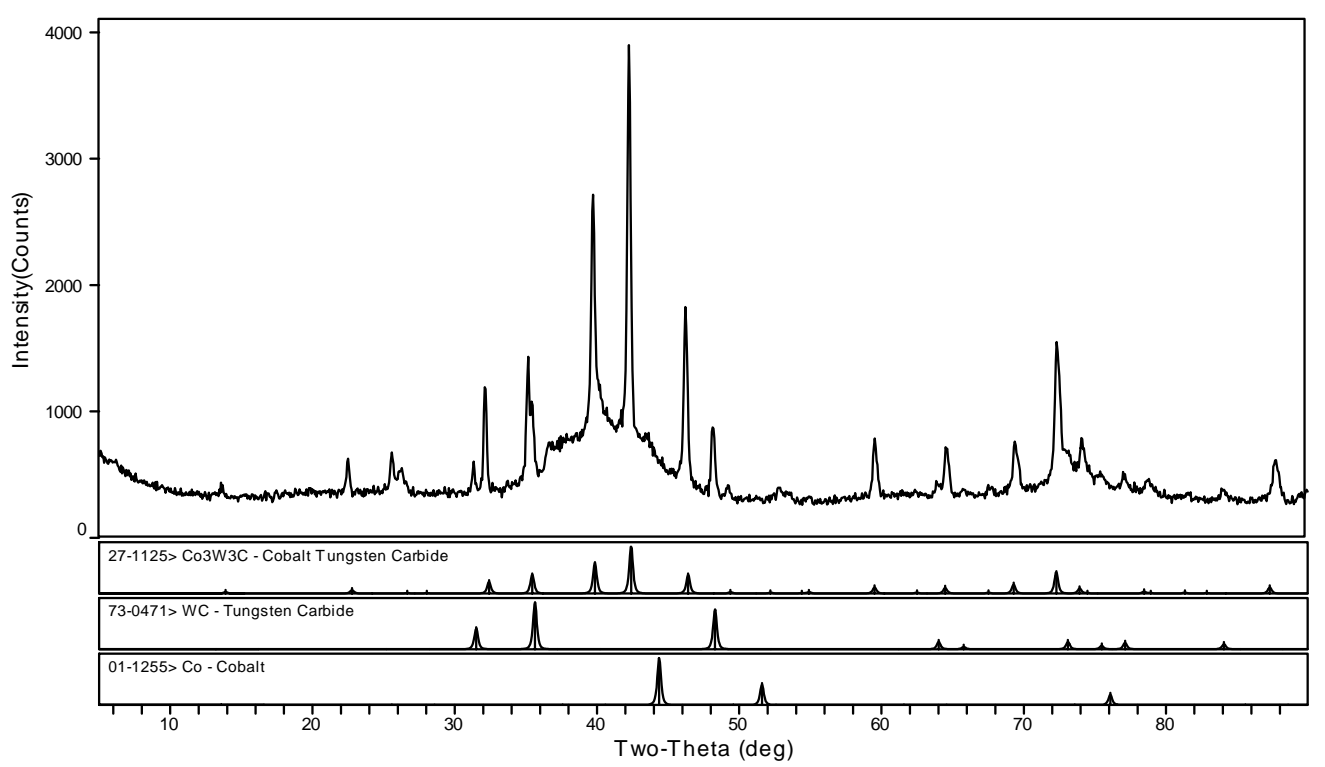

Figure 4-3 XRD spectrum of fresh Co-W-C ( $x=0.1)$

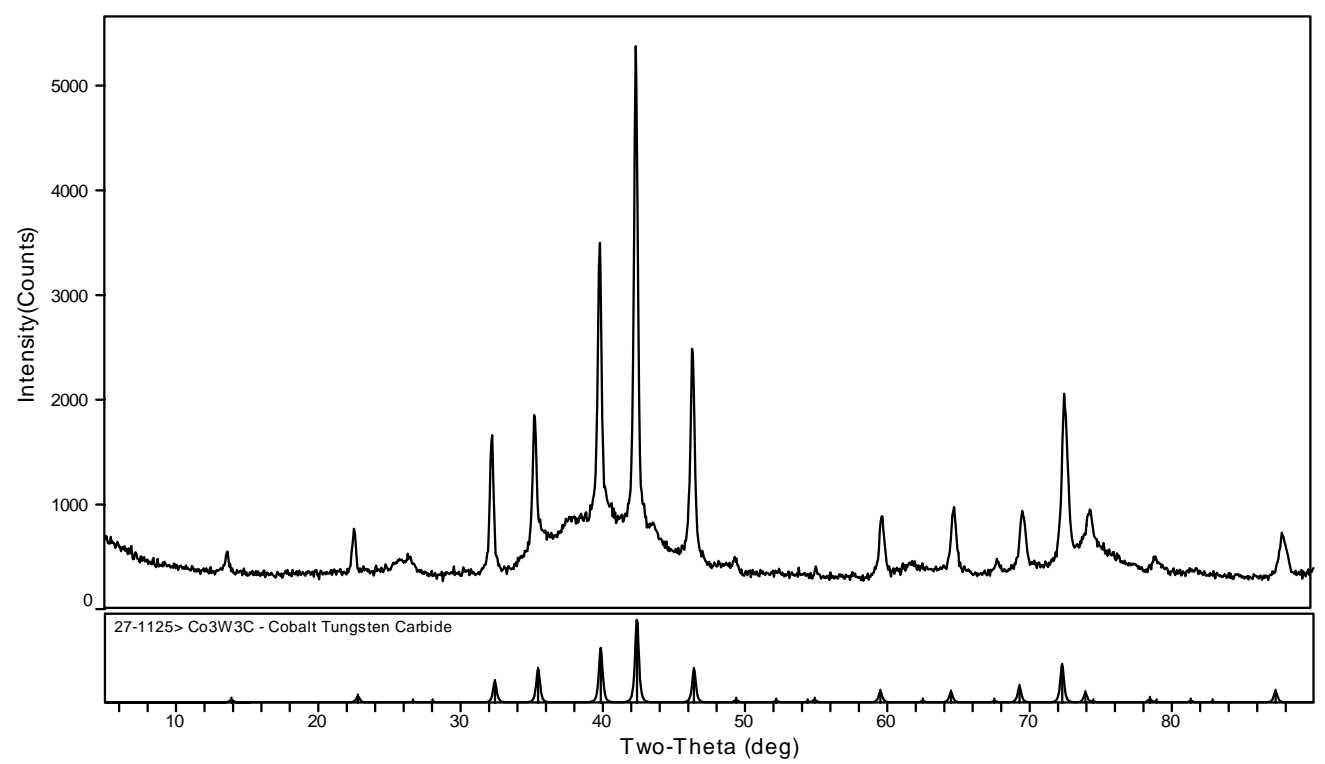

Figure 4-4 XRD spectrum of fresh Co-W-C ( $x=0.2)$ 


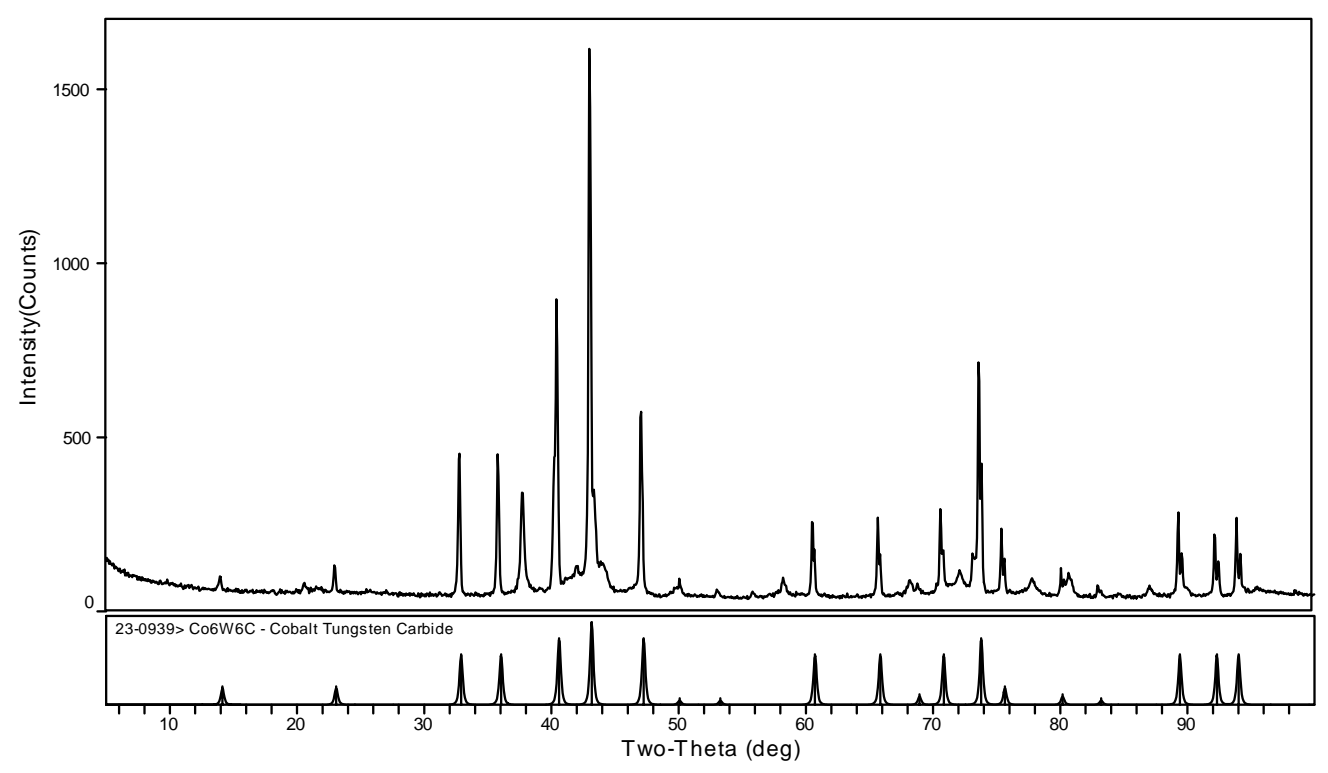

Figure 4-5 XRD spectrum of fresh Co-W-C $(x=0.5)$

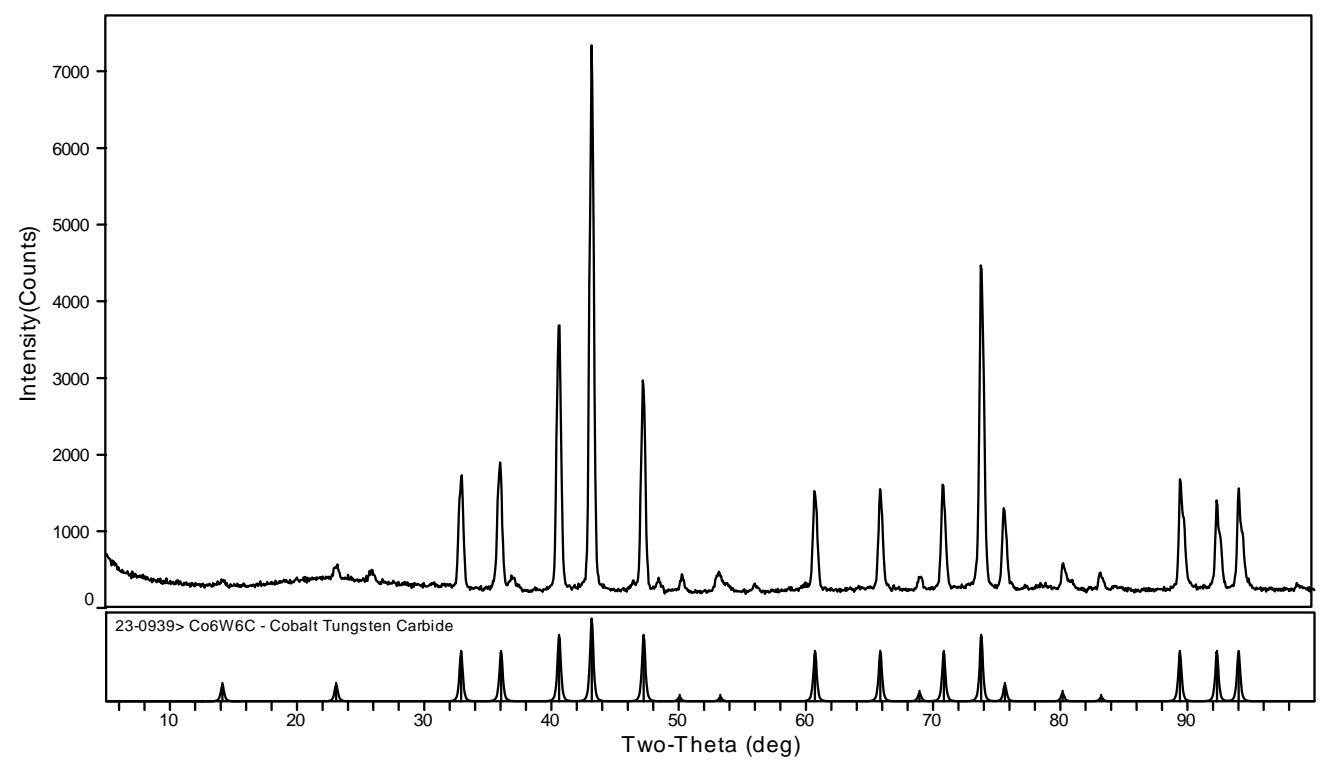

Figure 4-6 XRD spectrum of fresh Co-W-C $(x=0.75)$ 


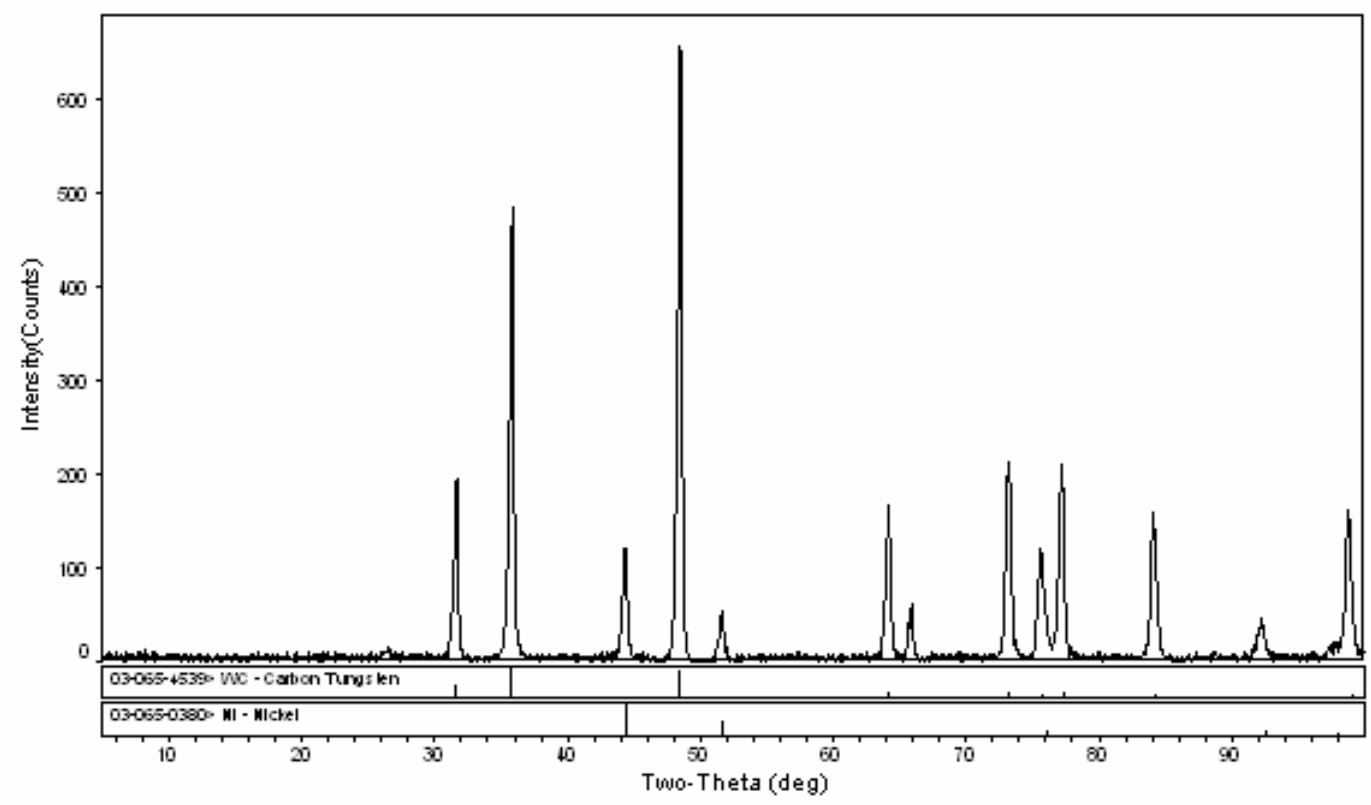

Figure 4-7 $\quad X R D$ spectrum of fresh Ni-W-C $(x=0.1)$

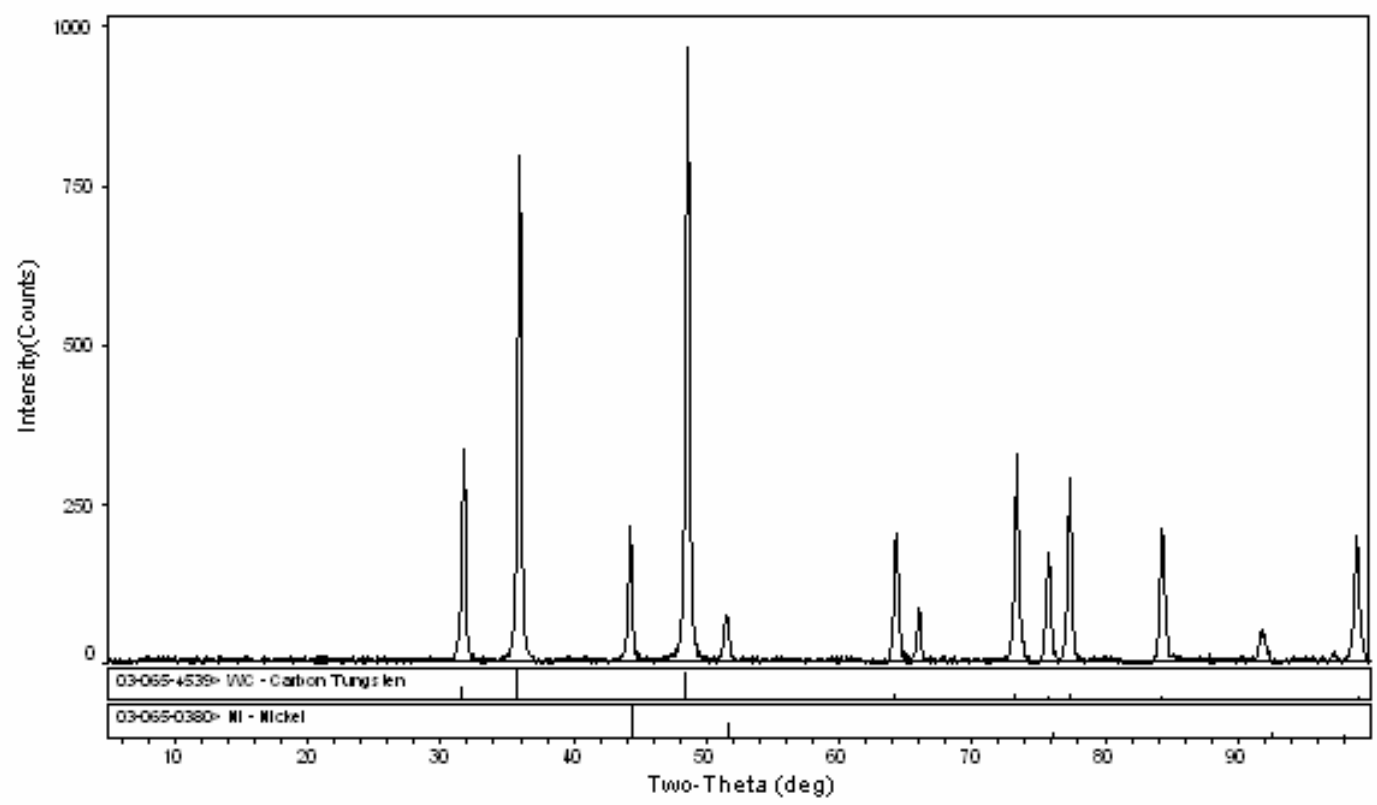

Figure 4-8 XRD spectrum of fresh Ni-W-C $(x=0.2)$ 


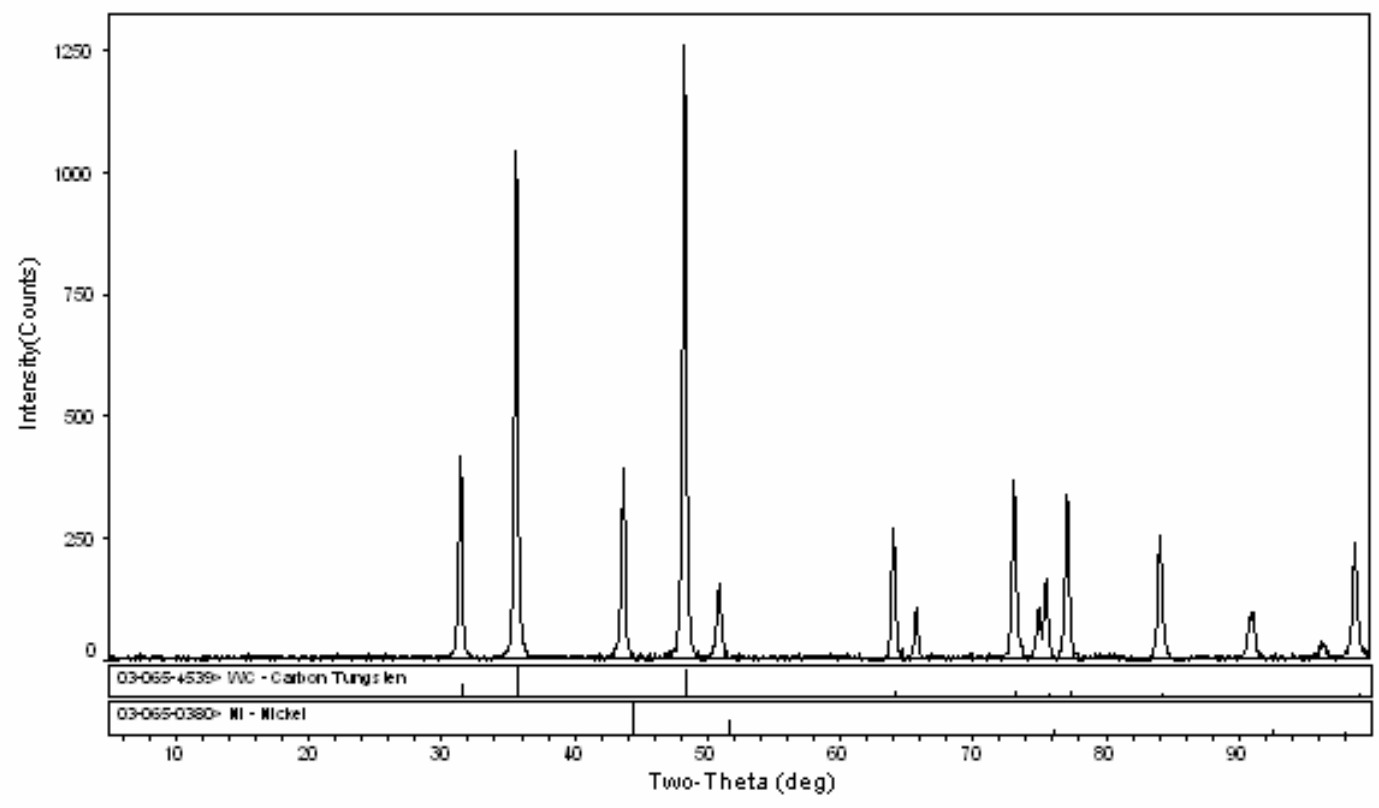

Figure 4-9 XRD spectrum of fresh Ni-W-C ( $x=0.5)$

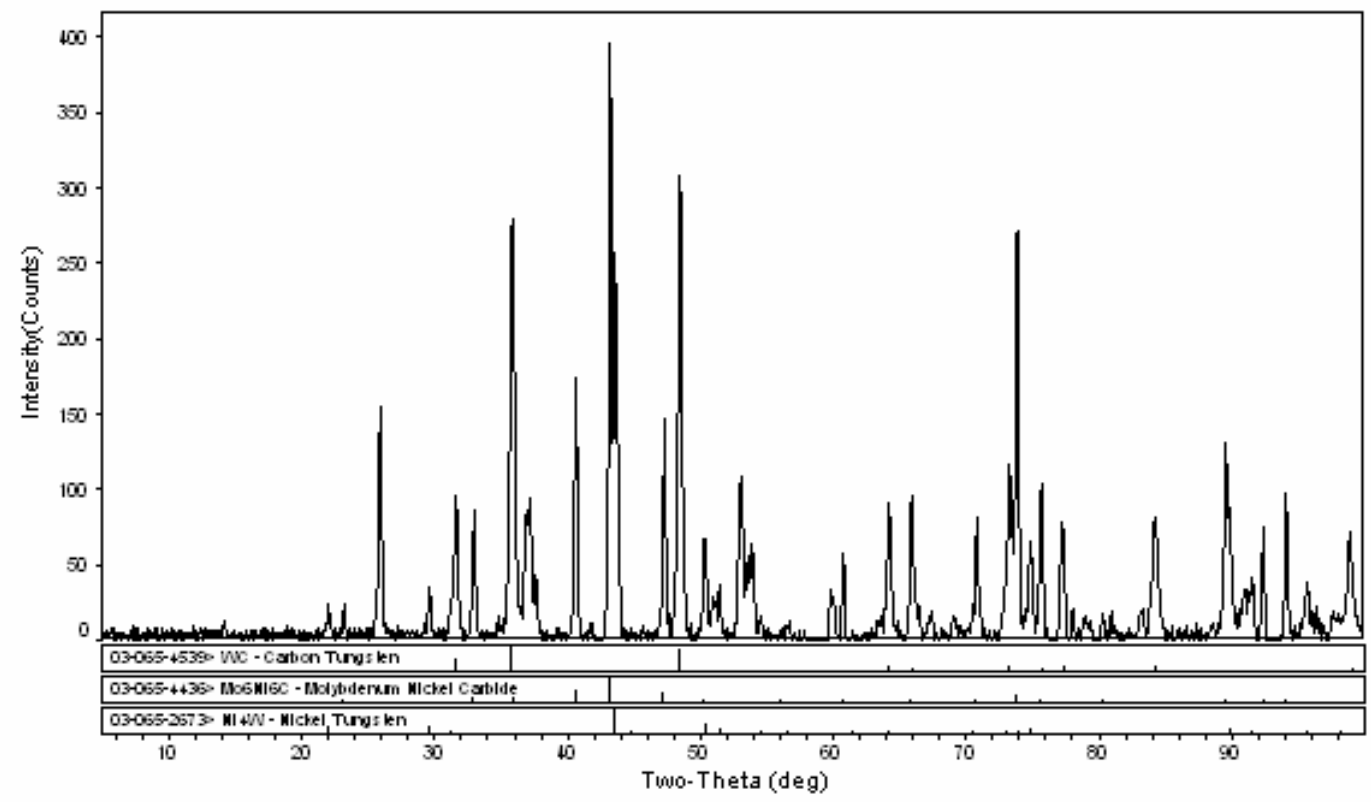

Figure 4-10 XRD spectrum of fresh Ni-W-C $(x=0.75)$ 
However, as shown in Figures 4-7 to 4-9, the nickel-based carbides made with $\mathrm{x}$ values of $0.1,0.2$ and 0.5 , all have bulk structures of $\mathrm{Ni}$ and $\mathrm{WC}$. Even at $0.75, \mathrm{Ni}_{6} \mathrm{~W}_{6} \mathrm{C}$ cannot be produced with high purity. For values of $\mathrm{x}$ equal to $0.75, \mathrm{Ni}_{6} \mathrm{~W}_{6} \mathrm{C}$ appears in the bulk phase mixed with $\mathrm{WC}$ and a minor amount of bimetallic alloy. Clearly equation 4-1 is not the only criterion and the metal components have a role to play. Ni-W-C has a different ternary phase diagram from Co-W-C at the carburization temperature.

Table 4-4 Bulk components of carbide catalysts with different ratios of $\mathrm{CO}_{2} / \mathrm{CO}$

\begin{tabular}{|c|c|c|}
\hline \multirow{2}{*}{$\boldsymbol{C O}_{2} /$ CO ratio } & \multicolumn{2}{|c|}{ Bulk components } \\
\cline { 2 - 3 } & Co-W-C & $N i-W-C$ \\
\hline 0.1 & $\mathrm{Co}_{3} \mathrm{~W}_{3} \mathrm{C}+\mathrm{Co}+\mathrm{WC}$ & $\mathrm{Ni}+\mathrm{WC}$ \\
\hline 0.2 & $\mathrm{Co}_{3} \mathrm{~W}_{3} \mathrm{C}$ & $\mathrm{Ni}+\mathrm{WC}$ \\
\hline 0.5 & $\mathrm{Co}_{6} \mathrm{~W}_{6} \mathrm{C}$ & $\mathrm{Ni}+\mathrm{WC}$ \\
\hline 0.75 & $\mathrm{Co}_{6} \mathrm{~W}_{6} \mathrm{C}$ & $\mathrm{Ni}_{6} \mathrm{~W}_{6} \mathrm{C}+\mathrm{WC}+\mathrm{Ni}_{4} \mathrm{~W}$ \\
\hline
\end{tabular}

Measurement of only bulk components is insufficient to characterize the heterogeneous catalyst. Moreover, the synthesis of these carbides involves phase transformations with exposure to a carburizing gas mixture at elevated temperatures; therefore, it is conceivable that the surface composition may be different from the bulk composition. To characterize the surface properties, hence to obtain a better understanding how the catalyst works for the reaction, investigations such as TPR, SEM and EDAX were carried out. 
Figure 4-11 is the TPR spectrum of fresh $\mathrm{Co}_{6} \mathrm{~W}_{6} \mathrm{C}(\mathrm{x}=0.75)$. Two reduction peaks are observed, one at $400^{\circ} \mathrm{C}$, and the other one around $700^{\circ} \mathrm{C}$. In addition, one small shoulder is visible near $600^{\circ} \mathrm{C}$. Figure 4-12 is the TPR spectrum for $\mathrm{Co}_{6} \mathrm{~W}_{6} \mathrm{C}$ sample from Nanodyne Company. This sample has an XRD pattern very similar to the in-house material when the ratio of $\mathrm{CO}_{2} / \mathrm{CO}$ is equal to 0.75 . Likewise, two reduction peaks are observed in the Nanodyne material, but these two peaks became closer than in Figure 4-11. One peak is at $400^{\circ} \mathrm{C}$ and the other one is at approximately $500^{\circ} \mathrm{C}$. Finally Figure $4-13$ is the TPR spectrum for Ni-W-C $(x=0.75)$. Except for the small hump near $300^{\circ} \mathrm{C}$, the shapes of the other two peaks are similar to those in the Co-W-C $(\mathrm{x}=0.75)$ sample, while the position shifts to higher temperature. The first reduction peak appears near $600^{\circ} \mathrm{C}$, and the second one is close to $815^{\circ} \mathrm{C}$. The distance between two peaks for Ni-W-C is a little narrower that for Co-W-C. The higher temperature of the reduction peaks in nickel tungsten carbide implies that metallic oxides therein are more stable than cobalt tungsten carbide.

Even though the catalysts are manufactured via carburization at high temperature $\left(850^{\circ} \mathrm{C}\right)$, and no oxides are detected in the bulk components from XRD results, the appearance of reduction peaks in TPR spectra indicates the existence of some form of oxides. Those oxides may be present on the surface of the catalyst. This will be addressed in later experiments, and some evidence will also be shown to explain the absence and effect of those metallic oxides. For the in-house carbides, the source of 
oxidation might come from oxygen left over in the carburization stage during the preparation process, produced by

$$
2 \mathrm{CO}_{2} \leftrightarrow 2 \mathrm{CO}+\mathrm{O}_{2}
$$

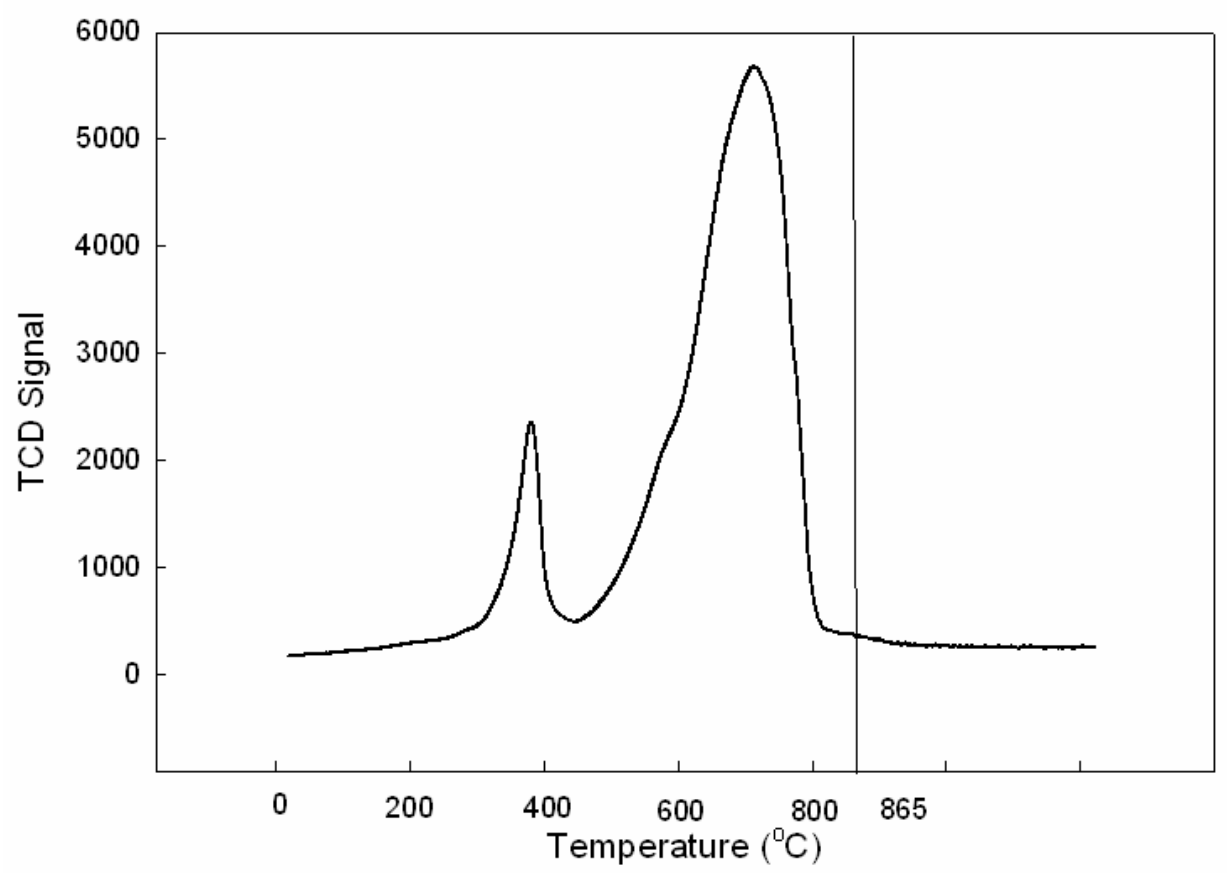

Figure 4-11 TPR spectrum of fresh Co-W-C ( $x=0.75)$ 


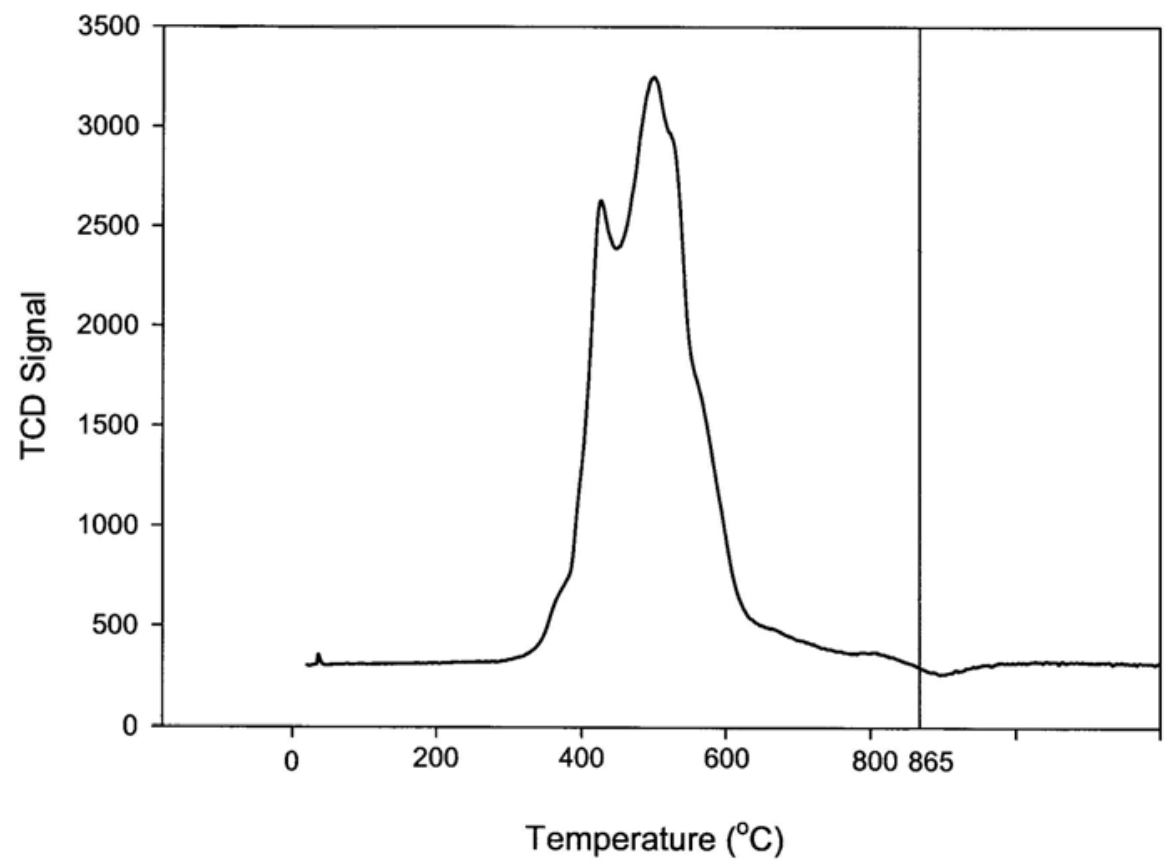

Figure 4-12 TPR spectrum of fresh $\mathrm{Co}_{6} \mathrm{~W}_{6} \mathrm{C}$ from Nanodyne Company

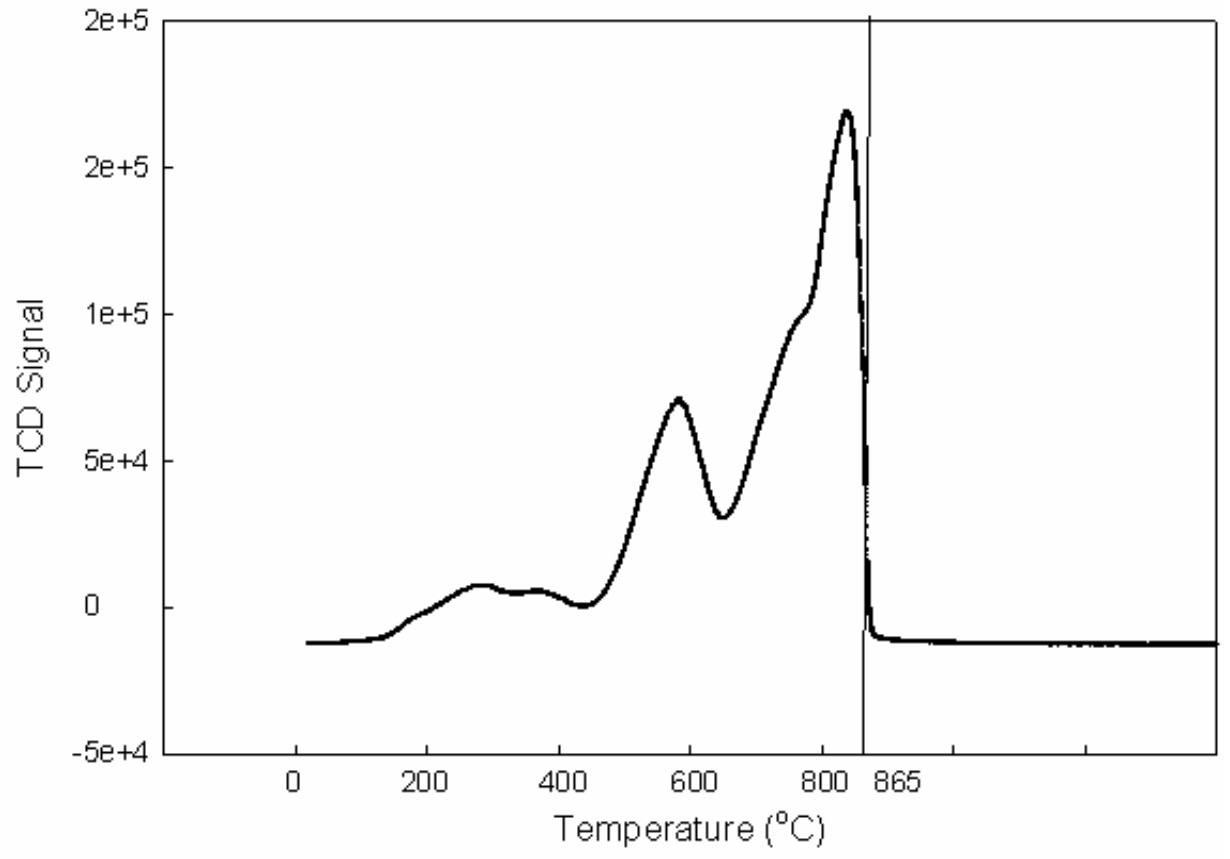

Figure 4-13 TPR spectrum of Ni-W-C $(x=0.75)$ 
Figure 4-14 is the SEM image of a fresh bimetallic carbide catalyst, $\mathrm{Co}_{6} \mathrm{~W}_{6} \mathrm{C}$ $(\mathrm{x}=0.75)$. Figure 4-15 is its corresponding EDAX pattern. In Figure 4-14, crystal-like morphology is uniformly arranged on the surface of the catalyst. Elemental analysis from EDAX also confirms even presence of elements $\mathrm{Co}, \mathrm{W}$ and $\mathrm{C}$ on the surface of this catalyst. The atomic ratio $\mathrm{Co} / \mathrm{W}$ is close to 1.0 , corresponding to the chemical formula $\mathrm{Co}_{6} \mathrm{~W}_{6} \mathrm{C}$. Different areas of the sample were scanned by elemental mapping. The three dominant elements, $\mathrm{Co}, \mathrm{W}$, and $\mathrm{C}$, are found to be uniformly distributed.

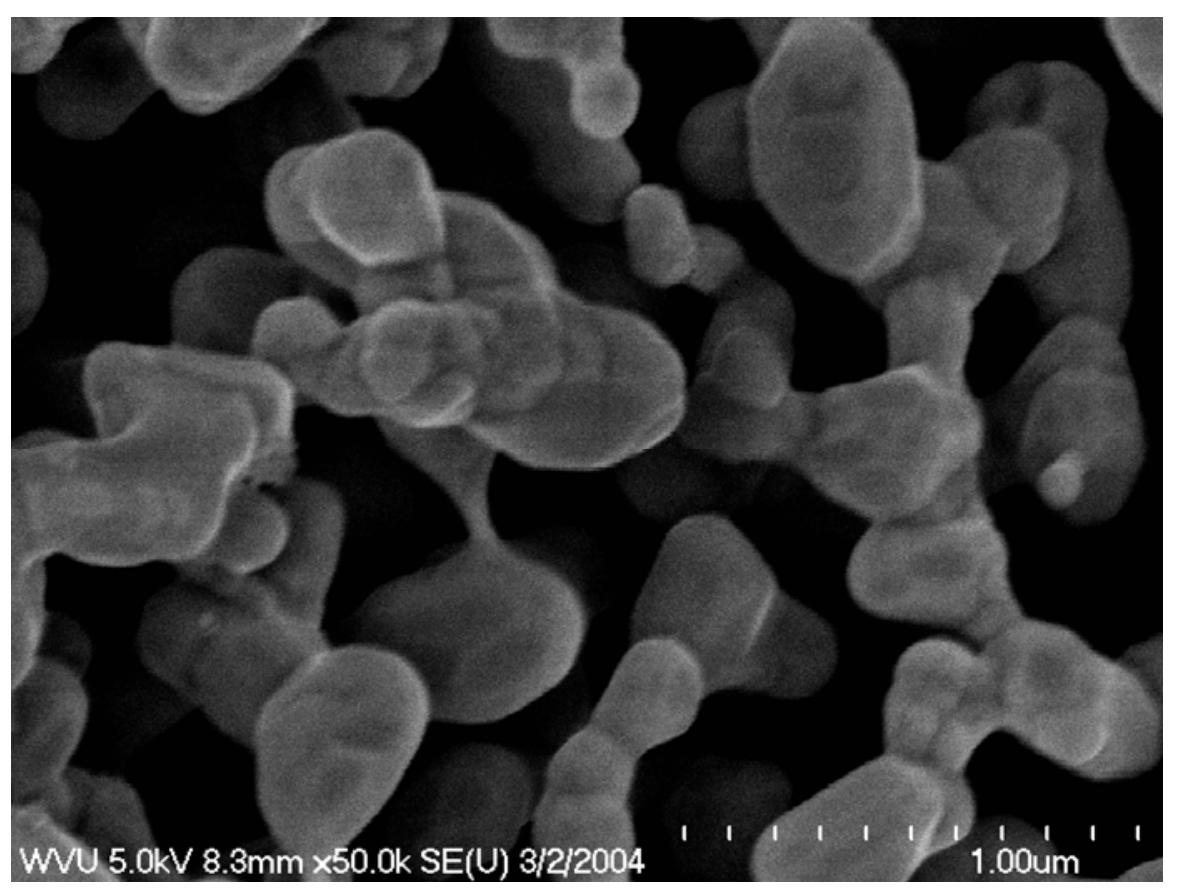

Figure 4-14 SEM image of fresh Co-W-C catalyst $(x=0.75)$ 


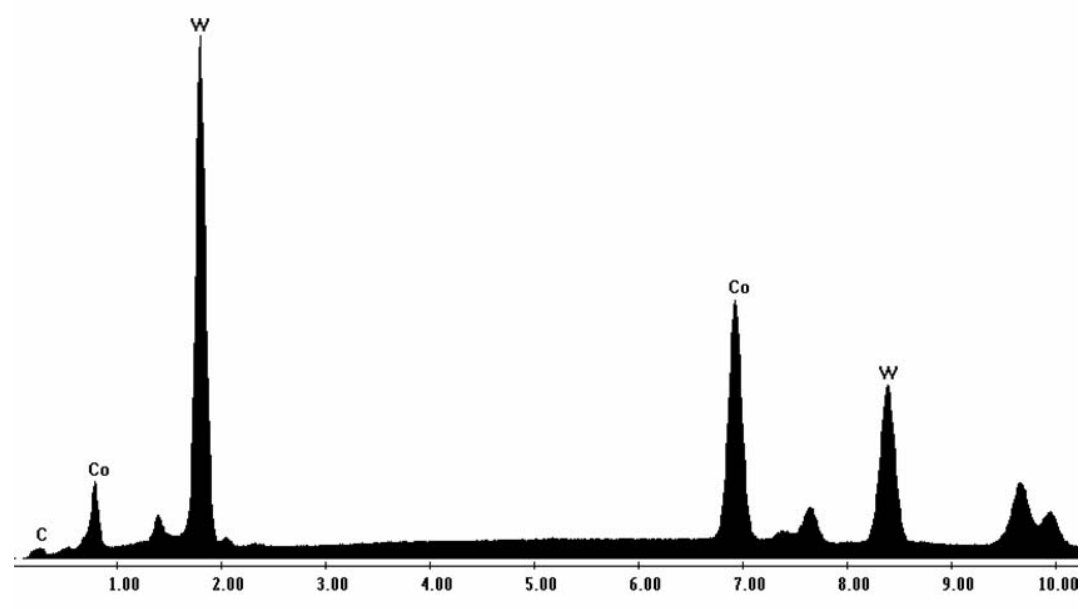

Figure 4-15 EDAX pattern of fresh Co-W-C catalyst $(x=0.75)$

Figure 4-16 and Figure 4-17 are SEM images for fresh nickel tungsten carbides, made with two different ratios of $\mathrm{CO}_{2} / \mathrm{CO}$. Three different resolutions were used. Nickel tungsten carbide has a more compact morphology compared to cobalt tungsten carbide (Figure 4-14). In the nickel tungsten carbide made with $\mathrm{CO}_{2} / \mathrm{CO}=0.75$ (Figure 4-16), a mixture of different morphologies is observed. In addition to the crystal-like structure as in cobalt tungsten carbide, cluster-like and spot-like structures are also present on the surface of the catalyst. With the help of EDAX (Figure 4-18 to Figure 4-20), it was found that the chemical composition varies with these different morphological structures, especially the ratio between two metallic elements, Ni and W. The atomic ratio of $\mathrm{Ni}$ to $\mathrm{W}$ is equal to 0.57 for the crystal-like structure, and 0.65 for the cluster-like structure, while very close to 1 for the spot-like structure. As shown in Figure 4-17, nickel tungsten carbide made with $\mathrm{CO}_{2} / \mathrm{CO}=0.5$ has a more uniform 
morphology while the compactness is similar to Figure 4-16. This difference is in accordance with XRD measurements, in which a clear pattern of Ni and WC is present in the sample with the ratio equal to 0.5 , while a mixture phase is present in the sample with the ratio equal to 0.75 . The EDAX pattern (Figure 4-21) shows a close equality of $\mathrm{Ni}$ and $\mathrm{W}$ in the material made with the ratio equal to 0.5 . The particle size of the Ni-W-C sample made with the ratio equal to 0.75 is relatively larger than the one made with the ratio equal to 0.5 . This could be attributed to the formation of bimetallic carbide $\left(\mathrm{Ni}_{6} \mathrm{~W}_{6} \mathrm{C}\right)$ in the material made with $\mathrm{CO}_{2} / \mathrm{CO}=0.75$. Finally, in Figures 4-18 through 4-21, some traces of oxygen are detected on the surfaces of both carbide catalysts in EDAX. Recall that oxygen has not been found among the bulk components with XRD measurements. 

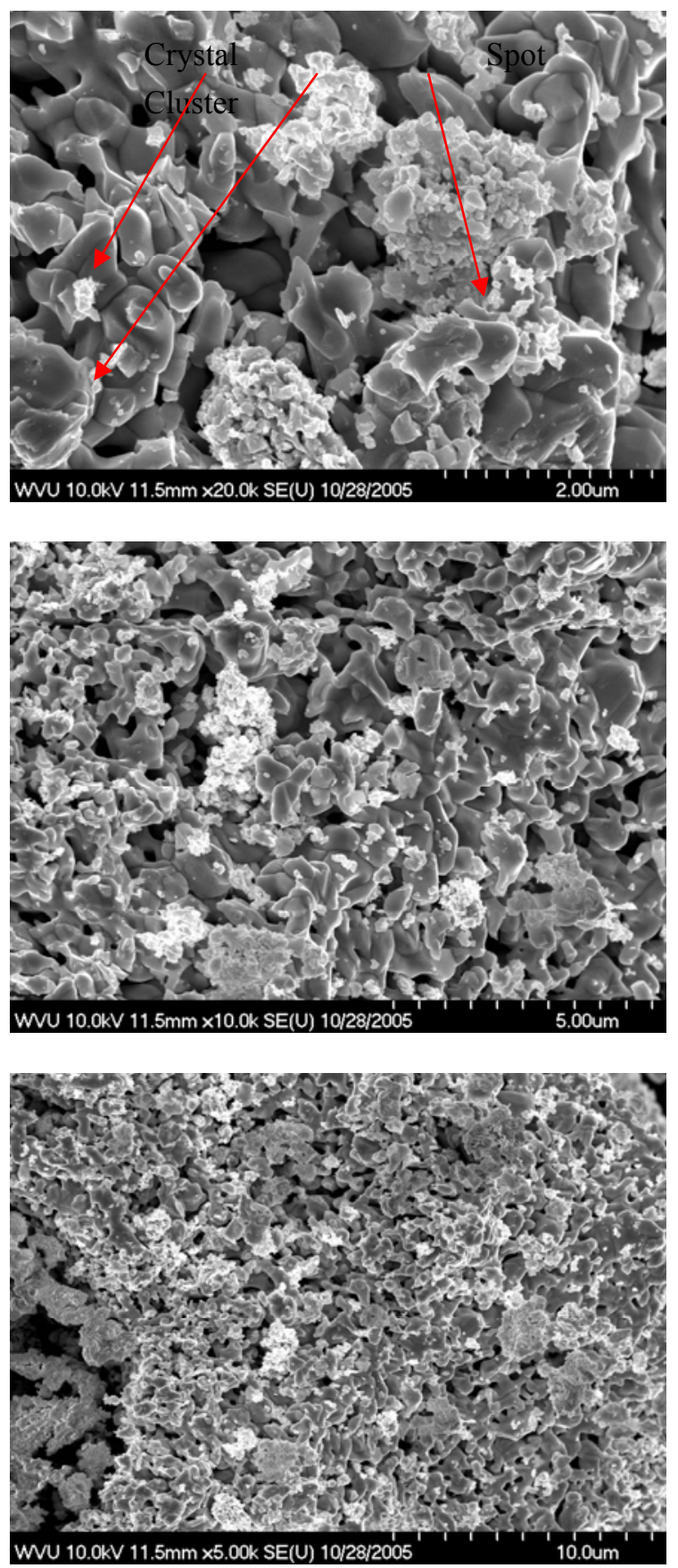

Figure 4-16 SEM of fresh Ni-W-C $(x=0.75)$
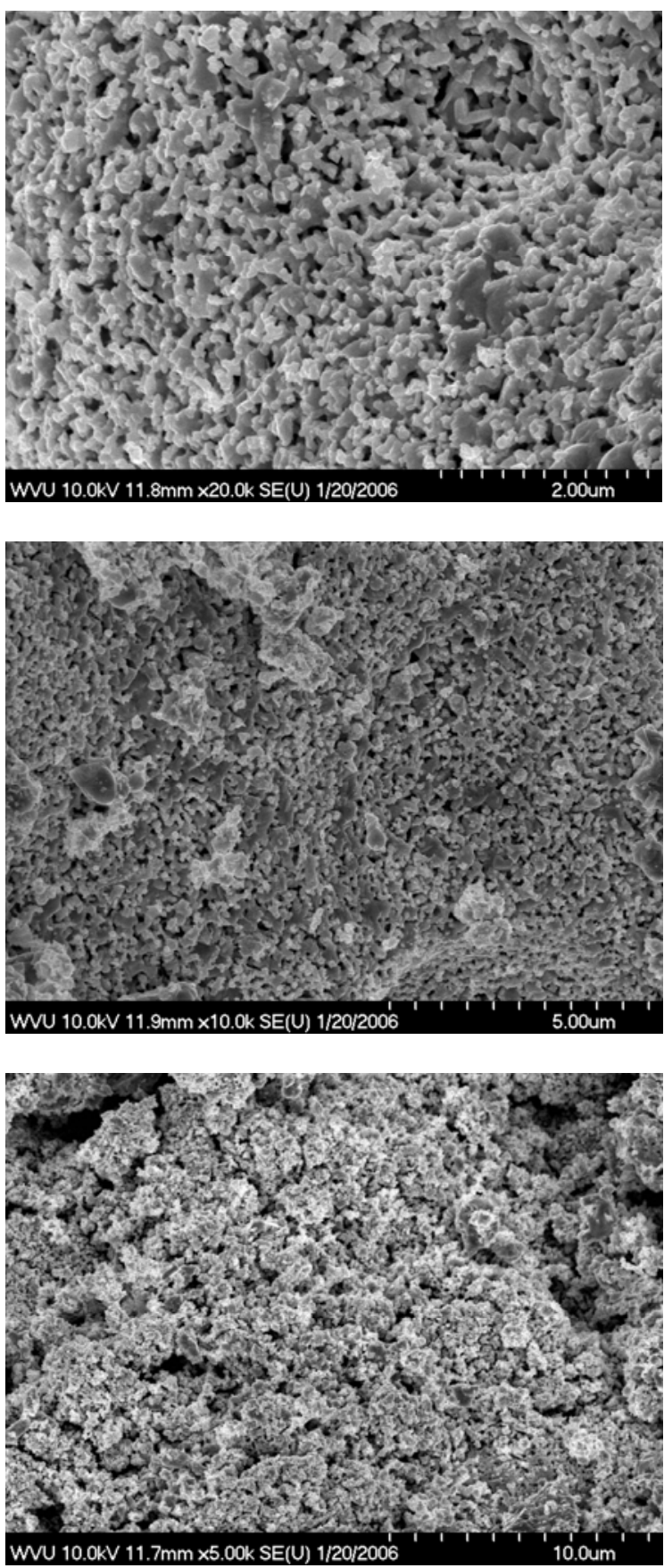

Figure 4-17 SEM of fresh Ni-W-C $(x=0.5)$ 


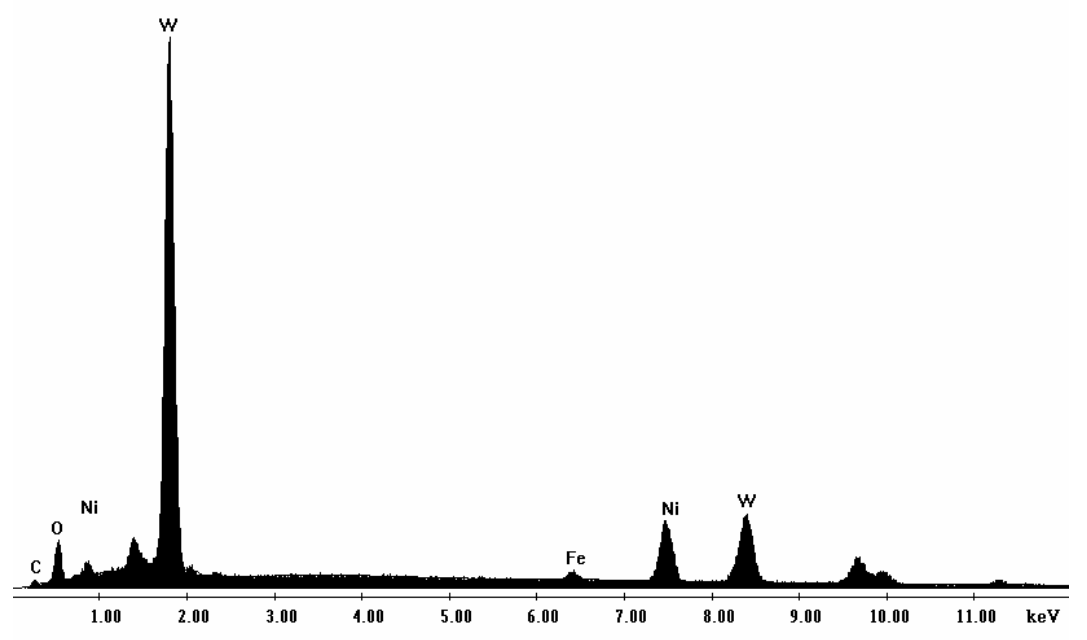

Figure 4-18 EDAX pattern of fresh crystal-like Ni-W-C $(x=0.75)$

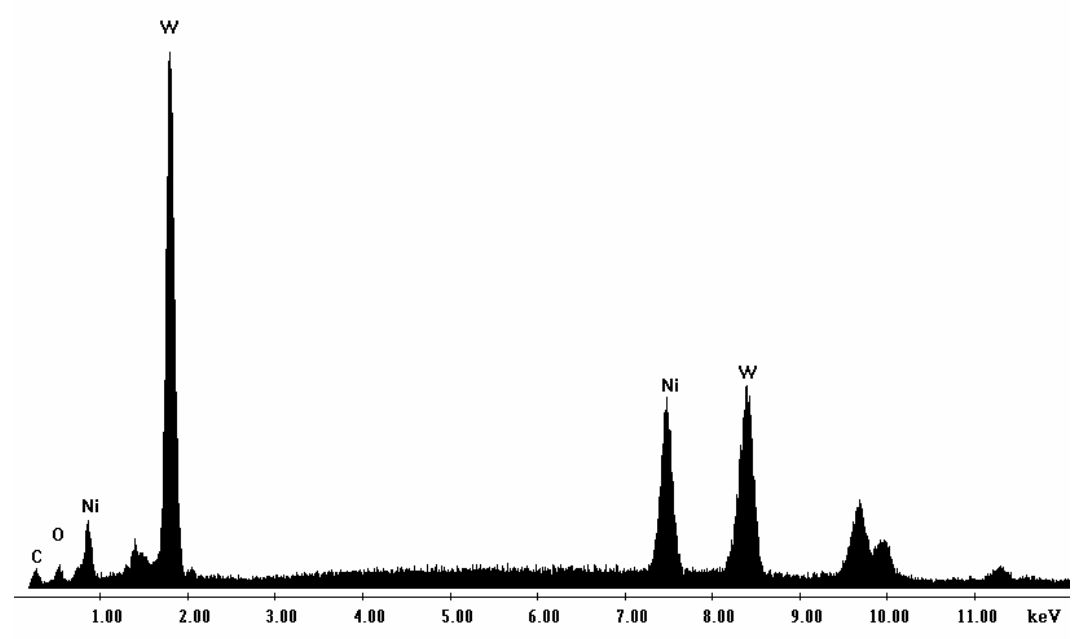

Figure 4-19 EDAX pattern of fresh cluster-like Ni-W-C catalyst $(x=0.75)$ 


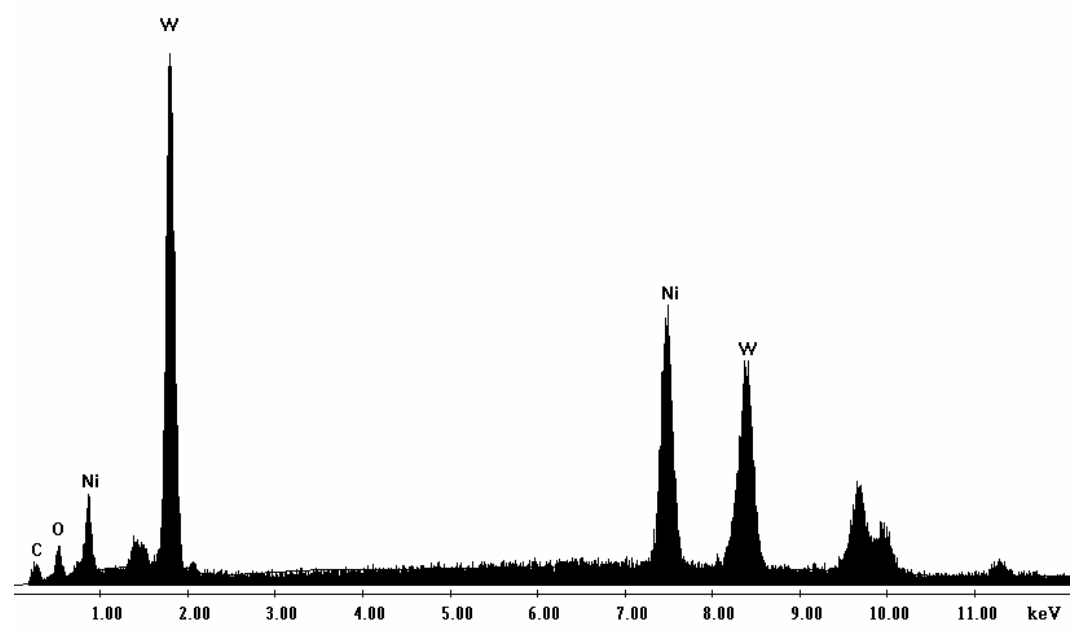

Figure 4-20 EDAX pattern of fresh spot-like Ni-W-C catalyst $(x=0.75)$

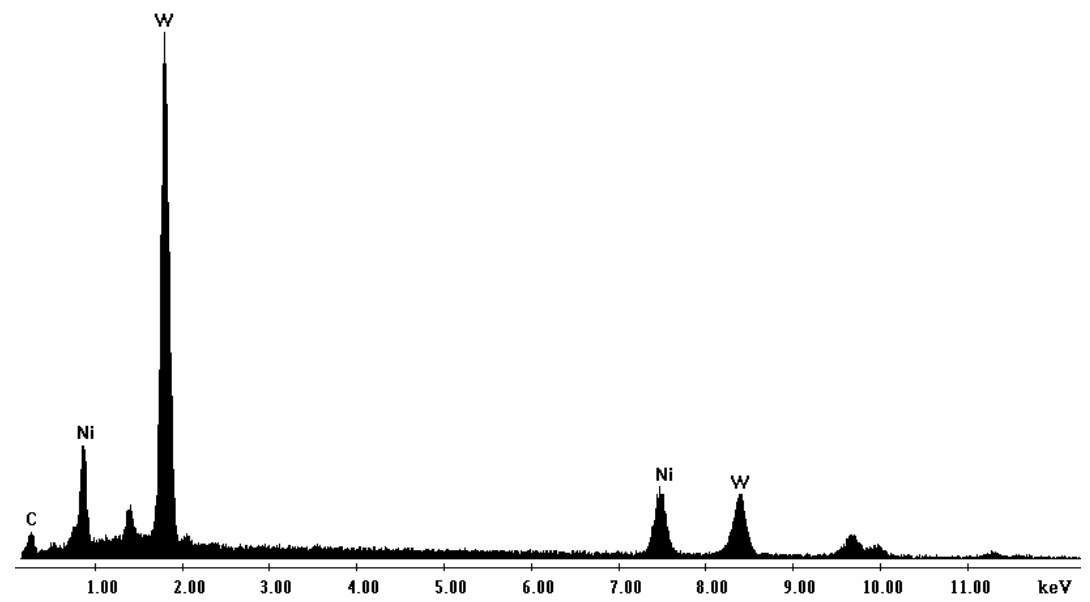

Figure 4-21 EDAX pattern of fresh Ni-W-C catalyst $(x=0.5)$ 


\subsection{Summary}

Early-transition-metal carbide catalysts have been successfully made in-house. By changing the metallic elements therein, four types of carbides have been prepared: Co-W-C, Ni-W-C, Co-Mo-C and Ni-Mo-C. In the carburization process to prepare the carbides, the $\mathrm{CO}_{2} / \mathrm{CO}$ ratio affects the final phase by varying the process carbon activity through the Boudouard reaction. The bimetallic carbide can be formed as the ratio $\mathrm{x}$ reaches a certain value, 0.5 for $\mathrm{Co}-\mathrm{W}-\mathrm{C}$ and 0.75 for Ni-W-C.

Detailed characterization results have been presented for both Co-W-C and Ni-W-C. XRD patterns show the trend of phase transformation with changing $\mathrm{CO}_{2} / \mathrm{CO}$ ratio. Pure $\mathrm{Co}_{6} \mathrm{~W}_{6} \mathrm{C}$ can be obtained with using $\mathrm{CO}_{2} / \mathrm{CO}=0.75$, which has a very similar XRD pattern to the sample from Nanodyne company. Reduction peaks in TPR spectra indicate the presence of oxides, perhaps left over from the preparation procedure. The morphology and elemental analysis of the catalysts was obtained with SEM \& EDAX. Some traces of oxygen are found in EDAX patterns for these in-house carbides. 


\section{CHAPTER 5 CATALYTIC STUDY OF Co-W-C CATALYST}

\subsection{Introduction}

The cobalt-tungsten-carbide catalyst prepared using the method described in Chapter 4 is active for hydrogenation and dehydrogenation reactions [62]. In this chapter are presented results when the catalytic performance of cobalt tungsten carbide was tested for three different reactions: methane dry reforming (DRM), methane steam reforming (SRM), and methanol steam reforming (SRMeOH). First, the catalytic reactivity and stability was studied using $\mathrm{Co}-\mathrm{W}-\mathrm{C}$ made with different ratios of $\mathrm{CO}_{2}$ to $\mathrm{CO}\left(\mathrm{x}=\mathrm{CO}_{2} / \mathrm{CO}\right)$. The spent catalysts were collected for characterization to investigate phase changes after those reactions. Finally, dry reforming (DRM) and steam reforming (both SRM and SRMeOH) were compared in terms of reactivity, stability and reaction rate constants.

For DRM, the effect of temperature history on the catalytic performance was studied. Spent catalysts before and after exposure to high temperature were characterized. In addition, to address the significance of this bimetallic carbide catalyst, a physical-mixture of Co and $\mathrm{WC}$ and in-situ temperature-reduced $\mathrm{WO}_{3}$ (no Co) were also studied for DRM. 


\subsection{Catalyst study on DRM}

5.2.1. Reactivity and stability of Co-W-C catalysts prepared with different ratios of $\mathrm{CO}_{2}$ to $\mathrm{CO}$

The reactivity and stability of the catalysts were tested by running the reaction under fixed conditions. Typically $0.3 \mathrm{~g}$ of catalyst was used for each test, and weight-based space velocity was set at $9,000 \mathrm{scc} / \mathrm{hr} / \mathrm{g}$-cat. The data recorded by on-line GC allows the amount of the effluent gases to be known, based on the calibration data of the standard gases. The conversions of the feed gases and the yields of the products are calculated from:

$$
\begin{aligned}
& \text { Conversion of } \mathrm{CH}_{4}, \quad \boldsymbol{X}_{\mathrm{CO}_{2}}=\frac{\left[\mathrm{CH}_{4}\right]_{\text {in }}-\left[\mathrm{CH}_{4}\right]_{\text {out }}}{\left[\mathrm{CH}_{4}\right]_{\text {in }}} \times \mathbf{1 0 0} \% \\
& \text { Conversion of } \mathrm{CO}_{2}, \quad \boldsymbol{X}_{\mathrm{CO}_{2}}=\frac{\left[\mathrm{CO}_{2}\right]_{i n}-\left[\mathrm{CO}_{2}\right]_{\text {out }}}{\left[\mathrm{CO}_{2}\right]_{\text {in }}} \times \mathbf{1 0 0} \% \\
& \text { Yield of CO, } \quad \mathbf{Y}_{\mathrm{CO}}=\frac{[\mathrm{CO}]_{\text {out }}}{\left[\mathrm{CO}_{2}\right]_{\text {in }}+\left[\mathrm{CH}_{4}\right]_{\text {in }}} \times \mathbf{1 0 0} \% \\
& \text { Ratio of } \mathrm{H}_{2} / \mathrm{CO}, \quad \boldsymbol{R}=\frac{\left[\boldsymbol{H}_{2}\right]_{\text {out }}}{[\mathbf{C O}]_{\text {out }}} \\
& \text { Carbon Balance, } \quad \mathbf{C B}=\frac{\left[\mathrm{CO}_{2}\right]_{\text {out }}+\left[\mathrm{CH}_{4}\right]_{\text {out }}+[\mathrm{CO}]_{\text {out }}}{\left[\mathrm{CO}_{2}\right]_{\text {in }}+\left[\mathrm{CH}_{4}\right]_{\text {in }}} \times 100 \%
\end{aligned}
$$

Conversions and yields are very important parameters for the reactivity of the catalyst. From stoichiometric reaction equation of DRM (Equation 1-3), the ratio R should be close to unity, which is different from $\mathrm{R}$ for the other two types of methane 
reforming. However, this ratio may shift from unity because side reactions can take place, such as reverse water gas shift (RWGS, equation 1-6), reverse Boudouard reaction ( $R B$, equation 1-5), and carbon decomposition ( $C D$, equation 1-4). The carbon balance is used to evaluate the coke deposition as well as the extent of side reactions (CD and RB). The stability of the catalyst can be determined by monitoring conversions and yields during long-term testing (more than 100 hours) at $850^{\circ} \mathrm{C}$ and $3.4 \mathrm{~atm}$.

With the help of CHEMCAD 5.5.x software, equilibrium calculations have been performed for the reaction system. Eight species are considered in the whole system, six reacting species $\left(\mathrm{CH}_{4}, \mathrm{CO}_{2}, \mathrm{H}_{2}, \mathrm{CO}, \mathrm{H}_{2} \mathrm{O}\right.$ and $\left.\mathrm{C}(\mathrm{s})\right)$ and two inert ones (He and $\mathrm{Ar}$ ). The feed stream has the same total flow rate $(45 \mathrm{scc} / \mathrm{min})$ and composition $\left(\mathrm{CH}_{4} / \mathrm{CO}_{2} / \mathrm{He} / \mathrm{Ar}=30 \% / 30 \% / 4 \% /\right.$ balance $)$ as used in the real reaction system at $3.4 \mathrm{~atm}$.

Figure 5-1 shows the calculated equilibrium conversions of $\mathrm{CH}_{4}$ and $\mathrm{CO}_{2}$ as well as the ratios $\mathrm{H}_{2} / \mathrm{CO}$ and $\mathrm{H}_{2} \mathrm{O} / \mathrm{CO}$. In Figure 5-1A, $\mathrm{CH}_{4}$ conversion increases continuously with temperature, while $\mathrm{CO}_{2}$ conversion decreases at first and then increases as the temperature rises. At $850^{\circ} \mathrm{C}$, the reaction can have an equilibrium conversion of $94 \%$ for $\mathrm{CH}_{4}$ and $88 \%$ for $\mathrm{CO}_{2} . \mathrm{CH}_{4}$ conversion is always higher than that of $\mathrm{CO}_{2}$. The big gap between the equilibrium conversions of $\mathrm{CH}_{4}$ and $\mathrm{CO}_{2}$ near $600^{\circ} \mathrm{C}$ can be attributed to the fact that carbon deposition becomes thermodynamically significant, and this consumes more $\mathrm{CH}_{4}$. Also equilibrium carbon balance increases with temperature too. The equilibrium ratio of $\mathrm{H}_{2} / \mathrm{CO}$ decreases with temperature 

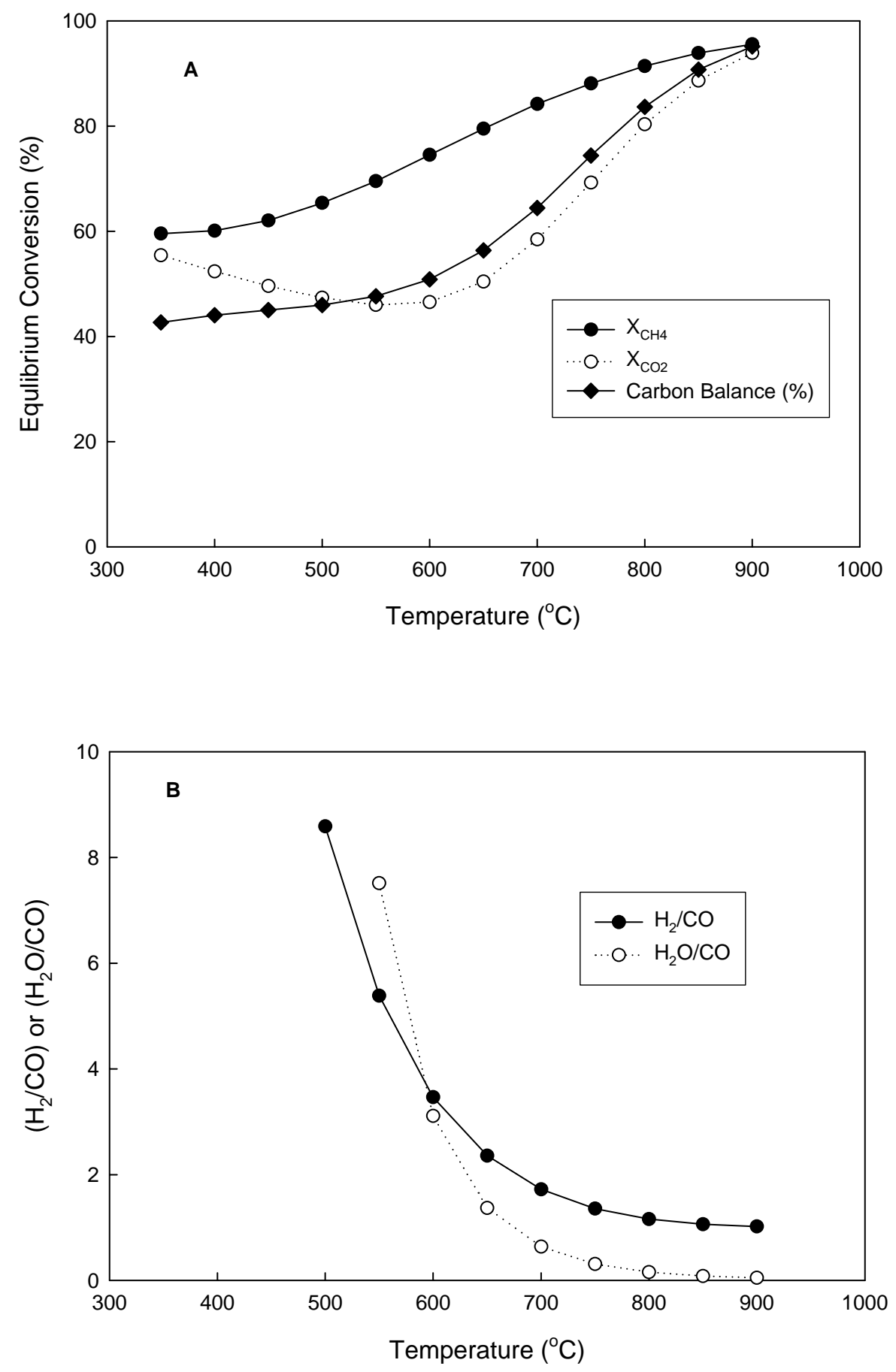

Figure 5-1 Equilibrium calculation of multiple reactions for DRM system as a function of temperature
A: Equilibrium conversions and carbon balance
B: $\mathrm{H}_{2} / \mathrm{CO}$ or $\mathrm{H}_{2} \mathrm{O} / \mathrm{CO}$ ratio

Reaction conditions: $P_{\text {tot }}=3.4 \mathrm{~atm}, \mathrm{~V}_{\text {tot }}=45 \mathrm{scc} / \mathrm{min}, \mathrm{CH}_{4} / \mathrm{CO}_{2} / \mathrm{He} / \mathrm{Ar}=30 \% / 30 \% / 4 \% / 36 \%$ 
because RWGS is more thermodynamically favorable at high temperatures. At lower temperatures, WGS is thermodynamically favorable, which gives a higher equilibrium ratio of $\mathrm{H}_{2} / \mathrm{CO}$. In addition, in the presence of small amount of $\mathrm{H}_{2} \mathrm{O}, \mathrm{SRM}$ can be thermodynamically significant, which increases $\mathrm{H}_{2} / \mathrm{CO}$. As the temperature approaches $900^{\circ} \mathrm{C}$, equilibrium conversions of $\mathrm{CH}_{4}$ and $\mathrm{CO}_{2}$ are almost equal, and the $\mathrm{H}_{2} / \mathrm{CO}$ ratio is also close to unity, indicating the whole reaction system appears to be dominated by DRM.

These calculation results are different from that done by Vannice et al. [13], who used the program ARL SOLGASMIX (see Appendix B-1). In their work, both $\mathrm{CH}_{4}$ and $\mathrm{CO}_{2}$ conversions increase with temperature. Moreover, $\mathrm{CO}_{2}$ conversion is always higher than $\mathrm{CH}_{4}$ due to RWGS equilibrium. In addition, $\mathrm{H}_{2} / \mathrm{CO}$ increases monotonically with temperature, approaching 1 at the higher values. The differences can be attributed to the fact that there is no carbon involved in the equilibrium calculations of Vannice et al. [13], and reactions $\mathrm{RB}$ and $\mathrm{CD}$ have not been taken into account. Using CHEMCAD 5.5.x, the results of Vannice et al. can be reproduced (see Appendix B-2) by removing solid carbon from the equilibria reaction system, thereby eliminating $\mathrm{RB}$ and $\mathrm{CD}$ reactions. It is shown later that the laydown of carbon is an essential component, at least for the present catalytic system.

Before the catalysts were inserted, a blank DRM run was carried out to test the reactivity of the reactor itself. The objective is to check the catalytic activity of the 
stainless steel reactor itself, even though it has been passivated as described in Chapter 3 . During the blank run, a certified gas mixture with $\mathrm{CH}_{4} / \mathrm{CO}_{2} / \mathrm{He} / \mathrm{Ar}(30 \% / 30 \%$ / 4\% /balance) was fed into the reactor after passing through the mass flow controller. The reaction pressure was kept constant at $3.4 \mathrm{~atm}$, so that the partial pressure of each reactant $\left(\mathrm{CH}_{4}\right.$ and $\left.\mathrm{CO}_{2}\right)$ was kept at $1 \mathrm{~atm}$. The total flow rate was fixed at $45 \mathrm{scc} / \mathrm{min}$, the same amount to be used for testing the catalyst. The reaction temperature was increased from $700^{\circ} \mathrm{C}$ up to $850^{\circ} \mathrm{C}$ at intervals of $50^{\circ} \mathrm{C}$. Figure $5-2$ shows the results of a DRM blank run in terms of reactant conversions. Almost no catalytic activity is found at $700^{\circ} \mathrm{C}$. Even as the temperature is raised to $850^{\circ} \mathrm{C}$, the conversions are only $6 \%$ for $\mathrm{CH}_{4}$ and $7.5 \%$ for $\mathrm{CO}_{2}$.

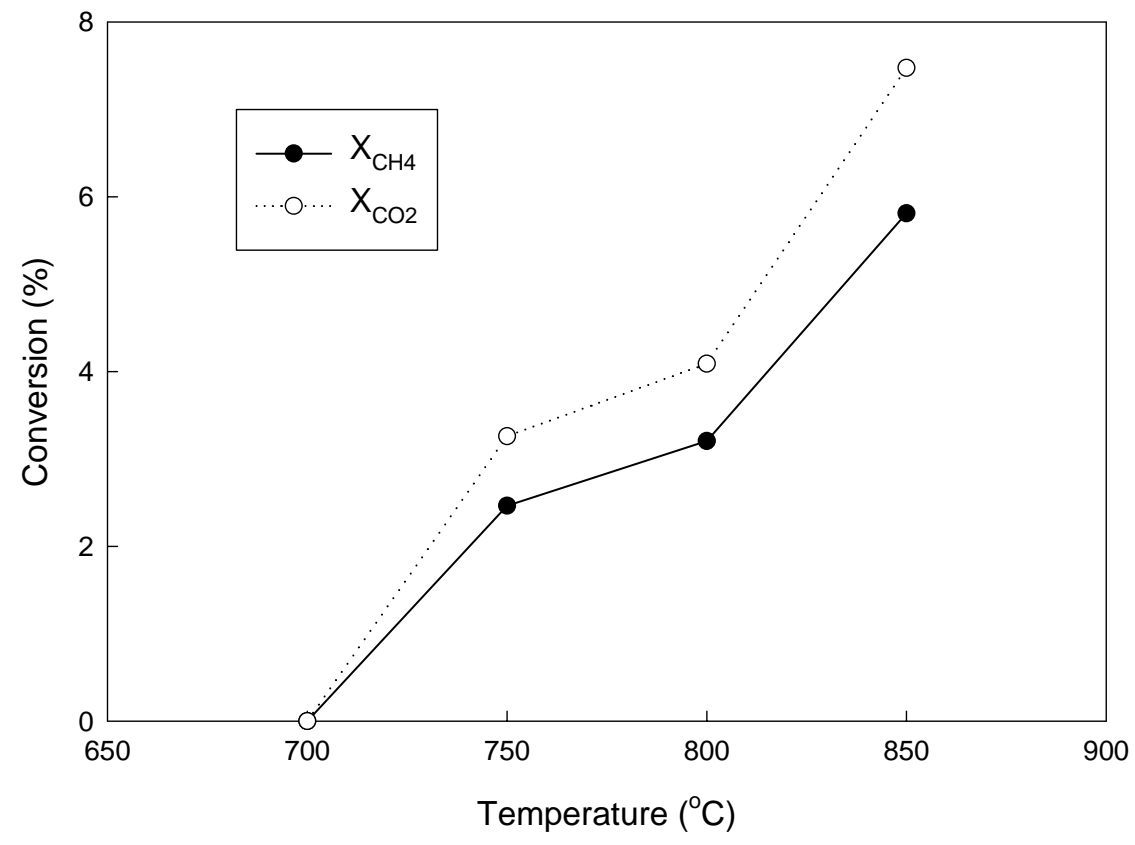

Figure 5-2 Conversion of $\mathrm{CH}_{4}$ and $\mathrm{CO}_{2}$ for the blank run 
Figures 5-3 through 5-6 are the results for the reactivity and stability of the Co-W-C catalysts manufactured using four different ratios of $\mathrm{CO}_{2}$ to $\mathrm{CO}$. For all these catalysts, a period of induction time is observed before the catalyst reaches the steady state, and the highest value of $\mathrm{H}_{2} / \mathrm{CO}$ ratio is obtained in this period. Moreover, the higher the ratio of $\mathrm{CO}_{2}$ to $\mathrm{CO}$ used to make the catalyst, the longer the induction time required to reach the steady state. For the $\mathrm{x}=0.1$ sample, which already contains $\mathrm{WC}$ and Co in the fresh material (see Figure 4-3), an induction time is still required, even though this period of time is shorter than that for other three samples.

After the steady state is reached, the values of carbon balance are all between $85 \%$ and $90 \%$. All four catalysts were found to be active and stable for DRM for over 100 hours, holding conversions at $70-80 \%$ at steady state and carbon balances are around $90 \%$. From Figure $5-1$ at $850^{\circ} \mathrm{C}$, equilibrium conversions are $94 \%$ for $\mathrm{CH}_{4}$ and $89 \%$ for $\mathrm{CO}_{2}$, and equilibrium carbon balance is $94 \%$.

When the $\mathrm{CO}_{2} / \mathrm{CO}$ ratio is equal to 0.1 (Figure 5-3), the $\mathrm{H}_{2} / \mathrm{CO}$ ratio is higher than unity at unsteady state (the first 20 hours), and the conversion of $\mathrm{CH}_{4}$ is much higher than $\mathrm{CO}_{2}$. The ratio of $\mathrm{H}_{2} / \mathrm{CO}$ can be as high as 2 at the beginning of the reaction, indicating less RWGS and less RB take place in this period. However, as the steady state is reached, the conversion of $\mathrm{CH}_{4}$ becomes several percentages lower than that of $\mathrm{CO}_{2}$, and $\mathrm{H}_{2} / \mathrm{CO}$ approaches unity. At this point, it can be deduced that more RWGS and RB reactions take place, while less $\mathrm{CD}$ takes place. For the $\mathrm{CO}_{2} / \mathrm{CO}$ ratio 
of 0.75 (Figure 5-6), the steady state conversion of $\mathrm{CH}_{4}$ is higher than that of $\mathrm{CO}_{2}$, which means that less RWGS and RB reactions take place, while more CD takes place. In the other two intermediate cases, when the $\mathrm{CO}_{2} / \mathrm{CO}$ ratio values are 0.2 and 0.5 (Figure 5-4 and Figure 5-5), the catalysts have similar performance to the one with ratio equal to 0.75 .

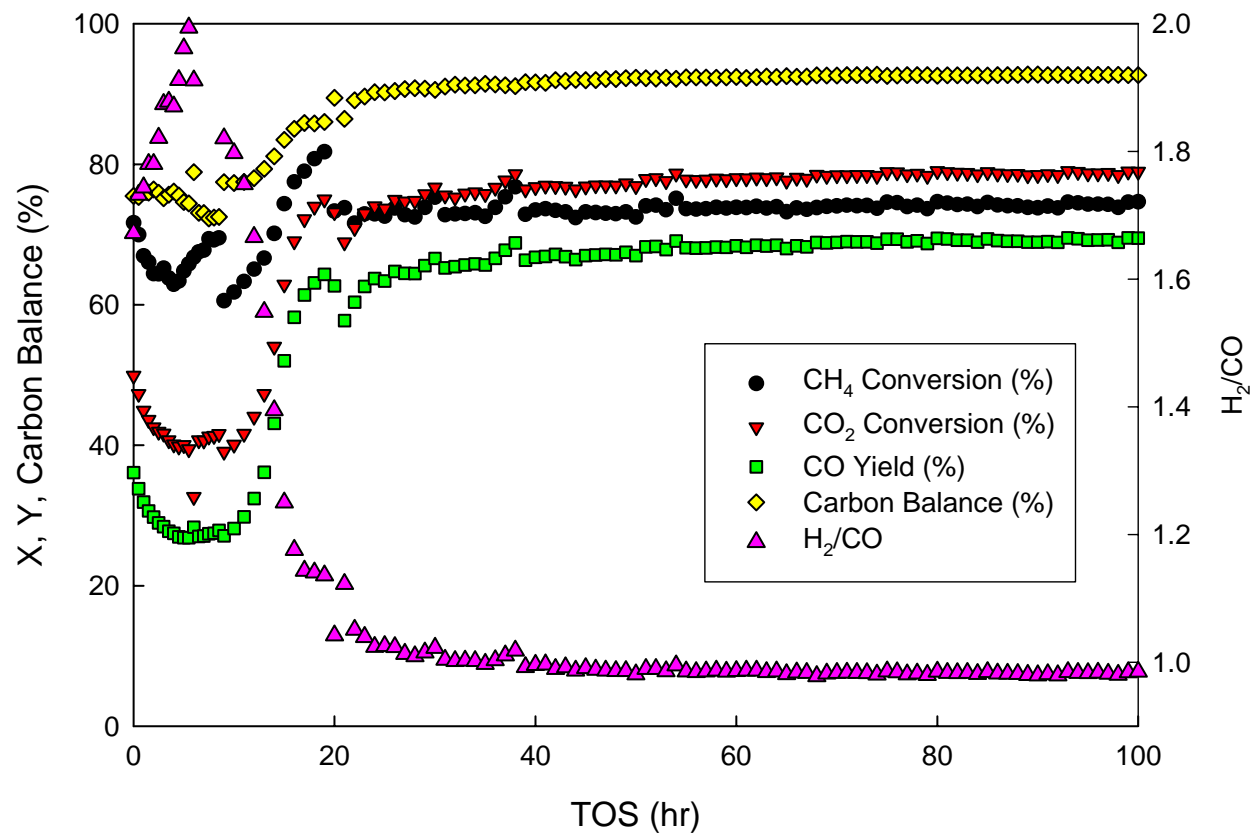

Figure 5-3 Reactivity and stability test for Co-W-C ( $\mathrm{x}=0.1)$ 


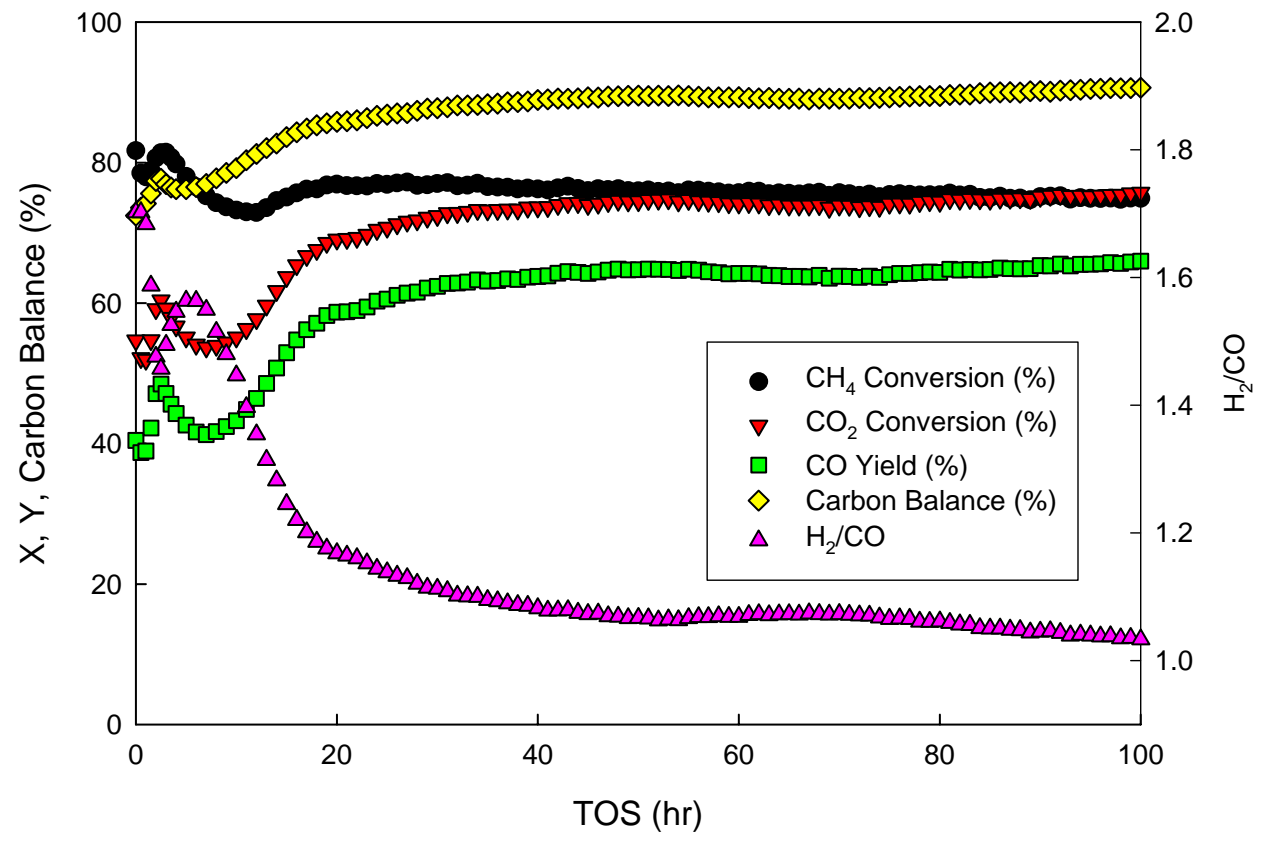

Figure 5-4 Reactivity and stability test for Co-W-C $(x=0.2)$

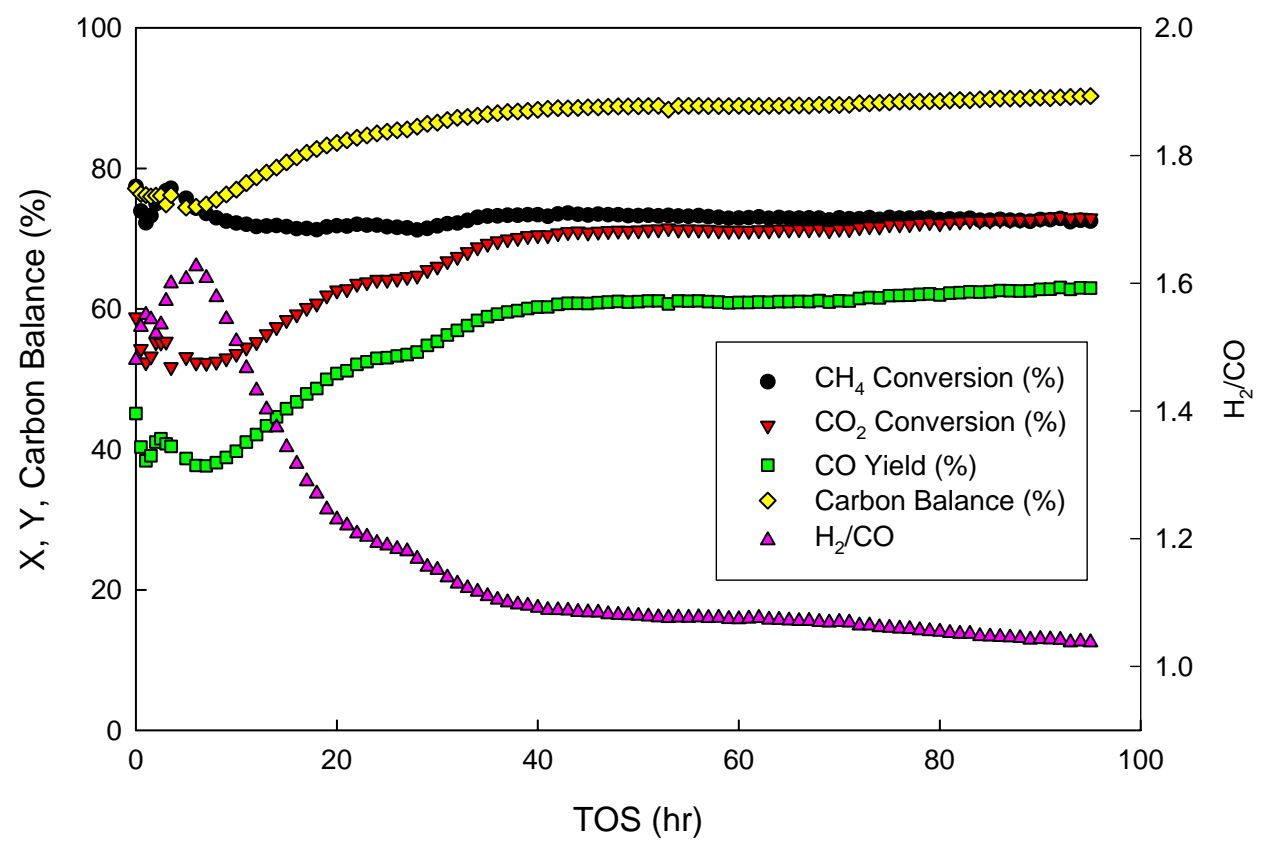

Figure 5-5 Reactivity and stability test for Co-W-C $(x=0.5)$ 


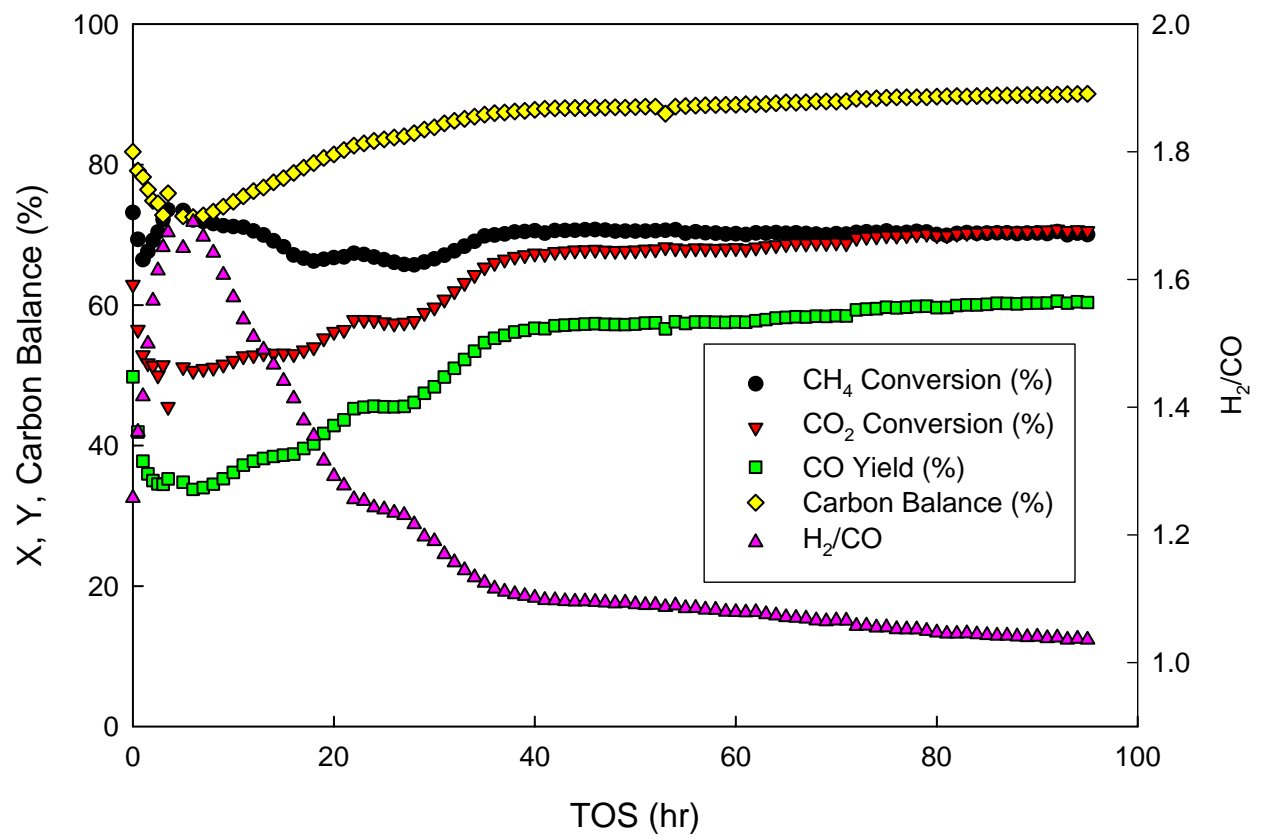

Figure 5-6 Reactivity and stability test for Co-W-C ( $x=0.75)$

\subsubsection{Characterization of spent catalyst after catalytic test}

XRD measurements for fresh $\mathrm{Co}-\mathrm{W}-\mathrm{C}$ catalysts have been presented in Figures 4-3 through 4-6. After the reaction, the spent catalysts were collected and characterized by XRD (Figure 5-7 to Figure 5-9). For the $\mathrm{x}=0.1$ sample (Figure 5-7), a similar XRD pattern as the fresh catalyst is observed, in addition to carbon deposits produced from the reaction. But the relative amounts of those components $\left(\mathrm{Co}_{3} \mathrm{~W}_{3} \mathrm{C}, \mathrm{WC}\right.$ and $\left.\mathrm{Co}\right)$ are different from those in the fresh catalyst (Figure 4-3). A larger amount of WC is seen after the catalyst is exposed to reactants at $850^{\circ} \mathrm{C}$ for 100 hours. For the $\mathrm{x}=0.2$ and 0.75 catalysts (Figure 5-8 and Figure 5-9), only WC, Co and carbon deposits are present in the bulk phase. 


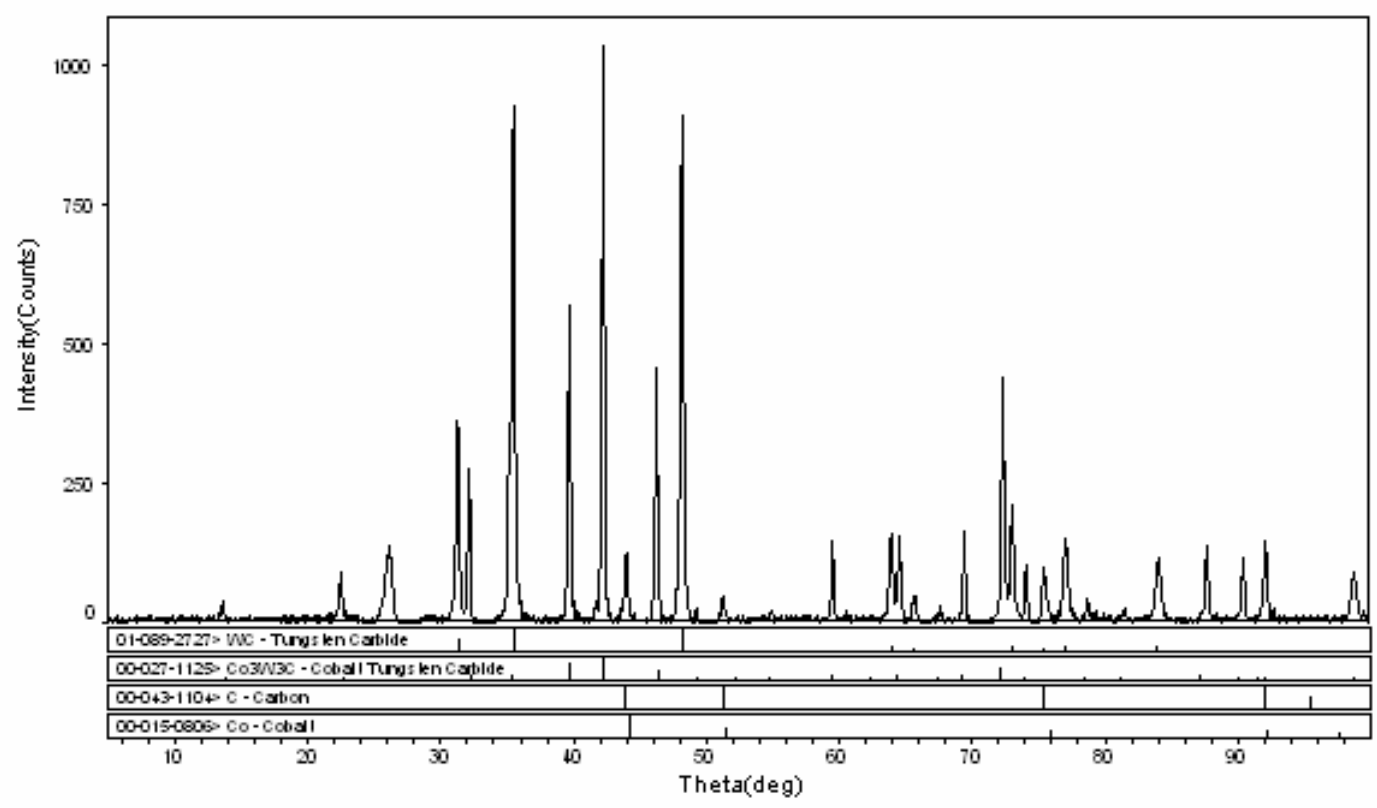

Figure 5-7 XRD pattern of spent Co-W-C $(x=0.1)$

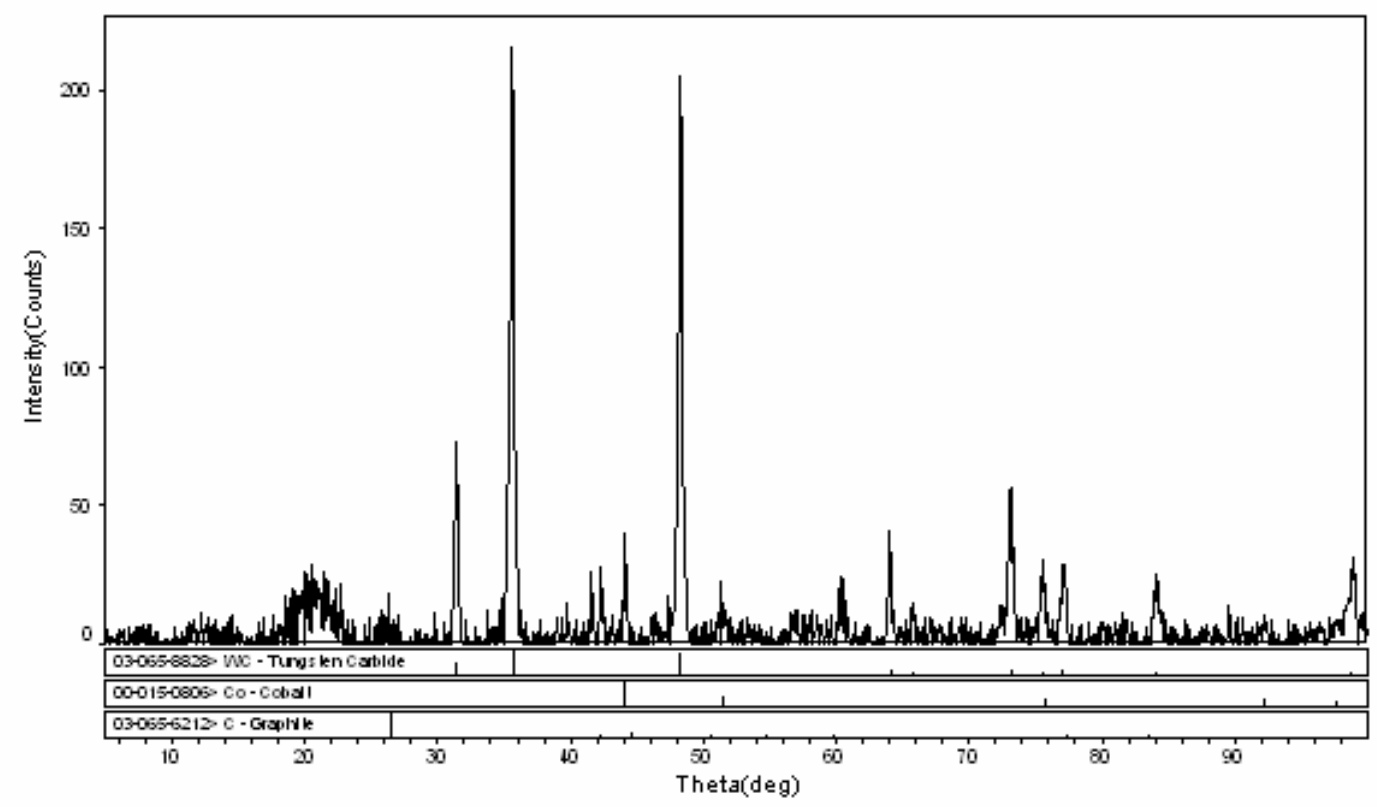

Figure 5-8 XRD pattern of spent Co-W-C $(x=0.2)$ 


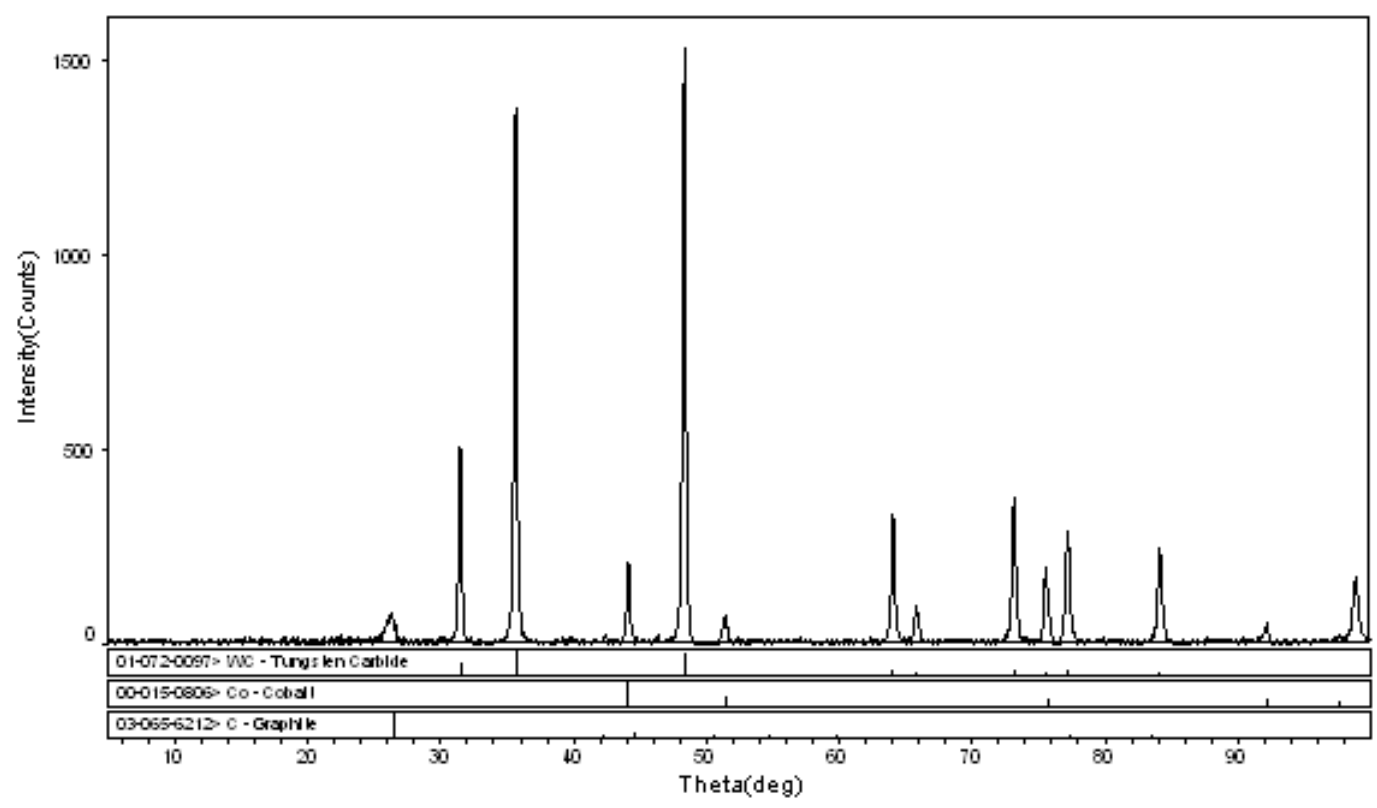

Figure 5-9 XRD pattern of spent Co-W-C ( $x=0.75)$

The carbide goes through the phase change from bimetallic carbide $\mathrm{Co}_{6} \mathrm{~W}_{6} \mathrm{C}$ (or $\mathrm{Co}_{3} \mathrm{~W}_{3} \mathrm{C}$ ) in the fresh samples to $\mathrm{Co}$ and $\mathrm{WC}$ in the spent catalysts. This change probably takes place in the induction period, consistent with low carbon balance in the reactivity and stability tests. The change could proceed in the following way:

$$
\begin{aligned}
& \mathrm{Co}_{6} W_{6} C+5 C \rightarrow 6 C o+6 W C \\
& \text { or } \\
& \mathrm{Co}_{3} W_{3} C+2 C \rightarrow 3 C o+3 W C
\end{aligned}
$$

with the added carbon from $\mathrm{CD}$ and RB. The catalyst transforms into the active solid phase mixture, $\mathrm{Co}, \mathrm{WC}$ and $\mathrm{C}$, after it is exposed to the reactants at $850^{\circ} \mathrm{C}$. As a part of 
the solid active phase, the presence of carbon could probably be the reason why the carbide catalyst (made using $\mathrm{x}=0.1$ ) has good stability and high resistance to coke formation. The source of carbon deposits is probably from methane decomposition because $\mathrm{CH}_{4}$ conversion is much higher than $\mathrm{CO}_{2}$ conversion in the induction period. Once a sufficient amount of carbon is deposited, there is little net addition of carbon onto the catalyst, as indicated by a carbon balance closer to $100 \%$ after the catalyst reaches the steady state. Unlike the traditional nickel-based catalyst, the in-house cobalt tungsten carbide catalyst can maintain stable reactivity after the necessary amount of carbon is laid down on the surface, exhibiting high resistance to further coke formation and hence deactivation. 


\subsubsection{Comparison between $\mathrm{Co}_{6} \mathrm{~W}_{6} \mathrm{C}$ and $\mathrm{WC}$}

From the XRD measurements (Figures 5-7 through 5-9), the stable and active form for DRM contains a mixture of $\mathrm{Co}$ and $\mathrm{WC}$ as bulk phase. In this work, two comparisons were performed with the in-house carbide, which would address the significance of developing this bimetallic carbide catalyst.

First, $\mathrm{Co}_{6} \mathrm{~W}_{6} \mathrm{C}$ was compared with a physical-mixture of $\mathrm{Co}$ and WC. Commercial $\mathrm{Co}_{3} \mathrm{O}_{4}$ and $\mathrm{WC}$ were physically mixed. The absolute amounts of Co and $\mathrm{W}$ were the same as those used in reactions over $\mathrm{Co}_{6} \mathrm{~W}_{6} \mathrm{C}$. The testing procedure was also the same as that used for $\mathrm{Co}_{6} \mathrm{~W}_{6} \mathrm{C}$, including reduction with flowing $\mathrm{H}_{2}$ before testing. Figure 5-10 shows the results for the physical-mixture at $850^{\circ} \mathrm{C}$ and $3.4 \mathrm{~atm}$. The conversions for the physical-mixture are compared to those using $\mathrm{Co}_{6} \mathrm{~W}_{6} \mathrm{C}(\mathrm{x}=0.75)$ in Figure 5-11. The testing for the physical-mixture catalyst had to be stopped after 23 hours on stream because of excessive coke formation, leading to a pressure drop higher than 100 psig inside the reactor. For the physical-mixture, $\mathrm{CH}_{4}$ conversion increases with time on stream in the testing range, while $\mathrm{CO}_{2}$ conversion reaches its highest level after around 10 hours and then decreases. The difference between conversions increases with time on stream and can be due to significant coke formation from methane cracking. Note that, different from $\mathrm{Co}_{6} \mathrm{~W}_{6} \mathrm{C}$, the carbon balance for the physical-mixture does not improve with time on stream, moving away from $100 \%$ as the reaction proceeds. 


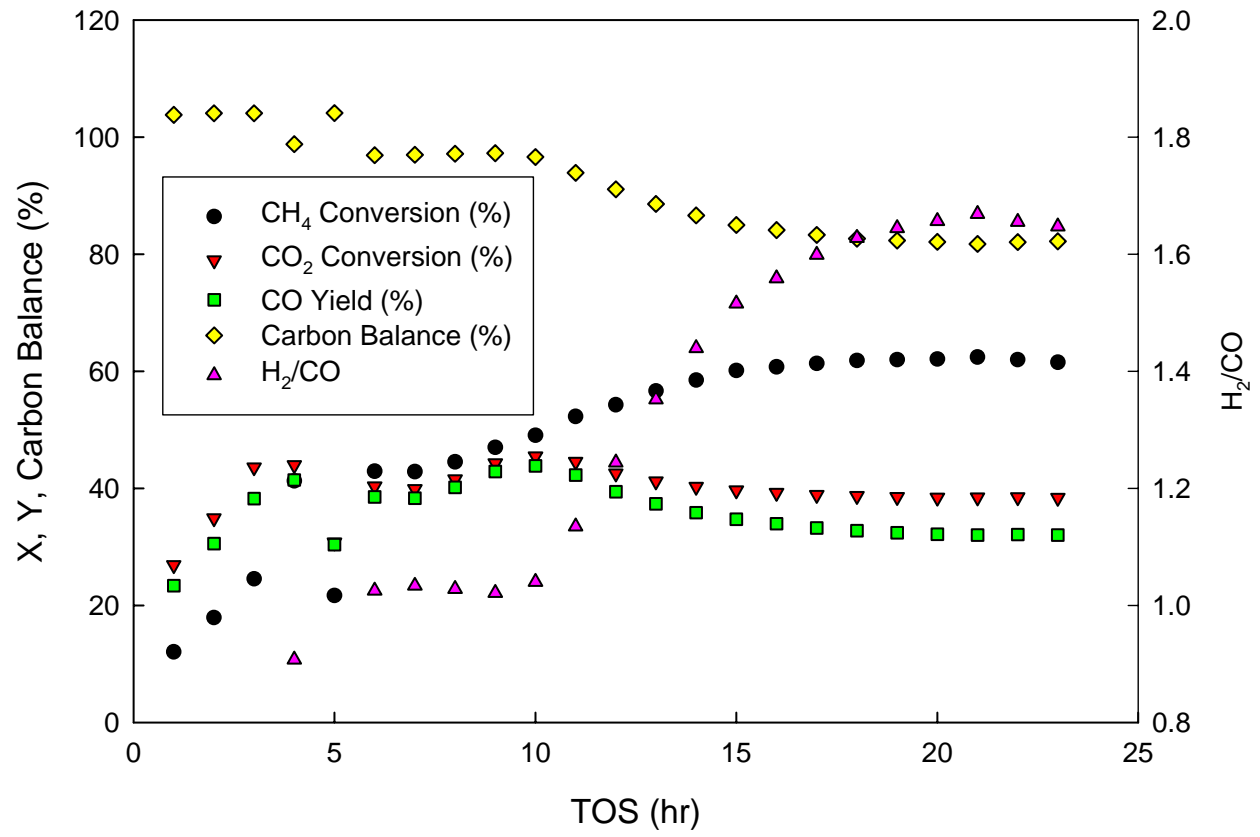

Figure 5-10 Reactivity and stability test for the physical-mixture of Co + WC

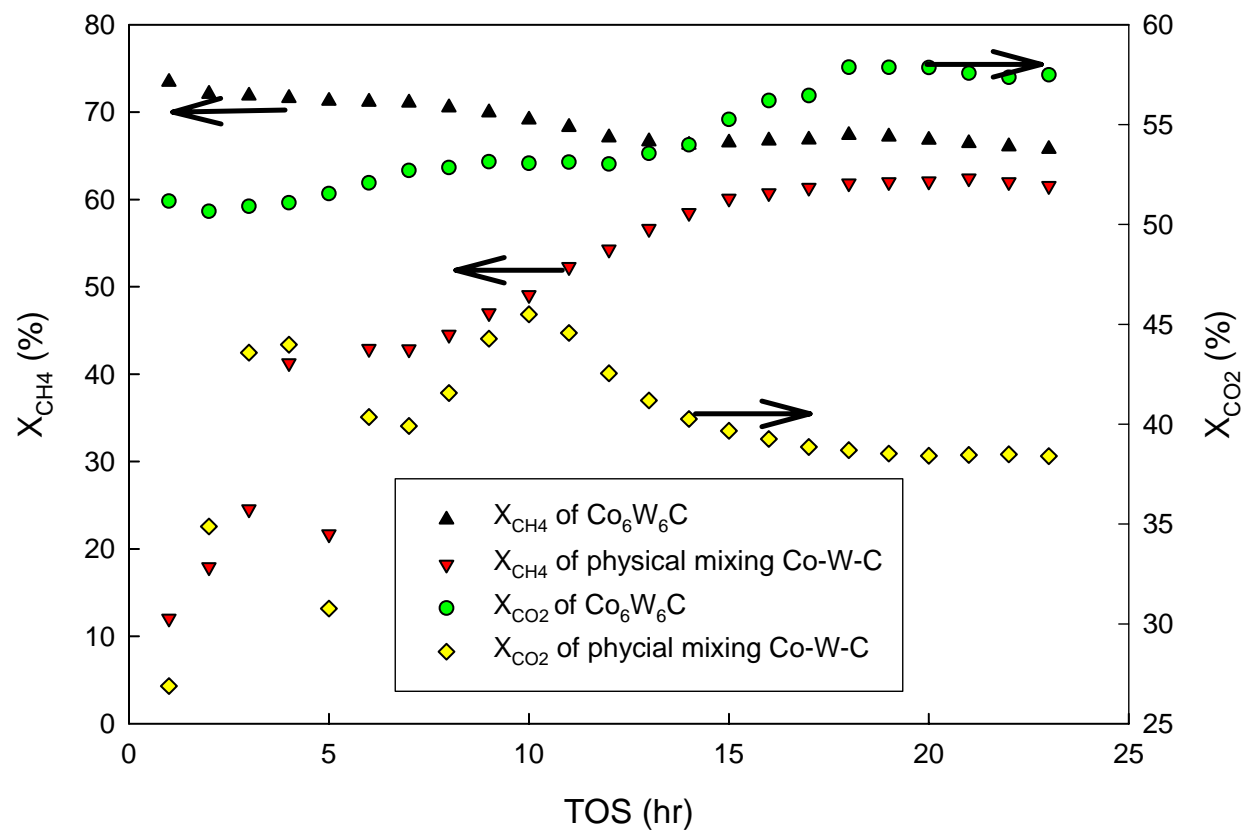

Figure 5-11 Comparison of conversions over $\mathrm{Co}_{6} \mathrm{~W}_{6} \mathrm{C}(\mathrm{x}=0.75)$ \& the physical-mixture 
As shown in Figure 5-11, the conversions with $\mathrm{Co}_{6} \mathrm{~W}_{6} \mathrm{C}$ are much higher than those with physical Co-W-C mixture. After 15 hours on stream, $\mathrm{CO}_{2}$ conversion of $\mathrm{Co}_{6} \mathrm{~W}_{6} \mathrm{C}$ is $40 \%$ greater than that of the physical-mixture catalyst, corresponding to much better stability and lower coke formation. The in-house bimetallic carbide Co-W-C exhibits much better catalytic performance than the physical Co-W-C mixture, in terms of both reactivity and stability.

After the reaction, the physical-mixture (Co and WC) was removed from the reactor for XRD measurement, and the pattern is presented in Figure 5-12. The main bulk phase components here are also $\mathrm{Co}$ and $\mathrm{WC}$, similar to what is found in the spent catalyst of $\mathrm{Co}_{6} \mathrm{~W}_{6} \mathrm{C}$. But the amount of carbon is not detected. As discussed earlier, the accumulation of a certain amount of carbon in the $\mathrm{Co}_{6} \mathrm{~W}_{6} \mathrm{C}$ catalyst is probably necessary for activity and stability. For the physical-mixture catalyst, low resistance to coke formation might be due to insufficient carbon accumulation inside the catalyst. Alternatively, those carbon deposits may be different from those produced from $\mathrm{Co}_{6} \mathrm{~W}_{6} \mathrm{C}$, and these probably cover the surface of the catalyst and blocking the active sites. In any case, the behavior of the $\mathrm{Co}_{6} \mathrm{~W}_{6} \mathrm{C}$ catalyst is superior to that of a physical-mixture of Co and WC.

In a second set of experiments, the WC was prepared in-situ using the temperature programmed reduction/carburization (TPR) of $\mathrm{WO}_{3}$, and used immediately for DRM. It was hypothesized that fresh in-situ TPR may lead to a more active WC. 


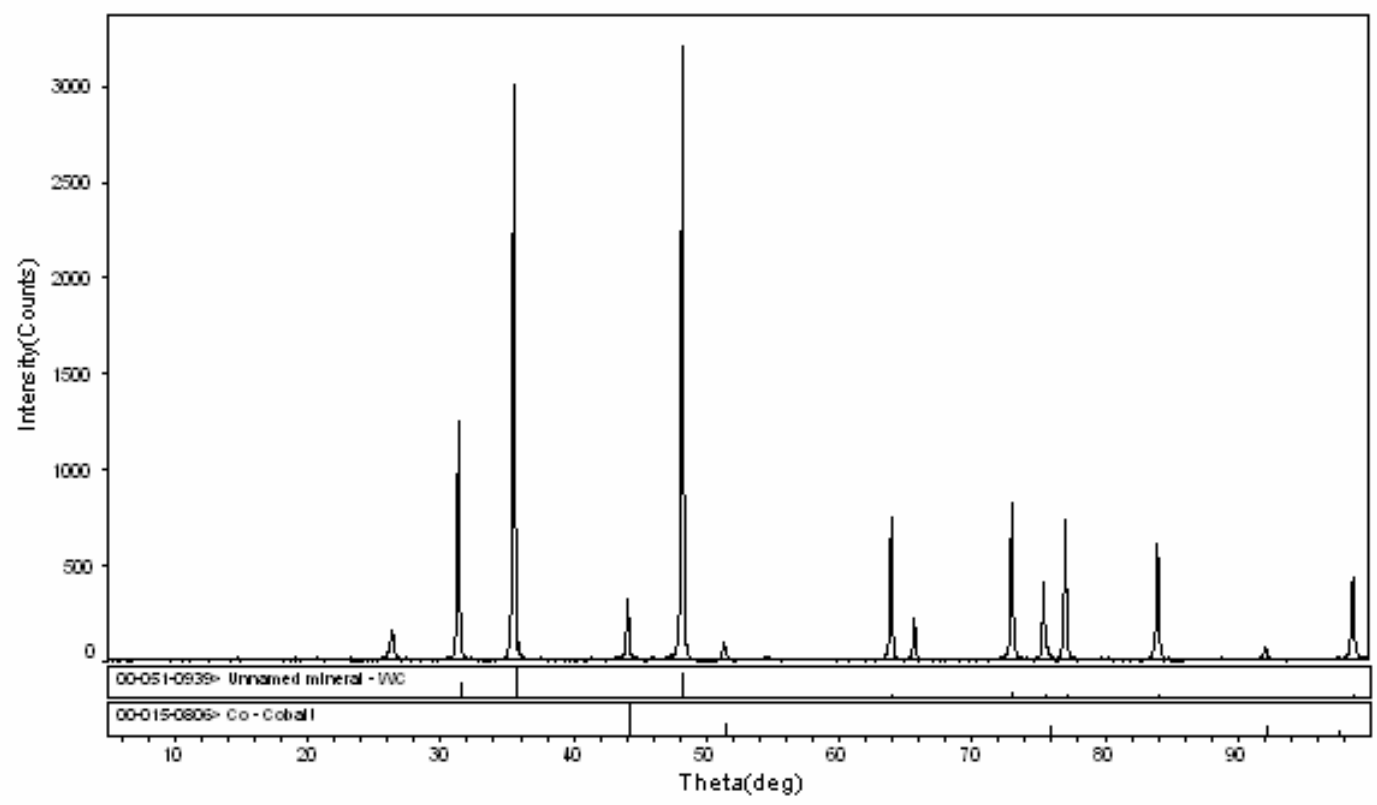

Figure 5-12 XRD pattern of spent physical-mixture Co-W-C after $850^{\circ} \mathrm{C}$

The method of Green et al. [2, 89] was used. However, Green et al. noted that the catalysts must be tested immediately after the metal oxide is completely carburized in the reactor. Moreover, at low reaction pressure, these carbides tend to deactivate shortly with time on stream, due to the formation of oxides. Here, $0.28 \mathrm{~g}$ of $\mathrm{WO}_{3}$ was loaded in the reactor, and was carburized with flowing $\mathrm{CH}_{4} / \mathrm{H}_{2}(10 \% \mathrm{v} / \mathrm{v})$ from room temperature to $827^{\circ} \mathrm{C}$ at a slow heating rate of $1^{\circ} \mathrm{C} / \mathrm{min}$. Afterwards, the temperature was held at $827^{\circ} \mathrm{C}$ for another 6 hours for complete carburization. The $\mathrm{CH}_{4} / \mathrm{H}_{2}$ mixture was then replaced by the reactant gases.

The testing procedure was kept the same as for in house Co-W-C carbide catalyst. With the same reaction conditions, $\mathrm{T}=850^{\circ} \mathrm{C}$ and $\mathrm{P}=3.4 \mathrm{~atm}$ with a total flow rate of 45 
scc/min. The testing results are presented in Figure 5-13. At low times on stream, the reactivity is reasonable, $60 \%$ conversion for $\mathrm{CH}_{4}$ and $70 \%$ conversion for $\mathrm{CO}_{2}$. However, severe deactivation is observed after only one hour. The $\mathrm{H}_{2} / \mathrm{CO}$ ratio also decreases with time on stream, especially in the first several hours. After 5 hours, the catalyst reaches steady state, where the conversions are very low, only $10 \%$ conversion for $\mathrm{CH}_{4}$ and $30 \%$ conversion for $\mathrm{CO}_{2}$. Carbon balance is close to $100 \%$ (within experimental error), indicating no $\mathrm{C}$ deposition during the reaction. The conversion of $\mathrm{CO}_{2}$ is always higher than that of $\mathrm{CH}_{4}$, which means more $\mathrm{RB}$ while less $\mathrm{CD}$ takes place in the reaction system.

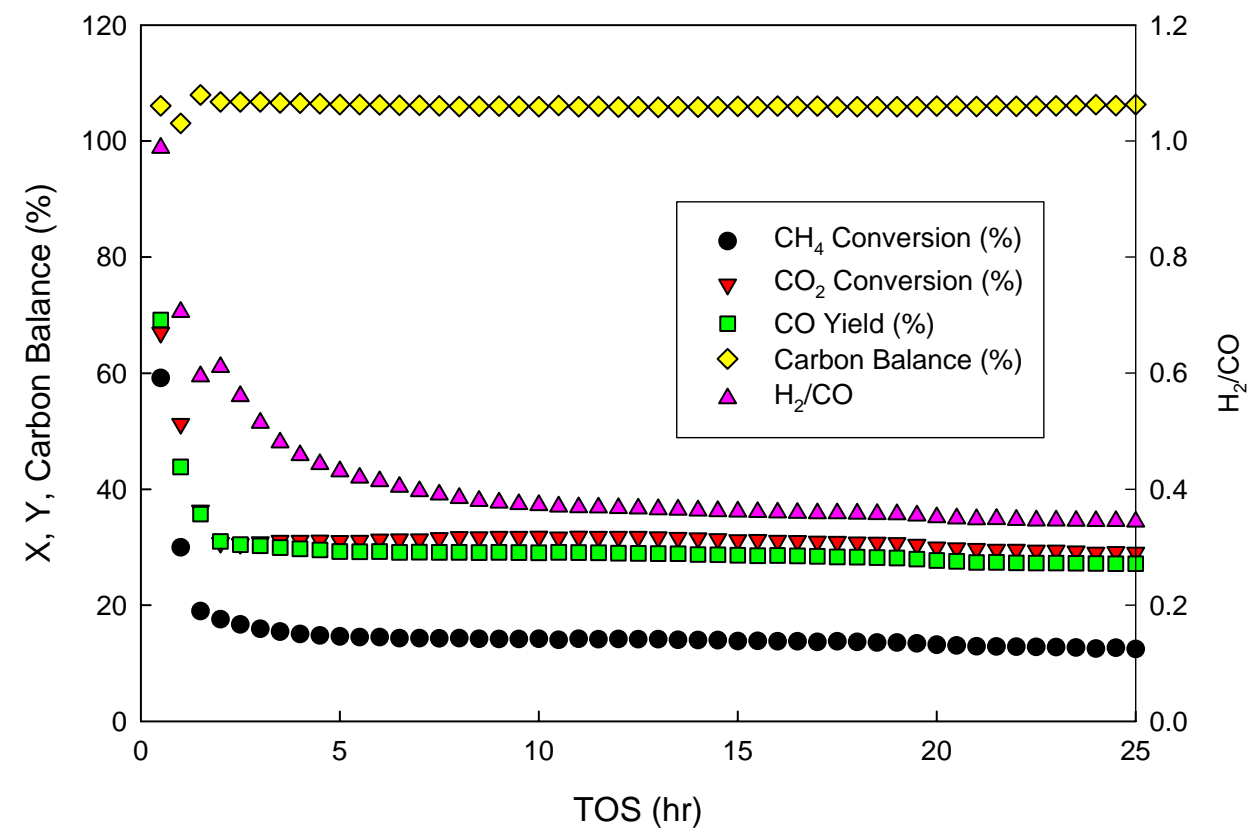

Figure 5-13 Reactivity and stability test for in-situ TPR prepared WC from $\mathrm{WO}_{3}$ 
Comparing the catalytic performance of $\mathrm{Co}_{6} \mathrm{~W}_{6} \mathrm{C}$ and in-situ temperature-programmed-carburized WC, the latter deactivates quickly under the conditions applied in this testing, even though a mild reactivity can be achieved at the very beginning. Hence this material too does not explain the high activity and selectivity of $\mathrm{Co}_{6} \mathrm{~W}_{6} \mathrm{C}$. Once again, carbon deposition seems to be the key to the performance of the bimetallic carbide catalyst in DRM.

\subsubsection{Investigation of effect of exposure to high temperature on the catalytic performance of bimetallic carbide catalyst}

In the previous tests of catalytic activity and stability, the reaction temperature was fixed at $850^{\circ} \mathrm{C}$, at which temperature the cobalt tungsten carbide catalyst has been shown to be stable and active for DRM. In this part, a temperature ramp was designed by increasing and decreasing the temperature to investigate the effect of exposure to high temperature on the catalytic performance of the bimetallic carbide catalyst. However, all the other reaction parameters were kept the same as before, including reaction pressure, feed ratio of the reactants and space velocity. At each temperature stage, the catalyst was held for at least 20 hours until it reached steady state, and then the catalyst was quickly heated or cooled to the next stage. The specific temperature progression consisted of at least the following steps:

$$
700^{\circ} \mathrm{C} \rightarrow 600{ }^{\circ} \mathrm{C} \rightarrow 850{ }^{\circ} \mathrm{C} \rightarrow 700{ }^{\circ} \mathrm{C} \rightarrow 600^{\circ} \mathrm{C} \rightarrow 500{ }^{\circ} \mathrm{C}
$$


Three different carbide catalysts (ratios of $\mathrm{CO}_{2} / \mathrm{CO}$ equal to $0.1,0.2$ and 0.75 ) were tested using this designed temperature progression. While using catalysts made with $\mathrm{CO}_{2} / \mathrm{CO}$ ratios equal to 0.1 and 0.2 , the temperature at the final stage was brought back to $700^{\circ} \mathrm{C}$. Qualitatively, there is no significant difference among these three carbide catalysts with regards to the effect of exposure to high temperature on the catalytic performance.

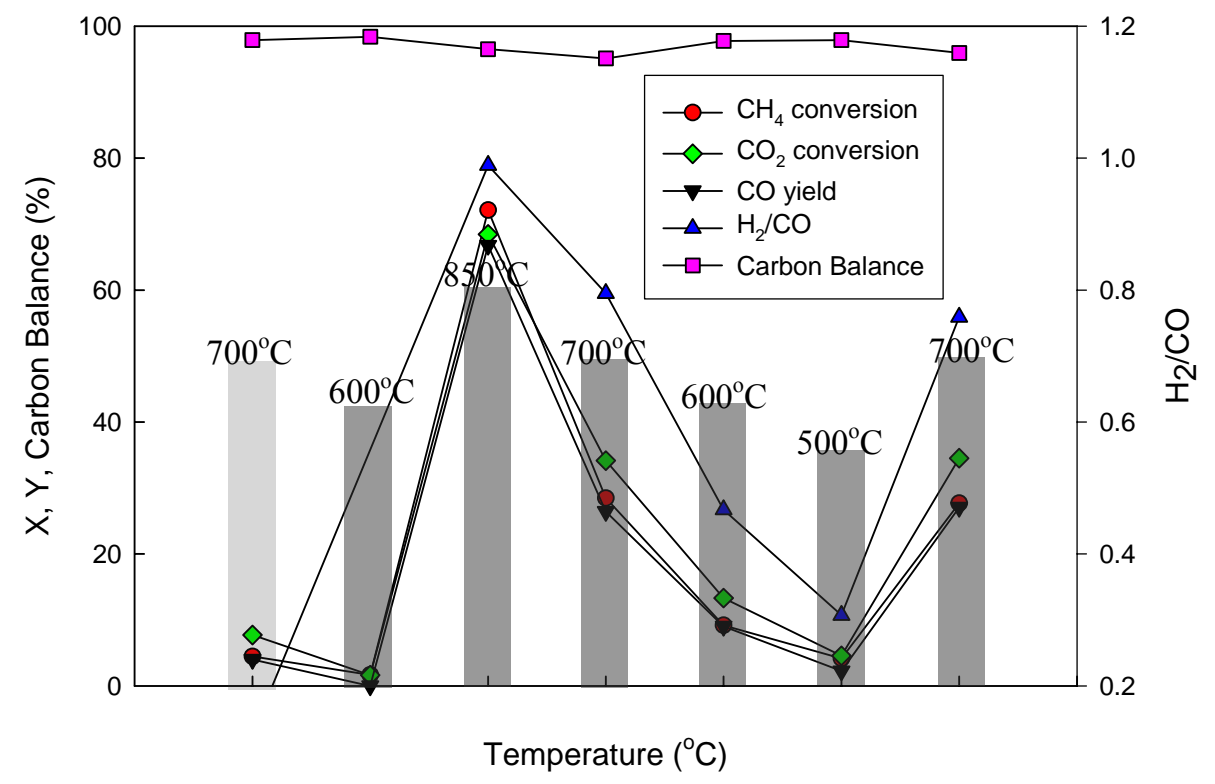

Figure 5-14 Effect of exposure to high temperature $(x=0.1)$ 


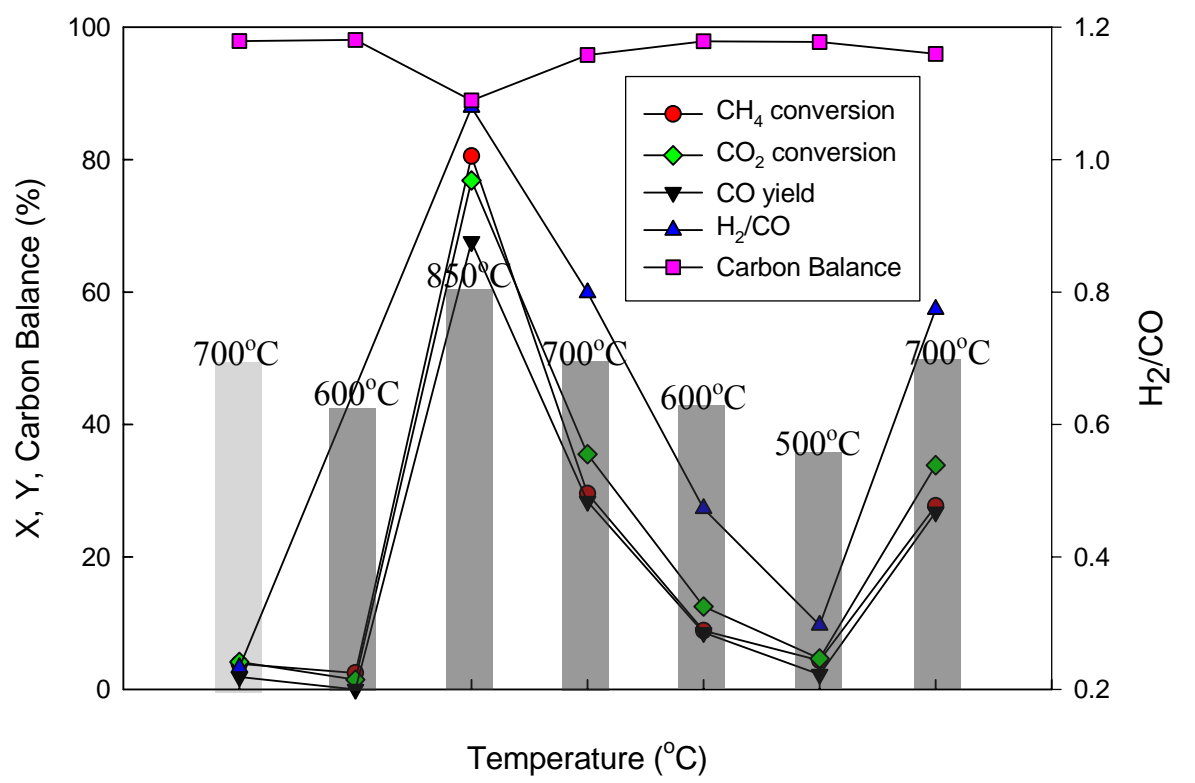

Figure 5-15 Effect of exposure to high temperature $(x=0.2)$

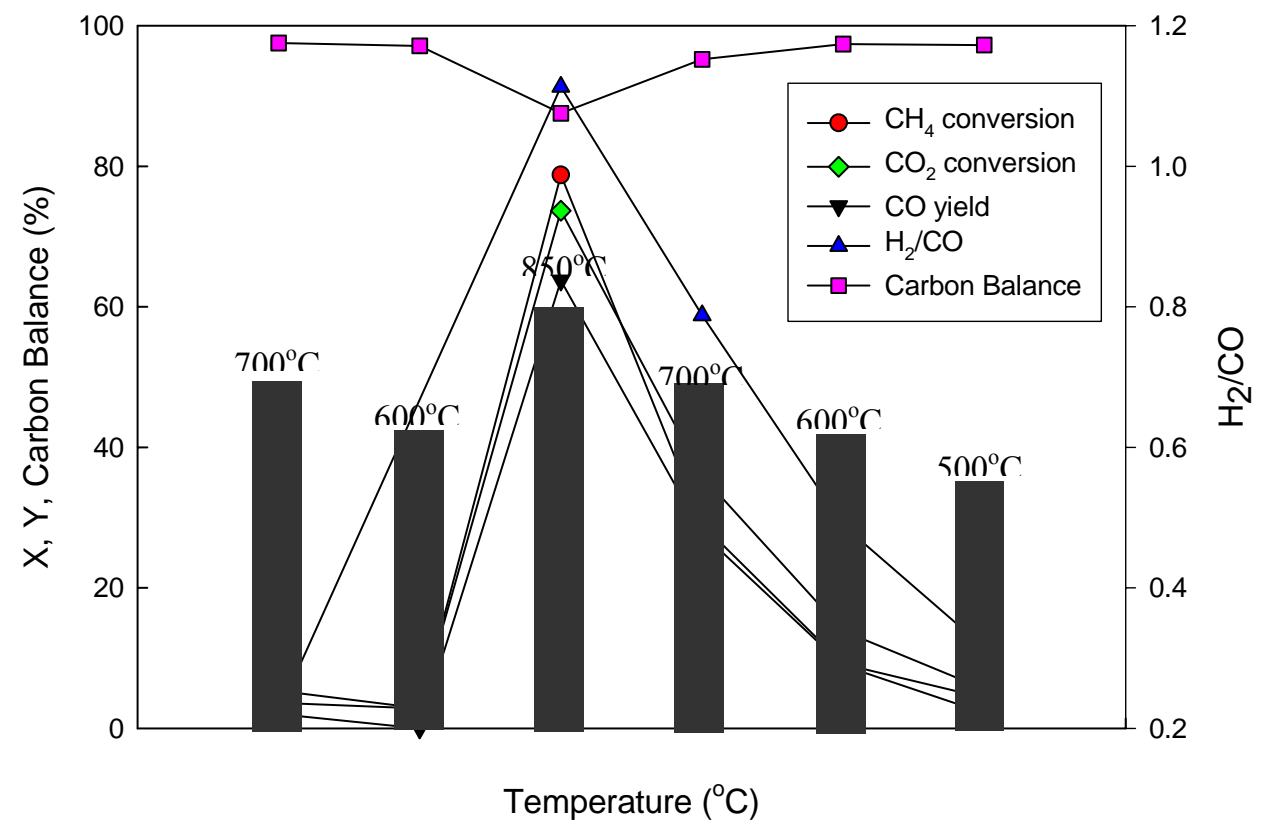

Figure 5-16 Effect of exposure to high temperature $(x=0.75)$ 
For convenience of explanation, the three different $700^{\circ} \mathrm{C}$ stages are termed as the first, the second, and the third $700^{\circ} \mathrm{C}$ stage, based on the order in the temperature progression. For all three catalysts, the reactivity of the catalysts improves significantly after their exposure to a temperature of $850^{\circ} \mathrm{C}$. For example, the conversions and the yields at the first $700^{\circ} \mathrm{C}$ stage are negligibly low, only around $4 \%$, in Figures 5-14 through 5-16. As the reactivity is so low, there is apparently no carbon deposition, and the carbon balance is very close to $100 \%$. The ratio of $\mathrm{H}_{2} / \mathrm{CO}$ at this stage is also far below 1 (around 0.3), which is attributed to the other side reactions. Both RB and RWGS decrease the value of $\mathrm{H}_{2} / \mathrm{CO}$ ratio, via either consuming $\mathrm{H}_{2}$ or producing $\mathrm{CO}$.

As the temperature reaches $850^{\circ} \mathrm{C}$, which was used in the previous reactivity and stability tests, the conversions and yields both increase dramatically, in the range of $70 \%$ to $80 \%$. In the meanwhile, the value of the carbon balance drops as the catalyst is active for the reaction and more carbon deposits are formed. Since the main reaction, DRM, is dominant at this reaction stage, the ratio of $\mathrm{H}_{2}$ to $\mathrm{CO}$ approaches 1 , which is consistent with the stoichiometry of the reaction (equation 1-3).

Afterwards, the three catalysts are brought to the second $700^{\circ} \mathrm{C}$ stage. In all cases, even though the carbon balance rises to approach $100 \%$, the reactivity of the catalysts at this stage increases considerably, compared to the first $700^{\circ} \mathrm{C}$ stage. The conversions for both $\mathrm{CH}_{4}$ and $\mathrm{CO}_{2}$ can reach $30 \%$, and the yield of $\mathrm{CO}$ is also about 26-28\%. This indicates that the catalysts are active for DRM at this temperature stage, 
i.e., after they are exposed to high temperature. The $\mathrm{H}_{2} / \mathrm{CO}$ ratio is about 0.8 , between the value for first $700^{\circ} \mathrm{C}$ stage and unity, showing the main reaction (DRM) is more dominant than in the first $700^{\circ} \mathrm{C}$ stage. This improvement after exposure to $850^{\circ} \mathrm{C}$ is noted at other temperatures as well. In fact, the catalytic performance at $500^{\circ} \mathrm{C}$ after the catalyst is exposed to $850^{\circ} \mathrm{C}$ is comparable to the performance at the first $700^{\circ} \mathrm{C}$ stage.

In the tests where the temperature was brought for the third time to $700^{\circ} \mathrm{C}$, there is very little difference between the catalytic performance at the second and third $700^{\circ} \mathrm{C}$ stages. This conclusion could be drawn from Figures 5-15 and 5-16, where the tested materials are the carbide catalysts prepared with $\mathrm{CO}_{2} / \mathrm{CO}=0.1$ and 0.2 . This evidence implies that the catalyst becomes a stable and active phase after being exposed to $850^{\circ} \mathrm{C}$, without further deactivation in the tested range.

\subsubsection{Characterization of the catalyst before and after exposure to high temperature}

The previous studies on the effect of temperature history on catalyst reactivity indicate that exposure to high temperature plays an important role in the catalytic performance of these cobalt tungsten carbide catalysts, regardless of which ratio of $\mathrm{CO}_{2} / \mathrm{CO}$ is used in the preparation procedure. Accordingly, surface and bulk properties were investigated on the spent catalysts, both before and after exposure to $850^{\circ} \mathrm{C}$. Four different techniques, XRD, SEM, EDAX and NEXAFS, were used. All the catalysts 
measurements were done on the sample prepared with the ratio $\mathrm{CO}_{2} / \mathrm{CO}=0.75$. XRD was obtained on all three samples.

Firstly, XRD patterns of the spent catalyst are shown in Figure 5-17 Figure 5-22. As mentioned in Chapter 4, the fresh catalysts have a bulk component of carbide, without any appearance of oxides in the bulk phase. After the reactivity and stability tests for over 100 hours at $850^{\circ} \mathrm{C}$, the spent catalysts have bulk components of $\mathrm{Co}, \mathrm{WC}$ and some deposited carbon, as can be seen from Figure 5-7 to Figure 5-9. In Figures 5-17, 5-19 and 5-21, XRD patterns of the spent catalysts before exposure to $850^{\circ} \mathrm{C}$ (taken at the first $700^{\circ} \mathrm{C}$ stage), the bulk phase contains not only the starting material, $\mathrm{Co}_{6} \mathrm{~W}_{6} \mathrm{C}$, and an active phase, WC, but also some cobalt tungsten oxides, $\mathrm{CoWO}_{4}$. However, no oxides are observed in Figures 5-18, 5-20 and 5-22, in which the spent catalysts were taken at the second $700^{\circ} \mathrm{C}$ stage (for $\mathrm{x}=0.75$ ) or the third $700^{\circ} \mathrm{C}$ stage (for $\mathrm{x}=0,1$ and 0,2 ), i.e. after exposure to high temperature. Only $\mathrm{WC}, \mathrm{Co}$ and $\mathrm{C}$ are present in the bulk components of the spent catalyst after exposure to $850^{\circ} \mathrm{C}$, i.e., no $\mathrm{Co}_{6} \mathrm{~W}_{6} \mathrm{C}$ and no $\mathrm{CoWO}_{4}$. Also note that these different patterns are qualitatively the same as those in Figure 5-7 through Figure 5-9, which corresponds to those after exposure to $850^{\circ} \mathrm{C}$. 


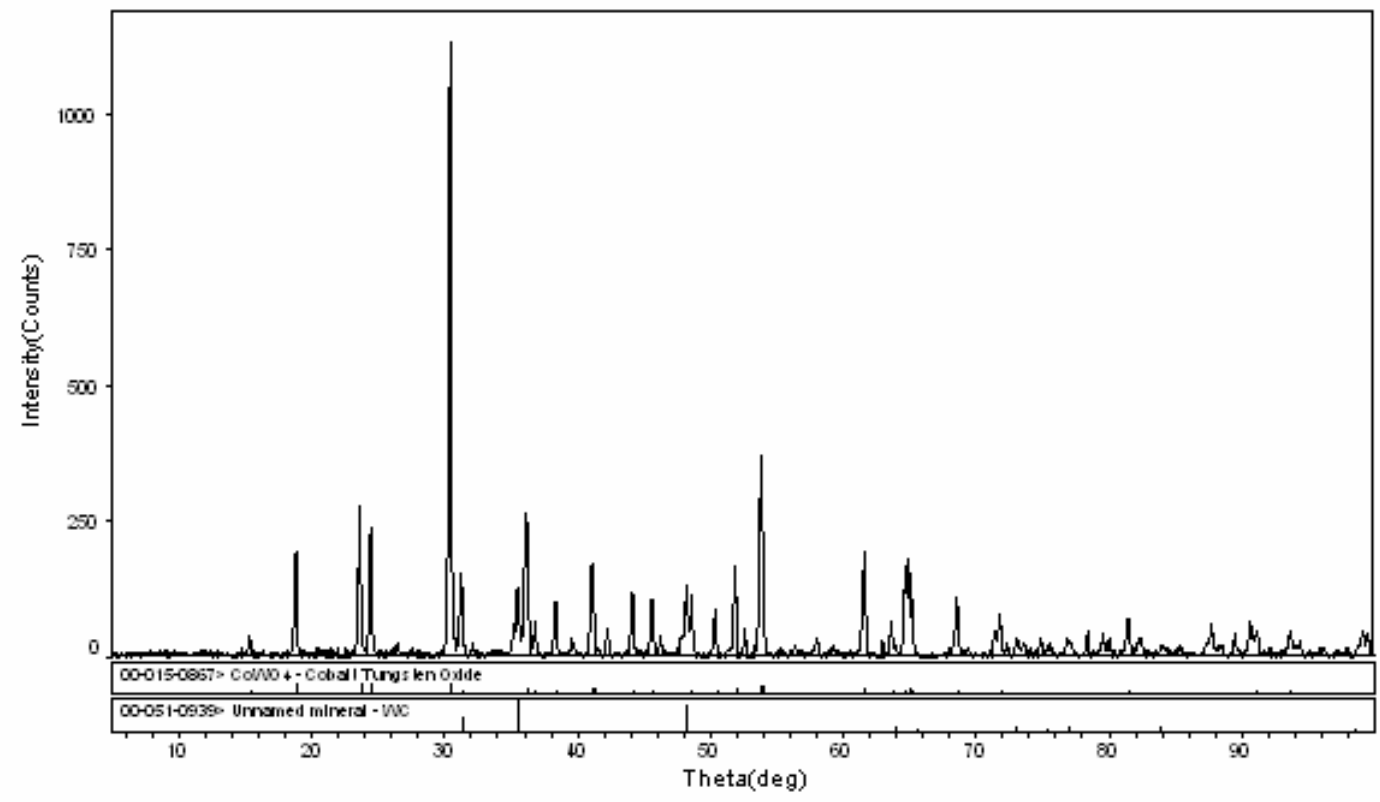

Figure 5-17 XRD pattern of spent Co-W-C $(x=0.1)$ after the first $700^{\circ} \mathrm{C}$ stage, i.e. before exposure to $850^{\circ} \mathrm{C}$

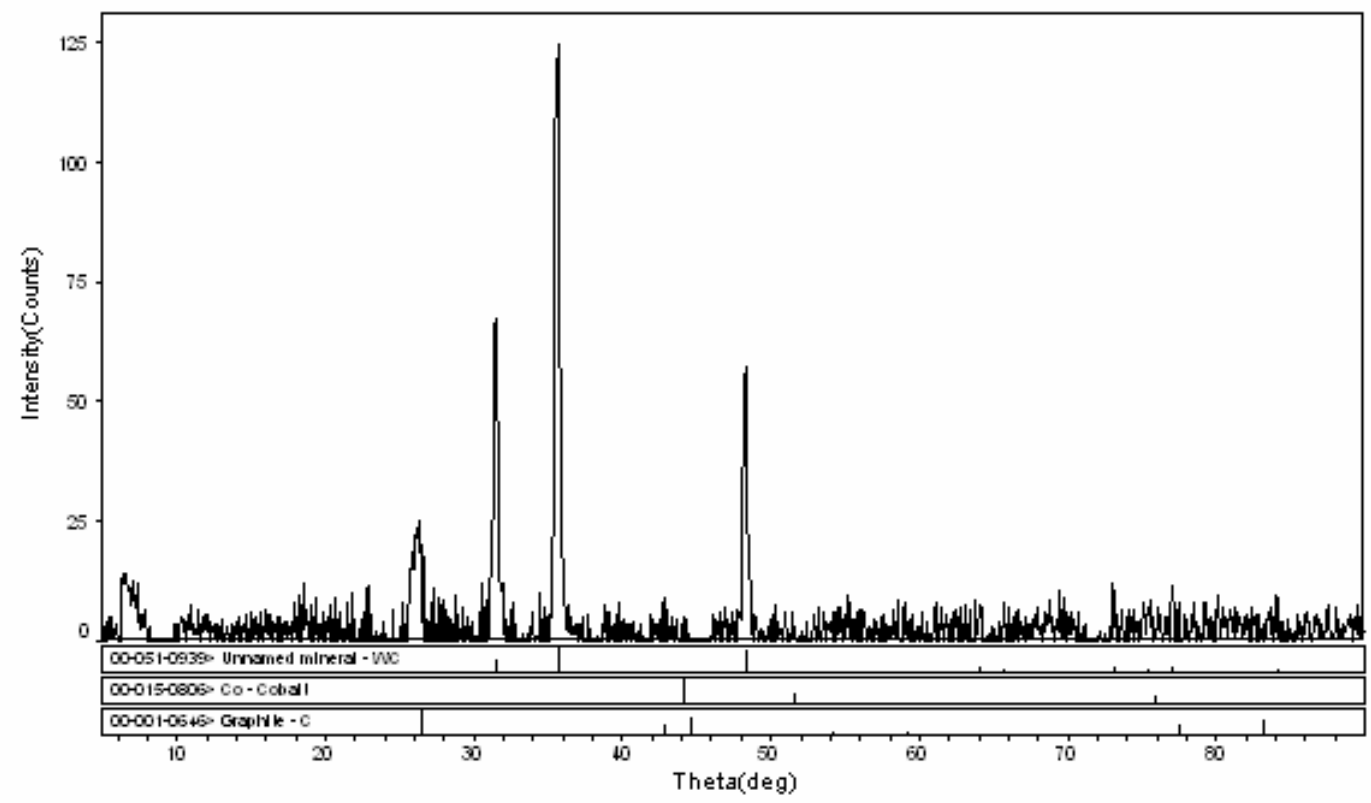

Figure 5-18 XRD pattern of spent Co-W-C $(x=0.1)$ after the third $700^{\circ} \mathrm{C}$ stage and exposure to $850^{\circ} \mathrm{C}$ 


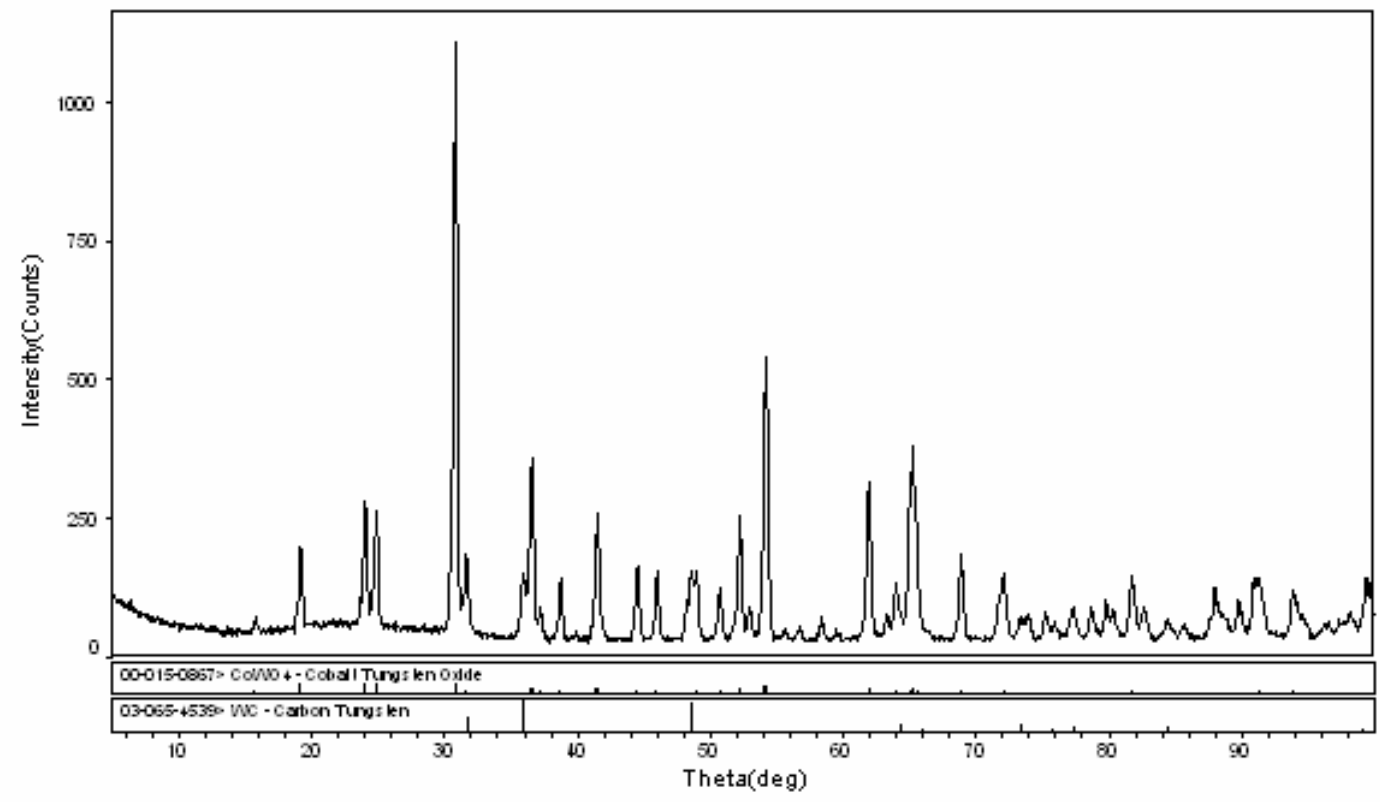

Figure 5-19 XRD pattern of spent $\mathrm{Co}-\mathrm{W}-\mathrm{C}(\mathrm{x}=0.2)$ after the first $700^{\circ} \mathrm{C}$ stage, i.e. before exposure to $850^{\circ} \mathrm{C}$

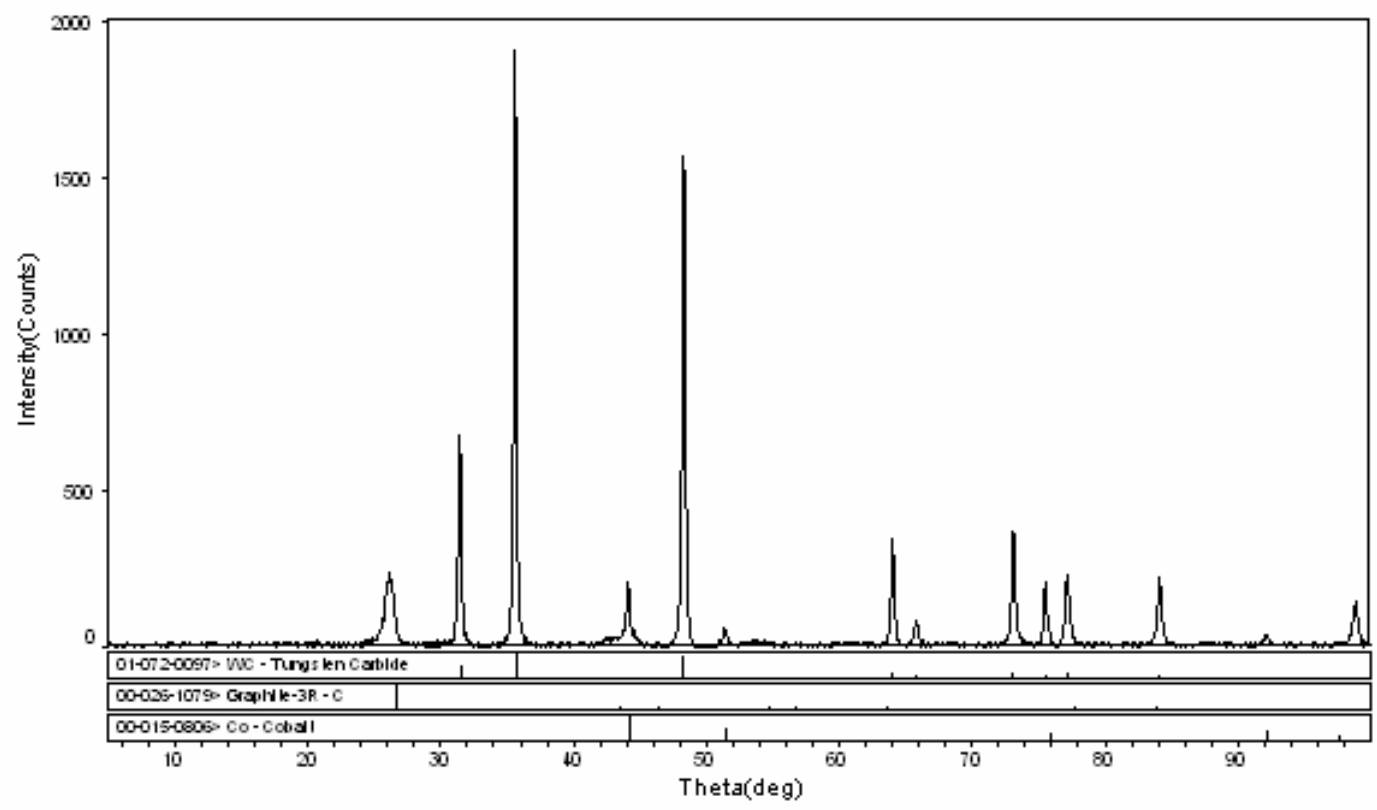

Figure 5-20 XRD pattern of spent Co-W-C $(x=0.2)$ after the third $700^{\circ} \mathrm{C}$ stage and exposure to $850^{\circ} \mathrm{C}$ 


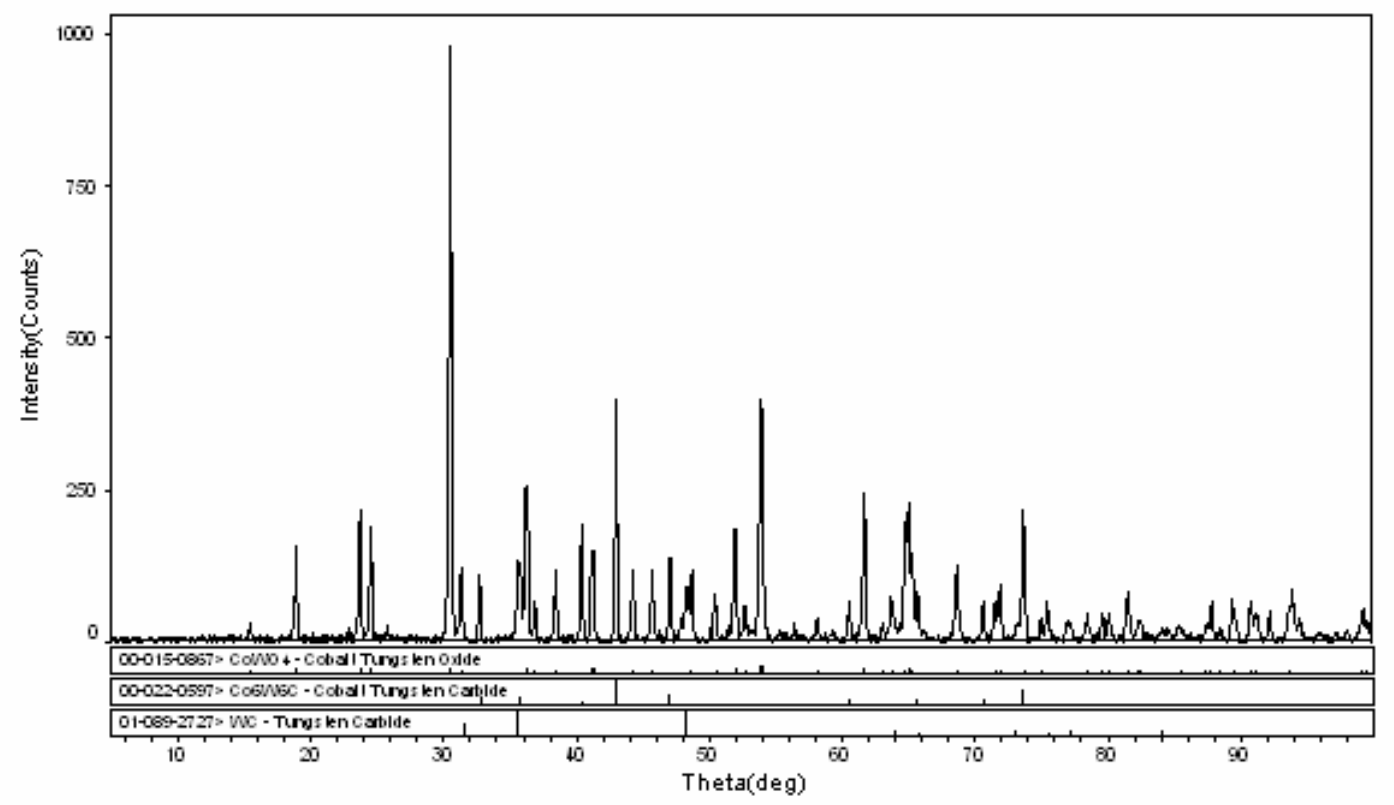

Figure 5-21 $X R D$ pattern of spent Co-W-C $(x=0.75)$ after the first $700^{\circ} \mathrm{C}$ stage, i.e. before exposure to $850^{\circ} \mathrm{C}$

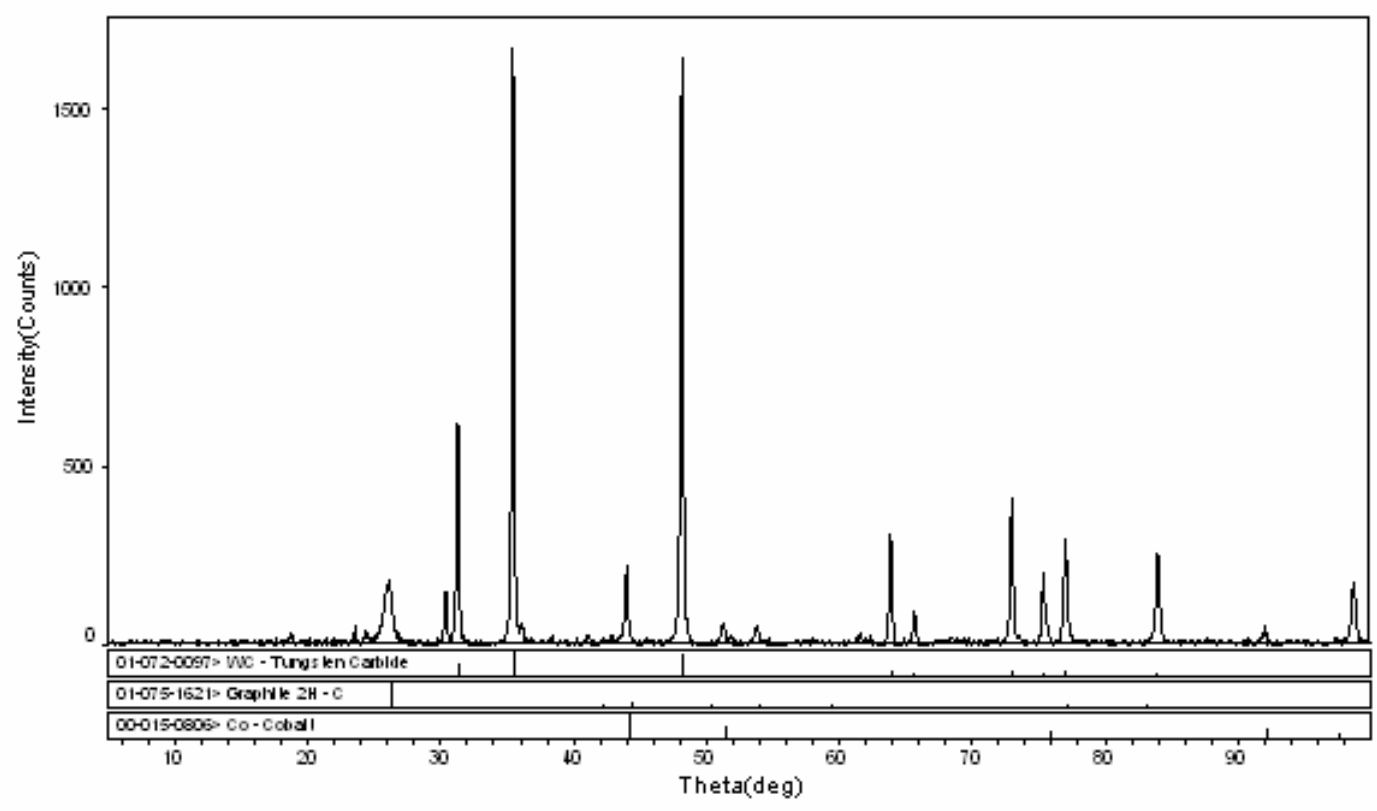

Figure 5-22 XRD pattern of spent Co-W-C $(x=0.75)$ after the second $700^{\circ} \mathrm{C}$ stage and exposure to $850^{\circ} \mathrm{C}$ 
Secondly, Figure 5-23 and Figure 5-24 are SEM microscopic images of the spent catalysts $\left(\mathrm{CO}_{2} / \mathrm{CO}=0.75\right)$ at two $700^{\circ} \mathrm{C}$ stages, one before exposure to $850^{\circ} \mathrm{C}$ and one after. After the catalyst is exposed to high temperature, it presents a more compact structure in the morphology. But the appearance of the spent catalyst taken at the first $700^{\circ} \mathrm{C}$ stage is more compact than that of the fresh catalyst, which is presented in Figure 4-13. The interconnectivity among the particles becomes stronger after reaction, and is even stronger as the catalyst is exposed to higher temperature. Carbon deposits are clearly visible among the spent catalyst after exposure to high temperature $\left(850^{\circ} \mathrm{C}\right)$, in the form of either whiskers or tubes (Figure 5-25). Whisker carbon deposits have been reported to be the most common form of coke with nickel-based catalyst in methane reforming, while tube-like carbon deposits are not seen therein. Considerable carbon deposits on the spent catalyst after exposure to high temperature account for its most compact structure. In contrast, not much carbon is observed in the spent catalyst before it is exposed to $850^{\circ} \mathrm{C}$. The presence or absence of carbon in the different spent catalysts are consistent with XRD patterns and calculated carbon balances in Figure 5-14 through Figure 5-16.

Elemental analysis was carried out using EDAX for these two spent catalysts $\left(\mathrm{CO}_{2} / \mathrm{CO}=0.75\right)$ taken at different temperature stages. The EDAX pattern for fresh catalyst (Figure 4-14) consists mainly of $\mathrm{Co}$ and $\mathrm{W}$, with traces of $\mathrm{C}$ and $\mathrm{O}$. As shown in Figure 5-26 and Figure 5-27, the amounts of carbon and oxygen in these two spent 
catalysts differ to a great extent from those in the fresh material. When the catalyst is exposed only to $700^{\circ} \mathrm{C}$, the oxygen peak is enhanced significantly, indicating the presence of some oxides on the surface of the spent catalyst. The EDAX pattern (Figure 5-27) for the spent catalyst after exposure to $850^{\circ} \mathrm{C}$ provides analytic evidence of the presence of carbon deposits. In Figure 5-27, a dominant peak of carbon appears at $0.283 \mathrm{keV}$, attributed to the characteristic edge energy of carbon element. EDAX mapping was also scanned for these catalysts, including the fresh one and two spent ones. In all cases, the distribution of all chemical elements $(\mathrm{Co}, \mathrm{W}, \mathrm{C}$ and $\mathrm{O})$ on the surface of the catalysts is even.

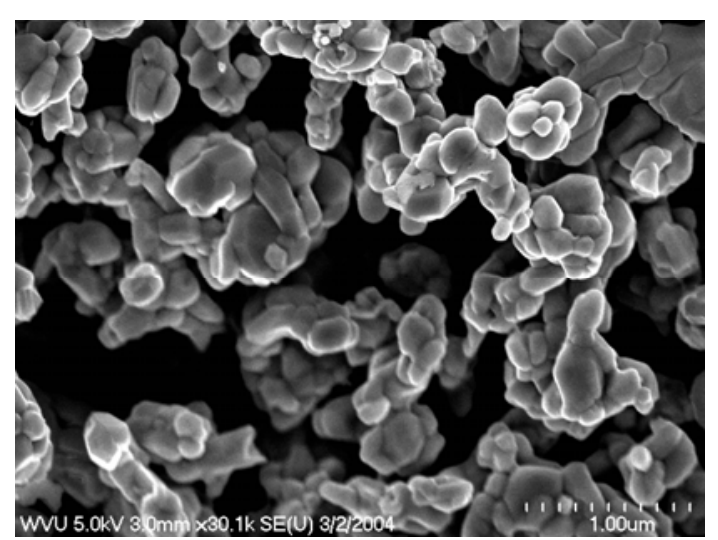

Figure 5-23 SEM of spent Co-W-C $(x=0.75)$ before $850^{\circ} \mathrm{C}$

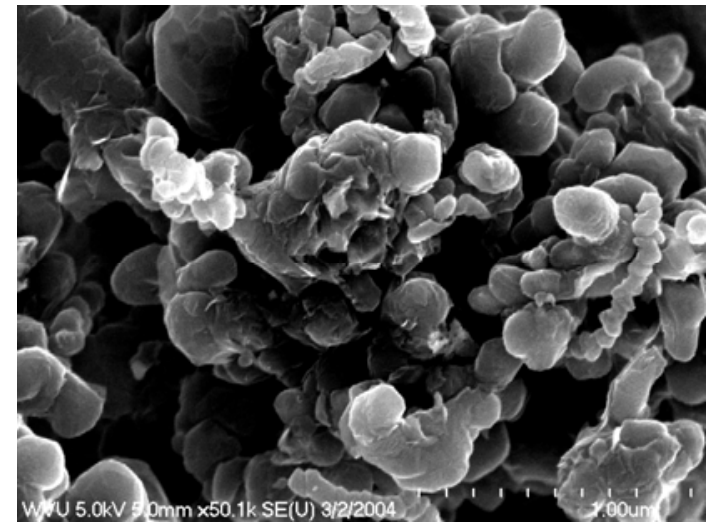

Figure 5-24 SEM of spent Co-W-C $(\mathrm{x}=0.75)$ after $850^{\circ} \mathrm{C}$ 

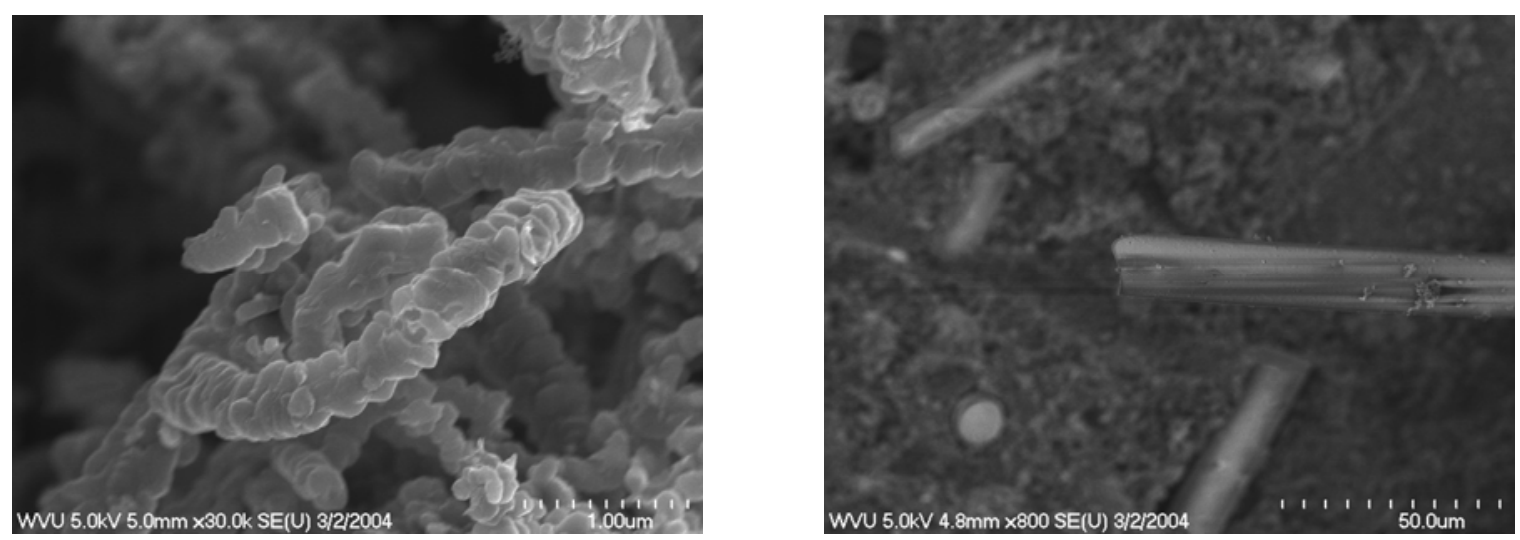

Figure 5-25 SEM Images of carbon deposits on spent Co-W-C ( $\mathrm{x}=0.75)$ after $850^{\circ} \mathrm{C}$

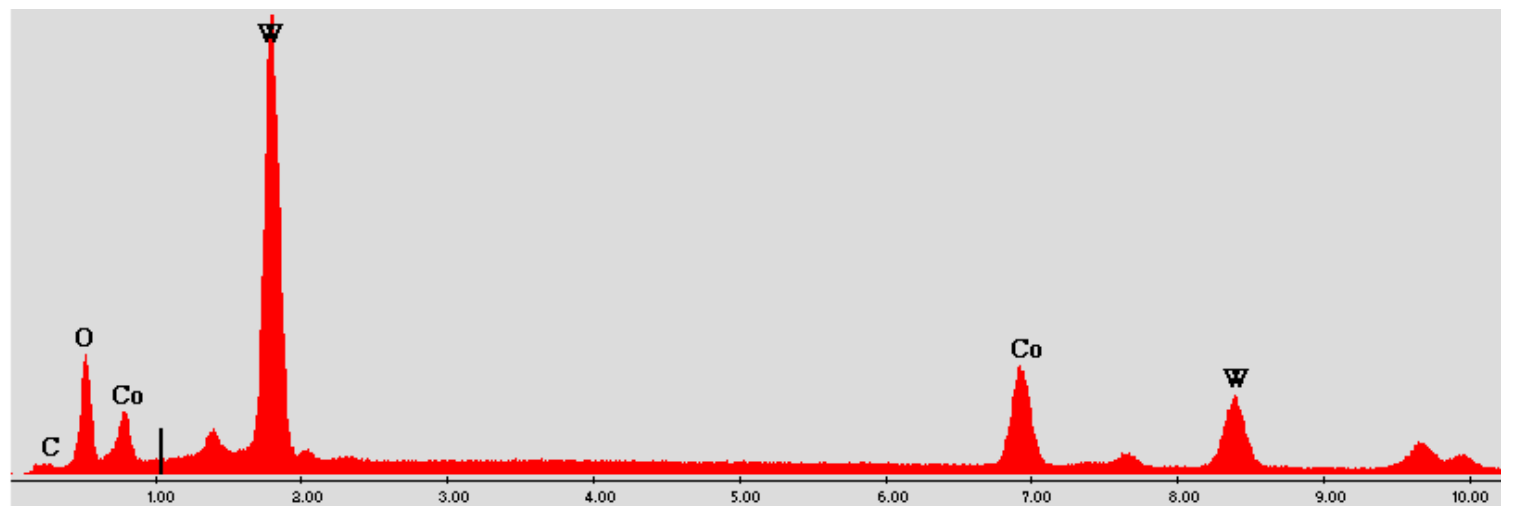

Figure 5-26 EDAX pattern of spent Co-W-C $(x=0.75)$ before exposure to $850^{\circ} \mathrm{C}$

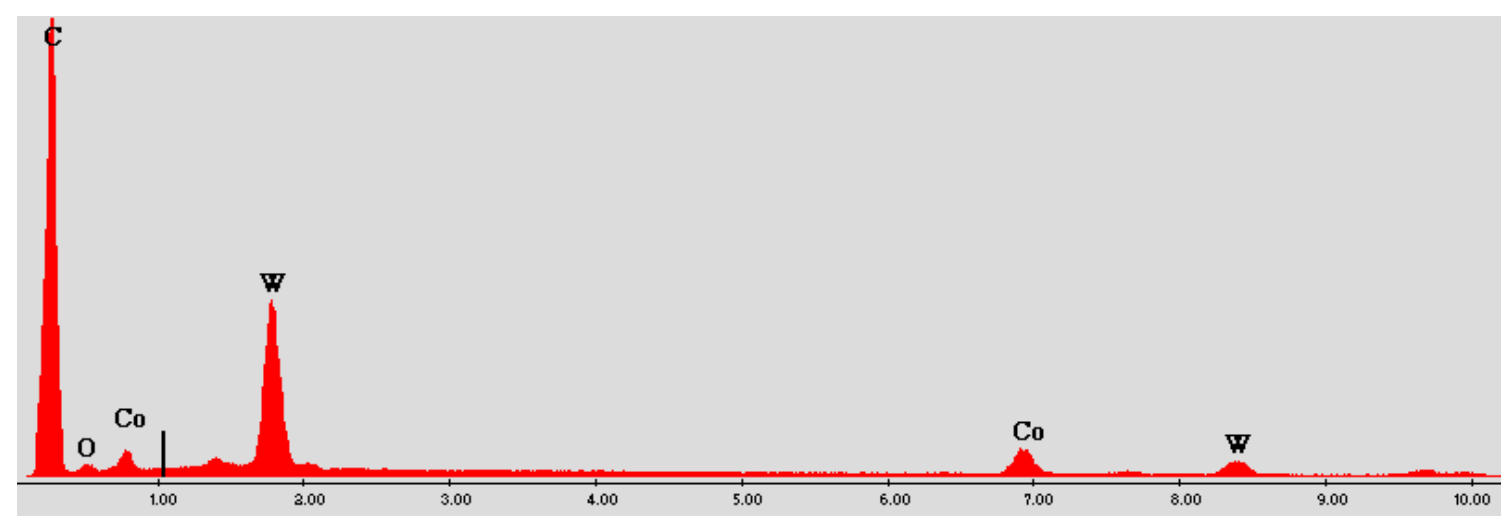

Figure 5-27 EDAX pattern of spent Co-W-C (x=0.75) after exposure to $850^{\circ} \mathrm{C}$ 
For fresh and spent catalysts Co-W-C $(\mathrm{x}=0.75)$ obtained at different temperature stages, carbon K-edge features, oxygen K-edge features and cobalt L-edge features have been investigated using NEXAFS. This work was done by Chen et al. These results are presented in Figures 5-28 through 5-30. The electron yield only is recorded. This is sensitive to the top few atomic layers and can provide surface features of the material [90].

From the carbon K-edge feature (Figure 5-28), carbidic carbon (peaks at $288.4 \mathrm{eV}$ and $289.8 \mathrm{eV}$ ) is present on the surface of fresh Co-W-C catalyst. Here, carbidic carbon refers to $\mathrm{C}$ which is bonded to metal atoms, and should be in the form of $\mathrm{Co}_{6} \mathrm{~W}_{6} \mathrm{C}$ in this work. As the catalyst is exposed to the reactant, even before $850^{\circ} \mathrm{C}$, the carbidic carbon starts to disappear from the surface. At the same time, small peaks of graphitic carbon appear (peaks at $285.7 \mathrm{eV}$, and $291.9 \mathrm{eV}$ ). After the catalyst is exposed to reactants at $850^{\circ} \mathrm{C}$, the catalyst surface is mostly covered by graphitic carbon, intense peaks of which stand out at $285.7 \mathrm{eV}, 291.9 \mathrm{eV}, 292.7 \mathrm{eV}$ and $297.3 \mathrm{eV}$ [88]. This graphitic carbon does not in general cause severe catalytic deactivation, or reduce the catalytic performance. On the contrary, this carbon prevents serious coke formation with time on stream, and maintains a stable carbon balance in the reaction testing.

From the oxygen K-edge features (Figure 5-29), the peak at $533 \mathrm{eV}$ decreases (in the order of: fresh Co-W-C, the first $700^{\circ} \mathrm{C}$ stage [before exposure to $850^{\circ} \mathrm{C}$ ], and the second $700^{\circ} \mathrm{C}$ stage [after exposure $850^{\circ} \mathrm{C}$ ]). The other two peaks (at $540 \mathrm{eV}$ and 
$566.5 \mathrm{eV}$ ) are present but may be changing in intensity for all the three samples. There may be at least two different forms of oxides existing on the surface of the fresh catalyst. When the catalyst is exposed to the reactants, the first peak $(533 \mathrm{eV})$ diminishes; the peak disappears when the catalyst is exposed to $850^{\circ} \mathrm{C}$. Combining this result with that from $\mathrm{XRD}$, there is the reason to believe that this peak should be assigned to $\mathrm{CoWO}_{4}$. This species has been proved to be ineffective for DRM.

From the cobalt L-edge spectra (Figure 5-30), a significant amount of cobalt is detected near the surface region before the catalyst is exposed to $850^{\circ} \mathrm{C}$, which can be known from the difference of peak area. This can be seen in data for both fresh catalyst and the first $700^{\circ} \mathrm{C}$ stage. After the sample is exposed to $850^{\circ} \mathrm{C}$ (i.e. the second $700^{\circ} \mathrm{C}$ stage), surface Co seems almost to disappear from the surface region (Note that this graph is multiplied by a factor of 5 for clarity). Hence oxides present on the surface after the catalyst is exposed to $850^{\circ} \mathrm{C}$ should be tungsten oxides because no cobalt is found on the surface. 


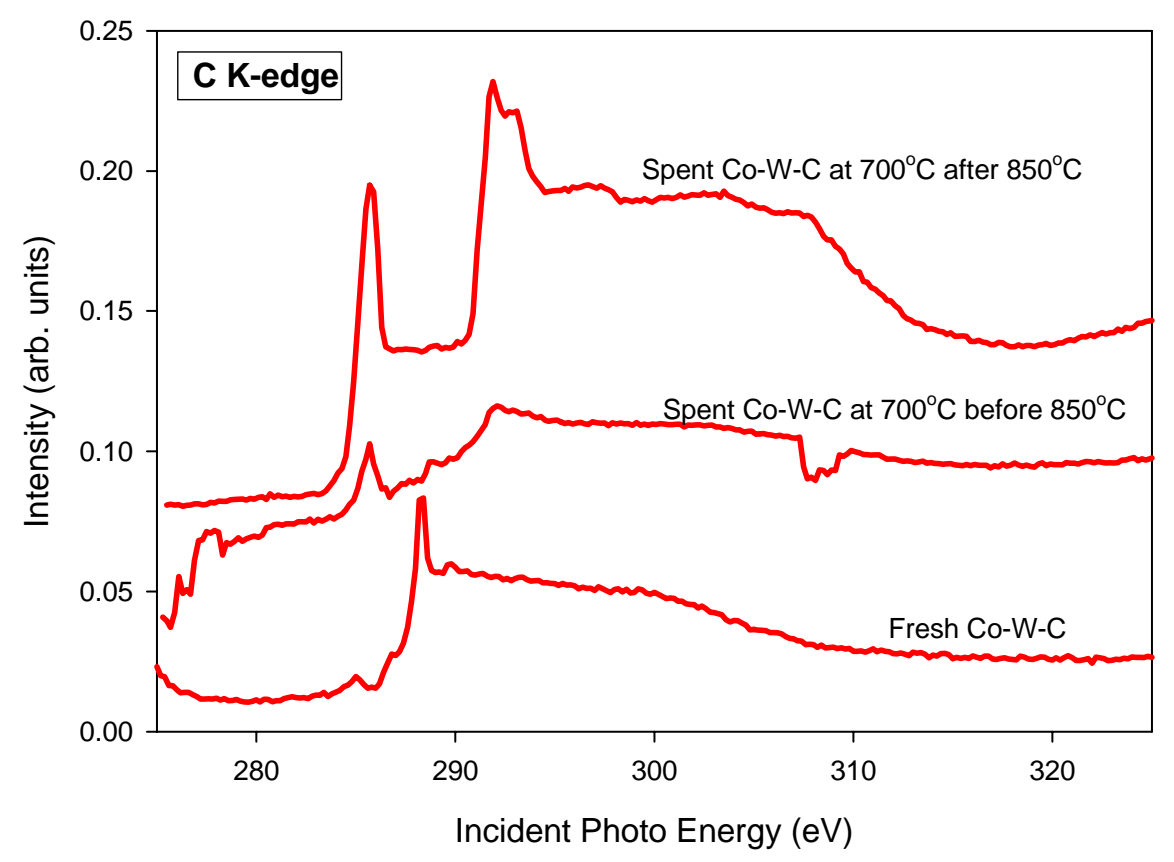

Figure 5-28 Carbon K-Edge NEXAFS of Co-W-C $(x=0.75)$

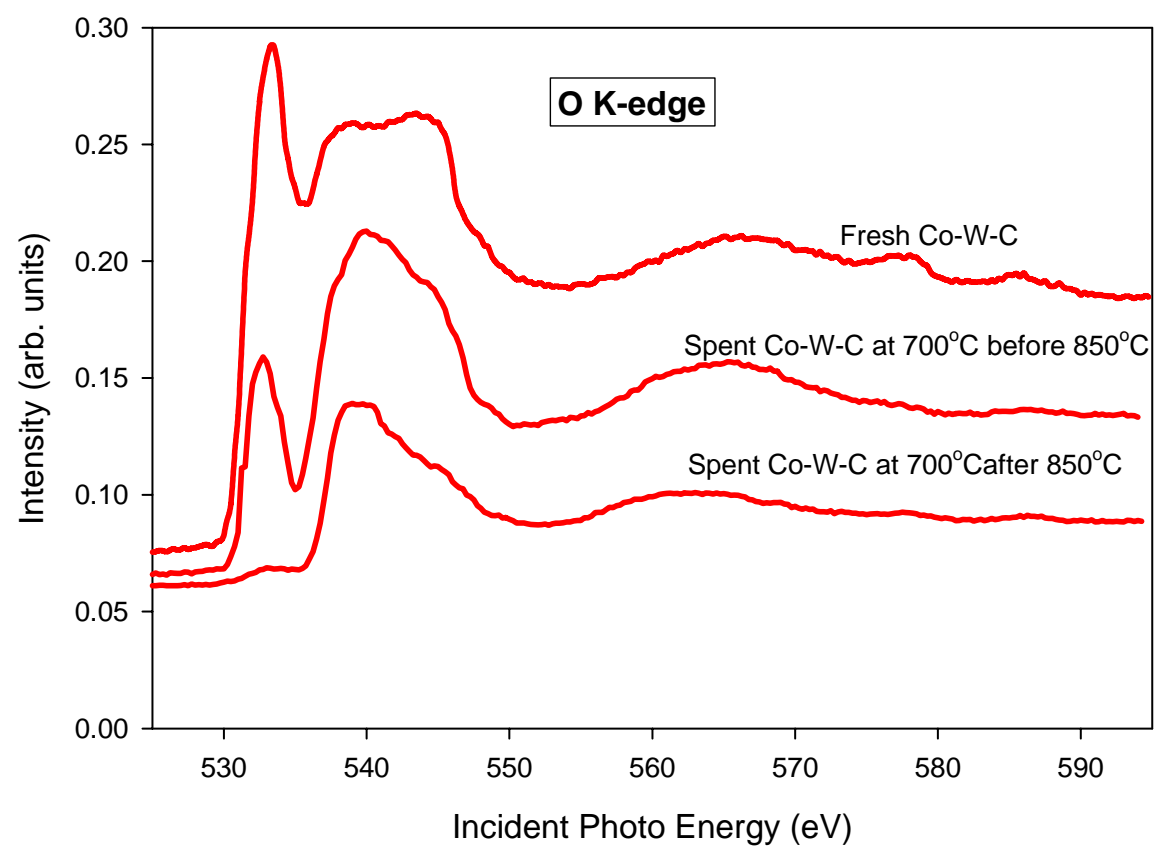

Figure 5-29 Oxygen K-Edge NEXAFS of Co-W-C ( $x=0.75)$ 


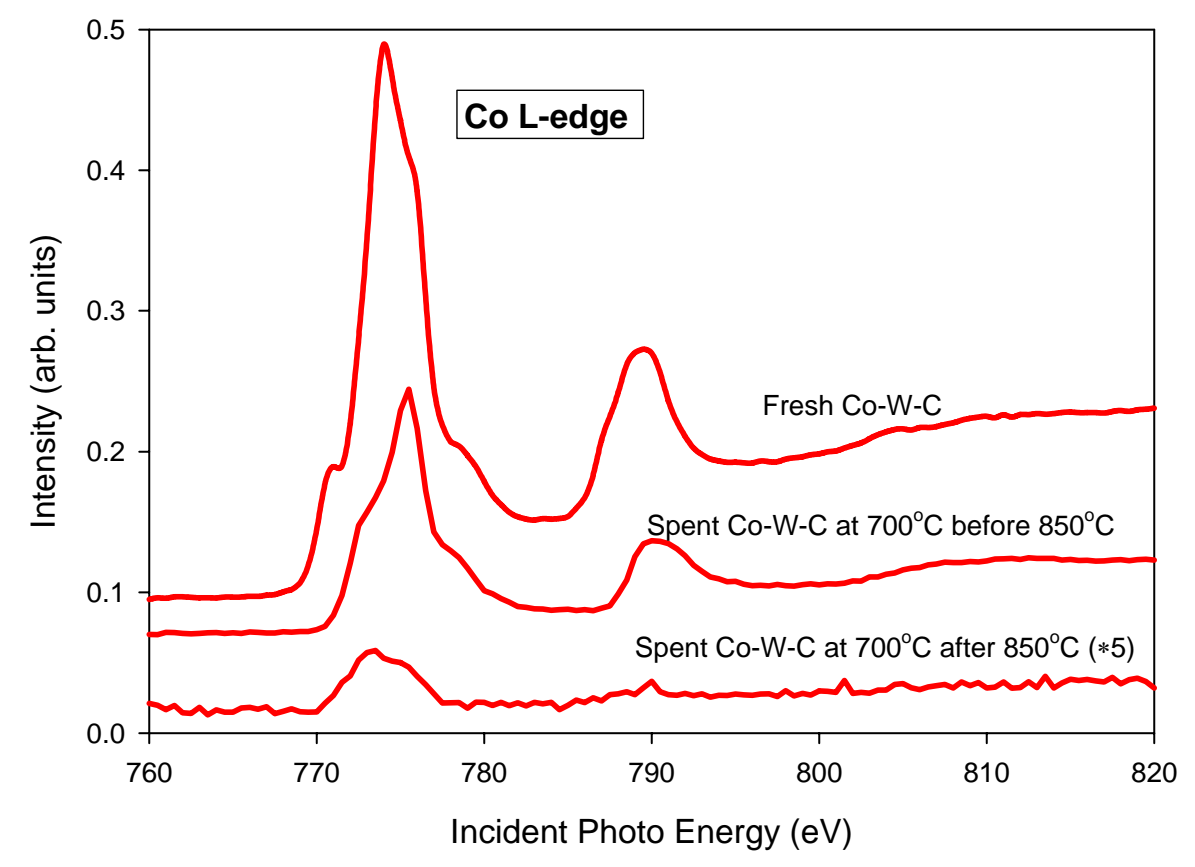

Figure 5-30 Cobalt L-Edge NEXAFS of Co-W-C $(x=0.75)$

In a word, the results from these different characterization measurements are consistent and convincingly explain the reason why exposure to high temperature makes a big difference on the catalytic performance of Co-W-C catalysts. The following summary will be focused on the material made using $x=0.75$.

For fresh catalyst, only bimetallic carbide, $\mathrm{Co}_{6} \mathrm{~W}_{6} \mathrm{C}$, is found in the bulk phase using XRD. Only very little amount of $\mathrm{C}$ and $\mathrm{O}$ are detected using EDAX elemental analysis. In NEXFAS measurement, carbidic carbon and significant amount of oxides are present on the surface of the fresh carbide catalyst.

For the spent catalyst at the first $700^{\circ} \mathrm{C}$ stage (before exposure to $850^{\circ} \mathrm{C}$ ), $\mathrm{XRD}$ 
patterns convey the information that both carbides and oxides are present in the bulk components, and the oxide is found to be in the form of $\mathrm{CoWO}_{4}$. SEM and EDAX results indicate the presence of significant amount of $\mathrm{O}$ at this first $700^{\circ} \mathrm{C}$ stage. NEXAFS features indicate that the catalyst surface is primarily covered by both carbides and oxides even when it is only exposed to reactants at $700^{\circ} \mathrm{C}$. But the absolute amount of oxides is less than that in fresh catalyst. In the mean time, a small amount of graphitic carbon starts to show up.

For the spent catalyst at the second $700^{\circ} \mathrm{C}$ stage (after exposure to $850^{\circ} \mathrm{C}$ ), the bulk phases are shown to be WC, Co and C from the XRD pattern. Different forms of carbon are observed in SEM images, and a large peak of $\mathrm{C}$ shows up in EDAX pattern at this second $700^{\circ} \mathrm{C}$ stage, After the catalyst is exposed to $850^{\circ} \mathrm{C}$, metal oxides $\left(\mathrm{CoWO}_{4}\right)$ disappear from the surface region, while some form of tungsten oxides are still present on the surface. In the mean while, much more graphite is produced to cover the surface.

Comparing the catalytic performance and characterization results before and after exposure to high temperature, the low catalytic activity at the first $700^{\circ} \mathrm{C}$ stage is probably caused by the appearance of oxides, while a mixture of WC, Co and C is proved to be the stable and active phases for DRM.

Based on the above results from temperature-stepped reactions, the following hypothesis may be developed. In the catalyst preparation process, some oxygen may be left over on the surface of catalysts. This could occur via equation 4-3, implied from 
the reduction peak in TPR pattern (Figure 4-11). Even though there is no indication of oxides except carbides in the bulk phase from XRD patterns (Figure 4-3 Figure 4-6), oxygen can be seen on the surface using EDAX and NEXAFS. As the reaction takes place at low temperature $\left(\leq 850^{\circ} \mathrm{C}\right)$, the oxygen on the surface of the catalyst converts the carbides $\left(\mathrm{Co}_{6} \mathrm{~W}_{6} \mathrm{C}\right.$ or $\left.\mathrm{Co}_{3} \mathrm{~W}_{3} \mathrm{C}\right)$ into the metallic oxides $\left(\mathrm{CoWO}_{4}\right)$, perhaps via the following reactions:

$$
\begin{aligned}
& \mathrm{Co}_{6} \mathrm{~W}_{6} \mathrm{C}+(26-x) \mathrm{O}_{s} \rightarrow 6 \mathrm{CoWO}_{4}+x \mathrm{CO}+(1-x) \mathrm{CO}_{2} \\
& \text { or } \\
& \mathrm{Co}_{3} \mathrm{~W}_{3} \mathrm{C}+(14-x) \mathrm{O}_{s} \rightarrow 3 \mathrm{CoWO}_{4}+x \mathrm{CO}+(1-x) \mathrm{CO}_{2}
\end{aligned}
$$

The presence of $\mathrm{CoWO}_{4}$ makes the catalyst catalytically ineffective. When the reaction temperature is sufficiently high $\left(850^{\circ} \mathrm{C}\right.$ and above $)$, reactant methane could react with surface oxides and convert them to the catalytically active form (Co, WC and C in the bulk phase), for DRM. This conversion reaction could be described:

$$
\mathrm{CoWO}_{4}+2 \mathrm{CH}_{4} \rightarrow \mathrm{Co}+\mathrm{WC}+\mathrm{C}+4 \mathrm{H}_{2} \mathrm{O}
$$

Once the stable and active phase is formed, the reaction will be catalyzed even if the temperature is brought down back to a low value again, provided no oxygen is left to re-form the oxides. The active phase is maintained after the reaction temperature is brought back to $700^{\circ} \mathrm{C}$. Of course, Arrhennius-type temperature effects would result in lower conversions at lower temperatures. Moreover, as long as the dry reforming 
continues, the $\mathrm{H}_{2}$ produced would maintain a reduction environment for the catalyst and prevent the production of oxides.

To provide more evidence for the above working hypothesis, two more experiments were carried out. In the first experiment, the fresh catalyst $\left(\mathrm{Co}_{6} \mathrm{~W}_{6} \mathrm{C}\right)$ was reduced with only flowing $\mathrm{H}_{2}$ at $400^{\circ} \mathrm{C}$ for 1 hour, and then flushed with $\mathrm{Ar}$ at $400^{\circ} \mathrm{C}$ for another hour. Afterwards, the catalyst was removed from the reactor for XRD measurement (Figure 5-31). The catalyst has the same bulk component as fresh one, $\mathrm{Co}_{6} \mathrm{~W}_{6} \mathrm{C}$. In the second experiment, the fresh catalyst $\left(\mathrm{Co}_{6} \mathrm{~W}_{6} \mathrm{C}\right)$ was reduced with reducing with $\mathrm{H}_{2}$ at $400^{\circ} \mathrm{C}$ for 1 hour and flushing with $\mathrm{Ar}$ at $400^{\circ} \mathrm{C}$ for another hour. Next the catalyst was exposed to the reactant mixture $\left(\mathrm{CH}_{4} / \mathrm{CO}_{2} / \mathrm{He} / \mathrm{Ar}\right)$ at $700^{\circ} \mathrm{C}$ for 20 hours. Then the feed was switched to Ar while the temperature was raised to $850^{\circ} \mathrm{C}$. Finally, the reactor was cooled and the catalyst was taken out for XRD. Figure 5-32 indicates that this sample had a mixture of bulk phases, including oxides $\left(\mathrm{CoWO}_{4}\right.$ and $\left.\mathrm{WO}_{2}\right)$ and metallic alloy $\left(\mathrm{Co}_{3} \mathrm{~W}\right)$.

The results from the first experiment suggest that reduction using only $\mathrm{H}_{2}$ is insufficient to convert the carbide catalyst into the stable and active form (Co, WC and C) for methane dry reforming. However, there is also no appearance of metallic oxides $\left(\mathrm{CoWO}_{4}\right.$, for example), as the catalyst has not been exposed to the reactants. The second experiment confirms again that some oxides $\left(\mathrm{CoWO}_{4}\right)$ can be produced at lowtemperature $\left(700^{\circ}\right)$ exposure to the reactant gases. Exposure to inert gas (Ar) at high 


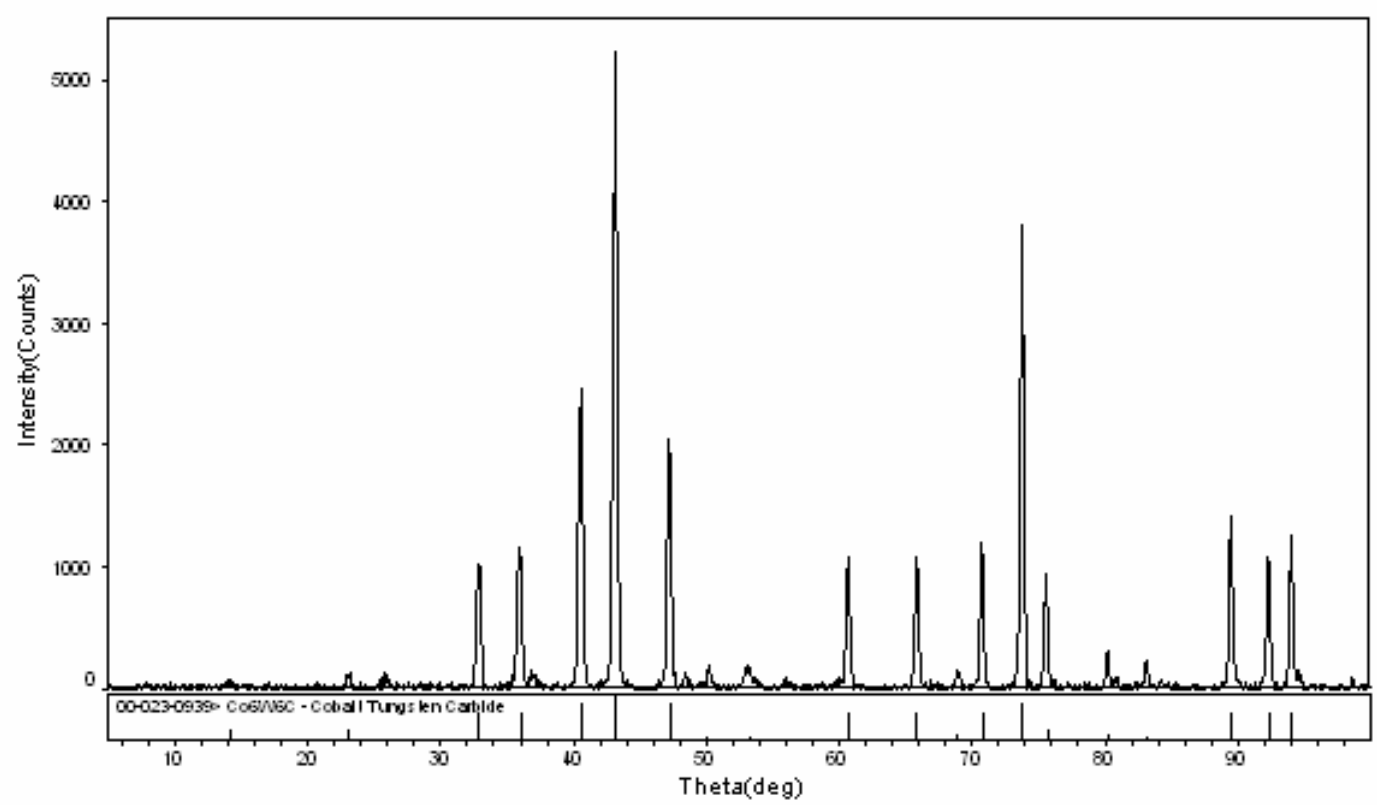

Figure 5-31 XRD pattern of fresh Co-W-C $(x=0.75)$ only reduced with $\mathrm{H}_{2}$

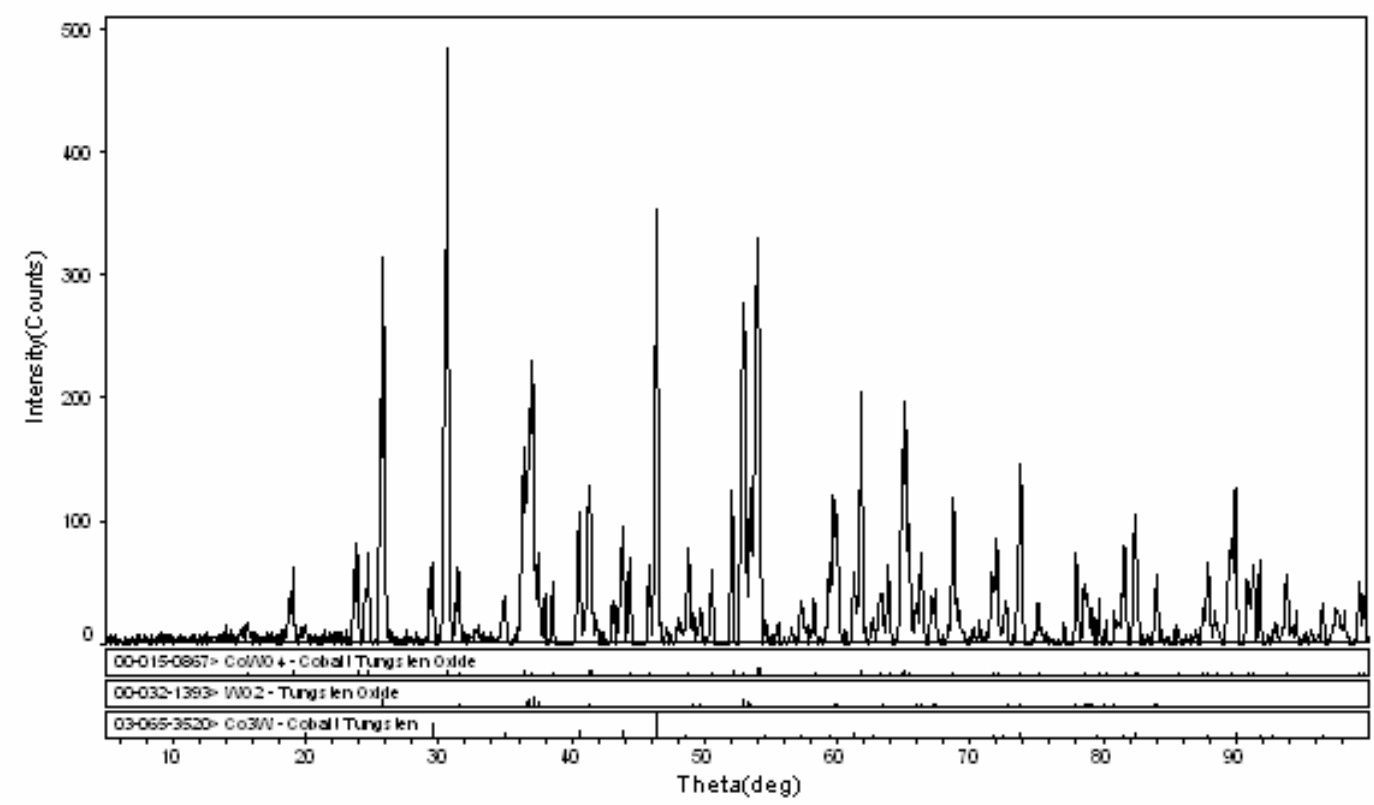

Figure 5-32 XRD pattern of spent Co-W-C $(x=0.75)$ flushed with $\mathrm{Ar}$ at $850^{\circ} \mathrm{C}$ 
temperature $\left(850^{\circ} \mathrm{C}\right)$ does not help the removal of those produced oxides. Therefore, the in-house carbide catalyst must be reduced and carburized at high temperature to exhibit good catalytic performance for methane dry reforming. Ostrovski et al. [91] reported that methane-containing gas can provide strongly reducing and carburizing conditions to convert oxides into carbides. But feeding with pure methane will cause severe coke formation for our carbide catalyst in DRM. Simultaneously feeding $\mathrm{CO}_{2}$ at $850^{\circ} \mathrm{C}$ will prevent serious carbon deposits, while providing enough carburization for the transformation into active phase, Co and WC. 


\subsection{Catalyst study on SRM with bimetallic carbide catalyst}

After the series of studies on DRM, SRM was investigated with this bimetallic carbide catalyst. Except for changing the reactant from carbon dioxide to steam, all the other reaction conditions were the same as in DRM. Water was pumped into the reactor from the top with an HPLC pump without pre-vaporization. The feeding rate for water was constant at $0.05 \mathrm{cc} / \mathrm{min}$ and the reaction temperature was $850^{\circ} \mathrm{C}$, therefore it should be very easy and quick for this small amount of water to evaporate and turn into gas phase before it reaches the catalyst bed.

Figure 5-33 is the equilibrium calculation for the SRM reaction system with CHEMCAD 5.5.x. software. Seven species are considered in the whole system, six reacting species $\left(\mathrm{CH}_{4}, \mathrm{CO}_{2}, \mathrm{H}_{2}, \mathrm{CO}, \mathrm{H}_{2} \mathrm{O}\right.$ and $\left.\mathrm{C}(\mathrm{s})\right)$ and inert gas He. The feed stream has the same total flow rate $(120 \mathrm{scc} / \mathrm{min})$ and composition $\left(\mathrm{CH}_{4} / \mathrm{H}_{2} \mathrm{O} / \mathrm{He}=\right.$ $46 \% / 49 \% / 5 \%$ ) as used in the real reaction system at $1 \mathrm{~atm}$. Equilibrium conversions for both reactants increase with temperature. $\mathrm{X}_{\mathrm{H} 2 \mathrm{O}, \mathrm{e}}$ is higher than $\mathrm{X}_{\mathrm{CH} 4 . \mathrm{e}}$ at low temperatures $\left(\mathrm{T}<550^{\circ} \mathrm{C}\right)$, and becomes less than $\mathrm{X}_{\mathrm{CH} 4}$ at higher temperatures.

Appendix B-3 is the equilibrium calculation results for SRM reaction system excluding the presence of solid carbon therein. Unlike the previous DRM reaction system, the involvement of solid carbon in the SRM reaction system affects the equilibrium for this system significantly only between $500^{\circ} \mathrm{C}$ and $750^{\circ} \mathrm{C}$. In this intermediate range, the carbon balance in Figure 5-33 can explain the difference between 
Figure 5-33 and Appendix B-3. In the intermediate range, the carbon balance is significantly lower than $100 \%$, and is only $80 \%$ at $600^{\circ} \mathrm{C}$, indicating significant equilibrium deposition of carbon in this range. This is caused by the competition between the main reaction $(\mathrm{SRM})$ and side reactions $(\mathrm{CD}$ as well as $\mathrm{RB}$, both of which can produce carbon). As the temperature increases, coke formation is inhibited by the more-dominating SRM; thereby improving the equilibrium carbon balance back to $100 \%$, and no significant deposition of $\mathrm{C}$ at equilibrium.

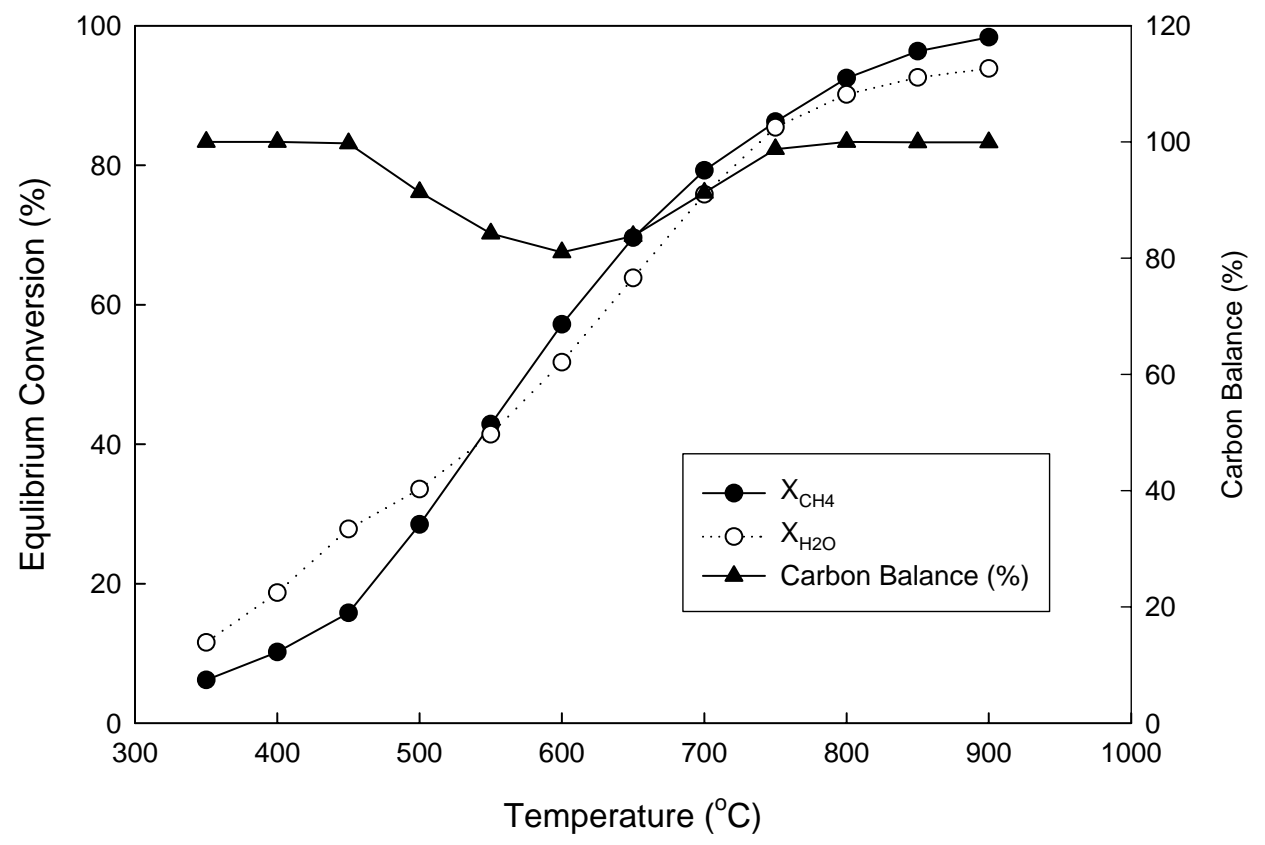

Figure 5-33 Equilibrium calculation of multiple reactions for SRM system as a function of temperature

Reaction conditions: $\mathrm{P}_{\text {tot }}=1 \mathrm{~atm}, \mathrm{~V}_{\text {tot }}=200 \mathrm{scc} / \mathrm{min}, \mathrm{CH}_{4} / \mathrm{H}_{2} \mathrm{O} / \mathrm{He}=46 \% / 49 \% / 5 \%$

Figure 5-34 presents the testing result for SRM with this bimetallic carbide 
catalyst $(x=0.75)$ for 72 continuous hours on stream. Methane conversion is only between $5 \%$ and $10 \%$ at 1 atm and $850^{\circ} \mathrm{C}$, which is very low compared to that in DRM and much lower than the equilibrium values in Figure 5-33. Carbon balance is around $95 \%$, which is close to the equilibrium carbon balance at this temperature. Therefore, it can be concluded that this bimetallic carbide catalyst is not catalytically active for SRM. For the whole run, carbon balance is close to $100 \%$. Hence the deposition (or otherwise) of carbon once again appears to have an effect on the conversion (or otherwise) of the bimetallic carbide to a different form, so as to improve the kinetics of SRM.

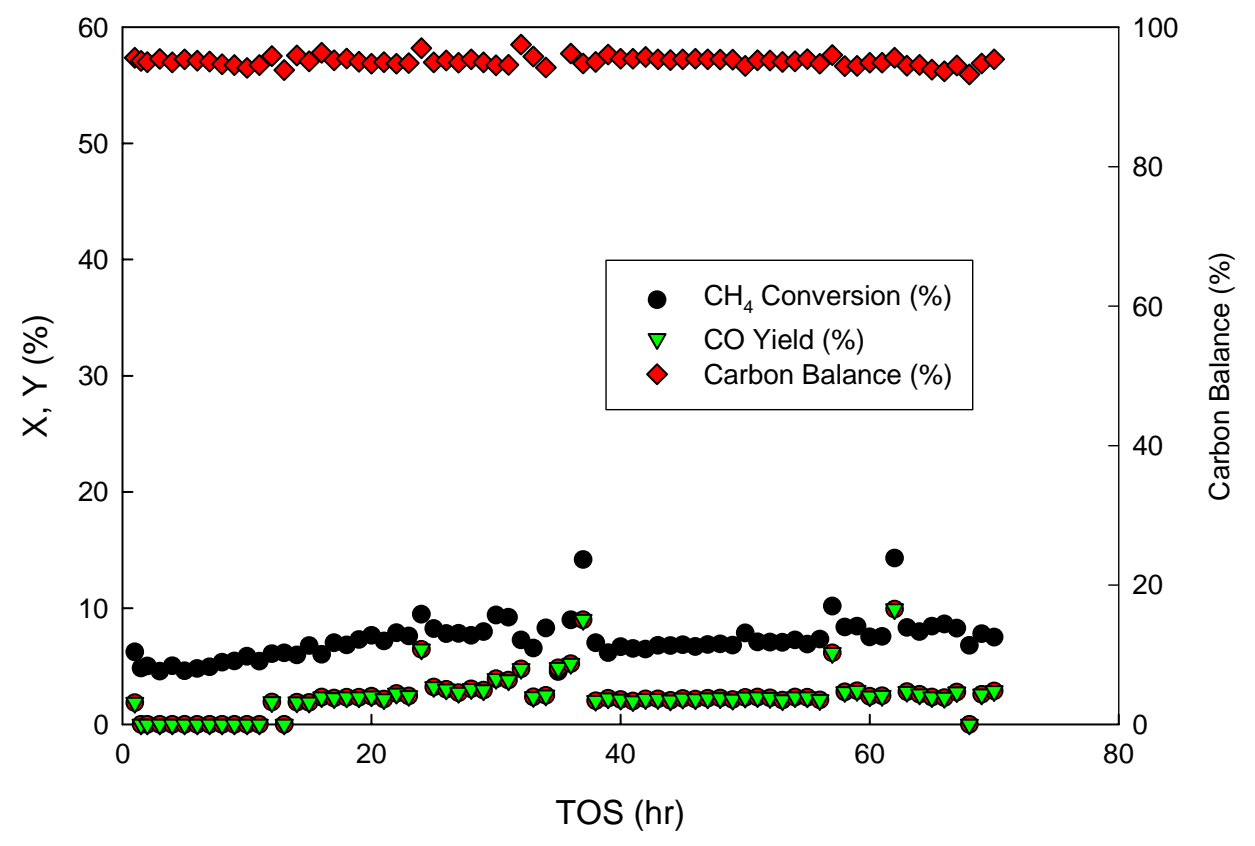

Figure 5-34 Reaction test for SRM with Co-W-C ( $x=0.75), T=850^{\circ} \mathrm{C}, \mathrm{P}=1 \mathrm{~atm}$

To quantify the ineffectiveness of this bimetallic carbide catalyst for SRM, a 
comparison of reaction rate constants was made for SRM with that for DRM. The reaction rate constant for methane consumption was calculated using a pseudo-second-order model as follows:

$$
-\boldsymbol{r}_{\mathrm{CH}_{4}}=\boldsymbol{k}_{\mathrm{SRM}} \boldsymbol{P}_{\mathrm{CH}_{4}} \boldsymbol{P}_{\mathrm{H}_{2} \mathrm{O}} \text { for SRM }
$$

and

$-\boldsymbol{r}_{\mathrm{CH}_{4}}=\boldsymbol{k}_{\mathrm{DRM}} \boldsymbol{P}_{\mathrm{CH}_{4}} \boldsymbol{P}_{\mathrm{CO}_{2}}$ for DRM

The computed value of $\mathrm{k}_{\mathrm{SRM}}$ is

$\mathrm{k}_{\mathrm{SRM}}=0.0142 \mathrm{~mol} / \mathrm{hr} / \mathrm{g} / \mathrm{atm}^{2}$

This is two orders smaller than the value for dry reforming

$$
\mathrm{k}_{\mathrm{DRM}}=4.31 \mathrm{~mol} / \mathrm{hr} / \mathrm{g} / \mathrm{atm}^{2}[92]
$$

Obviously, DRM proceeds much faster than SRM of methane over this in-house carbide catalyst. An active phase is present in the DRM system, while it is absent in the SRM system. This may explain why the bimetallic carbide catalyst is active for DRM while less so for SRM.

The presence of water may be the poisoning source for the carbide activity to prevent the formation of active phase. LaMont et al. [93] found that $\mathrm{CO}_{2}$ and $\mathrm{H}_{2} \mathrm{O}$ could deactivate $\mathrm{Mo}_{2} \mathrm{C}$ by oxidizing it to $\mathrm{MoO}_{2}$, which had been shown to be inactive for methane reforming (both dry and steam) reactions. A definition of "Stability Ratio" as the ratio of carburization gases to oxidation gases was first proposed by Darujati et al. 
$[65,94]$. The Stability Ratio, $\mathrm{R}_{\mathrm{s}}$, is defined as:

$$
\boldsymbol{R}_{s}=\frac{\boldsymbol{P}_{\mathrm{H}_{2}}+\boldsymbol{P}_{\mathrm{CO}}}{\boldsymbol{P}_{\mathrm{CO}_{2}}+\boldsymbol{P}_{\mathrm{H}_{2} \mathrm{O}}}
$$

Oxidation occurs if this ratio is equal to 0.8 or lower for $\mathrm{Mo}_{2} \mathrm{C}$ in the study of LaMont et al. [93]. The presence of both $\mathrm{CO}_{2}$ and $\mathrm{H}_{2} \mathrm{O}$ will deactivate $\mathrm{Mo}_{2} \mathrm{C}$ catalyst under certain reaction conditions which are not exactly applicable for this bimetallic carbide catalyst. It could be inferred that $\mathrm{CO}_{2}$ and $\mathrm{H}_{2} \mathrm{O}$ do not function as the oxidizing source to this bimetallic carbide catalyst in the same way or to the same extent. Following the argument of Darujati et al. [65], we hypothesized that the potential deactivation could be prevented by co-feeding a reduction gas $(\mathrm{CO})$ in the SRM with the bimetallic carbide catalyst. However, this method did not help to improve the catalytic performance.

Further, the fact that reaction mechanisms are different for DRM and SRM may affect the performance of the bimetallic carbide catalyst. In SRM, methane dissociation is the rate-determining step, and the reaction rate is very restricted at low reaction pressure. Computation results of reaction rate constants also provide supporting information in this aspect. As introduced in Chapter 2, Iyer et al. [76] put forward the reaction mechanism of DRM over $\mathrm{Co}_{6} \mathrm{~W}_{6} \mathrm{C}$. Reactant $\mathrm{CO}_{2}$ reacts on the active sites * to dissociate into $\mathrm{CO}$ and $\mathrm{O}^{*}$. $\mathrm{O}^{*}$ will help further dissociation of $\mathrm{CH}_{\mathrm{x}}{ }^{*}$. According to Bodrov and Apel'baum's statement of reaction mechanism for SRM [78], adsorbed 
$\mathrm{CH}_{4}$ dissociates consecutively into $\mathrm{CH}_{2}{ }^{*}$, which would react with $\mathrm{H}_{2} \mathrm{O}$ to produce $\mathrm{CO}$ * and $\mathrm{H}_{2}$. Afterwards, $\mathrm{CO}$ would come out of the surface by releasing the active site. Low reactivity is probably because that the dissociated $\mathrm{CH}_{2} *$ may not react easily with $\mathrm{H}_{2} \mathrm{O}$ directly over bimetallic carbide catalyst, especially as the reaction is operated under atmospheric pressure. 


\subsection{Catalyst study on SRMeOH with bimetallic carbide catalyst}

The main reaction for $\mathrm{SRMeOH}$ is:

$$
\mathrm{CH}_{3} \mathrm{OH}+\mathrm{H}_{2} \mathrm{O} \rightarrow \mathrm{CO}_{2}+3 \mathrm{H}_{2}
$$

Basically, $\mathrm{H}_{2}, \mathrm{CO}, \mathrm{CO}_{2}$ and $\mathrm{CH}_{4}$ are expected to be detected in the effluent gas phase, besides an internal standard (assumed at this point to be He). As described previously, the first three gases can be produced via SRMeOH (equation 1-9) and the reverse water gas shift (RWGS) reaction (equation 1-6). Generation of these three gases also can lead to formation of alkanes $\left(\mathrm{CH}_{4}\right)$ by:

$$
\mathrm{CO}_{2}+4 \mathrm{H}_{2} \leftrightarrow \mathrm{CH}_{4}+2 \mathrm{H}_{2} \mathrm{O}
$$

or

$$
\mathrm{CO}+3 \mathrm{H}_{2} \leftrightarrow \mathrm{CH}_{4}+\mathrm{H}_{2} \mathrm{O}
$$

RWGS as well as reaction 5-16 may change the selectivity and therefore affect the products distribution.

With excessive methanol contained in the feedstock, solid carbon easily forms due to complete decomposition of methanol:

$$
\mathrm{CH}_{3} \mathrm{OH} \rightarrow \mathrm{C}+\mathrm{H}_{2}+\mathrm{H}_{2} \mathrm{O}
$$

Similar to DRM and SRM, equilibrium calculations for $\mathrm{SRMeOH}$ reaction as a function of temperature were carried out using CHEMCAD 5.5.x software In this reaction system, altogether nine species will be considered, consisting of the seven 
reacting species $\left(\mathrm{CH}_{3} \mathrm{OH}, \mathrm{CH}_{4}, \mathrm{CO}_{2}, \mathrm{H}_{2}, \mathrm{CO}, \mathrm{H}_{2} \mathrm{O}\right.$ and $\left.\mathrm{C}(\mathrm{s})\right)$ and two inerts (He and $\left.\mathrm{Ar}\right)$. The requirement for a small amount of a second inert will be discussed later. The existence of the second inert is not expected to change the results, relative to a single inert with the same total inert partial pressure. To be comparable to the real reaction system, the feed stream has the same composition $\left(\mathrm{CH}_{3} \mathrm{OH} / \mathrm{H}_{2} \mathrm{O} / \mathrm{He} / \mathrm{Ar}=\right.$ $9.1 \% / 10.7 \% / 4 \% / 76.2 \%)$ and the total pressure is fixed at 1 atm. Figure 5-35 shows the calculation results: $\mathrm{A}$ is for equilibrium conversions and carbon balance; $\mathrm{B}$ is for equlibrium fluid-phase outlet distribution (i.e. with the exclusion of solid carbon); $\mathrm{C}$ is for the ratio of $\mathrm{H}_{2}$ /carbon oxides. Calculations span temperatures from $200 \mathrm{~K}$ to $1200 \mathrm{~K}$.

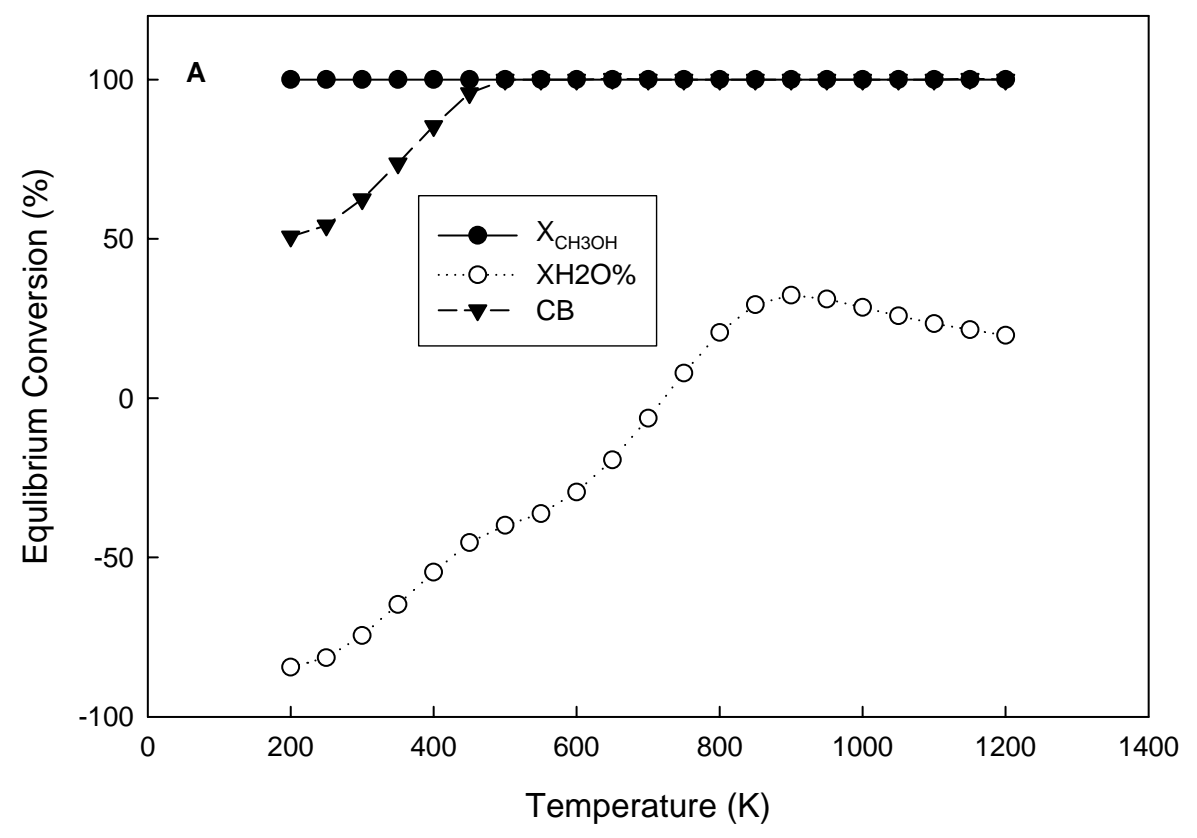



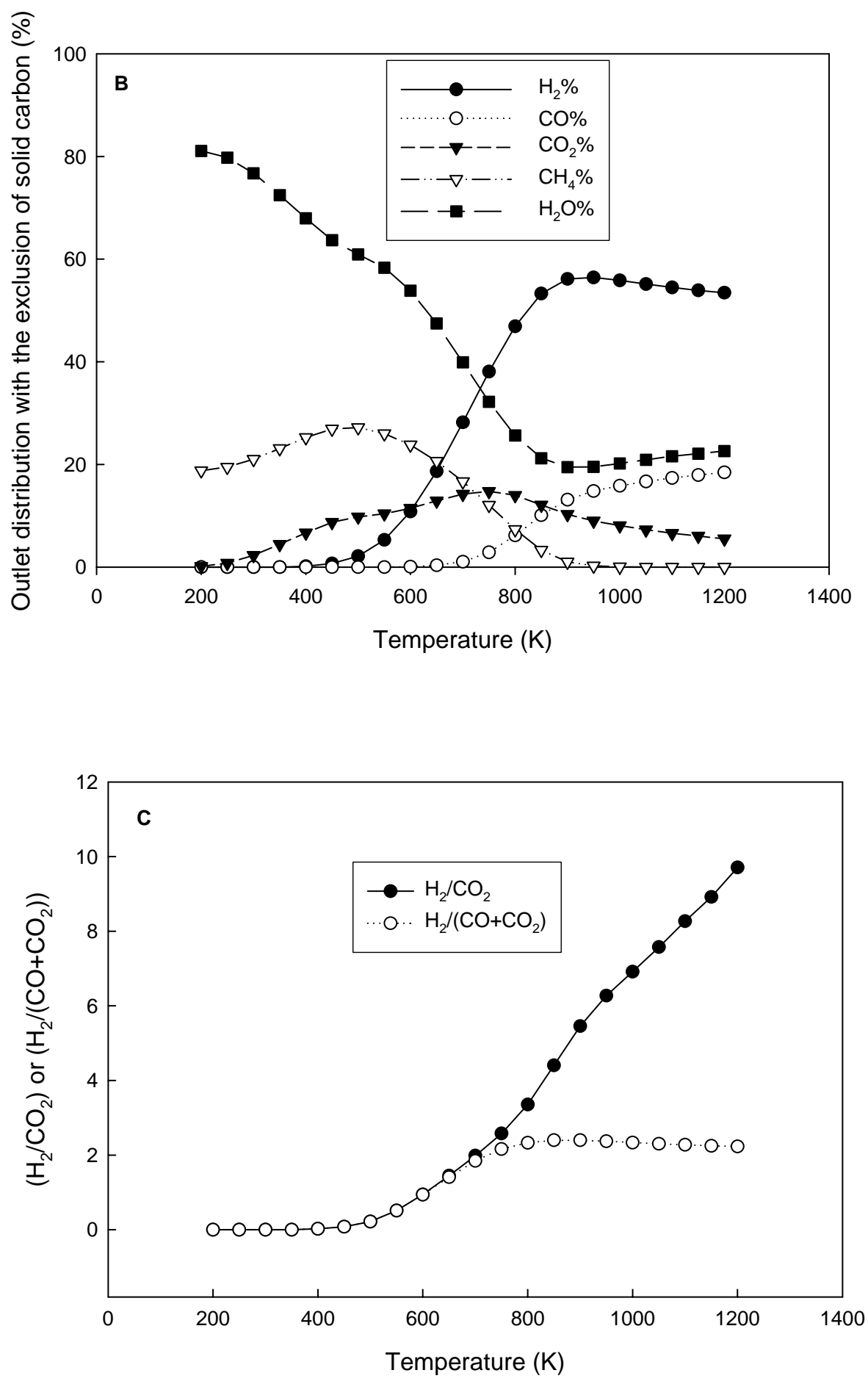

Figure 5-35 Equilibrium calculation of multiple reactions for SRMeOH system as a function of temperature
A: Equilibrium conversions
B: Outlet distribution
C: $\mathrm{H}_{2} / \mathrm{CO}_{2}$ or $\mathrm{H}_{2} \mathrm{O} /\left(\mathrm{CO}+\mathrm{CO}_{2}\right)$ ratio

Reaction conditions: $\mathrm{P}_{\text {tot }}=1 \mathrm{~atm}, \mathrm{CH}_{4} / \mathrm{H}_{2} \mathrm{O} / \mathrm{He} / \mathrm{Ar}=9.1 \% / 10.7 \% / 4 \% / 76.2 \%$ 
As shown in Figure 5-35A, the equilibrium conversion for $\mathrm{CH}_{3} \mathrm{OH}$ is $100 \%$ in the whole range. But the equilibrium conversion for $\mathrm{H}_{2} \mathrm{O}$ is negative before $750 \mathrm{~K}$, suggesting that at equilibrium, $\mathrm{H}_{2} \mathrm{O}$ is being produced instead of being reacted in this temperature range. Even after $750 \mathrm{~K}$, the equilibrium conversion of $\mathrm{H}_{2} \mathrm{O}$ is far lower than that of $\mathrm{CH}_{3} \mathrm{OH}$, and decrease after $900 \mathrm{~K}$. Carbon balances increase from $50 \%$ at $200 \mathrm{~K}$ to $100 \%$ at $500 \mathrm{~K}$, and are maintained at $100 \%$ at higher temperatures, indicating that equilibrium carbon deposits form only at lower temperature range and may disappear at higher temperature. Since all $\mathrm{CH}_{3} \mathrm{OH}$ has been converted in the whole range, only 5 species appear in the $\mathrm{GC}$ trace (besides internal standard $\mathrm{He}$ ): $\mathrm{H}_{2}, \mathrm{CO}, \mathrm{CO}_{2}, \mathrm{CH}_{4}$ and $\mathrm{H}_{2} \mathrm{O}$, see Figure 5-35-B.

For those species containing hydrogen, $\mathrm{H}_{2} \mathrm{O}$ is dominant below $750 \mathrm{~K}$ (where its equilibrium conversion is negative as seen in Figure 5-35B). After $750 \mathrm{~K}$, the equilibrium concentration of $\mathrm{H}_{2}$ becomes higher than $\mathrm{H}_{2} \mathrm{O}$. At the lowest temperatures, the equilibrium concentration of $\mathrm{CH}_{4}$ is higher than that of $\mathrm{H}_{2}$, but this order changes after $650 \mathrm{~K}$. Since then, the equilibrium concentration of $\mathrm{CH}_{4}$ continues to decrease, and it completely disappears in the outlet after $1000 \mathrm{~K}$.

For those species containing carbon, the equilibrium concentration of $\mathrm{CO}_{2}$ increases at lower temperatures and decreases when the temperature is higher than $500 \mathrm{~K}$. But the equilibrium concentration of $\mathrm{CO}_{2}$ starts to drop after $800 \mathrm{~K}$, at which temperature RWGS becomes thermodynamically favorable. In contrast, equilibrium $\mathrm{CO}$ increases 
with temperature from zero, and exceeds equilibrium $\mathrm{CO}_{2}$ after $800 \mathrm{~K}$. Therefore, the reaction temperature plays an important role in the equilibrium product distribution of $\mathrm{SRMeOH}$ reaction system, due to the thermodynamic competition among several reactions.

In Figure $5-35 \mathrm{C}$, the equilibrium ratios of $\mathrm{H}_{2} / \mathrm{CO}_{2}$ and $\mathrm{H}_{2} /\left(\mathrm{CO}+\mathrm{CO}_{2}\right)$ are very close to each other at temperatures lower than $700 \mathrm{~K}$. In other words, very little $\mathrm{CO}$ is produced at low temperatures. At higher temperatures, the equilibrium ratio of $\mathrm{H}_{2} / \mathrm{CO}$ rises, while the equilibrium $\mathrm{H}_{2} /$ total carbon oxides ratio roughly remains at a constant level. In other words, more $\mathrm{CO}$ and less $\mathrm{CO}_{2}$ are produced at high temperatures. This change further provides the evidence that WGS or RWGS reactions shift the equilibrium product distribution, depending on the temperature applied for equilibrium calculation.

Parallel to the equilibrium calculations done for DRM and SRM, Appendix B-4 presents the calculation results for $\mathrm{SRMeOH}$ without considering solid carbon in the reaction system. At high temperatures, there is no significant difference observed in equilibrium conversions and outlet distributions between Figure 5-35 and Appendix B-4. However, at low temperatures, less $\mathrm{H}_{2} \mathrm{O}$ is produced in the absence of solid carbon, i.e. equilibrium conversion of $\mathrm{H}_{2} \mathrm{O}$ become less negative. For outlet distribution, the system containing solid carbon (Figure 5-35) has a higher content of $\mathrm{CH}_{4}$ and a lower content of $\mathrm{CO}_{2}$ at low temperatures. Hence, the presence of $\mathrm{C}$ plays a role in equilibrium concentrations and conversions at low temperatures. 


\subsubsection{Results of SRMeOH with different ratios of methanol to water}

The catalyst used here is still $\mathrm{Co}_{6} \mathrm{~W}_{6} \mathrm{C}$ (made with $\mathrm{CO}_{2} / \mathrm{CO}=0.75$ ). A premixed liquid solution of methanol and water was pumped into the reactor by the HPLC pump at a rate of $0.05 \mathrm{cc} / \mathrm{min}$. Using He only as both internal standard and inert gas, i.e., as the only gas in the feed stream, brought about an excessive amount of He in the effluent. In this case, the calculation based on the He peak in GC chromatography became extremely inaccurate. Accordingly, a gas mixture with 5\%He/balance Ar was introduced in the gas feed, where He was used as internal standard while Ar was used as carrier gas. The liquid-phase reactants (methanol and water) would be vaporized under experimental conditions before reaching the catalyst bed located in the center of the reactor. All the reactions were operated at atmospheric pressure.

The first factor taken into account was the ratio of methanol to water. Table 5-1 summarizes the observations.

Table 5-1 Observations of SRMeOH at different ratios of $\mathrm{CH}_{3} \mathrm{OH}$ to $\mathrm{H}_{2} \mathrm{O}$

\begin{tabular}{|c|l|}
\hline $\mathbf{C H}_{3} \mathbf{O H}: \mathbf{H}_{2} \mathbf{O}$ (wt \%) & \multicolumn{1}{c|}{ Observations } \\
\hline $90: 10$ & $\begin{array}{l}\text { High conversion can be obtained at } 350^{\circ} \mathrm{C} \\
\text { Reaction has to be stopped after 16hrs } \\
\Delta \text { P high due to coke formation }\end{array}$ \\
\hline $80: 20$ & $\begin{array}{l}\text { Good reactivity at } 350^{\circ} \mathrm{C} \text { while still large amount of coke formed } \\
\text { Reaction has to be stopped after } 27 \text { hours }\end{array}$ \\
\hline $70: 30$ & $\begin{array}{l}\text { Carbon deposits as the temperature reaches } 450^{\circ} \mathrm{C} \\
\text { Pressure drop increases to } 100 p s i g \text { after } 43 \mathrm{hrs}\end{array}$ \\
\hline $60: 40$ & $\begin{array}{l}\text { Mild reactivity } \\
\text { Low coke formation }\end{array}$ \\
\hline $50: 50$ & No obvious $\mathrm{H}_{2}$ peak seen until $550^{\circ} \mathrm{C}$ \\
\hline $10: 90$ & Low reactivity, no reaction at $450^{\circ} \mathrm{C}$ \\
\hline
\end{tabular}


For the one extremity, if the ratio is too high (i.e. excessive methanol is fed), coke rapidly deposits on the surface of the bimetallic carbide catalyst and the pressure of the reactor increases dramatically, even though a large amount of $\mathrm{H}_{2}$ can be produced. Rapid coke deposition may also cause physical damage to the reactor. Even for a ratio of 70:30 (wt $\left.\%, \mathrm{MeOH} / \mathrm{H}_{2} \mathrm{O}\right)$, the pressure drop inside the reactor increased to over 100 psig after 43 hours, and the reaction had to be stopped at that point. But a high conversion of methanol can be obtained at a relatively low temperature $\left(350^{\circ} \mathrm{C}\right)$ at the ratio equal to $90: 10\left(\mathrm{wt} \%, \mathrm{MeOH} / \mathrm{H}_{2} \mathrm{O}\right)$. For the other extremity, if the ratio is too low (i.e. too much water is fed), the reforming process is seriously retarded and the reactivity is very low. Even in the case when the ratio is 50:50 (wt \%, MeOH/ $\left.\mathrm{H}_{2} \mathrm{O}\right)$, no significant amount of hydrogen can be produced, even at temperature as high as $550^{\circ} \mathrm{C}$, which is already much higher than typical operating temperatures for SRMeOH. Besides, too much unreacted water in the effluent makes GC analysis difficult and inaccurate.

By investigating several different ratios, an "optimum" ratio of $\mathrm{CH}_{3} \mathrm{OH}$ to $\mathrm{H}_{2} \mathrm{O}$ was selected, based on the observations and reactivity results. As methanol and water is premixed at ratio of 60:40 (wt \%), mild reactivity can be achieved with low coke formation at a reaction temperature above $450^{\circ} \mathrm{C}$. These are the conditions used in the thermodynamic calculations of the previous section and in most of the experiments described below. 


\subsubsection{Effect of time on stream on SRMeOH}

Notwithstanding the above discussion, we used the ratio of methanol to water as 90\%:10\% (wt) to study the effect of time on stream (TOS) on catalyst reactivity. The reason is that high reactivity is attainable at low temperature with this ratio. The carrier gas was brought into the reactor with the ratio of $\mathrm{CH}_{3} \mathrm{OH}: \mathrm{H}_{2} \mathrm{O}:$ inert $=9: 1: 65$. The reaction was run at atmospheric pressure and $350^{\circ} \mathrm{C}$. The results are presented in Figure $5-36$.

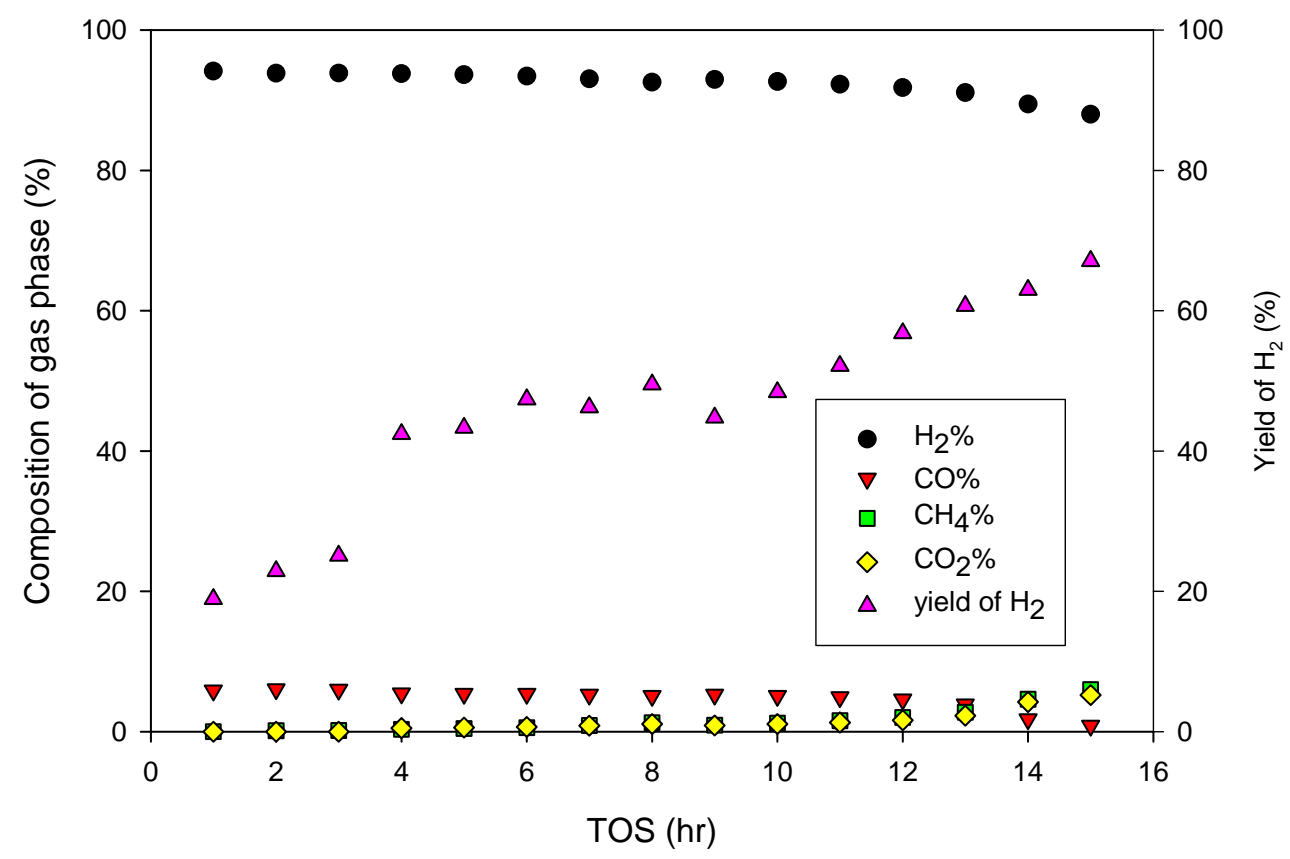

Figure 5-36 Effect of TOS on SRMeOH $\left(\mathrm{CH}_{3} \mathrm{OH}: \mathrm{H}_{2} \mathrm{O}=90: 10\right.$, wt \%)

A hydrogen-rich product mixture could be observed. But after 16 hours on stream, too much coke was formed, and the pressure drop inside the reactor went up to 
the extremely high value of 100 psig.

The gas products include $\mathrm{H}_{2}, \mathrm{CO}, \mathrm{CH}_{4}$ and $\mathrm{CO}_{2}$. The yield of hydrogen, the dominant product, increases with time on stream, therefore it can be inferred that the catalytic reactivity increases as the reaction proceeds in this testing range. Because the water content is much lower than the stoichiometric concentration for $\mathrm{SRMeOH}$, WGS is suppressed to a great extent even though it is thermodynamically favorable in this temperature range. This accounts for why more $\mathrm{CO}$ is produced than $\mathrm{CO}_{2}$. But the relative of ratio of $\mathrm{CO}_{2} / \mathrm{CO}$ increases slightly as the reaction proceeds, indicating that more WGS takes place with increasing TOS.

\subsubsection{Product distribution of $\mathrm{SRMeOH}$ at different temperatures}

Table 5-2 shows the effect of temperature on product distribution, now using the ratio of $\mathrm{CH}_{3} \mathrm{OH}: \mathrm{H}_{2} \mathrm{O}=60: 40$ (wt\% basis), which is the optimum ratio selected based on the observations described in Table 5-1. With this ratio, the reactivity is negligible if the temperature is lower than $450^{\circ} \mathrm{C}$, and very little product is detected in this range. The temperature used for this investigation was increased from $450^{\circ} \mathrm{C}$ up to $850^{\circ} \mathrm{C}$ at intervals of $100^{\circ} \mathrm{C}$, and then was brought back to $450^{\circ} \mathrm{C}$ again in steps of $100^{\circ} \mathrm{C}$. Below $650^{\circ} \mathrm{C}$, the pressure drop $(\Delta \mathrm{P})$ inside the reactor goes up with time on stream due to coke formation, and the highest value can reach as high as 80 psig. As mentioned earlier, equilibrium calculations show that solid carbon forms at low temperatures (lower than 
$450 \mathrm{~K}$, approximately $175^{\circ} \mathrm{C}$ ), while being removed at higher temperatures. Compared to the equilibrium situation, the actual temperature for the start of coke removal seems to be postponed to an even higher temperature $\left(650^{\circ} \mathrm{C}\right)$. Moreover, coke formation is alleviated after the temperature reached $650^{\circ} \mathrm{C}$; even more methanol is converted at higher temperature. Thereafter, the pressure drop decreases close to 0 , and this feature $(\Delta \mathrm{P} \approx 0)$ remains stable until the temperature is brought back to $450^{\circ} \mathrm{C}$.

The values in Table 5-2 indicate that the product distribution varies with temperature. The mole fraction of $\mathrm{CO}$ concentration is higher than that of $\mathrm{CO}_{2}$ reforming at the same temperature. After the catalyst is exposed to high temperature $\left(850^{\circ} \mathrm{C}\right)$, and the temperature is now stepped down, the difference between mole fractions becomes even larger. As the temperature is brought back to $450^{\circ} \mathrm{C}$, only $\mathrm{CO}$ is observed in the gas phase (besides $\mathrm{H}_{2}$ ); no peak of $\mathrm{CO}_{2}$ or $\mathrm{CH}_{4}$ is observed in $\mathrm{GC}$ trace. The ratio of $\mathrm{H}_{2} /\left(\mathrm{CO}+\mathrm{CO}_{2}\right)$ stays around 2.2. This value is very close to the equilibrium ratio of $\mathrm{H}_{2} /$ carbon oxides calculated in Figure 5-35 C.

As the mixture of methanol and water is fed into the reactor, the main reaction taking place in this study should be methanol steam reforming:

$$
\mathrm{CH}_{3} \mathrm{OH}+\mathrm{H}_{2} \mathrm{O} \rightarrow \mathrm{CO}_{2}+3 \mathrm{H}_{2}
$$

producing $\mathrm{H}_{2}$ and $\mathrm{CO}_{2}$ at a molar ratio of $\mathrm{H}_{2} / \mathrm{CO}_{2}$ equal to $3: 1$. 
Table 5-2 Gas product distribution for $\mathrm{CH}_{3} \mathrm{OH}: \mathrm{H}_{2} \mathrm{O}=6: 4$ (wt basis)

\begin{tabular}{|c|c|c|c|c|c|}
\hline \multirow{2}{*}{$\mathrm{T}\left({ }^{0} \mathrm{C}\right)$} & \multicolumn{4}{|c|}{ Gas components } & \multirow{2}{*}{$\mathrm{H}_{2} /(\mathrm{CO}+\mathrm{CO} 2)$} \\
\hline & $\mathrm{H}_{2} \%$ & $\mathrm{CO} \%$ & $\mathrm{CH}_{4} \%$ & $\mathrm{CO}_{2} \%$ & \\
\hline 450 & 64 & 18 & 6.4 & 11 & 2.19 \\
\hline 550 & 64 & 15 & 7.4 & 14 & 2.22 \\
\hline 650 & 67 & 21 & 1.8 & 9.4 & 2.20 \\
\hline 750 & 68 & 19 & 1.9 & 11 & 2.28 \\
\hline 850 & 68 & 19 & 2.0 & 10 & 2.31 \\
\hline 750 & 68 & 19 & 2.3 & 11 & 2.26 \\
\hline 650 & 67 & 25 & 3.3 & 4.7 & 2.24 \\
\hline 550 & 65 & 27 & 3.9 & 4.3 & 2.05 \\
\hline 450 & 69 & 31 & 0 & 0 & 2.21 \\
\hline
\end{tabular}

However, the higher concentrations of $\mathrm{CO}$ observed in the products in place of $\mathrm{CO}_{2}$ implies that the RWGS reaction

$$
\mathrm{CO}_{2}+\mathrm{H}_{2} \rightarrow \mathrm{CO}+\mathrm{H}_{2} \mathrm{O}
$$

takes place simultaneously. This reaction also consumes some $\mathrm{H}_{2}$ and decreases its productivity. Higher temperatures are more favorable for RWGS reaction thermodynamically. In the extreme case, as the concentration of $\mathrm{CO}_{2}$ approaches zero (the last row in Table 5-2), only $\mathrm{CO}$ and $\mathrm{H}_{2}$ are present in the outlet products and the net overall reaction appears to be methanol decomposition:

$$
\mathrm{CH}_{3} \mathrm{OH} \rightarrow \mathrm{CO}+2 \mathrm{H}_{2}
$$

This gives the ratio of $\mathrm{H}_{2} / \mathrm{CO}$ equal to $2: 1$. In the intermediate situation, the value of the ratios of $\mathrm{H}_{2} /\left(\mathrm{CO}+\mathrm{CO}_{2}\right)$ should fall between 2 and 3 .

The shift from SRMeOH to methanol decomposition is affected by the reaction extent of RWGS, which in turn is largely determined by the operating temperature. The 
higher the reaction temperature is the more the effect of RWGS. Also, $\mathrm{CH}_{3} \mathrm{OH}$ is easier than $\mathrm{CH}_{4}$ to decompose, especially at elevated temperature.

From previous studies, in-house bimetallic carbide Co-W-C is stable and active for DRM at $850^{\circ} \mathrm{C}$. It can be assumed that a high reaction temperature is required for this carbide catalyst to exhibit good catalytic performance with necessary laydown of carbon. However, for SRMeOH over the bimetallic carbide, RWGS will become important at high temperatures, and this appears to bring about the shift of the reaction from $\mathrm{SRMeOH}$ to a net decomposition of methanol. Therefore a conflict exists between the proper operating temperature of the bimetallic carbide catalyst and the features of $\mathrm{SRMeOH}$. The high operating temperatures required severely limit the application of the catalyst in $\mathrm{SRMeOH}$.

\subsubsection{Empirical kinetic study for $\mathrm{SRMeOH}$ with this in-house bimetallic carbide catalyst}

As stated previously, at high reaction temperature, the whole system proceeds more like methanol decomposition instead of $\mathrm{SRMeOH}$, and almost all the methanol will be converted as the temperature is over $650^{\circ} \mathrm{C}$. To quantify the reaction system with this carbide catalyst, an empirical kinetic study has been carried out at relatively low temperature range. Three different temperatures were used in this study, $350^{\circ} \mathrm{C}, 400^{\circ} \mathrm{C}$ and $450^{\circ} \mathrm{C}$. From the reactor output data, reaction rates, methanol conversion, $\mathrm{H}_{2}$ yield 
and carbon balance were calculated. The results are presented in Figure 5-37.

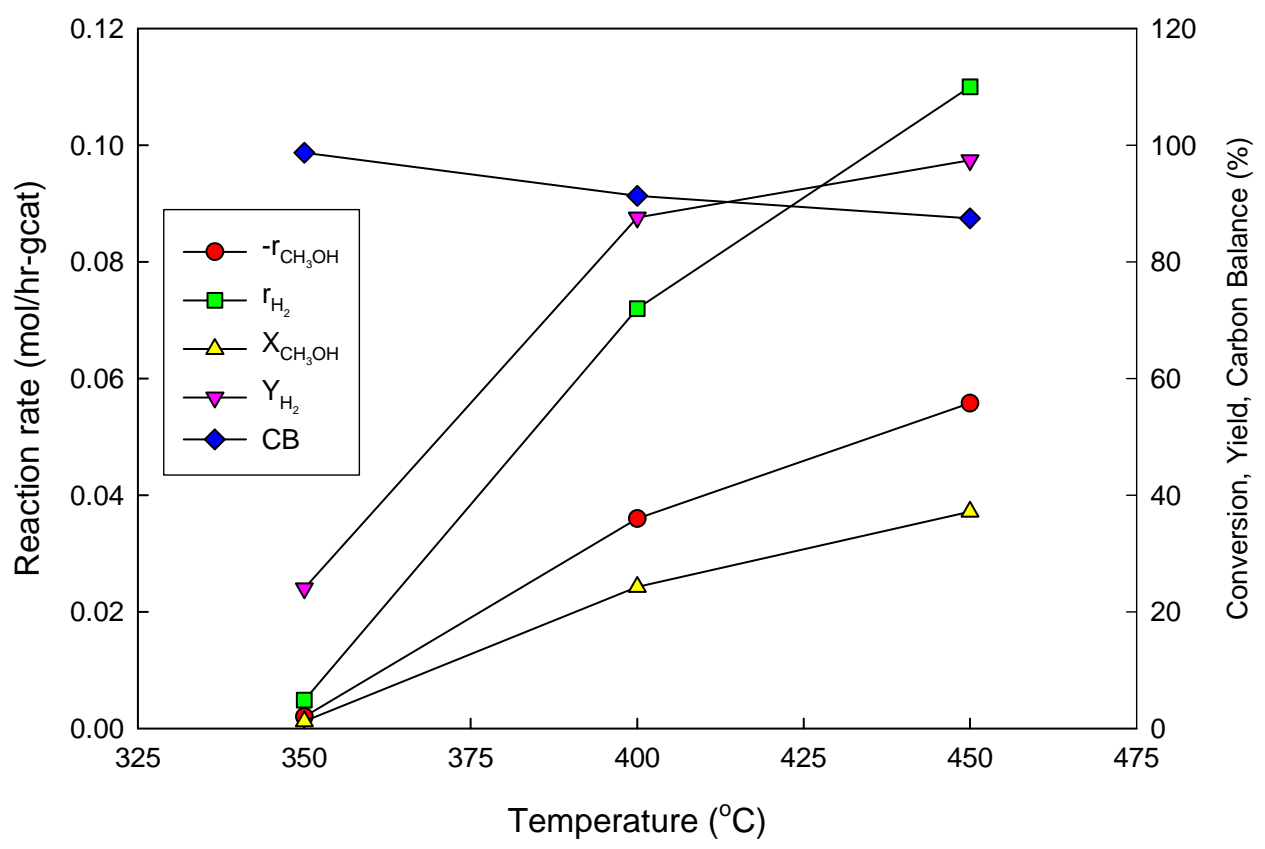

Figure 5-37 Reaction results for SRMeOH with Co-W-C ( $\mathrm{x}=0.75)$ at low temperature range

As shown in Figure 5-37, the reaction rates, as well as conversion and yield, increase with temperature in this range. $\mathrm{H}_{2}$ production rate is about twice the consumption rate of $\mathrm{CH}_{3} \mathrm{OH}$. But the carbon balance decreases as the temperature goes up, suggesting that more coke is laid down on the surface of the catalyst at higher temperatures.

In addition, to investigate the effect of exposure to high temperature, the reaction rates, conversion, yield and carbon balance are also calculated for two temperature points 
$\left(450^{\circ} \mathrm{C}\right.$ and $\left.850^{\circ} \mathrm{C}\right)$ after exposure to high temperatures $\left(850^{\circ} \mathrm{C}\right)$. These results are presented in Figure 5-38.

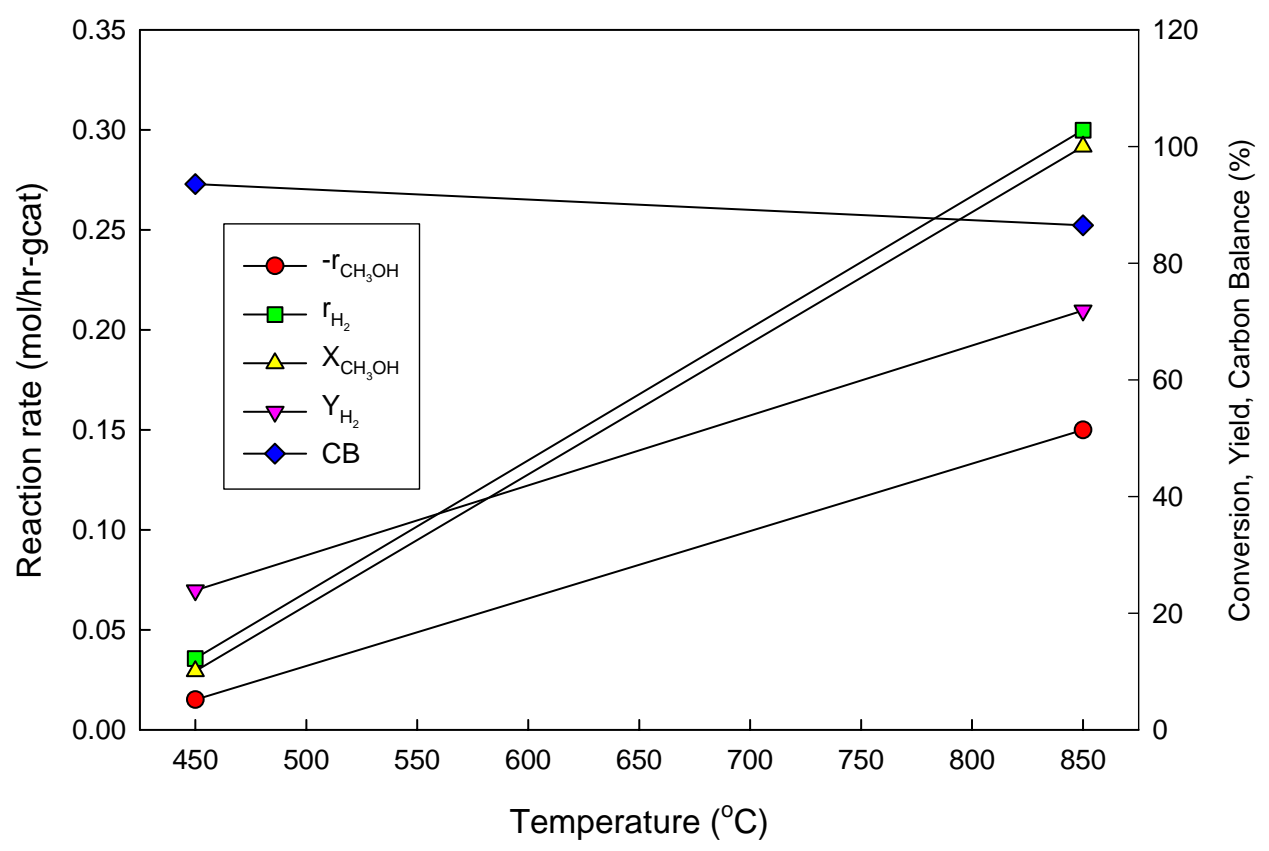

Figure 5-38 Reaction results for SRMeOH with $\mathrm{Co}-\mathrm{W}-\mathrm{C}(\mathrm{x}=0.75)$ after exposure to $850^{\circ} \mathrm{C}$

By comparing the data points at $450^{\circ} \mathrm{C}$ in Figures 5-37 and 5-38, the catalyst can be seen to deactivate after exposure to high temperature.

Similar to SRM, reaction rate constants for methanol consumption in SRMeOH were computed using a pseudo-second-order reaction model.

$$
-\boldsymbol{r}_{\mathrm{CH}_{3} \mathrm{OH}}=\boldsymbol{k}_{\mathrm{SRM}_{\mathrm{eOH}}} \boldsymbol{P}_{\mathrm{CH}_{3} \mathrm{OH}} \boldsymbol{P}_{\mathrm{H}_{2} \mathrm{O}} \text { for SRMeOH }
$$


Values of the reaction rate constant $\mathrm{k}_{\mathrm{SRMeOH}}$ at four different temperatures are presented in Table 5-3.

Table 5-3 Pseudo-second-order rate constants for methanol consumption

\begin{tabular}{|c|c|c|c|c|c|}
\hline \multirow{2}{*}{$\begin{array}{c}\text { Temperature } \\
\left({ }^{\circ} \mathrm{C}\right)\end{array}$} & \multicolumn{3}{|c|}{ Before exposure to $650^{\circ} \mathrm{C}$} & \multicolumn{2}{c|}{ After exposure to $650^{\circ} \mathrm{C}$} \\
\cline { 2 - 6 } & 350 & 400 & 450 & 450 & 850 \\
\hline $\begin{array}{c}k_{S R M e O H} \\
\left(\mathrm{~mol} / \mathrm{hr} / \mathrm{g} / \mathrm{atm}^{2}\right)\end{array}$ & 0.22 & 4.22 & 6.45 & 2.47 & 17.35 \\
\hline
\end{tabular}

The first three data points $\left(350^{\circ} \mathrm{C}\right.$, and $400^{\circ} \mathrm{C}$ and the first $\left.450^{\circ} \mathrm{C}\right)$ are taken before the reactants are exposed to $650^{\circ} \mathrm{C}$, and the second $450^{\circ} \mathrm{C}$ point is the one after exposure to $650^{\circ} \mathrm{C}$. The reaction rate increases significantly (20 times) as the temperature increases from $350^{\circ} \mathrm{C}$ to $400^{\circ} \mathrm{C}$. This trend continues as the temperature reaches $450^{\circ} \mathrm{C}$, but with a much smaller extent. However, the reaction rate for $450^{\circ} \mathrm{C}$ decreases from $6.45 \mathrm{~mol} / \mathrm{hr} / \mathrm{g} / \mathrm{atm}^{2}$ to $2.47 \mathrm{~mol} / \mathrm{hr} / \mathrm{g} / \mathrm{atm}^{2}$ after exposure to high temperature. This decrease may be due to catalyst deactivation. By comparing $\mathrm{k}$ values at $850^{\circ} \mathrm{C}$ for the three reactions (Table 5-3, equation 5-13 and equation 5-14), it can be seen that $\mathrm{SRMeOH}\left(\mathrm{k}_{\mathrm{SRMeOH}}=17.35 \mathrm{~mol} / \mathrm{hr} / \mathrm{g} / \mathrm{atm}^{2}\right)$ has a much higher pseudo-second-order reaction rate constant than $\mathrm{DRM} \quad\left(\mathrm{k}_{\mathrm{DRM}}=4.31 \mathrm{~mol} / \mathrm{hr} / \mathrm{g} / \mathrm{atm}^{2}\right)$ and $\mathrm{SRM}$ $\left(\mathrm{k}_{\mathrm{DRM}}=0.0142 \mathrm{~mol} / \mathrm{hr} / \mathrm{g} / \mathrm{atm}^{2}\right)$, suggesting that $\mathrm{SRMeOH}$ is an easier reaction than DRM and SRM.

After reviewing DRM, SRM and $\mathrm{SRMeOH}$ over this bimetallic carbide, it is 
found that the catalyst itself is stable and active for DRM, while much less so for steam reforming (both $\mathrm{SRM}$ and $\mathrm{SRMeOH}$ ). The presence of water probably makes a big difference on the catalytic performance of the carbide material. Co-fed steam as one of the reactants into the reaction system can prevent necessary carbon laydown on the surface of the catalyst. This will further retard the reduction and carburization of the catalyst, making the transformation of the catalyst into active phases impossible. In the absence of the active phases containing $\mathrm{Co}$, WC and $\mathrm{C}$, the catalyst cannot exhibit its catalytic reactivity to the reforming process. Therefore, for this bimetallic carbide material, the importance of carbon laydown can be further addressed here by comparing the different behavior in dry reforming and steam reforming processes.

\subsection{Summary}

In this chapter, the catalytic performance of cobalt tungsten carbide catalysts has been investigated for DRM, SRM and SRMeOH. When properly pretreated, this in-house carbide catalyst has high reactivity for DRM without noticeable coke formation or deactivation for over 100 hours. The ratio of $\mathrm{CO}_{2} / \mathrm{CO}$ in the preparation procedure has only a slight effect on the reactivity. By studying the effect of temperature history, it is found that this carbide is ineffective for DRM until it has been exposed to $850^{\circ} \mathrm{C}$. This is explained by phase transformation from oxides to carbides at high temperature in an atmosphere of reactants $\left(\mathrm{CH}_{4}\right.$ and $\left.\mathrm{CO}_{2}\right)$, the evidence of which has been provided by 
several characterization measurements, including XRD, SEM, EDAX and NEXAFS. Before the carbide material is exposed to $850^{\circ} \mathrm{C}$, some oxides are present, both in the bulk and on the surface. This has a negative effect on the catalyst reactivity. These surface oxides are probably $\mathrm{CoWO}_{4}$ (NEXAFS data). Those oxides disappear after exposure to $850^{\circ} \mathrm{C}$ in an atmosphere of reactants $\left(\mathrm{CH}_{4}\right.$ and $\left.\mathrm{CO}_{2}\right)$. This transforms to the material mixture containing graphitic carbon and tungsten oxides on the surface and WC $+\mathrm{Co}+\mathrm{C}$ in the bulk phase. This is a stable and active catalyst for DRM.

However, this catalyst is not promising for steam reforming, either SRM or $\mathrm{SRMeOH}$, at least under the reaction conditions in this study. The reaction rate of SRM is much slower than DRM. Even though $\mathrm{SRMeOH}$ has a much higher reaction rate, the reaction itself shifts from $\mathrm{SRMeOH}$ to methanol decomposition at high operating temperatures. The obvious conclusion can be drawn that the bimetallic carbide catalyst is ineffective for SRM and SRMeOH. The presence of steam as a reactant does not allow the transformation of the bimetallic carbide to the active species consisting of bulk phase $\mathrm{Co}, \mathrm{WC}$ and $\mathrm{C}$. 


\section{CHAPTER 6 CATALYTIC STUDY OF Ni-W-C CATALYST}

\subsection{Introduction}

Nickel tungsten carbide (Ni-W-C) made in-house will be investigated in this chapter. The work focuses only on methane dry reforming (DRM) reaction with Ni-W-C. Since a nickel-based catalyst has been traditionally used for methane reforming $[14,52]$, it is worthwhile to probe the catalytic properties of a bimetallic carbide catalyst containing nickel.

Following the testing procedures in Chapter 5, the study on nickel tungsten carbide starts from reactivity and stability testing under the same reaction conditions. The effect of exposure to high temperature on the catalytic performance of the catalyst is also examined. Similarly, several characterization techniques (XRD, SEM, EDAX, and NEAXFS) provide the information of both bulk and surface properties after the catalyst goes through the reaction. In addition, some parallel comparison will be made with cobalt tungsten carbide catalyst, including reactivity as well as effect of temperature history. 


\subsection{Reactivity and stability test for $\mathrm{Ni}-\mathrm{W}-\mathrm{C}$}

Two types of Ni-W carbides are used. One is made with $\mathrm{x}\left(\mathrm{CO}_{2} / \mathrm{CO}\right)=0.5$ and the other is made with $\mathrm{x}=0.75$. XRD patterns in Figures 4-9 and 4-10 indicate that the first has bulk phases of $\mathrm{Ni}$ and $\mathrm{WC}$, and the latter one has a bulk mixture of WC and $\mathrm{Ni}_{6} \mathrm{~W}_{6} \mathrm{C}$.

All the reaction conditions were the same as those used for Co-W-C. The test results are presented in Figures 6-1 and 6-2. Based on the values of conversions, CO yield, $\mathrm{H}_{2} / \mathrm{CO}$ ratio and carbon balance, the two $\mathrm{Ni}-\mathrm{W}-\mathrm{C}$ catalysts are also stable and active for DRM reaction over more than 100 hours. Both nickel tungsten carbides have trends similar to cobalt tungsten carbides in the reactivity and stability testing (see Figures 5-5 and 5-6). Even though they consist of different transition metals, the reactivity of these carbides is comparable. A period of induction is required for all carbides, and carbon balances improve after the catalysts reach steady state. 


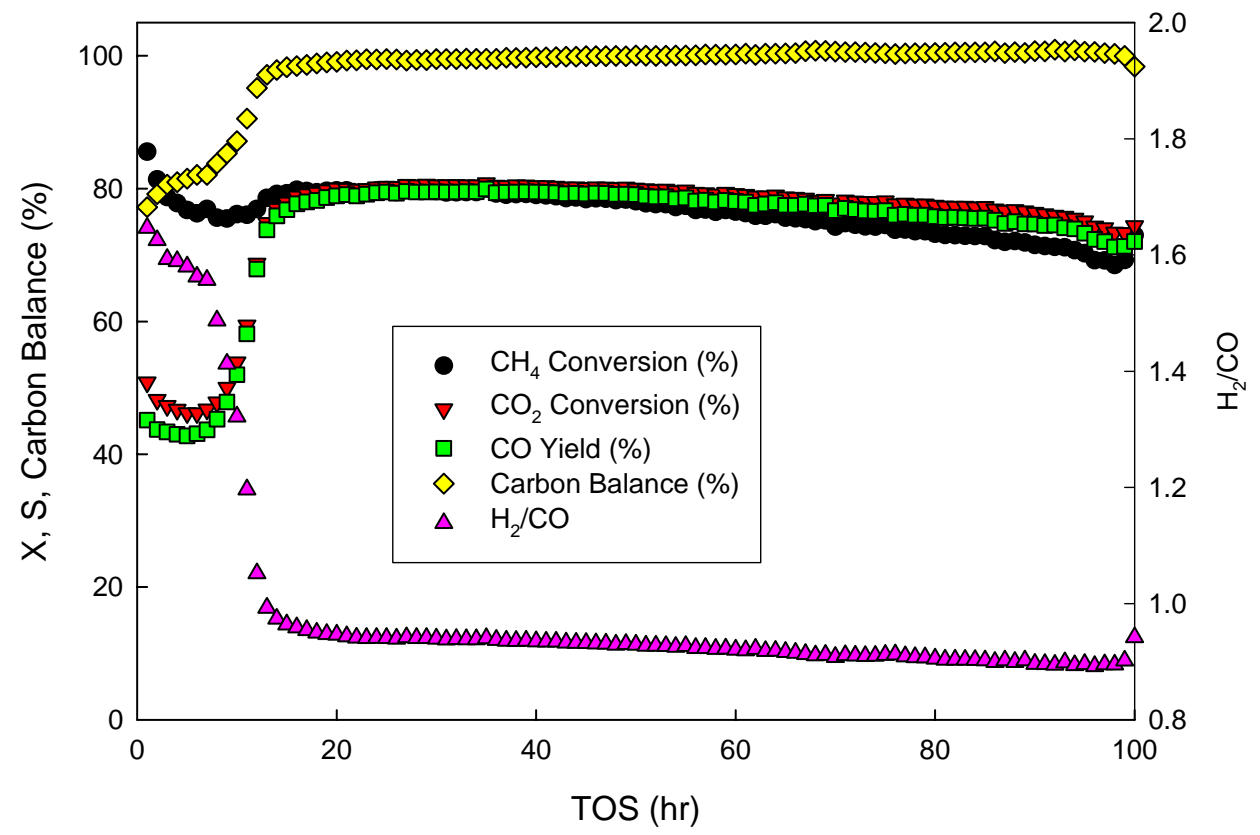

Figure 6-1 Reactivity and stability test for Ni-W-C ( $\mathrm{x}=0.5)$ $\mathrm{T}=850^{\circ} \mathrm{C}, \mathrm{P}_{\text {tot }}=3.4 \mathrm{~atm}, \mathrm{WHSV}=9,000 \mathrm{scc} / \mathrm{hr}-\mathrm{gcat}$

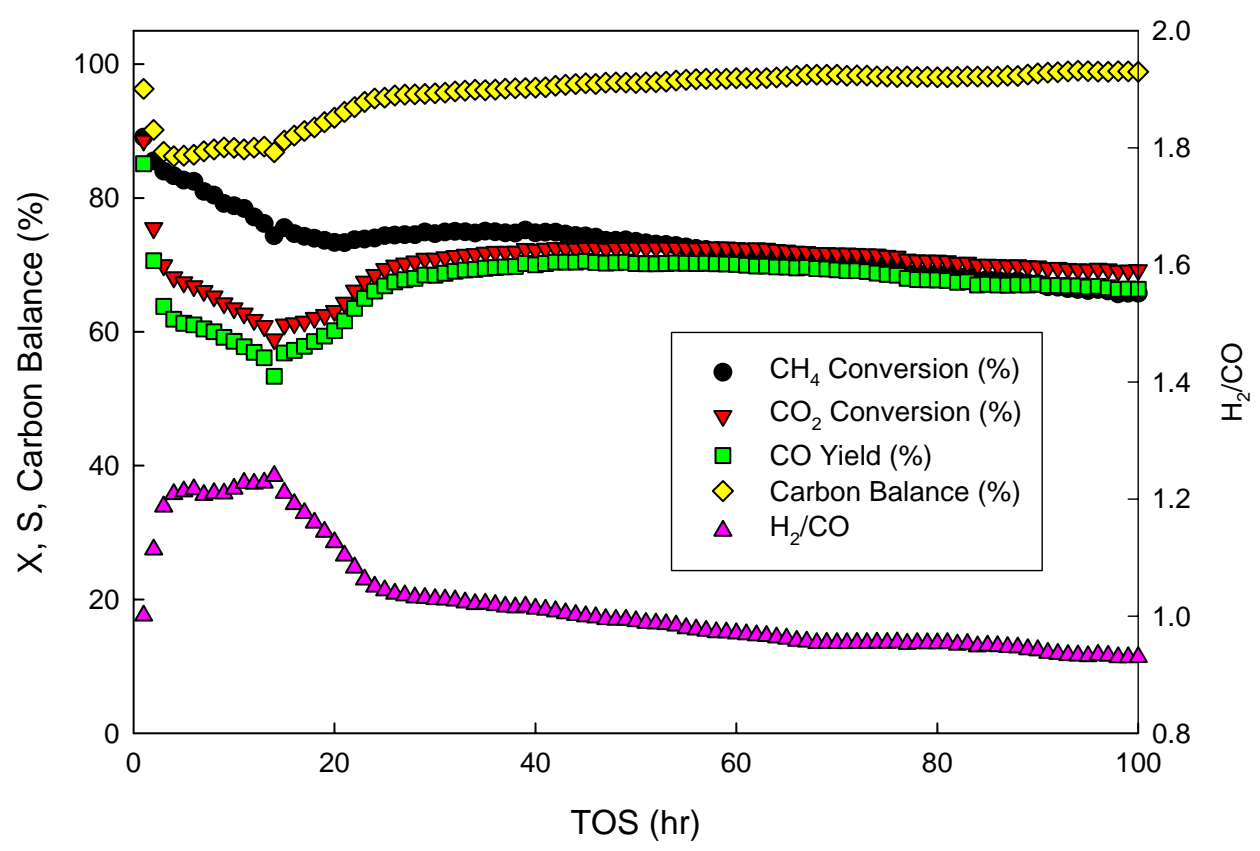

Figure 6-2 Reactivity and stability test for Ni-W-C ( $x=0.75)$ $\mathrm{T}=850^{\circ} \mathrm{C}, \mathrm{P}_{\text {tot }}=3.4 \mathrm{~atm}, \mathrm{WHSV}=9,000 \mathrm{scc} / \mathrm{hr}$-gcat 
However, by comparing Ni-W-C and Co-W-C made with the same ratio of $\mathrm{CO}_{2}$ to CO (i.e. Figure 6-1 vs. Figure 5-5, and Figure 6-2 vs. Figure 5-6), slight differences can be observed as follows. Even though there is a period of induction time for all carbides, the length of this period is shorter for nickel tungsten carbides than for cobalt tungsten carbides, regardless of the ratio of $\mathrm{CO}_{2} / \mathrm{CO}$ which is used in carburization process. For both cobalt tungsten carbides, there is a maximum for $\mathrm{H}_{2} / \mathrm{CO}$ ratio, appearing between the 10th and the 15 th hour on stream. For nickel tungsten carbides, there is only one peak of $\mathrm{H}_{2} / \mathrm{CO}$ ratio for the material made with $\mathrm{CO}_{2} / \mathrm{CO}=0.75$ (Figure 6-2), which is near the 15 th hour on stream. Also for Ni-W-C made with $\mathrm{CO}_{2} / \mathrm{CO}=0.75$ (Figure 6-2), the highest conversion for methane occurs at the very beginning. But for Co-W-C, the highest conversion for methane occurs at the time where the highest ratios of $\mathrm{H}_{2} / \mathrm{CO}$ appear. For Co-W-C, after steady state, $\mathrm{X}_{\mathrm{CH} 4}$ is less than $\mathrm{X}_{\mathrm{CO} 2}$, while for Ni-W-C, $\mathrm{X}_{\mathrm{CH} 4}$ is a little greater than $\mathrm{X}_{\mathrm{CO} 2}$. This indicates that more RWGS and more RB take place with the Ni-W-C catalyst. Also at steady state, the $\mathrm{H}_{2} / \mathrm{CO}$ ratio for $\mathrm{Ni}-\mathrm{W}-\mathrm{C}$ catalyst is about 0.2 lower than that for $\mathrm{Co}-\mathrm{W}-\mathrm{C}$, which further confirms the relative competition between the main reaction DRM and the side reactions, carbon deposition (CD), reverse water gas shift (RWGS) and reverse Boudouard (RB). Compared to Co-W-C, there may be more RB, and more RWGS with Ni-W-C, while less $\mathrm{CD}$ takes place in the reaction system. Carbon balances near $100 \%( \pm 5 \%)$ imply that not much coke is formed in the reaction process. Serious coke formation is the problem encountered with using traditional nickel based catalyst for DRM, even though high reactivity can be 
obtained initially [8, 54]. In Bradford's work [77] with supported nickel catalysts, $\mathrm{Ni} / \mathrm{Nb}_{2} \mathrm{O}_{5}$ lost $50 \%$ of its reactivity after 6 hours on stream. This problem is solved using this bimetallic carbide, as no deactivation is found due to coke formation for over 100 hours, as shown in Figures 6-1 and 6-2. It can be deduced that the interaction between $\mathrm{Ni}$ and $\mathrm{W}$ as well as the incorporation of $\mathrm{C}$ changes the properties of the surface, making it much less favorable for coke formation. Some lay down of carbon during the induction period may also be helpful for preventing severe coke formation later. 


\subsection{Investigation of exposure to high temperature on the catalytic performance of bimetallic carbide catalyst}

Similar to the work done for $\mathrm{Co}-\mathrm{W}-\mathrm{C}$, a temperature progression was also designed to investigate the effect of exposure to high temperature on the catalytic performance of Ni-W-C. Only the material prepared with $\mathrm{x}=0.75$ was used in this test. The results can be seen in Figure 6-3.

As shown in Figure 5-16, Co-W-C (with $\mathrm{x}=0.75$ ) has much higher reactivity after it is exposed to $850^{\circ} \mathrm{C}$, and no deactivation is observed even after the reaction temperature is brought back to a lower level. But for Ni-W-C, a symmetric pattern of data in Figure 6-3 indicates that there is no significant change before and after exposure to $850^{\circ} \mathrm{C}$. Without being exposed to high temperature, the conversions reach $26 \%$ for methane and $39 \%$ for carbon dioxide at $700^{\circ} \mathrm{C}$. There is also no deactivation trend after the catalyst is exposed at $850^{\circ} \mathrm{C}$. The reactivity seems to be repeatable in the temperature progression. The $\mathrm{H}_{2} / \mathrm{CO}$ ratio has the same trend as the reactivity and reaches the highest value $(0.98)$ at $850^{\circ} \mathrm{C}$. The higher the reactivity of the catalyst, the higher the $\mathrm{H}_{2} / \mathrm{CO}$ ratio it produces. But the carbon balance decreases with temperature, perhaps because more $\mathrm{CD}$ and $\mathrm{RB}$ take place at higher temperatures. Therefore, an obvious difference can be observed between $\mathrm{Co}-\mathrm{W}-\mathrm{C}$ and $\mathrm{Ni}-\mathrm{W}-\mathrm{C}$ with regards to the effect of exposure to high temperature. The effect is significant with Co-W-C while negligible with $\mathrm{Ni}-\mathrm{W}-\mathrm{C}$. The Ni-W-C material does not change at $850^{\circ} \mathrm{C}$, while the 
Co-W-C material does.

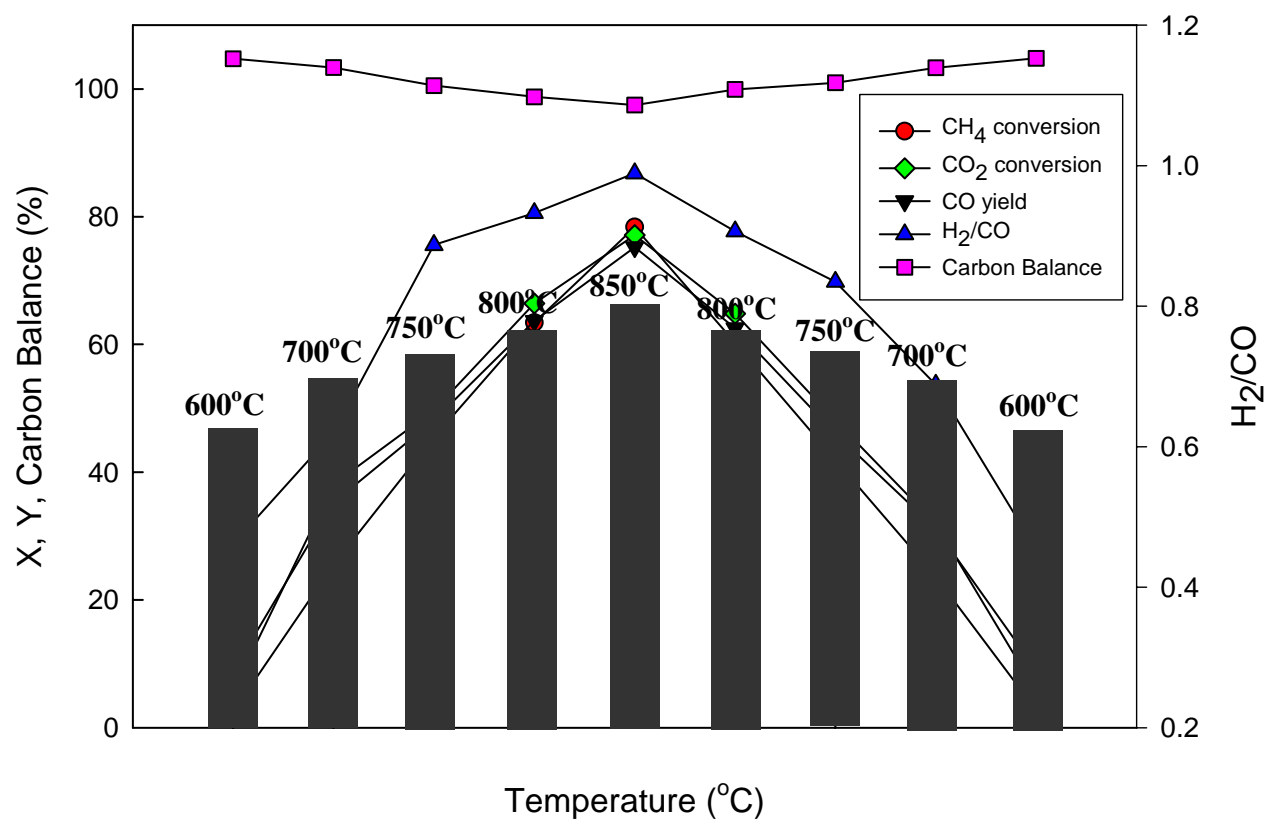

Figure 6-3 Effect of exposure to high temperature for Ni-W-C $(x=0.75)$

To make a quantitative comparison of catalytic properties of $\mathrm{Ni}-\mathrm{W}-\mathrm{C}$ and Co-W-C, the hydrogen production rate constants and the methane consumption rate constants were computed using a pseudo-second-order model.

$$
\boldsymbol{r}_{\mathrm{H}_{2}}=\boldsymbol{k}_{\mathrm{H}_{2}} \boldsymbol{P}_{\mathrm{CH}_{4}} \boldsymbol{P}_{\mathrm{CO}_{2}} \quad \text { for } \mathrm{H}_{2} \text { production rate }
$$

and

$-\boldsymbol{r}_{\mathrm{CH}_{4}}=\boldsymbol{k}_{\mathrm{CH}_{4}} \boldsymbol{P}_{\mathrm{CH}_{4}} \boldsymbol{P}_{\mathrm{CO}_{2}}$ for $\mathrm{CH}_{4}$ consumption rate

Figure 6-4 and Figure 6-5 show the relationship between the rate constants and temperature in the temperature progression using $\mathrm{Ni}-\mathrm{W}-\mathrm{C}$ and $\mathrm{Co}-\mathrm{W}-\mathrm{C}$ respectively. 


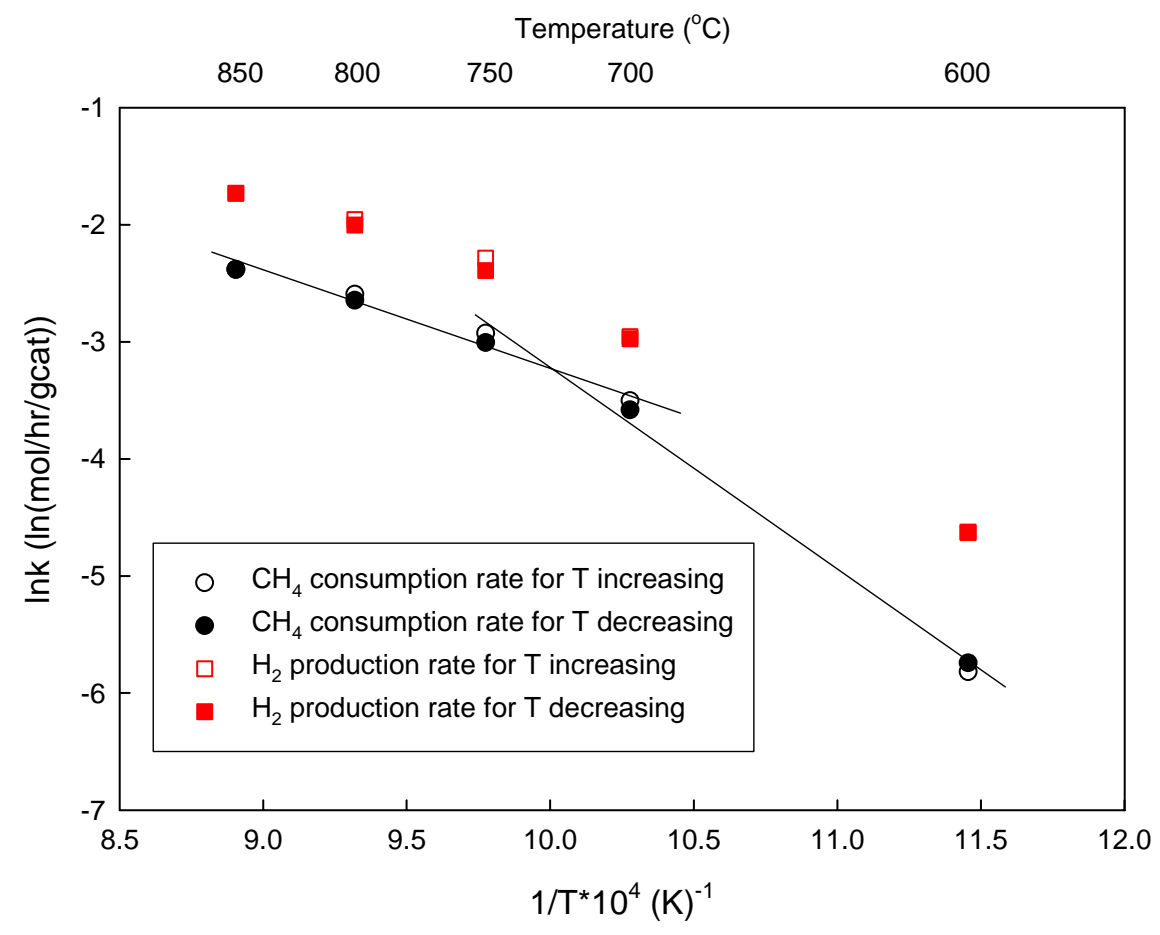

Figure 6-4 In k vs $1 / \mathrm{T}$ in temperature progression for Ni-W-C $(x=0.75)$

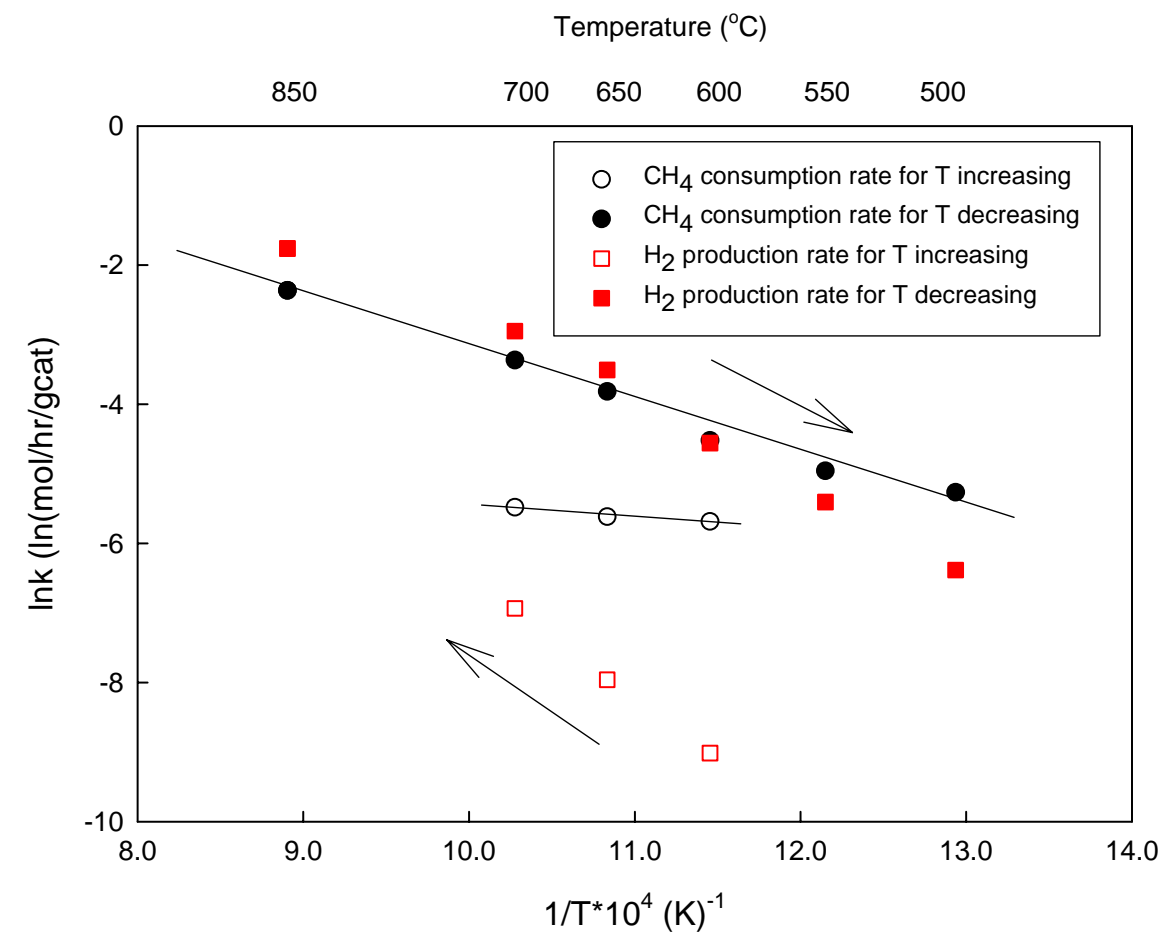

Figure 6-5 In $\mathrm{k}$ vs $1 / \mathrm{T}$ in temperature progression for Co-W-C $(x=0.75)$ 
For Ni-W-C catalyst, Figure 6-4, the reaction rate constants for $\mathrm{CH}_{4}$ consumption and $\mathrm{H}_{2}$ production are the same whether temperature increases or decreases, i.e., whether the catalyst has been exposed to $850^{\circ} \mathrm{C}$ or not. However, for Co-W-C catalyst, Figure 6-5, a significant gap is found between temperature increasing and decreasing, indicating that the reaction rates increase dramatically after exposure to elevated reaction temperature for further carburization.

The slopes of Figure 6-4 and 6-5 allow values of the apparent activation energy $\mathrm{E}_{\mathrm{a}}$ to be computed. The results, based on $\mathrm{CH}_{4}$ consumption rate constants only, are presented in Table 6-1.

Table 6-1 Computation of activation energy

\begin{tabular}{|c|c|c|c|}
\hline \multirow{2}{*}{ Catalyst } & Temperature Range $\left({ }^{\mathbf{0}} \mathbf{C}\right)$ & $\mathbf{E}_{\mathbf{a}}(\mathbf{K J} / \mathbf{m o l})$ & $\mathbf{R}^{2}$ \\
\hline \multirow{2}{*}{ Co-W-C } & $600 \rightarrow 650 \rightarrow 700$ & 14.26 & 0.9518 \\
\cline { 2 - 4 } & $850 \rightarrow 700 \rightarrow 650 \rightarrow 600 \rightarrow 550 \rightarrow 500$ & 62.77 & 0.9850 \\
\hline \multirow{2}{*}{ Ni-W-C } & $750 \leftrightarrow 700 \leftrightarrow 600$ & 142.60 & 0.9888 \\
\cline { 2 - 4 } & $850 \leftrightarrow 800 \leftrightarrow 750 \leftrightarrow 700$ & 72.57 & 0.9701 \\
\hline
\end{tabular}

Because the reaction rate constants are repeatable for $\mathrm{Ni}-\mathrm{W}-\mathrm{C}$ before and after exposure to $850^{\circ} \mathrm{C}$, reversible arrows are used in the column of temperature range, indicating data are repeatable in the processes of temperature increasing and decreasing. In contrast, for Co-W-C, forward arrows are used in that column to denote whether the temperature increases or decrease, because the reaction rate increases considerably after 
the catalyst is exposed to $850^{\circ} \mathrm{C}$. In Figure 6-4, the $\mathrm{Ni}-\mathrm{W}-\mathrm{C}$ sample has a steeper slope at lower temperatures $\left(600^{\circ} \mathrm{C} \leftrightarrow 700^{\circ} \mathrm{C} \leftrightarrow 750^{\circ} \mathrm{C}\right)$ than at high temperatures, implying that higher activation energy is required at lower temperatures. Accordingly, $\mathrm{E}_{\mathrm{a}}$ for $\mathrm{Ni}-\mathrm{W}-\mathrm{C}$ is calculated in two regions. For Ni-W-C, the value of $\mathrm{E}_{\mathrm{a}}$ at low temperatures is almost twice that at high temperatures. This is about what could be expected for a change from kinetic to mass-transfer control. For the Co-W-C catalyst (Figure 6-5), after exposure to high temperature, the data points fall into a straight line, from $850^{\circ} \mathrm{C}$ all the way down to $500^{\circ} \mathrm{C}$. But for $\mathrm{Co}-\mathrm{W}-\mathrm{C}$, before exposure to $850^{\circ} \mathrm{C}$, the data are almost horizontal, and $E_{a}$ is much lower. The difference in $E_{a}$ at different temperatures for the cobalt-based catalyst (a factor of 4) may be attributed to the reaction taking place on different phases. In the high-temperature range for both catalysts, the values of activation energies are close to each other, around $60-70 \mathrm{KJ} / \mathrm{mol}$. Hence at high temperatures, the active surfaces for the two catalysts may be considered to be similar, whereas a different surface may be seen at low temperatures for the Co-W-C catalyst. 


\subsection{Characterization of Ni-W-C carbide catalyst before and after exposure to $850^{\circ} \mathrm{C}$}

Similar to the work in Chapter 5, some characterization has been carried out for the Ni-W-C materials, which were similarly taken out at different stages. XRD, SEM, EDAX as well as NEXAFS for Ni-W-C are described below.

Figure 6-6 and Figure 6-7 are XRD patterns for Ni-W-C materials, which are taken at different temperature stages. Figure 6-6 is for the sample taken as the material was only exposed to reactants at $700^{\circ} \mathrm{C}$, and Figure 6-7 is for the sample also at $700^{\circ} \mathrm{C}$, but after exposure to $850^{\circ} \mathrm{C}$. No oxide peaks are found in the bulk phase, no matter whether the sample was exposed to high temperature or not. In both cases, the spent catalysts turn out to be mixtures of metal $\mathrm{Ni}$ and $\mathrm{WC}$, which should be the active phase according to the information from Co-W-C studies. It has also been shown in the previous chapter that the presence of oxides in Co-W-C can make the carbide catalyst inefficient for DRM. The absence of oxides in the spent catalyst of Ni-W-C even at the first $700^{\circ} \mathrm{C}$ stage, before exposure to $850^{\circ} \mathrm{C}$, is possibly the reason that this material can still be at least mildly active for DRM at that relatively low temperature. 


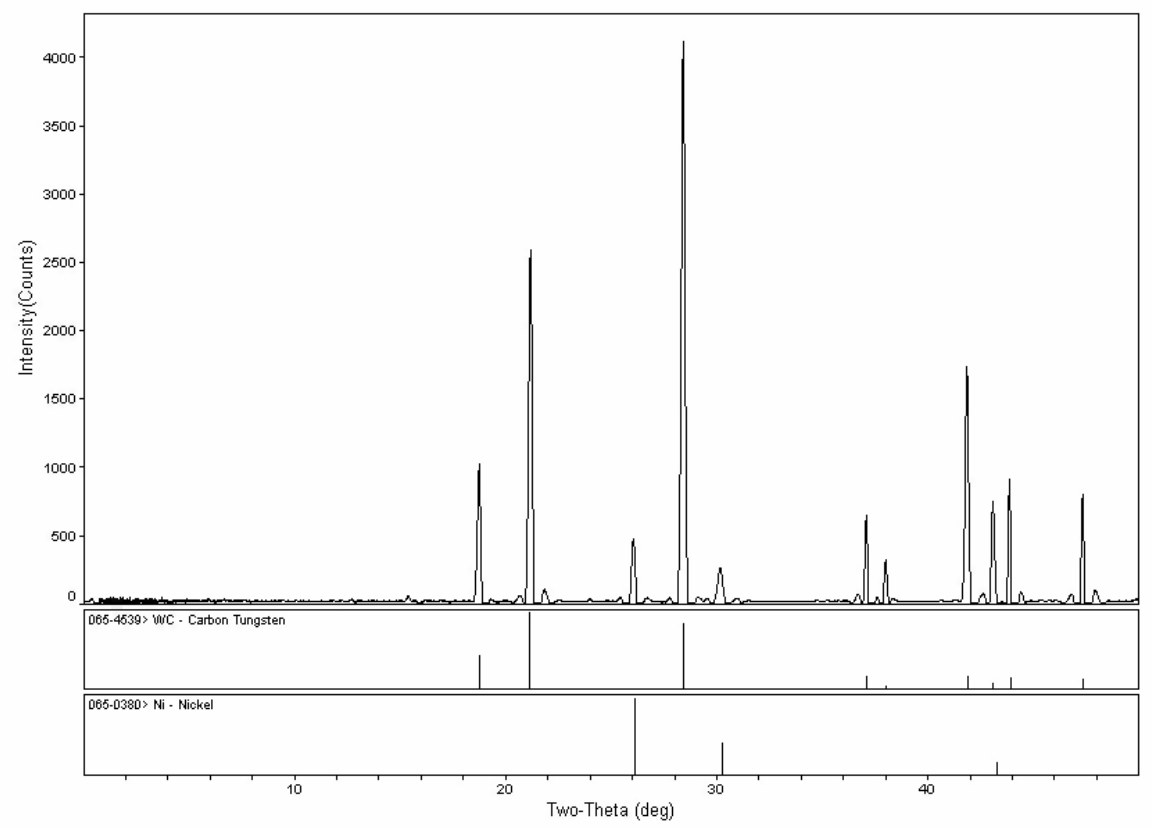

Figure 6-6 $X R D$ pattern of spent Ni-W-C $(x=0.75)$ at $1 s t 700^{\circ} \mathrm{C}$ stage, i.e.,before exposure to $850^{\circ} \mathrm{C}$

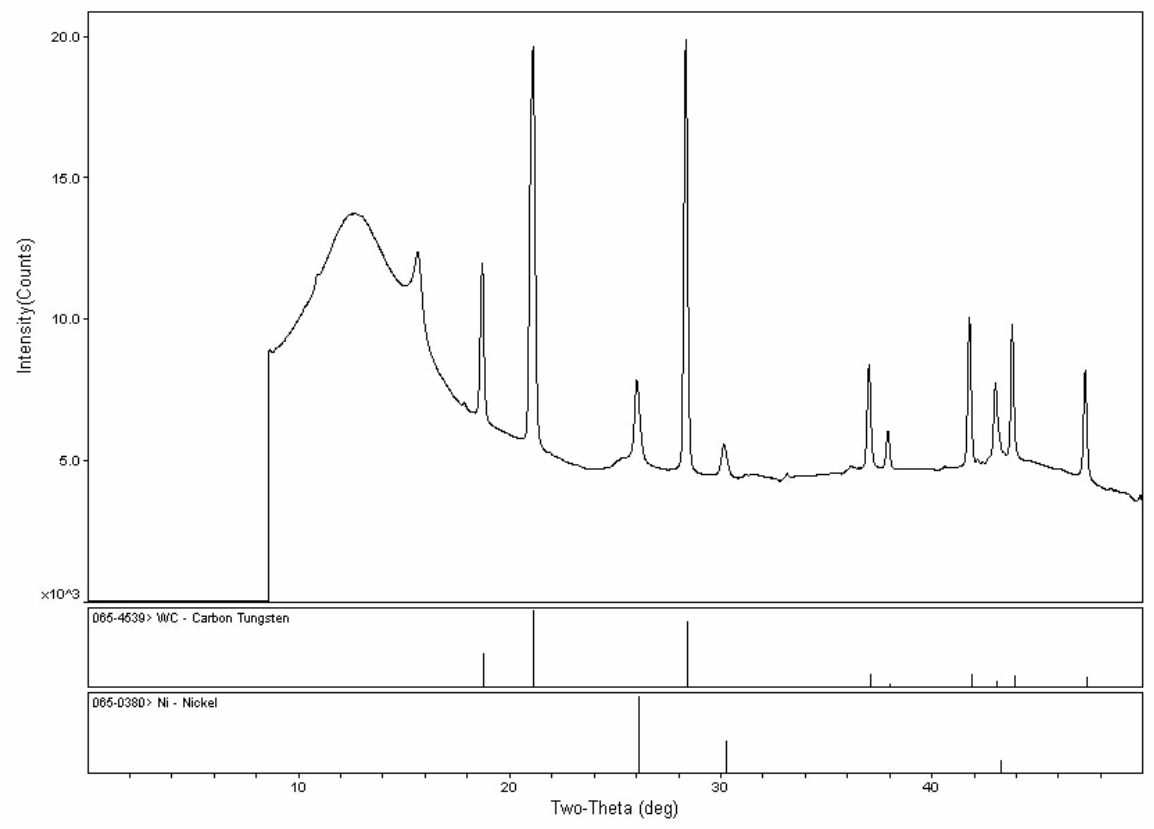

Figure 6-7 $X R D$ pattern of spent Ni-W-C $(x=0.75)$ at $2 \mathrm{nd} 700 \mathrm{oC}$ stage, i.e., after exposure to $850^{\circ} \mathrm{C}$ 
Next, surface properties of the catalysts were investigated using SEM (Figures 6-8 and 6-9) \& EDAX (Figures 6-10 and 6-11). Comparing two sets of images in Figure 6-8 and 6-9, the spent Ni-W-C after exposure to $850^{\circ} \mathrm{C}$ has a more uniform morphologic structure than the one before exposure to $850^{\circ} \mathrm{C}$. The atomic ratio of Ni to W does not vary much from position to position via EDAX mapping technique. At the same time, more carbon deposits can be seen after the catalyst is exposed to high temperatures. The EDAX analysis indicate that the spent catalyst at $700^{\circ} \mathrm{C}$ (before exposure to $850^{\circ} \mathrm{C}$ ), Figure $6-10$, has components very similar to the fresh Ni-W-C catalyst, Figure 4-20. However, after the catalyst is exposed to $850^{\circ} \mathrm{C}$, a much higher content of carbon is detected at $700^{\circ} \mathrm{C}$. This can be attributed to the carbon deposited on the surface of the catalyst at high reaction temperature. An important difference from Co-W-C catalyst is that there is no obvious trace of oxygen in the EDAX pattern of the spent Ni-W-C catalyst before exposure to $850^{\circ} \mathrm{C}$. This observation further confirms the absence of oxides in spent $\mathrm{Ni}-\mathrm{W}-\mathrm{C}$ catalyst without being exposed to $850^{\circ} \mathrm{C}$, and can also provide evidence that it can have higher reactivity for $\mathrm{DRM}$ at $700^{\circ} \mathrm{C}$ (before exposure to $850^{\circ} \mathrm{C}$ ) than $\mathrm{Co}-\mathrm{W}-\mathrm{C}$ catalyst. 

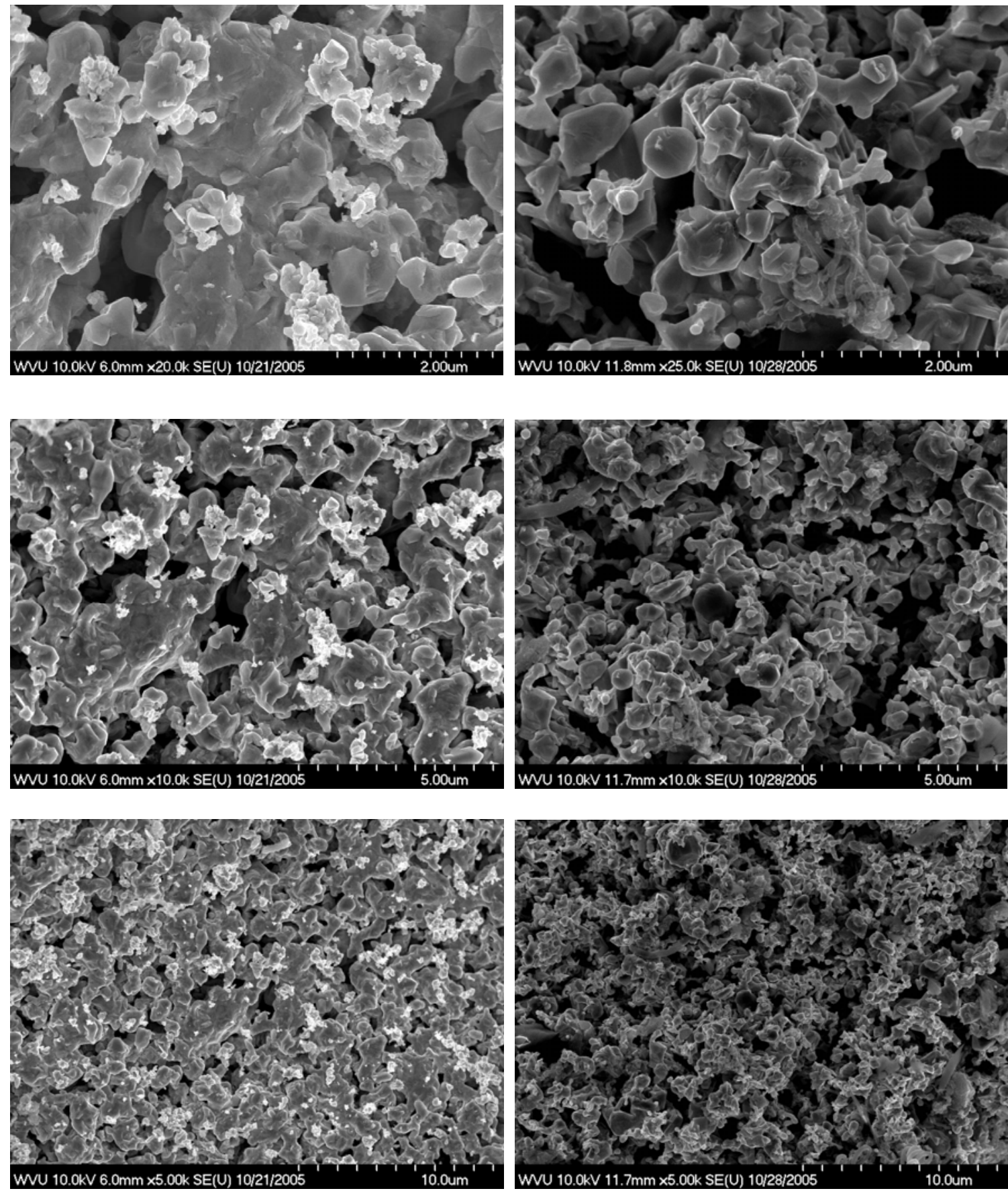

Figure 6-8 Ni-W-C $(x=0.75)$ spent catalyst at $1 \mathrm{st} 700^{\circ} \mathrm{C}$ (before exposure to $850^{\circ} \mathrm{C}$ )

Figure 6-9 Ni-W-C ( $x=0.75)$ spent catalyst at $2 \mathrm{nd} 700^{\circ} \mathrm{C}$ (after exposure to $850^{\circ} \mathrm{C}$ ) 


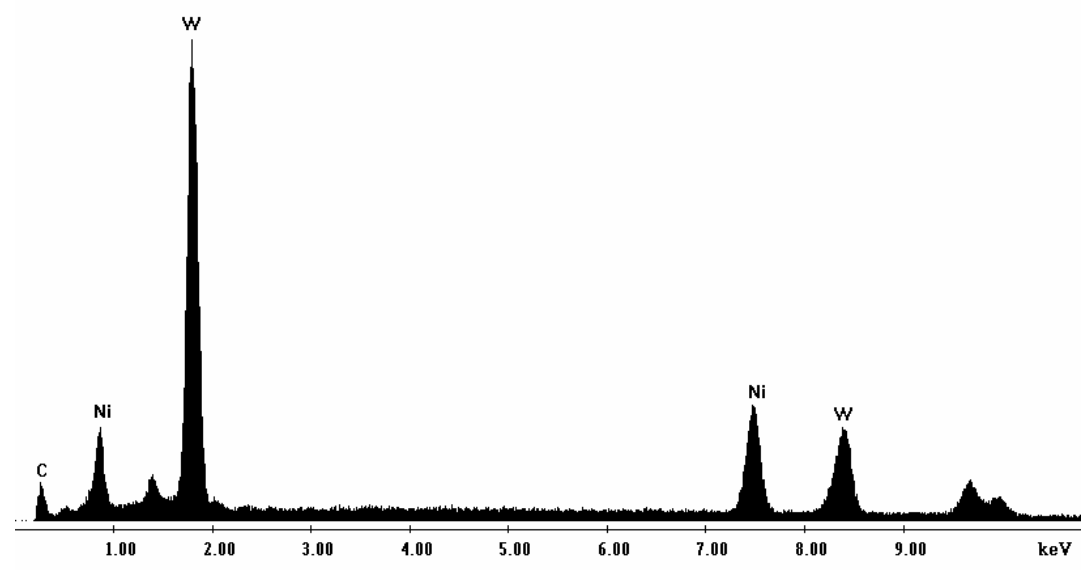

Figure 6-10 EDAX pattern of spent Ni-W-C $(x=0.75)$ at $1 \mathrm{st} 700^{\circ} \mathrm{C}$, i.e., before exposure to $850^{\circ} \mathrm{C}$

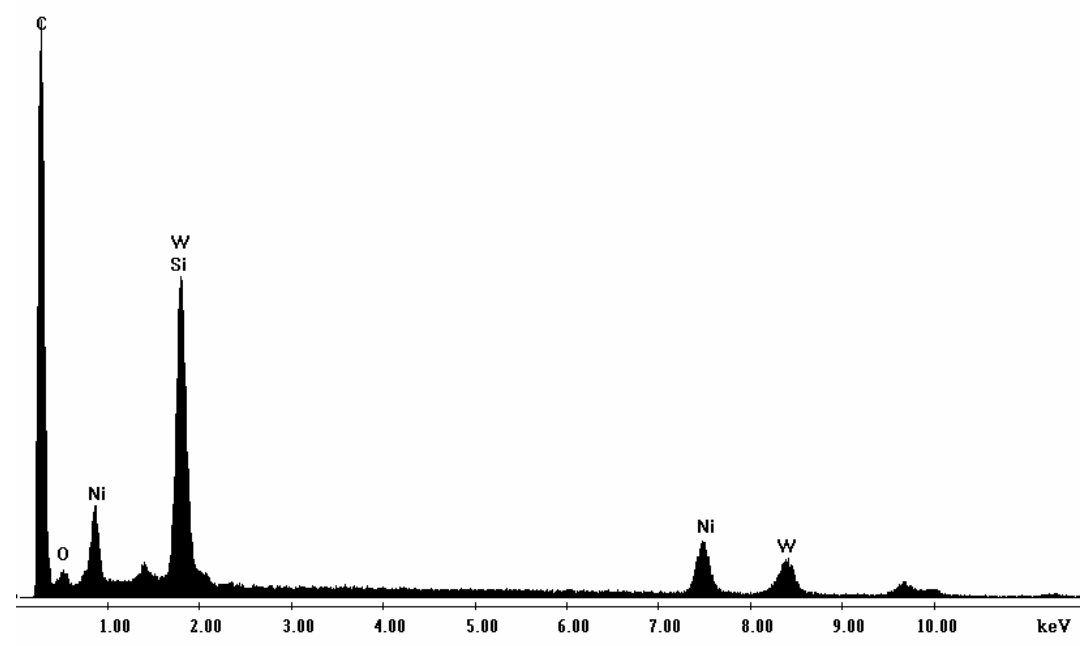

Figure 6-11 EDAX pattern of spent Ni-W-C $(x=0.75)$ at $2 \mathrm{nd} 700^{\circ} \mathrm{C}$, i.e., after exposure to $850^{\circ} \mathrm{C}$ 
Similar to Co-W-C, NEXAFS measurements have been applied to study carbon K-edge features, oxygen K-edge features and cobalt L-edge features for fresh and spent catalysts Ni-W-C $(x=0.75)$ obtained at different temperatures. The results are presented in Figures 6-12 to 6-14.

In the fresh Ni-W-C sample, carbon is present as the form of carbide carbon $\left(\mathrm{Ni}_{6} \mathrm{~W}_{6} \mathrm{C}\right.$ or WC) near the surface region, having an intense peak at $288.4 \mathrm{eV}$ (Figure 6-12). After the reaction at $700^{\circ} \mathrm{C}$, before exposure to $850^{\circ} \mathrm{C}$, this peak intensity trails off, while graphitic carbon peaks emerge. After the reaction goes to $850^{\circ} \mathrm{C}$ and returns to $700^{\circ} \mathrm{C}$, the surface is almost covered by graphitic carbon. Compared to Co-W-C, graphitic carbon is produced at a lower temperature for Ni-W-C. As shown in the early study above on the effect of exposure to high temperature, Ni-W-C at $700^{\circ} \mathrm{C}$ is just as active before exposure to $850^{\circ} \mathrm{C}$ as after exposure to $850^{\circ} \mathrm{C}$. This provides the evidence that graphitic carbon produced on the catalyst is also helpful to activate the carbide catalyst; besides that, it can stabilize the catalyst by preventing more coke formation.

In Figure 6-13 for oxygen K-edge features, the peak at $532.75 \mathrm{eV}$ decreases at $700^{\circ} \mathrm{C}$, before the catalyst has been exposed to reactants at $850^{\circ} \mathrm{C}$. Therefore the oxide, which may have negative effect on the catalytic performance, has already been reduced dramatically even at $700^{\circ} \mathrm{C}$, and vanishes after exposure to $850^{\circ} \mathrm{C}$. This is much different from the observations for Co-W-C. The broad peak near $539 \mathrm{eV}$ becomes 
sharper after the reaction, and even sharper as the reaction is taken at $850^{\circ} \mathrm{C}$. In the meanwhile, a broad peak at 566.5 becomes more visible as the reaction temperature increases to $850^{\circ} \mathrm{C}$. These two peaks probably belong to some form of oxides which do not affect the catalytic performance of the catalyst significantly.

Figure 6-14 is NEXAFS spectra of the nickel L-edge. Both this figure and the cobalt L-edge NEXAFS in Figure 5-30 have the common trend of the metal (Ni or $\mathrm{Co}$ ) peaks disappearing as the reaction temperature increases. In the fresh catalyst, a large amount of nickel is present near the surface region. After the reaction at $700^{\circ} \mathrm{C}$, a significant reduction in $\mathrm{Ni}$ is observed. As the reaction temperature goes to $850^{\circ} \mathrm{C}$ and returns to $700^{\circ} \mathrm{C}$, the surface Ni nearly completely disappears. Since no nickel is detected at this stage, it can also be inferred that those oxides still present on the spent catalysts should belong to tungsten oxides. 


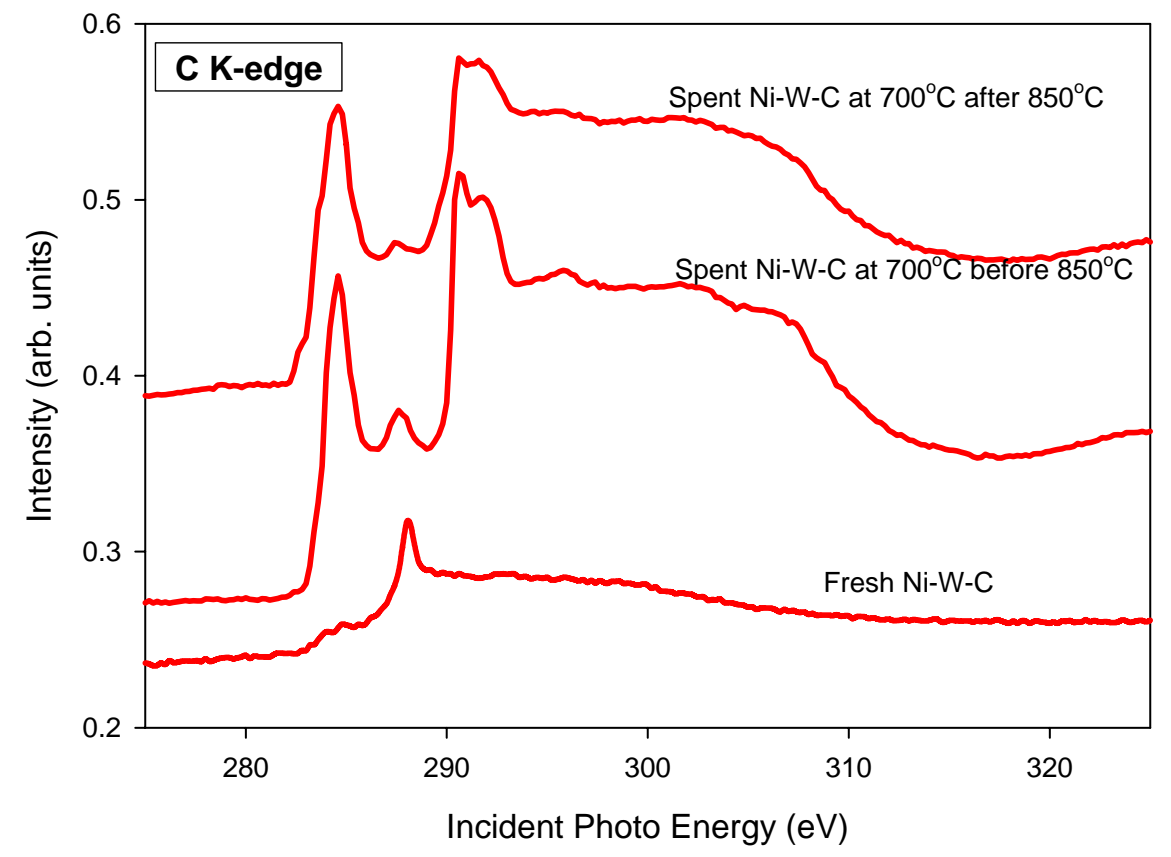

Figure 6-12 Carbon K-Edge NEXAFS for Ni-W-C $(x=0.75)$

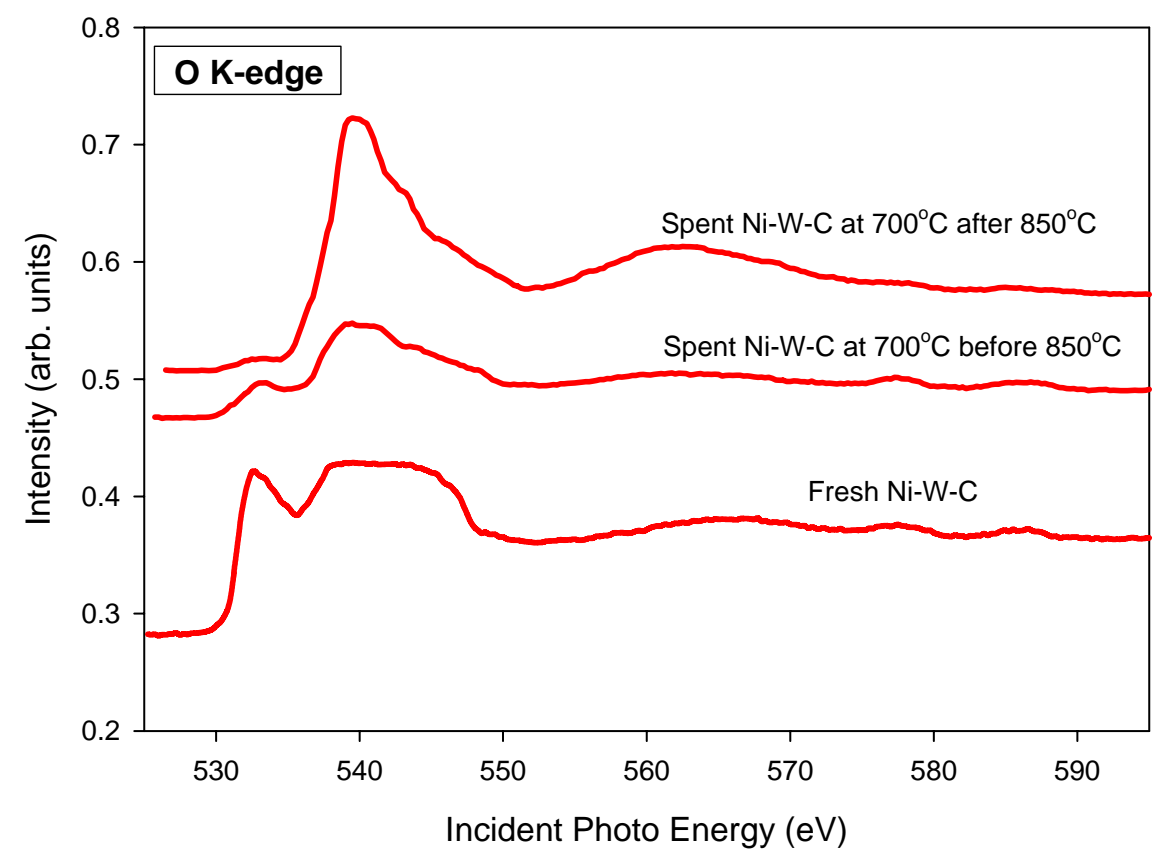

Figure 6-13 Oxygen K-Edge NEXAFS for Ni-W-C ( $x=0.75)$ 


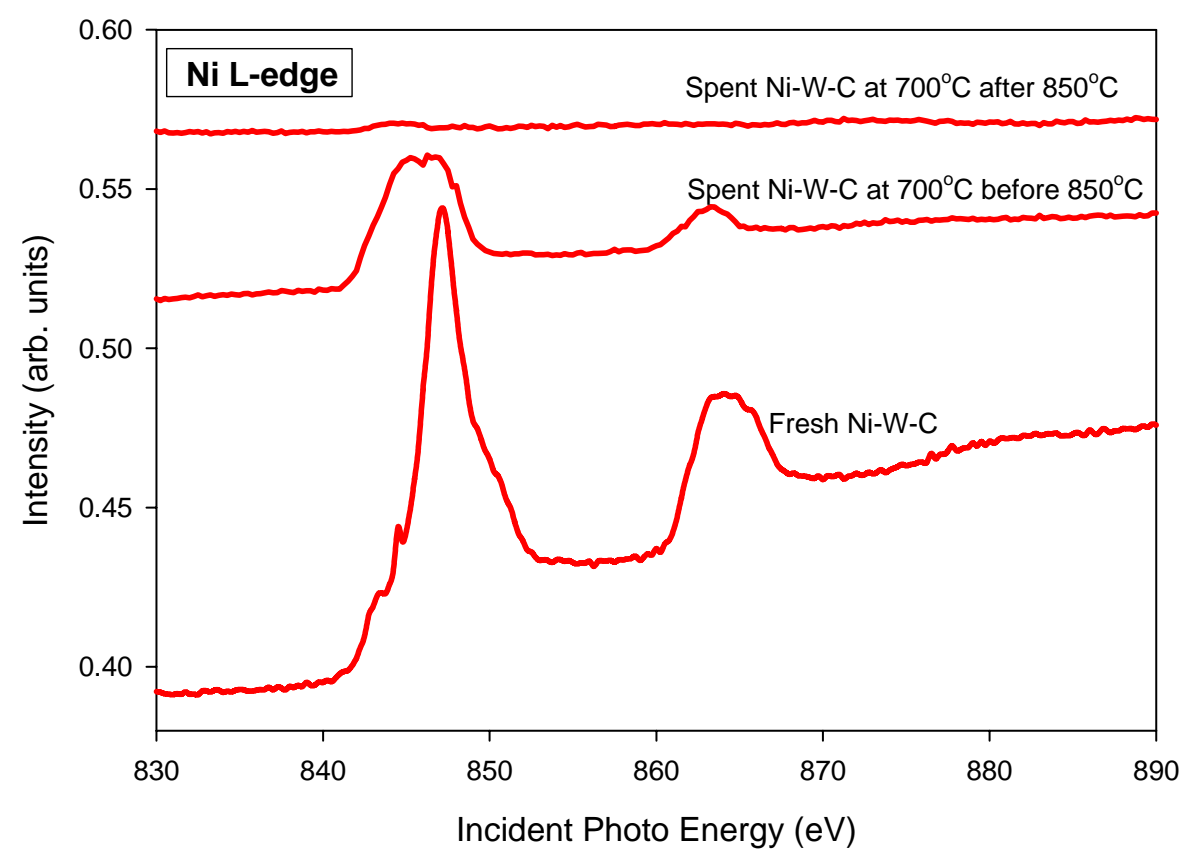

Figure 6-14 Nickel L-Edge NEXAFS for Ni-W-C $(x=0.75)$

With the help of the above characterization techniques, some convincing explanations can be made for the observations in last section, i.e. the effect of exposure to $850^{\circ} \mathrm{C}$ on the catalytic performance. In bulk phase measurement (XRD patterns), no oxides are found for Ni-W-C when it is only exposed to $700^{\circ} \mathrm{C}$. Using SEM and EDAX, there is no qualitative difference for $\mathrm{Ni}-\mathrm{W}-\mathrm{C}$ taken at $700^{\circ} \mathrm{C}$ at the two different temperature stages, before and after exposure to $850^{\circ} \mathrm{C}$, except that more carbon deposits are found on the spent Ni-W-C after exposure to $850^{\circ} \mathrm{C}$. As shown in NEXAFS spectra, even though Ni-W-C contains some oxide in the fresh stage, which is ineffective for $\mathrm{DRM}$, it can be largely reduced after reaction at $700^{\circ} \mathrm{C}$. Moreover, much graphitic carbon has already been produced at that $700^{\circ} \mathrm{C}$ stage to replace the carbidic carbon on 
the surface. Due to these two different observations in carbon and oxygen K-edge features, it can be deduced that it is necessary to reduce some ineffective oxide and produce some graphitic carbon to activate this carbide catalyst and maintain its reactivity for DRM. Besides these differences, Ni-W-C and $\mathrm{Co}-\mathrm{W}-\mathrm{C}$ share some similar NEXAFS features too. Firstly, both $\mathrm{Ni}$ and Co will disappear at the surface region after reaction. Secondly, even after the catalysts are exposed to $850^{\circ} \mathrm{C}$, some tungsten oxides can not be reduced completely.

\subsection{Summary}

With the reactivity and stability testing results, it can be summarized that this in-house Ni-W-C catalyst is active for DRM and has improved stability compared to traditional nickel-based catalyst. No significant change has been observed on catalytic reactivity before and after reaction at $850^{\circ} \mathrm{C}$. In each case, $\mathrm{Ni}+\mathrm{WC}$ are formed; this is the active phase. Ni-W-C exhibits mild reactivity at $700^{\circ} \mathrm{C}$, without being exposed to $850^{\circ} \mathrm{C}$, and does not require to be activated at high temperature as Co-W-C does. With the help of a series of characterization techniques, consistent results have been obtained. No oxides are present in the bulk phase, whether the reaction takes place at $700^{\circ} \mathrm{C}$ or $850^{\circ} \mathrm{C}$. The morphology does not have noticeable change for the materials taken at different temperature stage. Surface oxides, which have negative effect on the catalytic reactivity, have been dramatically reduced even at $700^{\circ} \mathrm{C}$. After the reaction, the surface is almost covered by graphitic carbon. 


\section{CHAPTER 7 CONCLUSIONS AND RECOMMENDATIONS FOR FUTURE WORK}

\subsection{Conclusions}

Carbides of transition metals, especially of tungsten and molybdenum, have been shown to be active for a wide range of hydroprocessing reactions [95]. Following the procedure in the patent by Polizzoti et al. [66, 67], a series of early-transition-metal carbide catalysts were successfully manufactured in this work. Different values of the $\mathrm{CO}_{2} / \mathrm{CO}$ ratio $(\equiv \mathrm{x})$ in the carburization process produce different final phases of material

for Co-W-C and Ni-W-C. Four different values of $\mathrm{x}$ were applied here: 0.1, 0.2, 0.5 and 0.75 .

After the catalysts were prepared, the fresh materials were characterized by XRD, TPR, SEM, EDAX and NEXAFS. From XRD patterns, bulk bimetallic $\mathrm{Co}_{6} \mathrm{~W}_{6} \mathrm{C}$ can be produced when $\mathrm{x}$ is above 0.5 . In contrast, the bimetallic phase can only be observed as the ratio $\mathrm{x}$ reaches 0.75 for Ni-W-C. Even so, it is a mixture of two carbides, WC and $\mathrm{Ni}_{6} \mathrm{~W}_{6} \mathrm{C}$. There are no oxides detected in the bulk phase of either Co-W-C or Ni-W-C. However, reduction peaks observed in TPR spectra for those carbides indicate the presence of oxides therein, which are probably left over from the preparation procedure and exist on the surface of the catalyst. With the help of SEM, a uniform structure is seen for $\mathrm{Co}-\mathrm{W}-\mathrm{C}(\mathrm{x}=0.75)$. But Ni-W-C does not have as uniform a morphology as Co-W-C made with the same value of $\mathrm{x}(0.75)$. In EDAX patterns for these carbides, 
some traces of oxygen are observed, providing further evidence for the presence of oxides in the surface of the fresh carbide materials.

The catalytic properties of $\mathrm{Co}-\mathrm{W}-\mathrm{C}$ were first investigated for methane dry reforming. Four such materials carburized with different ratios of $\mathrm{CO}_{2} / \mathrm{CO}$ were tested for reactivity and stability for over 100 hours. Satisfactory results were obtained with high reactivity and good stability as well as low coke formation. In further studies, it was shown that Co-W-C can be effective for DRM only after exposure to high temperature $\left(850^{\circ} \mathrm{C}\right)$. This allows the formation of active $\mathrm{Co}+\mathrm{WC}$ phases and removal of surface oxides from the catalysts. Using XRD measurements, the catalysts after reaction at $850^{\circ} \mathrm{C}$ are found to transform into $\mathrm{Co}+\mathrm{WC}+\mathrm{C}$, while bimetallic oxides $\mathrm{CoWO}_{4}$ are detected in the spent catalysts if exposure is only to $700^{\circ} \mathrm{C}$. These observations are applicable for the carbides carburized with all four ratios of $\mathrm{CO}_{2} / \mathrm{CO}$, and no qualitative difference is noticed among them. More evidence is provided by surface characterization via SEM, EDAX and NEXAFS. The presence of oxides before exposure to $850^{\circ} \mathrm{C}$ decreases the catalytic performance of Co-W-C for DRM, while this very low reactivity can be much improved after exposure. As the catalysts are exposed to the reactants at $850^{\circ} \mathrm{C}$, the bulk oxides are replaced by carbides, and the surface is covered by graphite. Once the stable and active solid phase is formed, it will remain even though the temperature is brought back to a lower level.

The catalytic performance of $\mathrm{Ni}-\mathrm{W}-\mathrm{C}$ was studied with the same method used for 
Co-W-C. For DRM, Ni-W-C has reactivity and stability comparable to Co-W-C, and has much higher resistance to coke formation than traditional nickel based catalyst. In the reaction test, it takes less induction time for $\mathrm{Ni}-\mathrm{W}-\mathrm{C}$ carbide to reach steady state, compared to $\mathrm{Co}-\mathrm{W}-\mathrm{C}$. Unlike $\mathrm{Co}-\mathrm{W}-\mathrm{C}$, no obvious difference is noticed regarding catalytic properties before and after exposure to $850^{\circ} \mathrm{C}$. Through bulk and surface characterization, this is explained by the fact that the fresh and spent $\mathrm{Ni}-\mathrm{W}-\mathrm{C}$ catalysts contain $\mathrm{Ni}+\mathrm{WC}$ phases, regardless of exposure to $850^{\circ} \mathrm{C}$. No oxides are present in the bulk phase of $\mathrm{Ni}-\mathrm{W}-\mathrm{C}$ even at $700^{\circ} \mathrm{C}$ before exposure to $850^{\circ} \mathrm{C}$. In addition, graphite starts to cover the surface at low temperature too, and the carbidic carbon is totally replaced by graphite at $850^{\circ} \mathrm{C}$.

Even though the in-house novel bimetallic carbides have been successfully applied in DRM, no satisfactory results were obtained for steam reforming, either SRM or $\mathrm{SRMeOH}$, at least under the reaction conditions in this study. Mechanistically, compared to DRM, the reaction rate of SRM is extremely slow over the carbides even at $850^{\circ} \mathrm{C}$. Even though $\mathrm{SRMeOH}$ has a much higher reaction rate than DRM, methanol decomposition (instead of $\mathrm{SRMeOH}$ ) really proceeds at high reaction temperature, which may be the proper operating range for the carbide to be effective. Catalytically, the reactivity is probably affected by co-feeding reactants. For DRM, $\mathrm{CO}_{2}$ is co-fed to reform $\mathrm{CH}_{4}$, while $\mathrm{H}_{2} \mathrm{O}$ is co-fed for steam reforming. Water probably prevents the lay-down of carbon. Without enough carbon lay-down, the active phase Co + WC does 
not form, and the material may not be active for the reforming processes. Therefore, the reason for the difference of catalytic performance of the carbide catalyst for dry reforming and steam reforming may be tied to the nature of co-feeds. The carbide might lose its catalytic reforming reactivity in the presence of $\mathrm{H}_{2} \mathrm{O}$. The detailed mechanism is still to be investigated in the future.

\subsection{Recommendations for future work}

\subsubsection{Further characterization of bimetallic carbide catalyst}

In this work, the in-house bimetallic carbide catalysts have already been characterized systematically, covering BET, XRD, TPR, SEM, EDAX and NEXAFS. These results provide useful and important information of both bulk and surface properties, and thereby help to explain those observations in the catalyst testing and evaluation. However, to understand deeply how the elements are organized inside and on the surface of the catalyst, more characterization work needs to be done in the future. Two features are expected to be described clearly. First is how the two different metallic atoms combine with each other in the bimetallic system. Secondly, the incorporation of carbon in the metal lattice is another significant interest to be investigated, which may alter physical and chemical properties from the parent metals [44]. 


\subsubsection{Investigation of the poisoning effect of water}

Strong evidence has been provided that this bimetallic carbide catalyst is stable, active and selective for DRM, while ineffective for steam reforming, whether SRM or SRMeOH. Thomson et al. [65] viewed $\mathrm{CO}_{2}$ and $\mathrm{H}_{2} \mathrm{O}$ as the oxidation source for $\mathrm{Mo}_{2} \mathrm{C}$ under fuel reforming conditions, and demonstrated that co-feeding reducing gas $\left(\mathrm{H}_{2}\right.$ or $\mathrm{CO}$ ) will solve the problem. For this in-house bimetallic carbide catalyst, very low reactivity is observed in steam reforming even with co-feeding reducing gases. Therefore, it is worthwhile to probe the mechanism of how the presence of water decreases the catalytic properties of this carbide catalyst. Afterwards, some modification may be made to improve these carbide catalysts to make them successfully applied in steam reforming too.

\subsubsection{Application of bimetallic carbide for other hydroprocessing}

Since 1960s, it has been known that early transition metal carbides have similar catalytic properties to noble metals for a wide range of reactions [62], particularly of hydrotreating reactions [96], such as ammonia synthesis and decomposition, Fisher-Tropsch synthesis [4], reforming of hydrocarbon reforming, and oxidation of liquid hydrocarbon [94]. In future work, this in-house bimetallic carbide could be tested for hydrocarbon or alcohol production. Fisher-Tropsch is going to be the main objective. To make the carbide catalyst active for Fisher-Tropsch reaction, iron is 
probably required to be added to replace cobalt or nickel. 


\section{REFRENCES}

1. H-S. Roh, K-W. Jun, S-C. Beak, and S-E Park, "Carbon Dioxide Reforming of Methane over $\mathrm{Ni} / \mathrm{\theta}-\mathrm{Al}_{2} \mathrm{O}_{3}$ Catalysts: Effect of Ni Content”, Bull. Korean Chem. Soc. 23(8): 1166-1168, 2002

2. J. R. H. Ross, A. N. J. van Keulen, M. E. S. Hegarty, K. Seshan, "The Catalytic Conversion of Natural Gas to Useful Products”, Catalysis Today, 30: 193-199, 1996

3. S. B. Wang and G. Q. Lu, "Carbon Dioxide Reforming of Methane to Produce Synthesis Gas over Metal-Supported Catalysts: State of the Art ”, Energy \& Fuels, 10: 896-904, 1996

4. C. Liang, W. Ma, Z. Feng, C. Li, "Activated Carbon Supported Bimetallic CoMo Carbides Synthesized by Carbothermal Hydrogen Reduction", Carbon, 41: $1833-1839,2003$

5. J. B. Claridge, A. P. E. York, A. J. Brungs, C. Marquez-Alvarez, J. Sloan, S. C. Tsang and M. L. H. Green, "New Catalysts for the Conversion of Methane to Synthesis Gas: Molybdenum and Tungsten Carbide”, Journal of Catalysis, 180: 85-100, 1998

6. S. Wang and G. Q. Lu, "Effects of Promoters on Catalytic Activity and Carbon Deposition of $\mathrm{Ni} / \gamma-\mathrm{Al}_{2} \mathrm{O}_{3}$ Catalysts in $\mathrm{CO}_{2}$ Reforming of $\mathrm{CH}_{4}$ ", Journal of Chemical Technology and Biotechnology, 75: 589-595, 2000

7. Z. Cheng, Q. Wu, J. Li, Q. Zhu, "Effects of Promoters and Preparation Procedures on Reforming of Methane with Carbon Dioxide over $\mathrm{Ni} / \mathrm{Al}_{2} \mathrm{O}_{3}$ Catalyst", Catalysis Today, 30: 147-155, 1996 
8. G. J. Kim, D-S. Cho, "The Reaction of $\mathrm{CO}_{2}$ with $\mathrm{CH}_{4}$ to Synthesize $\mathrm{H}_{2}$ and $\mathrm{CO}$ over Nickel-loaded Y-zeolites”, Catalysis Letters, 28: 41-52, 1994

9. Y-G. Chen, K.Tomishige, K. Yokoyama, and K. Fujimoto, "Catalytic Performance and Catalyst Structure of Nickel-Magnesia Catalysts for $\mathrm{CO} 2$ Reforming of Methane", Journal of Catalysis, 184: 479-490, 1999

10. A. N. J. van Keulen, K. Seshan, J. H. B. J. Hoebink, and J. R. H. Ross, "TAP Investigation of the $\mathrm{CO}_{2}$ Reforming of $\mathrm{CH}_{4}$ over $\mathrm{Pt} / \mathrm{ZrO}_{2}$ ", Journal of Catalysis, 166: $306-314,1997$

11. K. Seshan, H. W. ten Barge, W. Hally, A. N. J. van Keulen and J. R. H. Ross, "Carbon Dioxide Reforming of Methane in the Presence of Nickel and Platinum Catalysts Supported on ZrO2”, Natural Gas Conversion II: 285-290, 1994

12. Z. L. Zhang, V. A. Tsipouriari, A. M. Efstanthion, and X. E. Verykios, "Reforming of Methane with Carbon Dioxide to Synthesis Gas over Supported Rhodium Catalysts I: Effects of Support and Metal Crystallite Size on Reaction Activity and Deactivation Characteristics", Journal of Catalysis, 158: 51-63 (1996)

13. M. C. J. Bradford and M. A. Vannice, " $\mathrm{CO}_{2}$ Reforming of $\mathrm{CH}_{4}$ ", Catal. Rev.-Sci. Eng., 41(1): 1-42 (1999)

14. Z. Hou, O. Yokuta, T. Tanaka, and T. Yashima, "Investigation of $\mathrm{CH}_{4}$ Reforming with $\mathrm{CO}_{2}$ on Meso-Porous $\mathrm{Al}_{2} \mathrm{O}_{3}$-Supported Ni Catalysts", Catalysis Letters, 89(1-2): $121-127,2003$

15. M. C. J. Bradford, and M. A, Vannice, " $\mathrm{CO}_{2}$ Reforming of $\mathrm{CH}_{4}$ over Supported Pt 
Catalysts", Journal of Catalysis, 173: 157-171, 1998

16. C. Song, "Tri-Reforming: A New Process for Reducing $\mathrm{CO}_{2}$ Emissions", Chemical Innovation, 31(1): 21-26, January, 2001

17. B. L. Gustafson, J. V. Walden, "Conversion of Carbon Dioxide to Carbon Monoxide”, US Patent 5,068,057, November 26, 1991

18. K. S. Suslick, T. Hyeon, M. Fang, "Nanostructures Materials Generated by High Intensity Ultrasound Sonochemical Synthesis and Catalytic Studies”, Chem. Mater. 8: 2172-2179, 1996

19. W-S. Dong, H-S. Roh, Z-W. Liu, K-W. Jun, and S-E. Park, "Hydrogen Production from Methane Reforming Reactions over Ni/MgO Catalyst”, Bull. Korean Chem. Soc. 22(12): 1323-1327, 2001

20. H. Purnama, PhD thesis, Friz-Haber-Institut of Max-Planck-Society (MPG), 2003

21. P. H. Matter, D. J. Braden, and U. S. Ozkan, "Steam Reforming of Methanol to $\mathrm{H}_{2}$ over Nonreduced Zr-containing $\mathrm{CuO} / \mathrm{ZnO}$ Catalysts”, Journal of Catalysts, 223: $340-351,2004$

22. R. D. Cortright, R. R. Davda \& J. A. Dumesic, "Hydrogen from Catalytic Reforming of Biomass-derived Hydrocarbons in Liquid Water”, Nature, 418:964-967, Aug. 2002

23. J. W. Shabaker, R. R. Davda, G. W. Huber, R. D. Cortright, and J. A. Dumesic, "Aqueous-phase Reforming of Methanol and Ethylene Glycol over Alumina-supported Platinum Catalyst”, Journal of Catalysis, 214: 344-352, 2003

24. J. A Lercher, J. H. Bitter, W. Hally, W. Niessen, and K. Seshan, "Design of Stable 
Catalysts for Methane-Carbon Dioxide Reforming”, Studies in Surface Science and Catalysis, 101: 463-472, 1996

25. Z. Hou, O. Yokota, T. Tanaka, and T. Yashima, “A Novel $\mathrm{KCaNi} / \alpha-\mathrm{Al}_{2} \mathrm{O}_{3}$ Catalyst for $\mathrm{CH}_{4}$ Reforming with $\mathrm{CO}_{2}$ ", Catalysis Letters, 87(1-2), April, 2003

26. T. Osaki, T. Mori, "Role of Potassium in Carbon-Free $\mathrm{CO}_{2}$ Reforming of Methane on K-Promoted Ni/ $\mathrm{Al}_{2} \mathrm{O}_{3}$ Catalysts”, Journal of Catalysis, 204: 89-97, 2001

27. J. H. Bitter, K. Seshan, J. A. Lercher, "Deactivation and Coke Accumulation during $\mathrm{CO}_{2} / \mathrm{CH}_{4}$ Reforming over Pt Catalysts", Journal of Catalysis. 183:336-343, 1999

28. J. R. Rostrup-Nielsen, "Sulfur-Passivated Nickel Catalysts for Carbon-Free Steam Reforming", Journal of Catalysis, 85: 31-43, 1984

29. J. R. Rostrup-Nielsen and J-H. B. Hansen, " $\mathrm{CO}_{2}-$ Reforming of Methane over Transition Metals", Journal of Catalysis, 144: 38-49, 1993

30. B. Piccioni, “The Hydrogen Economy”, Technology Research, April, 1-38, 2004

31. J. P. Breen, R. H. Ross, "Methanol Reforming for Fuel-cell Applications: Development of Zirconia-containing Cu-Zn-Al Catalysts”, Catalysis Today, 51(3-4): $521-533,1999$

32. A. LÖfberg, A. Frennet, G. Leclercq, L. Leclercq, and J. M. Giraudon, "Mechanism of $\mathrm{WO}_{3}$ Reduction and Carburizaton in $\mathrm{CH}_{4} / \mathrm{H}_{2}$ Mixtures Leading to Bulk Tungsten Carbide Powder Catalysts”, Journal of Catalysis, 189: 170-183, 2000

33. A. Babilius, "Influence of Temperature on the Phases Changes of HVOF Sprayed Tungsten Carbide Coatings”, Materials Science, 9(3): 183-186, 2003 
34. J. S. Lee, S. T. Oyama and M. Boudart, "Molybdenum Carbide Catalysts I. Synthesis of Unsupported Powders", Journal of Catalysis, 106: 125-133, 1987

35. M. C. J. Bradford, M. A. Vannice, "Catalytic Reforming of Methane with Carbon Dioxide over Nickel Catalysts I. Catalyst Characterization and Activity”, Applied Catalysis A: General 142: 73-96, 1996

36. A. N. Fatsikostas, D. I. Kondarides, X. E. Verykios, "Steam Reforming of Biomass-Derived Ethanol for the Production of Hydrogen for Fuel Cell Application”, Chem. Communication, 851-852, 2001

37. F. Aupretre, C. Descorme, D. Duprez, "Hydrogen Production for Fuel Cells from the Catalytic Ethanol Steam Reforming”, Topics in Catalysis, 30/31: 487-491, July, 2004

38. G. A. Deluga, J. R. Salge, L. D. Schmidt, X. E. Verykios, "Renewable Hyrogen from Ethanol by Autothermal Reforming”, Science, 303: 993-997, February, 2004

39. C. Liu, R. Mallinson, L. Lobban, "Nonoxidative Methane Conversion to Acetylene over Zeolite in a Low Temperature Plasma”, Journal of Catalysis, 179: 326-334, 1998

40. J. K. Rajesh, S. K. Gupta, G. P. Rangaiah, Ajay K. Ray, "Multiobjective Optimization of Steam Reformer Performance Using Genetic Algorithm”, Ind. Eng. Chem. Res., 39: 706-717, 2000

41. P. D. F. Vernon, M. L. H. Green, A. K. Cheetham, A. T. Ashcroft, "Partial Oxidation of Methane to Synthesis Gas, and Carbon Dioxide as an Oxidizing Agent for Methane Conversion”, Catalysis Today, 13: 417-426, 1992

42. Q. Zhu, J. Yang, J. Wang, S. Ji, H. Wang, "Investigation on the Performance of 
Supported Molybdenum Carbide for the Partial Oxidation of Methane", Journal of Natural Gas Chemistry, 12: 23-30, 2003

43. J. W. Snoeck, G. F. Froment, M. Fowels, "Steam $/ \mathrm{CO}_{2}$ Reforming of Methane. Carbon Filament Formation by the Boudouard Reaction and Gasification by $\mathrm{CO}_{2}$, by $\mathrm{H}_{2}$, and by Steam: Kinetic Study”, Ind. Eng. Chem. Res., 41: 4252-4265, 2002

44. A. P. E. York, J. B. Claridge, A. J. Brungs, S. C. Tsang, M. L. H. Green, "Molybdenum and Tungsten Carbides as Catalysts for the Conversion of Methane to Synthesis Gas Using Stoichiometric Feedstocks”, Chem. Commun., 39-40, 1997

45. M. Prigent, "On Board Hydrogen Generation for Fuel Cell Powered Electric Cars: A Review of Various Available Techniques”, Revue De L'Institut Français Du Pėtrole, 52: 351-360, 1997

46. A. Masralir, B. Frank, A. Szizybalski, H. Soerijanto, A. Deshpande, M. Niederberger, R. Schomäcker, R. Schlögl, T. Ressler, "Steam Reforming of Methanol over $\mathrm{Cu} / \mathrm{ZrO}_{2} / \mathrm{CeO}_{2}$ Catalysts: a Kinetic Study", Journal of Catalysis, 230: 464-475, 2005

47. A. V. Makumin, M. S. Granovskii, E. B. Ivanov, V. M. Fomin, "Thermochemical Module for Hydrogen Production by Steam Reforming of Methanol”, Chemical and Petroleum Engineering, 39(11-12): 704-710

48. J. H. Bitter, K. Seshan, J. A. Lercher, "The State of Zirconia Supported Platinum Catalysts for $\mathrm{CO}_{2} / \mathrm{CH}_{4}$ Reforming”, Journal of Catalysis, 171: 279-286, 1997

49. J. H. Bitter, W. Hally, K. Seshan, J. G. van Ommen, J. A. Lercher, "The Role of Oxidic Support on the Deactivation of Pt Catalysts During the $\mathrm{CO}_{2}$ Reforming of 
Methane", Catalysis Today, 29: 349-353, 1996

50. A. T. Ashcroft, A. K. Cheetham, J. S. Foord, M. L. H. Green, C. P. Grey, A. J. Murrell , P. D. F. Vernon, "Selective oxidation of methane to synthesis gas using transition metal catalysts", Nature, 344: 319-321, 1990

51. M. C. J. Bradford, M. A. Vannice, "Metal-Support Interactions During the $\mathrm{CO}_{2}$ Reforming of $\mathrm{CH}_{4}$ over Model $\mathrm{TiO}_{\mathrm{x}} / \mathrm{Pt}$ Catalysts", Catalysis Letters, 48: 31-38, 1997

52. S. Wang, H. Y. Zhu, G. Q. Lu, "Preparation, Characterization, and Catalytic Properties of Clay-Based Nickel Catalysts for Methane Reforming”, Journal of Colloid and Interface Science, 204: 128-134, 1998

53. V. C. H. Kroll, H. M. Swaan, C. Mirodatos, "Methane Reforming Reaction with Carbon Dioxide over Ni/SiO 2 Catalyst”, Journal of Catalysis, 161: 409-422, 1996

54. S. Wang, G. Q. M. Lu, " $\mathrm{CO}_{2}$ Reforming of Methane on Ni Catalysts: Effects of the Support Phase and Preparation Technique", Applied Catalysis B: Environmental, 16: 269-277, 1998

55. A. T. Ashcroft, A. K. Cheetham, M. L. H. Green, P. D. F. Vernon, "Partial Oxidation of Methane to Synthesis Gas Using Carbon Dioxide”, Nature, 352: 225-226, 1991

56. Y. Li, X. Dong, W. Lin, "Methanol Steam Reforming Catalysts for Fuel Cell Driven Electric Vehicles”, Journal of Natural Gas Chemistry, 12: 71-73, 2003

57. N. Takezawa, N. Iwasa, "Steam Reforming and Dehydrogenation of Methanol: Difference in the Catalytic Functions of Copper and Group VIII Metals”. Catalysis Today, 36(1): 45-56, April, 1997 
58. Y. H. Chin, R. Dagle, J. L. Hu, A. C. Dohnalkova, Y. Wamg, "Steam Reforming of Methanol over Highly Active Pd/ZnO Catalyst”, Catalysis Today, 77(1-2): 79-88

59. H. Oguchi, T. Nishiguchi, T. Matsumoto, H. Kanai, K. Utani, Y. Matsumura, S. Imamura, "Steam Reforming of Methanol over $\mathrm{Cu} / \mathrm{CeO}_{2} / \mathrm{ZrO}_{2}$ Catalysts", Applied Catalysis A: General, 281: 69-73, 2005

60. E. S. Ranganathan, S. K. Bej, L. T. Thompson, "Methanol Steam Reforming over $\mathrm{Pd} / \mathrm{ZnO}$ and $\mathrm{Pd} / \mathrm{CeO}_{2}$ Catalysts”, Applied Catalysis A: General, 289: 153-162, 2005

61. W. Settapun, T. E. King, S. K. Bej, L. T. Thompson, "Molybdenum Carbides Supported Nickel Catalysts for Methanol Steam Reforming and Water Gas Shift”, http://icc2004.catalyse.cnrs.fr/CDROM/P4-181.pdf, 2004

62. R. B. Levy, M. Boudart, "Platinum-like Behavior of Tungsten Carbide in Surface Catalysis", Science, 181: 547-549, 1973

63. A. Fernández Guillermet , J. Häglund, G. Grimvall , "Cohesive properties of 4d-transition-metal carbides and nitrides in the NaCl-type structure", Physical Review B, 45: 11557-11567, 1992

64. M. E. Eberhart, J. M. Maclaren, in "The Chemistry of the Transition Metal Carbides and Nitrides", (S. T. Oyama Edit) pp107, Blackle, Glasgow, 1992

65. A. R. Darujati, D. C. LaMont, W. J. Thomson, “'Oxidation Stability of $\mathrm{Mo}_{2} \mathrm{C}$ Catalysts under Fuel Reforming Conditions”, Applied Catalysis A, 253: 397-407, 2003

66. E. L, Kugler, L. E. McCandlish, A. J. Jacobson, R. R. Chianelli, “Eta Phase Materials, 
Methods of Producing the Same, and Use Thereof as Catalysts for Alcohol Synthesis, Hydrocarbon Synthesis, Hydrocarbon Hydrogenation and Hydrocarbon conversion Reactions", US Patent 5,138,111, Aug 11, 1992

67. R. S. Polizzotti, L. E. McCandlish, E. L, Kugler, "Multiphase Composite Particle Containing a Distribution of Nonmetallic Compound Particles", US Patent 5,338,330, Aug 16, 1994

68. S. M. Stagg, E. Romeo, C. Padro, D. E. Resasco, "Effect of Promotion with Sn on Supported Pt Catalysts for $\mathrm{CO}_{2}$ Reforming of $\mathrm{CH}_{4}$ ", Journal of Catalysis, 178: $137-145,1998$

69. L. M. Aparcio, "Transient Isotopic Studies and Microkinetic Modeling of Methane Reforming over Nickel Catalysts”, Journal of Catalysis, 165: 262-274, 1997

70. P. Ferreira-Aparicio, C. Marquez-Alvarez, I. Rodriguez-Ramos, Y. Schuurman, A. Guerrero-Ruiz, C. Mirodatos, "A Transient Kinetic Study of the Carbon Dioxide Reforming of Methane over Supported Ru Catalysts”, Journal of Catalysis, 184: 202-212, 1999

71. V. Y. Bychkov, Y. P. Tyulenin, V. N. Korchak, "The Mechanism of Methane Reforming with Carbon Dioxide: Comparision of Supported Pt and $\mathrm{Ni}$ (Co) Catalysts”, Kinetics and Catalysis, 44(3): 384-390, 2003

72. U. Olsbye, T. Wurzel, L. Mlecako, "Kinetic and Reaction Engineering Studies of Dry Reforming of Methane over a Ni/La/ $\mathrm{Al}_{2} \mathrm{O}_{3}$ Catalysts", Ind. Eng. Chem. Res, 36: $5180-5188,1997$ 
73. M. C. J. Bradford, M. A. Vannice, "Catalytic Reforming of Methane with Carbon Dioxide over Nickel Catalysts II. Reaction Kinetics”, Applied Catalysis A: General 142: 97-122, 1996

74. S. M. Stagg-Williams, F. B. Noronha, G. Fedley, and D. E. Resasco, “ $\mathrm{CO}_{2}$ Reforming if $\mathrm{CH}_{4}$ over $\mathrm{Pt} / \mathrm{ZrO}_{2}$ Catalysts Promoted with $\mathrm{La}$ and Ce Oxides", Journal of Catalysis, 194: 240-249, 2000

75. J. H. Bitter, K. Seshan, J. A. Lercher, "Mono and Bifunctional Pathways of $\mathrm{CO}_{2} / \mathrm{CH}_{4}$ Reforming over Pt and Rh Based Catalysts", Journal of Catalysis. 176: 93-101, 1998

76. M. V. Iyer, MS Thesis, West Virginia University, 2001

77. M. C. J. Bradford, PhD thesis, Pennsylvania State University, 1997

78. I. M. Bodrov, and L. O. Apel'baum, Kinetics and Catalysis, 8: 326, 1967

79. M. B. Lee, Q. Y. Yang, S. L. Tang, S. T. Ceyer, "Activated Dissociative Chemisorption of CH4 on Ni (111): Observation of a Methyl Radical and Implication for the Pressure Gap in Catalysis”, J. Chem. Phys. 85(3): 1693-1694, 1, Aug, 1986

80. M. B. Lee, Q. Y. Yang, S. T. Ceyer, "Dynamics of the Activated Dissociative Chemisorption of $\mathrm{CH}_{4}$ and Implication for the Pressure Gap in Catalysis: A Molecular Beam-High Resolution Electron Energy Loss Study”, J. Chem. Phys. 87(5): 2724-2741, 1, Sep, 1987

81. B. A. Peppley, J. C. Amphlett, L. M. Kearns, R. F. Mann, "Methanol-steam Reforming on $\mathrm{Cu} / \mathrm{ZnO} / \mathrm{Al}_{2} \mathrm{O}_{3}$. Part 1: the Reaction Network", Applied Catalysis A,: General, 179(1-2): 21-29, 1999 
82. B. A. Peppley, J. C. Amphlett, L. M. Kearns, R. F. Mann, "Methanol-steam Reforming on $\mathrm{Cu} / \mathrm{ZnO} / \mathrm{Al}_{2} \mathrm{O}_{3}$. Part 2: A Comprehensive Kinetic Model”, Applied Catalysis A,: General, 179(1-2): 31-49, 1999

83. C. J. Jiang, D. L. Trimm, M. S. Wainwright, N. W. Cant, "Kinetic Study of Steam Reforming of Methanol over copper-based catalysts", Applied Catalysis A, 93(2): 245-255, 1993

84. C. J. Jiang, D. L. Trimm, M. S. Wainwright, N. W. Cant, "Kinetic mechanism for the reaction between methanol and water over a $\mathrm{Cu}-\mathrm{ZnO}-\mathrm{Al}_{2} \mathrm{O}_{3}$ catalyst", Applied Catalysis A, 97(2): 145-158, 1993

85. J. W. Niemantsverdriet, Spectroscopy in Catalysis: An Introduction, VCH Verlagsgesellschaft, Weinheim, 1993

86. M. G. White, Heterogeneous Catalysis, Princeton Hall, Englewood Cliffs, 1990

87. B. S. Liu, C. T. Au, "Sol-gel-Generated $\mathrm{La}_{2} \mathrm{NiO}_{4}$ for $\mathrm{CH}_{4} / \mathrm{CO}_{2}$ Reforming", Catalysis Letters, 85(3-4): 165-170, February, 2003

88. J. G. Chen, "NEXAFS Investigation of Transition Metal Oxides, Nitrides, Carbides, Sulfides and other Interstitial Compounds", Surface Science Reports, 30: 1-152, 1997

89. F. H. Ribeiro, R. A. D. Betta, G. J. Guskey, M. Boudart, "Preparation and Surface Composition of Tungsten Carbide Powders with High Specific Surface Area”, Chem. Mater. 3: 805-812, 1991

90. J. G. Chen, "Carbide and Nitride Overlayers on Early Transition Metal Surfaces: Preparation, Characterization, and Reactivities”, Chem. Rev. 96: 1477-1498, 1996 
91. O. Ostrovski, G. Zhang, "Reduction and Carburization of Metal Oxides by Methane-Containing Gas", AICHE Journal, 52(1): 300-310, 2006

92. M. V. Iyer, L. P. Norcio, E. L. Kugler, D. B. Dadyburjor, "Kinetic Modeling for Methane Reforming with Carbon Dioxide over a Mixed-Metal Carbide Catalyst", Industrial \& Engineering Chemistry Research, 42(12): 2712-2721, 2003

93. D. C. LaMont, W. J. Thomson, "Dry Reforming Kinetics over a Bulk Molybdenum Carbide Catalyst”, Chemical Engineering Science, 60: 3553-3559, 2005

94. D. C. LaMont, A. J. Gilligan, A. R. Darujati, A. S. Chellappa, W. J. Thomson, "The Effect of $\mathrm{Mo}_{2} \mathrm{C}$ Synthesis and Pretreatment on Catalytic Stability in Oxidative Reforming Environments”, Applied Catalysis A, 225: 239-253, 2003

95. S. Ramanathan, S. T. Oyama, "New Catalysts for Hydroprocessing: Transition Metal Carbides and Nitrides”, J. Phys. Chem. 99: 16365-16372, 1995

96. J. B. Claridge, A. P. E. York, A. J. Brungs, M. L. H. Green, "Study of the Temperature-Programmed Reaction Synthesis of Early Transition Metal Carbide and Nitride Catalyst Materials from Oxide Precursors”, Chem. Mater., 12: 132-142, 2000 


\section{APPENDIX}

\section{A. Calibration of MFC and GC}

Before running the experiment, the mass flow controller (MFC) and the GC are both required to be calibrated.

For MFC calibration, the actual flow rate corresponding to each setting point for its respective feeding line is first measured manually by bubble flow meter. As the gas passes through MFC before flowing into the reactor, the real velocity is measured (MSD value) at a set velocity (SET value). The relationship between the standard velocity (STP value) and the measured velocity can be established by the ideal gas law:

$$
\frac{\boldsymbol{P}_{S T P} V_{S T P}}{T_{S T P}}=\frac{\boldsymbol{P}_{M S D} V_{M S D}}{T_{M S D}}
$$

Afterwards, a linear regression can be correspondingly drawn between the SET value and STP value. This regression results can be used to set the flow rate in order to achieve a desired STP flow rate.

For GC calibration, Ar was used as carrier gas while He was used as internal standard. The absolute response factor for each species is affected by many factors, such as temperature, pressure, column properties. In all the later calculation, the relative response factor was taken instead of the absolute response factor. In fact, the relative response factors for each component are very consistent.

$$
\frac{A C_{i}}{A C_{H e}}=\frac{N_{i} F_{A i}}{N_{H e} F_{A H e}}=F_{R i} \frac{N_{i}}{N_{H e}}
$$


where:

AC: $\quad$ Area count of the peak in the GC pattern

$\mathrm{N}$ : Amount of the gas collected from the sampling valve

i: $\quad$ Species i

$\mathrm{F}_{\mathrm{A}}: \quad$ Absolute response factor

$\mathrm{F}_{\mathrm{R}}: \quad$ Relative response factor

Figure A-1 is a typical chromatography of the GC trace from methane dry reforming. Peaks of different species appear in the order of residence time from short to long as $\mathrm{He}<\mathrm{H}_{2}<\mathrm{CO}<\mathrm{CH}_{4}<\mathrm{CO}_{2}<\mathrm{H}_{2} \mathrm{O}$. Based on the $\mathrm{GC}$ calibration standard, the actual amount of each species can be known from the peak area and relative response factor based on the internal standard He.

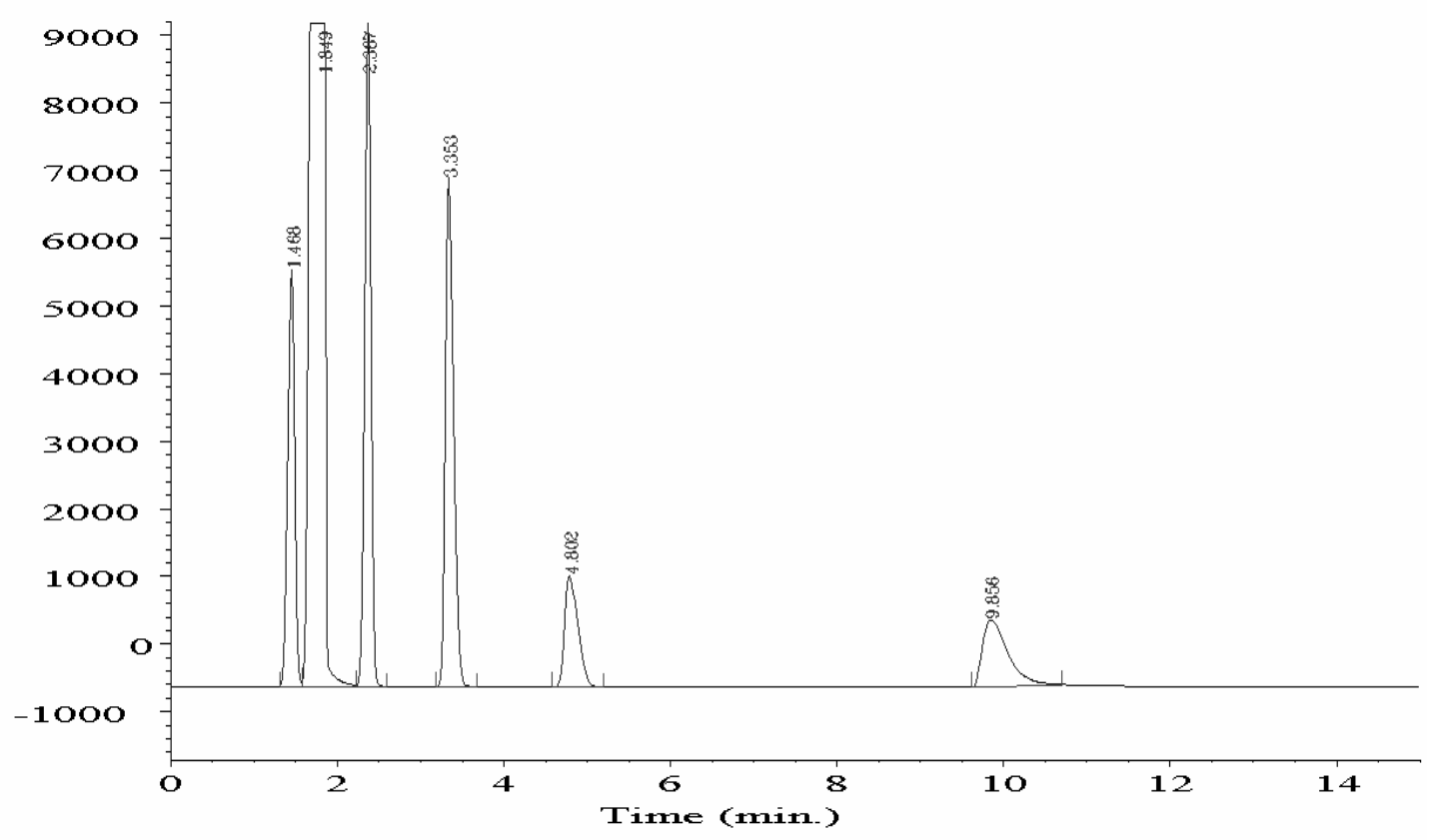

Figure A-1 Typical chromatography of the GC trace from DRM reaction 


\section{B. Equilibrium Calculations}

Figures B-1 and B-2 are equilibrium calculation results for multiple reactions (equations 1-3, 1-4, 1-5, 1-6 and 1-1) regarding DRM system. Vannice et al. reported the work earlier without considering the involvement of solid carbon, which will exclude the reactions of $\mathrm{RB}$ and $\mathrm{CD}$ (equations 1-4 and 1-5). Figure B-1 is the results calculated under the same reaction conditions Vannice et al. used with the absence of solid carbon. These calculations are identical to Vannice's results. This confirms the validity of the method used here. Figure B-2 is the ones calculated under the conditions used in this work, except that no solid carbon is involved in the calculations. There is no qualitative difference in the calculations results between Figure B-1 and B-2. But significant changes can be seen as the solid carbon is included in the reaction system (see Figure 5-1). This difference addresses the significance of the involvement of solid carbon in the real DRM reaction system. 
B-1. Multiple reactions for DRM system-I
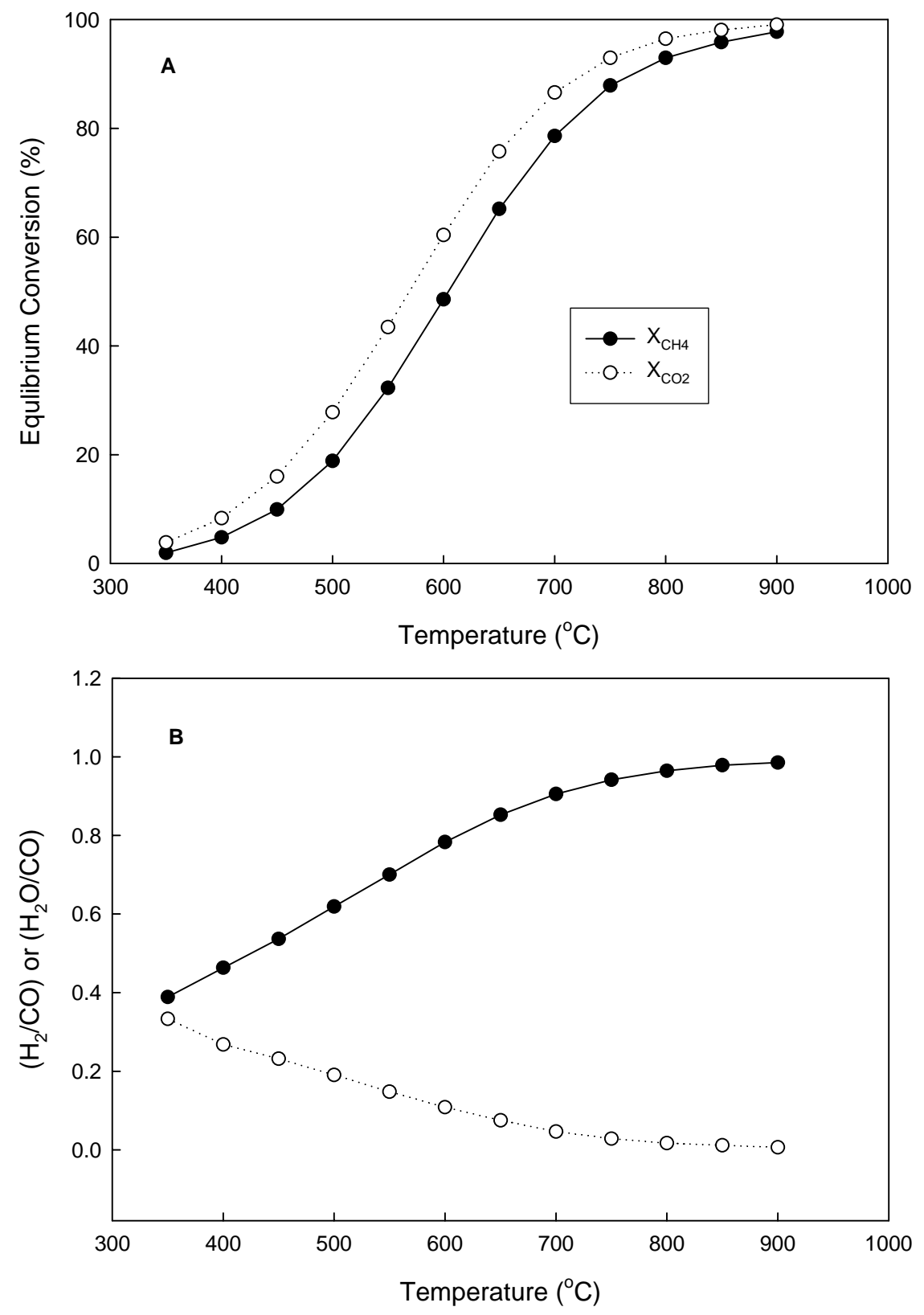

Figure B-1 Equilibrium calculation of multiple reactions for DRM system as a function of temperature (no carbon contained), refer to Vannice et al.'s work [13]

\section{A: Equilibrium conversions B: $\mathrm{H}_{2} / \mathrm{CO}$ or $\mathrm{H}_{2} \mathrm{O} / \mathrm{CO}$ ratio}

Reaction conditions: $\mathrm{P}_{\text {tot }}=1 \mathrm{~atm}, \mathrm{CH}_{4} / \mathrm{CO}_{2} / \mathrm{He}=1 / 1 / 1.8$ 
B-2. Multiple reactions for DRM system-II
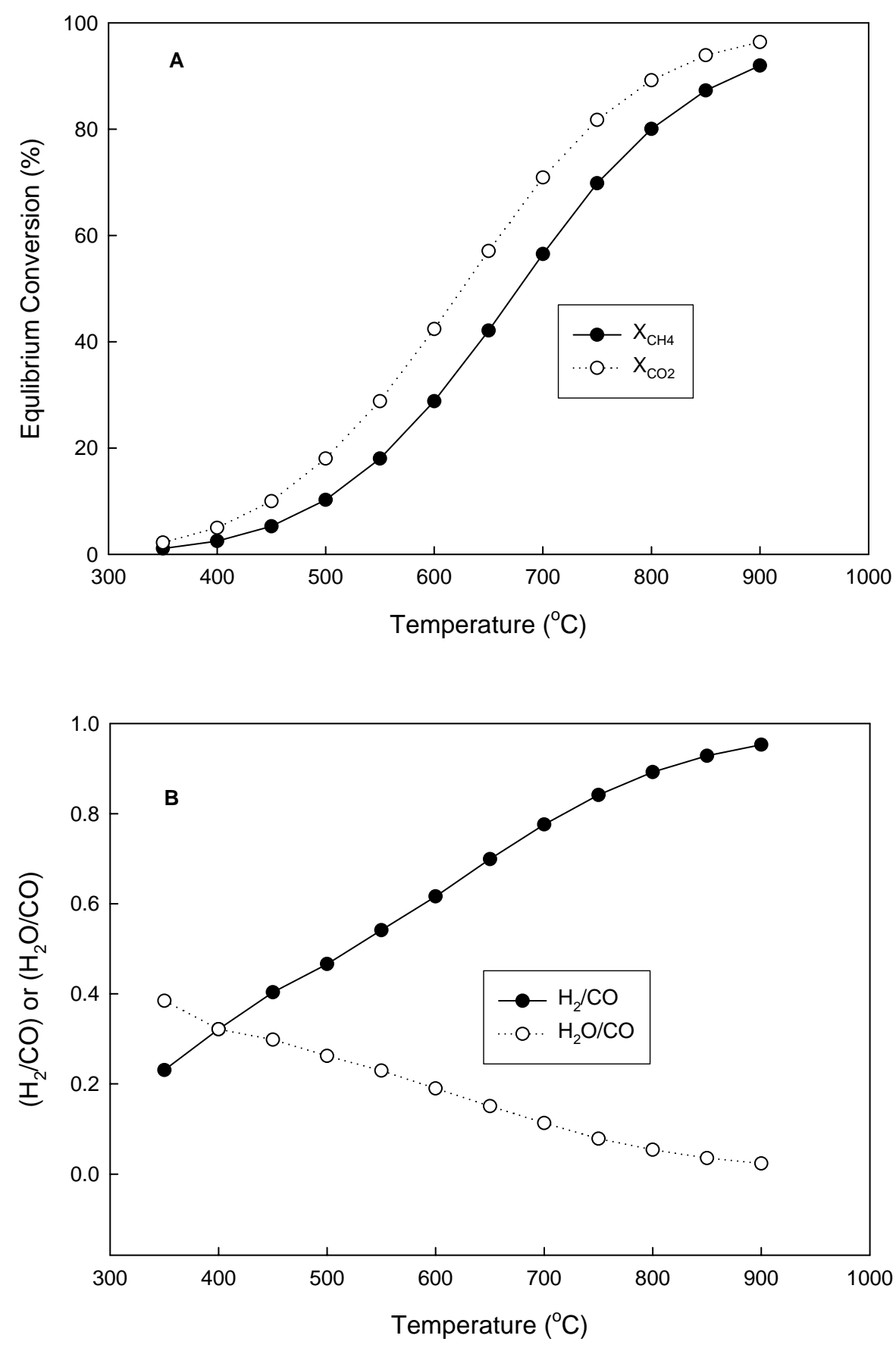

Figure B-2 Equilibrium calculation of multiple reactions for DRM system as a function of temperature (no carbon contained)
A: Equilibrium conversions
B: $\mathrm{H}_{2} / \mathrm{CO}$ or $\mathrm{H}_{2} \mathrm{O} / \mathrm{CO}$ ratio

Reaction conditions: $P_{\text {tot }}=3.4 a t m, V_{\text {tot }}=45 \mathrm{scc} / \mathrm{min}, \mathrm{CH}_{4} / \mathrm{CO}_{2} / \mathrm{He} / \mathrm{Ar}=30 \% / 30 \% / 4 \% / 36 \%$ 
B-3. Multiple reactions for SRM system

Figure B-3 is equilibrium calculation results for multiple reactions (equations 1-1, $1-3,1-4,1-5$ and 1-6) regarding SRM system. No solid carbon is involved in this calculation, which will exclude some side reactions, $\mathrm{CD}$ and $\mathrm{RB}$ (equations 1-4 and 1-5). No remarkable difference is noticed between Appendix B-3 and Figure 5-33, except in the middle range of the temperature. This indicates that the involvement of solid carbon does not have as significant impact on the equilibrium for SRM system as for DRM one.

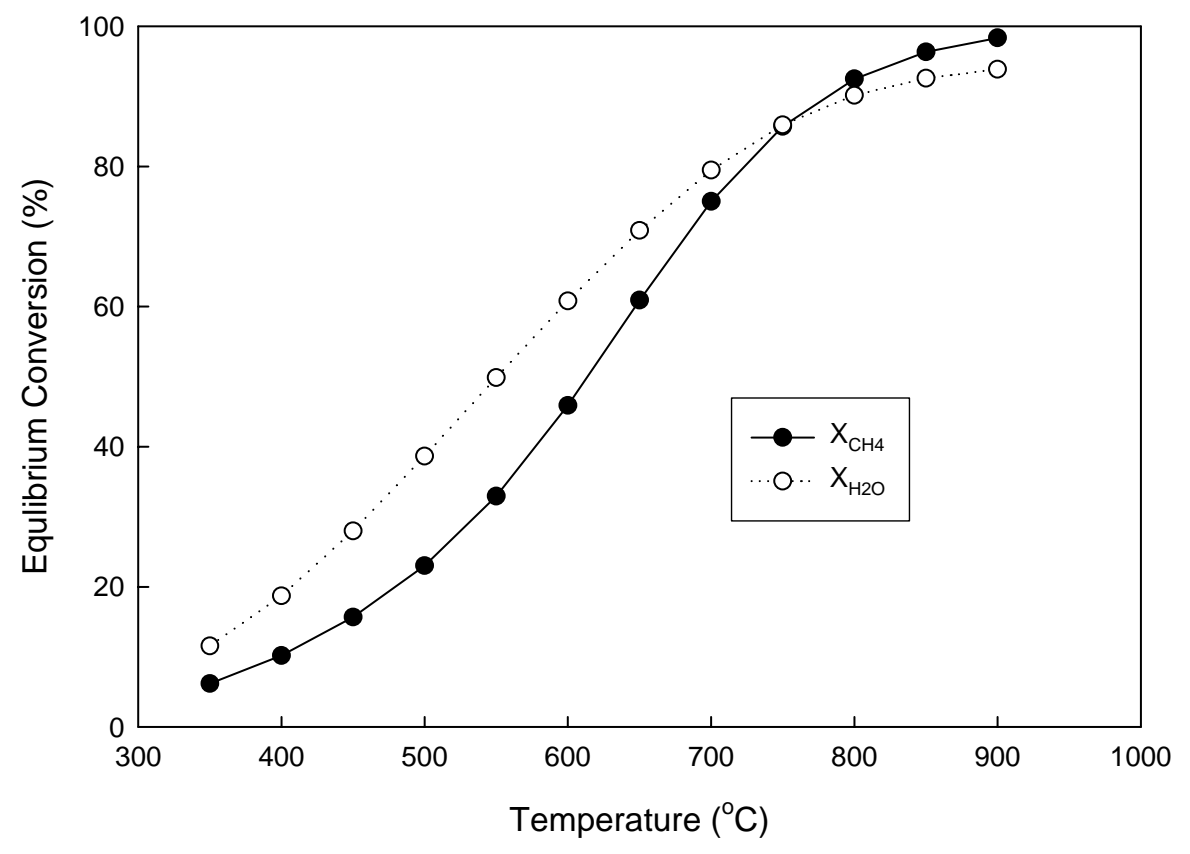

Figure B-3 Equilibrium calculation of multiple reactions for SRM system as a function of temperature (no carbon contained)

Reaction conditions: $P_{\text {tot }}=1$ atm, $V_{\text {tot }}=200 \mathrm{scc} / \mathrm{min}, \mathrm{CH}_{4} / \mathrm{H}_{2} \mathrm{O} / \mathrm{He}=46 \% / 49 \% / 5 \%$ 


\section{B-4. Multiple reactions for SRMeOH system}

Figure B-4 is equilibrium calculation results for multiple reactions (equations 1-9, $1-3,1-4,1-5$ and 1-6, 5-16, and 5-17) regarding $\mathrm{SRMeOH}$ system. No solid carbon is involved in this calculation, which will exclude some side reactions to produce carbon, CD and RB (equations 1-4, 1-5 and 5-17). The involvement of solid carbon only makes the different for equilibrium calculations at low temperatures.

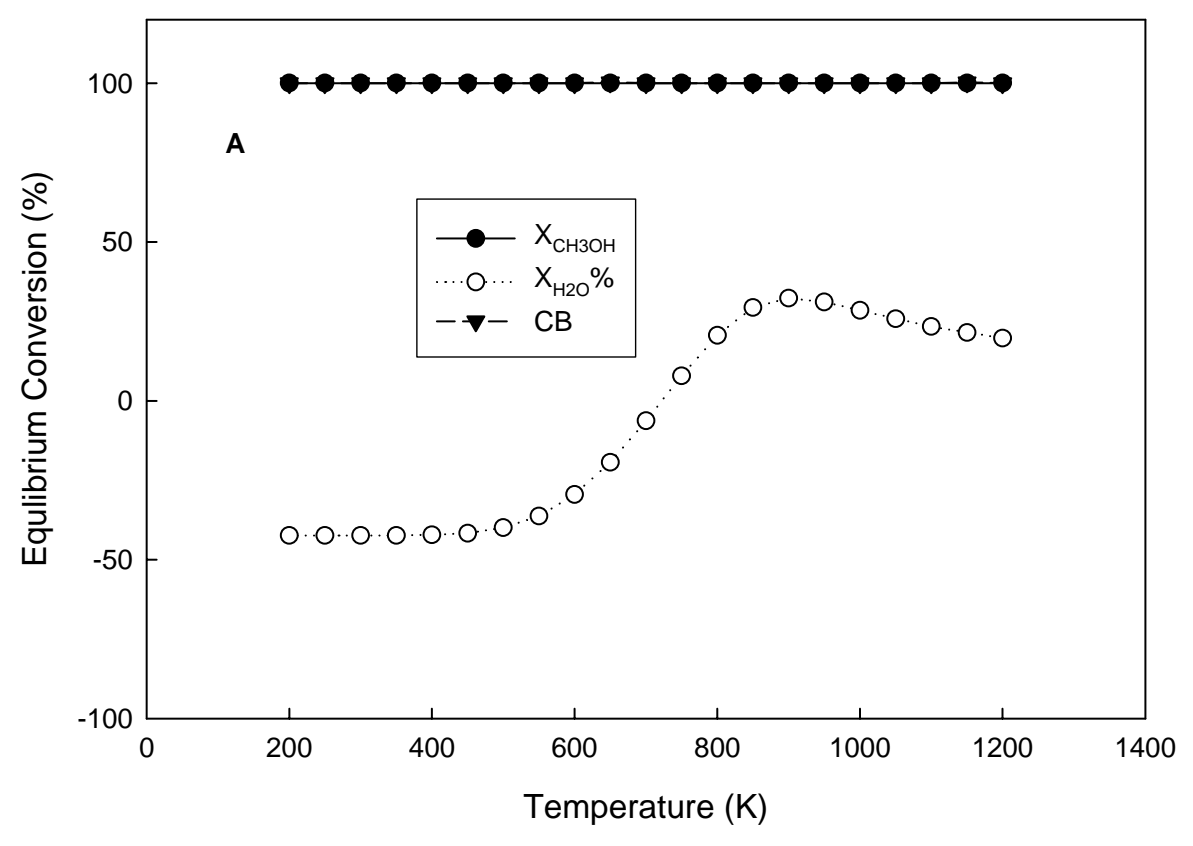



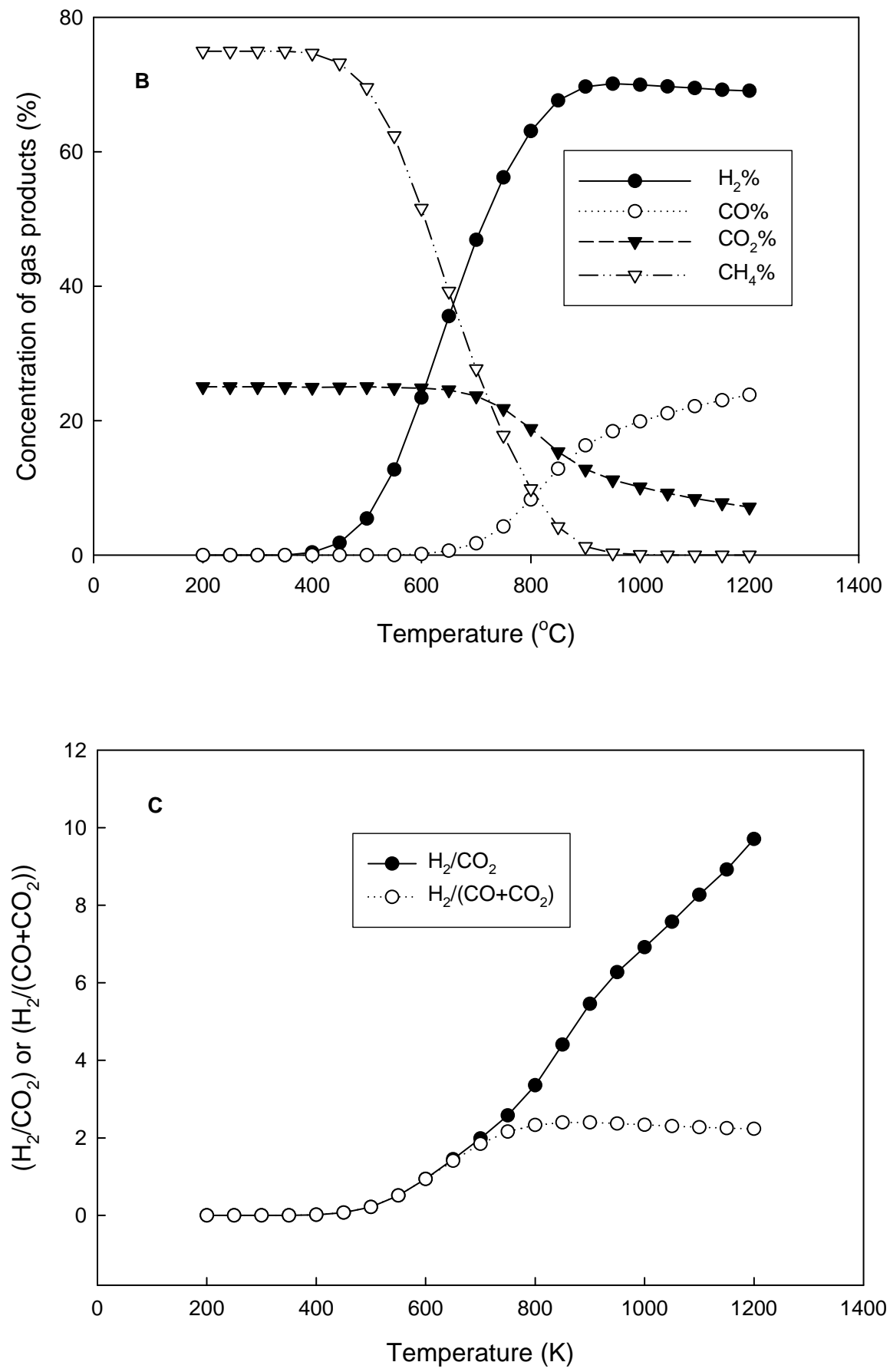

Figure B-4 Equilibrium calculation of multiple reactions for SRMeOH system as a function of temperature (no carbon contained)

A: Equilibrium conversions B: Outlet distribution $\mathrm{C}: \mathrm{H}_{2} / \mathrm{CO}_{2}$ or $\mathrm{H}_{2} \mathrm{O} /\left(\mathrm{CO}+\mathrm{CO}_{2}\right)$ ratio Reaction conditions: $\mathrm{P}_{\text {tot }}=1 \mathrm{~atm}, \mathrm{CH}_{4} / \mathrm{H}_{2} \mathrm{O} / \mathrm{He} / \mathrm{Ar}=9.1 \% / 10.7 \% / 4 \% / 76.2 \%$ 